\title{
HEAT TRANSFER IN PACKED BEDS \\ OF LOW TUBE/PARTICLE DIAMETER RATIO
}

by

Anthony George Dixon

Thesis submitted for the degree of Doctor of Philosophy

UNIVERSITY OF EDINBURGH

1978 
I declare that the work in this thesis is my own, and that the thesis has been

composed by me 


\section{ACKNOWLEDGEMENTS}

Eirst and foremost, my warmest thanks to Dr. David L. Cresswell for his advice, encouragement and patience throughout.

Secondly my thanks to those others who have, at various times, played supervisory roles: Dr. J.M. Aitchison, Mr. L.V. Lane and Dr. W.R. Paterson. Further I must thank Mr. D. Kitchin and his workshop staff at the University of Edinburgh, particularly Mr. A. Donachie, for their help in the laboratory; also Mrs. A. Johnson.. who typed the manuscript.

Finally I must acknowledge the financial support of the Science Research Council in the period 1975/78; also grateful thanks to Professor D.W.T. Rippin for providing the extra funds which made it possible for me to continue to work with Dr. Cresswell at the E.T.H. Zürich, Switzerland during 1977/78. 


\section{CONTENTS}

Chapter $1 \quad$ Packed Beds and Models

1.1 Introduction 1

1.2 Heat Transfer Models $\quad 5$

1.3 Dispersion Models 7

1.4 Boundary Conditions 9

$\begin{array}{ll}\text { References } & 12\end{array}$

Chapter $2^{\circ}$ Experimental Apparatus, Procedure and Results

2.1 Description of Apparatus $\quad 14$

2.2 Design and Operation 16

2.3 Preliminary Analysis of Results 22

2.4 Voidage Studies $\quad 25$

References 30

Chapter 3 Model Discrimination and Parameter Estimation

3.1 Angular Temperature Measurements 31

3.2 Least Squares Estimation 32

3.3 Solution of Model Equations $\quad 34$

3.4 Computation of Parameter Estimates 38

3.5 Model Discrimination $\quad 45$

3.6 Empirical Correlation of Parameters 60

References $\quad 64$

Chapter 4 Theoretical Prediction of Effective Heat Transfer Parameters 4.1 Introduction 66 
.iv.

4.2 Two-phase Continuum Model 67

4.3 Approximate Solutions 69

4.4 Model Matching 73

4.5 Relevant Heat Transfer Correlations 74

4.6 Accuracy of Approximate Solutions 82

$\begin{array}{ll}\text { References } & 88\end{array}$

Chapter 5 Comparison of Theory with Experimental Results

5.1 Selection of Data

5.2 Effective Radial Peclet Number

5.3 Apparent Wall Biot Number

5.4 Effective Axial Peclet Number

Conclusions and Recommendations for Further Work 
An experimental investigation of heat transfer in packed beds of low tube/particle diameter ratio is reported and the most widelyused two-dimensional homogeneous continuum models are thoroughly tested by statistical methods using the experimental data obtained.

It is shown that the omission of axial dispersion effects leads to significant lack-of-fit in such models and to parameter estimates which vary systematically with, bed depth. A model including axial dispersion is considered for each of two possible simplified downstream boundary conditions. This axiallydispersed model shows no lack-of-fit and yields depth-independent parameter estimates when the boundary condition is placed at infinity; when the alternative condition at bed exit is used this model shows little improvement over the model which omits axial dispersion.

A new theory for predicting the axial and radial effective thermal conductivities and the effective wall heat transfer coefficient is derived from a two-phase continuum model containing the essential underlying and independently measureable heat transfer processes. The theory gives good agreement with the results obtained in this work, in contrast with previouslyexisting theory, explains much of the confused literature data, and pin-points the remaining major areas of uncertainty. 
(a) The units of all dimensioned quantities are given, in the MKS system, in the relevant section of the nomenclature. Any departures from these units are specified at the point of usage.

(b) Literature references are given at the end of each chapter, where they are numbered; these numbers are underlined when cited in the text. Figures and equations are numbered consecutively in each chapter without regard to subsections. When one of these numbers is cited in the text it is prefixed with the chapter number in which it appears, except when cited within the same chapter e.g. eqn.(2.3) in any chapter except the second, where eqn. (3) would be used.

(c) The main points of the work in chapters 1-3 were presented at the Fifth International Symposium on Chemical Reaction Engineering at Houston, Texas in March 1978 and published in the proceedings:

A.G. Dixon, D.L. Cresswell and W.R. Paterson, Heat transfer in packed beds of low tube/particle diameter ratio, pp 238253 in D. Luss and V. Weekman (eds.), Chemical Reaction Engineering - Houston, ACS Symposium Series No. 65, (1978) 


\section{PACKED BEDS AND MODELS}

\subsection{Introduction}

A packed bed chemical reactor is an arrangement for carrying out gas-solid or liquid-solid chemical reactions on an industrial scale. The packed bed itself is an assembly of randomly-arranged particles held firmly in position within a reactor tube. The particles are often spherical and usually the same size. The reactant fluid is forced along the tube and flows in a random manner between and around the particles.

Packed bed reactors are most comonly used for catalytic reactions, in which case the particles are porous to give a high fluid-solid interfacial area, and are coated with the catalyst. Many industrially important catalytic reactions are strongly exothermic; some examples - with typical reaction temperature and heat evolved per mole of key reactant are shown in table 1 .

For such reactions the problem of heat removal is extremely important and has a great effect on design and operation of the packed bed. Build-up of excessive heat in the bed ('hot-spots') can lead to promotion of unwanted side reactions (complete combustion in cases (2) - (4) of table 1 ) and sintering of the catalyst. 


\section{Reaction}

1. $\mathrm{C}_{6} \mathrm{H}_{6}+3 \mathrm{H}_{2} \rightarrow \mathrm{C}_{6} \mathrm{H}_{12}$

benzene
Reaction temp.

$\left(\stackrel{{ }^{\circ} \mathrm{C}}{ }\right)$

$150-260$
${\underline{\Delta H^{\circ}}}^{\circ} 25^{\circ} \mathrm{C}-$

(k J/mole)

- 206

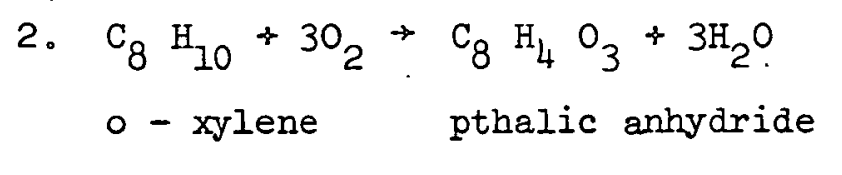

3. $\mathrm{C}_{2} \cdot \mathrm{H}_{4}+\frac{\mathrm{I}}{2} \mathrm{O}_{2} \rightarrow \mathrm{C}_{2} \mathrm{H}_{4} \mathrm{O}$

$240-290$

ethylene

ethylene oxide

4. $\mathrm{C}_{4} \mathrm{H}_{8}+3 \mathrm{O}_{2} \rightarrow \mathrm{C}_{4} \mathrm{H}_{2} \mathrm{O}_{3}+3 \mathrm{H}_{2} \mathrm{O}$

$430-480$

$-1134$

butyiene

maleic anhydride

5. $\mathrm{C}_{2} \mathrm{H}_{2}+\mathrm{H} \mathrm{Cl} \rightarrow \mathrm{C}_{2} \mathrm{H}_{3} \mathrm{Cl}$

$110-180$

$-103$

$340-450$

$-1128$

acetylene

vinyl chloride

Table $I$ : Some industrial exothermic catalytic reactions

The form of packed bed used for these reactions is that of a long thin tube, one of many in a bundle embedded in a heat exchange medium. Such tubes are many hundreds of particle diameters long, but only a few particle diameters across, thus facilitating heet loss radially through the walls of the tube. The study of the heat transfer properties of such a bundle usually begins with the study of the properties of a single packed tube, a difficult enough problem in itself. In spite of the obvious importance of such studies, there has been little work done on such tubes of low tube/particle diameter ratio ( 1 - $\underline{3}$ ), in contrast to the much vider literature available for beds of high ratio, which are more suited to reactions where heat transfer considerations play a smaller part. 
The designer of a packed bed reactor has the twin objectives of safety and efficient operation in mind. In order to achieve these such variables as flow rate, feed composition and temperature and wall, temperature may be adjusted on the industrial scale reactor, although such 'real-life' experimentation may be costly and difficult. Other physical variables, such as reactor dimensions, must be specified before construction, and hence the designer must resort to laboratory experiment to determine their effect. However the laboratory measurements cannot be applied directly to industrial situations, as usually every feature of these measurements is at a value different from any likely industrial scale value, and bed lengths and flow velocities will be at lower orders of magnitude. This is the 'scale-up' problem.

The standard procedure, therefore, is to construct a mathematical model of the reactor, which may be experimentally tested under laboratory conditions, and which will give reliable predictions under industrial conditions. Mathematical models are usually constructed from consideration of the physical and chemical processes occurring in the reactor. Any such model can only hope to represent the more important processes occurring, and is inevitably a compromise between. accurate description of the reactor and computational pragmatism. With the advent of high speed digital computers, however, more realistic models may be constructed and solved and more sophisticated methods of data analysis become available.

The decision as to which processes to incorporate in a model remains largely intuitive; however more recent work $\left(\underline{3}_{0} \underline{4}\right)$ has suggested that statistical methods be used to determine the adequacy of a model with regard to experimental data. The incorporation of such methods should lead to more rigorous model building procedures. 
The situation is further complicated by the inclusion in practically all models of: certain constants, or parameters. Some of these parameters, $e^{\prime} \cdot g$. bed voidage $\varepsilon$, may be measured directly from the apparatus; others, e.g. effective radial bed conductivity $k_{r}$ 。 must be estimated from experimental data, and are usually then correlated empirically against other variables e.g. feed flow rate. These correlations cannot be safely extrapolated, however, and to date there is considerable disagreement between different studies. A preferable procedure would be to predict the parameters theoretically. This is rarely done, however, and the usefulness of the models is thereby limited.

A packed bed reactor model must reflect the following areas:

(a) Chemical kinetics e.g. reaction rate

(b) Physical processes e.g. fluid flow, heat and mass transport. At the present state of the model-building art, it is usual to model various aspects of (a) and (b) separately, and combine the contributions to form the final model. As demonstrated above, heat transfer is one of the most important areas.

The aims of this work may thus be summed up as follows:

(i) To conduct an experimental investigation into the industrially important but often neglected case of heat transfer in packed beds of low tube/particle diameter ratio (low $d_{t} / d_{p}$ ).

(ii) To apply statistical methods to the selection of a model for this case using the data so found.

(iii) To provide theoretical predictions of the parameters to be used in the model selected. 


\subsection{Heat transfer models}

There are several choices of model describing packed bed chemical react or operation at steady-state, the usual industrial mode. Dynamic problems of start-up and reactor stability, although important, are beyond the scope of this work. The models have been described in some detail in various review publications $(\underline{5}-2)$ which also give references to the original papers; in view of this only a brief review is necessary here.

Since it is desired to model heat transfer as a separate process, those parts of the models relating to mass transfer and chemical reaction are omitted. The thermal properties of chemical reactions are well-established in the chemical literature, and few heat transfer experiments are carried out in the presence of reaction (10 is an example). How chemical reaction affects the physical heat transfer processes is a virtually unexplored area.

The physical heat transfer mechanisms believed to occur in packed beds are:

(a) forced convection in direction of flow (axial direction) caused by bulk flow of fluid.

(b) particle-to-particle conduction via finite area contacts and small pockets of stagnant fluid around each contact.

(c) particle-to-wall conduction similarly to (b).

(d) particle-to-fluid transfer via a fluid 'boundary layer' at the particle surface, usually taken for convenience to be of uniform thickness.

(e) fluid-to-wall heat transfer via a wall 'boundary layer'.

(f) molecular conduction through the fluid.

(g) mixing in the radial direction (perpendicular to flow) due to splitting and recombination of fluid streams. 
(h) mixing in axial direction similarly to (g).

(i) apparent axial heat transfer due to the fluid moving at different velocities at different radial positions.

(j) radiation between particle surfaces and between void spaces.

Natural convection effects are regarded as negligible. In laboratory experiments and for many industrial reactions ( $j$ ) may also be neglected, as radiation is negligible below $400^{\circ} \mathrm{C}$, although for higher temperatures it will play an important part.

No mathematical models yet developed account for each of these effects individually, indeed should such a model exist it would probably be too cumbersome for practical use; all models 'lump' different contributions into 'effective' processes.

Models may be classified into two groups, the stochastic and the deterministic. Virtually no examples of the former exist for heat transfer in packed beds, although single-phase mixing may be expressed in terms of a probability theory (그). Only deterministic models are considered here.

The first group of these are termed the finite-stage or cell models. These are the most closely related to physical reality, as they take explicit account of the discrete nature of the bed, regarding the void spaces as being a network of perfectly stirred tanks. A detailed account of the various types may be found in (9). An underlying assumption of the original model was that heat and mass transport are caused only by fluid mixing. While this may be the situation for mass transport, and hence the considerable success of the two-dimensional model in this area (12), it is true for heat transport only in the limiting case of extremely high flow rates. Attempts to remedy this deficiency (13) lead to a very much more complicated model. 
The second group of models are termed dispersion or diffusion models. These are based on energy balances over differential volumes in the bed, in which the flux is assumed to be smooth, and hence Fourier's law may be used. As such they are indefensible physically, but are justified by their success. This is due to the fact that the important gradients in the bed are the 'long-range' ones associated with radial and axial transfer and bulk flow, and 'short-range' discontinuities are smoothed out over a tube radius. This line of reasoning applies for the case of high $d_{t} / d_{p}$, but is a little more dubious for low $d_{t} / d_{p}$. Previous work ( $\underline{3}$ ) has indicated that radial temperature profiles are smooth enough to justify this type of model.

A third type of model has been briefly tried, the wave model (14), but has not found acceptance, and there is now some doubt as to its formulation.

Dispersion models are the most widely used for heat transfer, and appear to be the easiest form in which to incorporate the desired heat transfer mechanisms. Accordingly only this type of model is considered in the rest of this work.

\subsection{Dispersion models}

As both fluid and solid are present in a packed bed, it seems natural to take account of this in the model used. There are two main forms of such 'two-phase' models available in the literature. The first assumes each particle to be isolated in a cell of fluid which is at the same temperature at all points on the particle surface. This model thus precludes particle-to-particle and particle-to-wall heat transfer. As at least the former of these is 
believed to be important $\left(\underline{1}_{0} \underline{3}\right)$ at low $d_{t} / a_{p}$, this model must be discarded.

The second model (called the quasi-continuum model) represents these modes at the cost of dispensing with the physical notion of particles. The solid and fluid phases are both regarded as continuous. This model was first proposed in a restricted form omitting axial transport in both phases by Olbrich (15). The full form has no analytic solution and has not been tested experimentally. This model is further discussed in Chapter 4.

The most common models in use are the pseudo-homogeneous models, where the bed is considered as a single phase. The average temperature of the particle is assumed to be the same as that of the gas that would be at the same position as its centre. The fluid and solid effects are represented by lumped 'effective' radial and axial conductivities, $\mathrm{k}_{r}$ and $\mathrm{k}_{\mathrm{a}}$.

Further assumptions made for simplicity are:

(a) The physical properties of the fluid are constant in the bed ( $i . e$. density $\rho$ and specific heat $c_{p}$ )

(b) $\mathrm{k}_{\mathrm{r}}$ and $\mathrm{k}_{\mathrm{a}}$ are constants

(c) The fluid velocity is constant and equal to an average value $u$.

(d) The temperature is independent of angular position.

None of these assumptions is true, but making them gives models which are easier to solve. However experimental studies have found that there is a sharp decrease in radial conductivity near the wall, and this is usually idealised into a resistance at the wall, characterised by the effective heat transfer coefficient $h_{w}$.

There have been attempts to dispense with $h_{w}$, and include a radially-varying velocity profile and radial conductivity; however 
the problem of how to let $k_{r}$ and $u$ vary is a difficult one they are usually tied to bed voidage. The best results have been obtained by Froment and Leroux (16).

The model obtained from a heat balance over a differential volume of packed bed under assumptions (a) - (d) has been termed the axially-dispersed plug flow (ADPF) model and has equation

$$
\mathrm{Gc}_{\mathrm{p}} \frac{\partial \mathrm{T}_{\mathrm{b}}}{\partial \mathrm{z}}=\mathrm{k}_{r}\left(\frac{\partial^{2} \mathrm{~T}_{\mathrm{b}}}{\partial \mathrm{r}^{2}}+\frac{1}{\mathrm{r}} \frac{\partial \mathrm{T}_{\mathrm{b}}}{\partial r}\right)+\mathrm{k}_{\mathrm{a}} \frac{\partial^{2} \mathrm{~T}_{\mathrm{b}}}{\partial \mathrm{z}^{2}}
$$

The boundary conditions for (1) are discussed in section 1.4 . A more commonly used simplification of (1) is obtained by neglecting the effective axial dispersion term, and is termed the plug-flow (PF) model :

$$
\mathrm{Gc}_{\mathrm{p}} \frac{\partial \mathrm{T}_{\mathrm{b}}}{\partial z}=\dot{k}_{\mathrm{r}}\left(\frac{\partial^{2} \mathrm{~T}_{\mathrm{b}}}{\partial r^{2}}+\frac{1}{r} \frac{\partial \mathrm{T}_{b}}{\partial r}\right)
$$

Further simplifications to one-dimensional models are common, but for exothermic reactions the importance of radial gradients has been emphasised (17, 18$)$.

The PF and ADPF models are the main subjects of the present work.

\subsection{Boundary conditions}

The appropriate boundary conditions for equations (1) and (2) depend upon the reactor geometry. In this work it is proposed to consider the scheme shown in figure 1, similar to that used by Gunn and Khalid (4) and Paterson ( $\underline{3}$ ). 


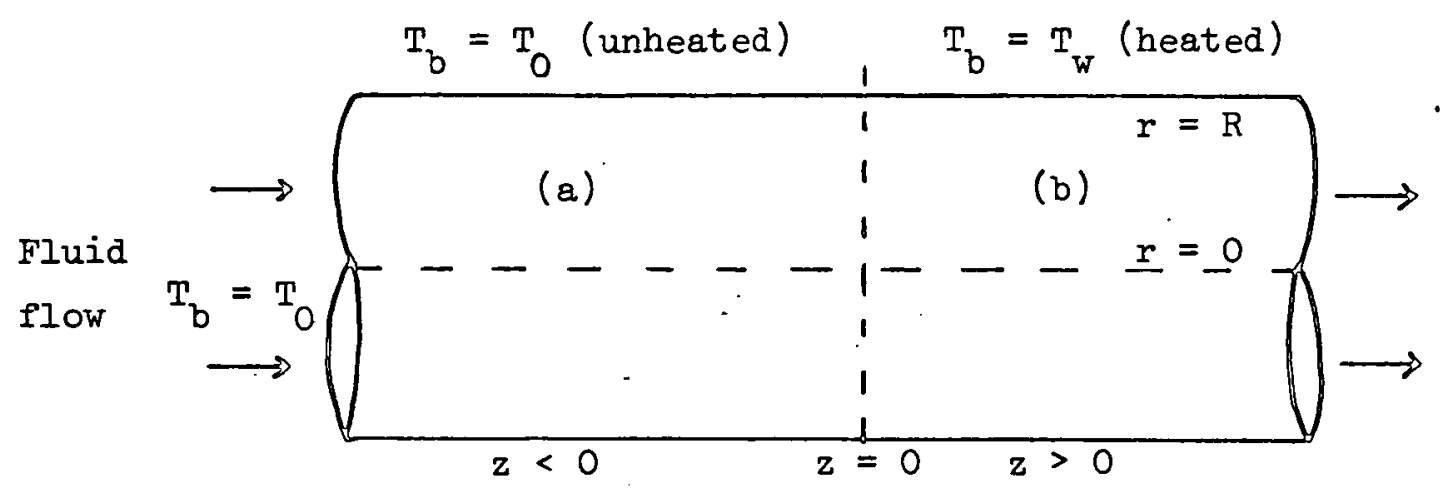

Figure 1 : Schematic description of packed bed

Both sections (a) and (b) are packed with spherical particles of uniform size.

At the centre-line there is the symmetry condition for both models

$$
r=0 \quad: \quad \frac{\hat{T} T_{b}}{\partial r}=0
$$

At the wall

$$
r=R:-k_{r} \frac{\partial T_{b}}{\partial r}=\cdot \begin{cases}h_{W}\left(T_{b}-T_{W}\right) & z>0 \\ h_{W}\left(T_{b}-T_{0}\right) & z<0\end{cases}
$$

For the PF model (4) is restricted to the domain $z>0$. This model also requires initial conditions at $\mathrm{z}=0$ :

$$
z=0: T_{b}=f(r)
$$

Many workers have taken $f(r) \equiv T_{0}$ as the inlet profile, others have measured at $z=0$ and fitted for $f(r)$. The latter procedure is undoubtedly correct in the absence of a calming section; in the present case, assuming no axial dispersion, the former condition is correct.

For the ADPF model equation (1) must be regarded as shorthand for the pair of identical equations yielded by separate energy balances 
in the two sections, made necessary by the form of equation (4). These are linked via continuity of temperature and flux at the adjoining plane, giving

$$
\begin{aligned}
& \mathrm{T}_{\mathrm{b}}\left(0^{+}\right)=\mathrm{T}_{\mathrm{b}}\left(0^{-}\right) \\
& \frac{\partial \mathrm{T}_{\mathrm{b}}}{\partial \mathrm{z}}\left(0^{+}\right)=\frac{\partial \mathrm{T}_{\mathrm{b}}}{\partial z}\left(0^{-}\right)
\end{aligned}
$$

under the assumption of constant $k_{a}$ in both sections.

For an upstream boundary condition the calming section is regarded as semi-infinite giving

$$
\mathrm{T}_{\mathrm{b}} \rightarrow \mathrm{T}_{0} \text {, as } \mathrm{z} \rightarrow-\infty
$$

The downstream condition is much less certain. An entirely rigorous procedure would be to perform another energy balance over the unpacked exit section (not shown in figure 1) and introduce another three effective heat transfer parameters for that section. However the presence of the thermocouple cross (see chapter 2) disturbs the flow patterns and the equations would be of doubtful validity.

Simpler alternatives are to treat the test section as semiinfinite ( $A D P F(I B C)$ model) giving

$$
\mathrm{T}_{\mathrm{b}} \rightarrow \mathrm{T}_{\mathrm{w}} \text { as } \quad \mathrm{z} \rightarrow \infty
$$

as was done by Gunn and Khalid (ㄴ) ; or, for shorter beds, to assume plug-flow in the space above the packing ( $A D P F(F B C)$ model) giving

$$
z=L: \frac{\partial \mathrm{T}_{\mathrm{b}}}{\partial \mathrm{z}}=0
$$

Both possibilities are examined in chapter 3 where the solutions of the above models are displayed, and the abilities of the different models to predict experimental data are examined. 


\section{$\underline{\text { References }}$}

1) J.B.Agnew and O.E.Potter, Heat transfer properties of packed tubes of small diameter, Trans.Inst.Chem.Eng. 48, T 15 (1970).

2) W.E.Olbrich and O.E.Potter, Heat transfer in small diameter packed beds, Chem.Eng.Sci.27, 1723 (1972).

3) W.R.Paterson, Some aspects of the mathematical modelling of fixed bed chemical reactors, Ph.D. thesis, University of Edinburgh (1975).

4) D.J.Gunn and M.Khalid, Thermal dispersion and wall heat transfer in packed beds, Chem.Eng.Sci. 30, 261 (1975).

5) R.H.Wilhelm。 Progress towards the à priori design of chemical reactors, Pure and App.Chem. 5, 403 (1962).

6) G.F.Froment, Analysis and design of fixed bed catalytic reactors, Proc. Ist ISCRE, Washington (1970).

7) G.F.Froment, Fixed bed reactors. Steady state conditions, Proc. 2nd ISCRE, Amsterdam (1972).

8) N.R.Amundson, Mathematical models of fixed bed reactors, Ber. Bunsenges. 74,90 (1970).

9) V.Hlavacek and J.Votruba, Steady state operation of fixed bed reactors and monolithic structures, in Chemical reactor theory a review, Prentice-Hall, New Jersey (1977), editors L.Lapidus and N.R.Amundsion.

10) R.D.Hawthorn, G.H.Ackerman and A.C.Nixon, A mathematical model of a packed-bed heat-exchanger reactor for dehydrogenation of methylcyclohexane : comparison of predictions with experimental results, AIChE J. 14,69 (1968).

11) D.J.Gunn, Theory of axial and radial dispersion in packed beds, Trans.Inst.Chem.Eng. 47, T351 (1969).

12) W.E.Olbrich, J.B.Agnew and O.E.Potter, Dispersion in packed beds and the cell model, Trans.Inst.Chem.Eng. 44, T207 (1966). 
13) Y.Ohki, E.O'Shima, H.Inoue and S.Yagi, Temperature and concentration distribution in a packed bed reactor, Kagaku Kögaku (Abridged English edition) 4, 316 (1966).

14) W.E.Stewart, Transport phenomena in fixed-bed reactors, Chem. Eng.Prog.Symp.Ser. 58,61 (1965).

15) W.E.0lbrich, A two-phase diffusional model to describe heat transfer processes in a non-adiabatic packed tubular bed, Proc. 'CHEMECA' '70 Conf., Inst.Chem.Eng.Symp.Ser.33,101 (1971)

16) J.J.Leroux and G.F.Froment, Velocity, temperature and conversion profiles in fixed bed catalytic reactors, Chem.Eng.Sci. 32, $853(1977)$.

17) J.M.Smith, Heat transfer in fixed-bed reactors - interpretative review, Chem.Eng.J.' 5,109 (1973)

18) J.J.Carberry and D.White, On the role of transport phenomena in catalytic reactor behaviour. Digital simulation of naphthalene oxidation over $\mathrm{V}_{2} \mathrm{O}_{5}$, Ind.Eng.Chem. $61,(7), 27$ (1969). 


\section{EXPERIMENTAL APPARATUS, PROCEDURE AND RESULTS}

\subsection{Description of apparatus}

The experimental part of this work is an extension to cylindrical packed beds of the preliminary work for annular beds done by Paterson (1.3). The apparatus was therefore broadly similar to his, and in some places identical.

The general experimental layout is shown in figure 1. The bed itself consisted of two tubular sections of internal diameter $70.8 \mathrm{~mm}$, insulated at the join by a sandwich of two rubber gaskets with a PVC gasket between them. Twelve thermocouples entered the bed radially through the PVC gasket.

The lower bed section, termed the calming section, was a pyrex tube which was packed but unheated. The packing rested on a steel grid which separated the calming section from a short unpacked section into which the air feed line ran. Two thermocouples measured the air feed temperature at the grid, entering radially at the grid gasket. One was at the bed centre and one at the wall.

The fluid used in the bed was air, supplied via a $12.7 \mathrm{~mm}$ compressed air line and passing through a silica gel drying region. The air flow-rates were controlled by a gate valve followed by a parallel battery of rotameters, each with its own valve. Flow rates of up to 180 litres/minute at $25^{\circ} \mathrm{C}$ and $0-2$ p.s.i.g. could be obtained.

The upper bed section, or test section, was a packed brass tube sitting inside an outer brass tube, thus forming an annulus. In the annular gap steam was forced under pressure, exiting at the bottom of the test section via a tap and piping leading to a cold water bath. The steam supply was controlled by a valve. Since it was under pressure it was necessary to measure the wall temperature. 
Battery of rotameters

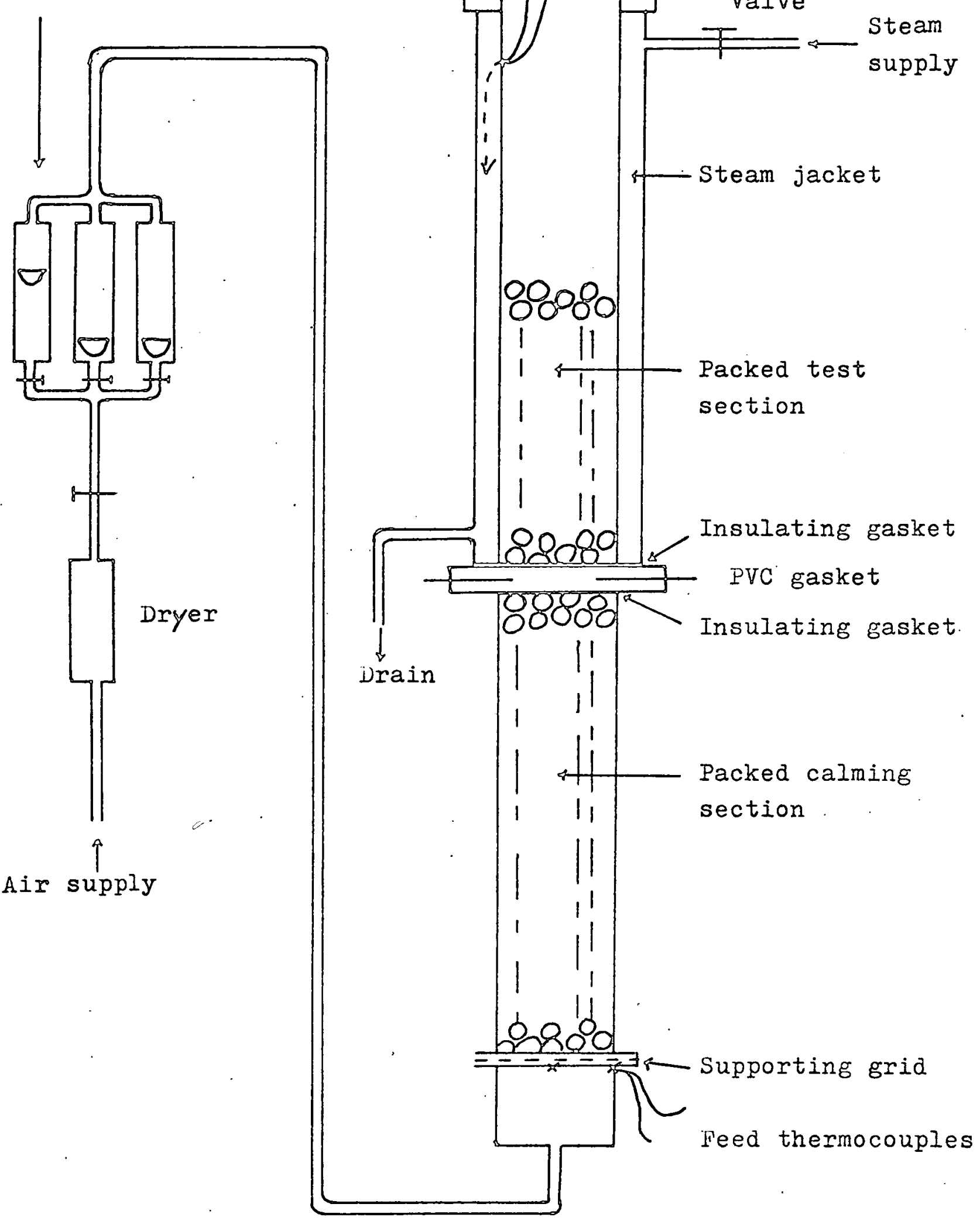

Figure 1: Schematic diagram of experimental apparatus 
This was effected by six thermocouples soldered, within the annular gap, onto the test section wall. The first was $24 \mathrm{~mm}$ above the test section inlet, the others following at $80 \mathrm{~mm}$ intervals. Their leads emerged in the inner tube, but well above the highest packing used.

Both sections were packed with identical particles to provide a continuous length of packing.

The temperature distribution in the air stream leaving the packing was measured by $\mathrm{Cr} / \mathrm{Al}$ thermocouples supported by a brass cross similar to that used by De Wasch and Froment (I) and shown in figure 2. This was supported by screwed rods from a cross with notched arms so as to fit the top of the bed tightly. The distance between support and measurement crosses was adjusted by nuts on the screwed rods.

The 8-armed brass cross held 32 thermocouples arranged as shown in figure 3. 4 thermocouples were on each arm, in the configurations denoted $A$ and $B$. The numbers refer to the distances from bed centre, in $\mathrm{mm}$. Hence 4 measurements at $90^{\circ}$ intervals were taken at each of 8 radial positions ( $\mathrm{r}=9,11,13,18,24,29,31$ and $33 \mathrm{~mm})$.

Also shown in figure 3 are the positions of the i2 thermocouples at the test section entrance (hereafter referred to as giving 'entrance' data). From these 2 measurements at $180^{\circ}$ intervals were taken at each of 6 radial positions $(r=12,16,23,28,31$ and $34 \mathrm{~mm})$.

The various thermocouples were connected, via selector boxes, to 'Comark' electronic thermometers, with an ice/water cold junction.

\subsection{Design and operation}

Paterson ( $\underline{1.3}$ ) considered some alternatives in both design and operation of the apparatus and his relevant conclusions may be summarised here. 


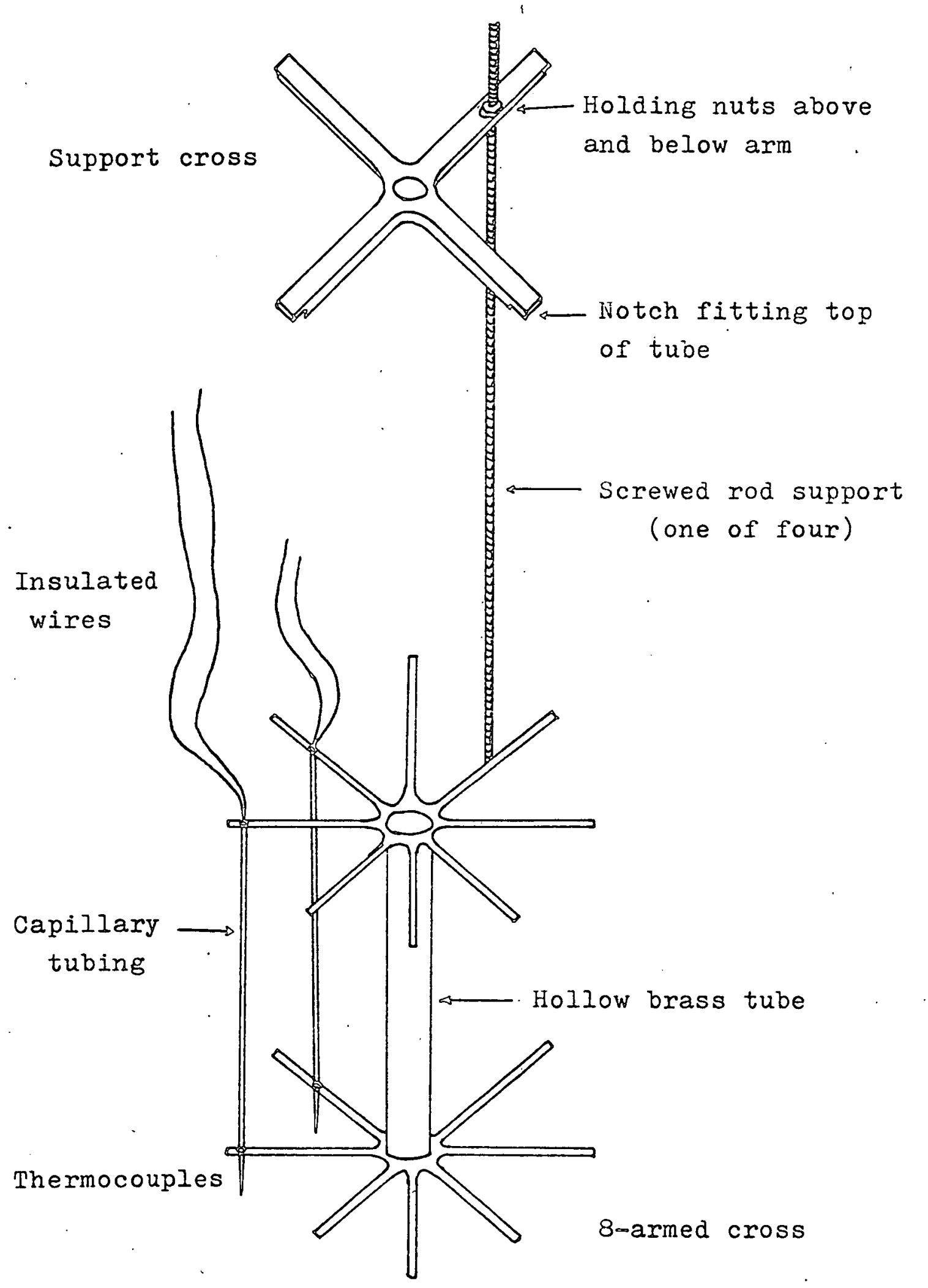

Figure 2 : Thermocouple cross at bed exit, support rod and cross at top of bed tube. 


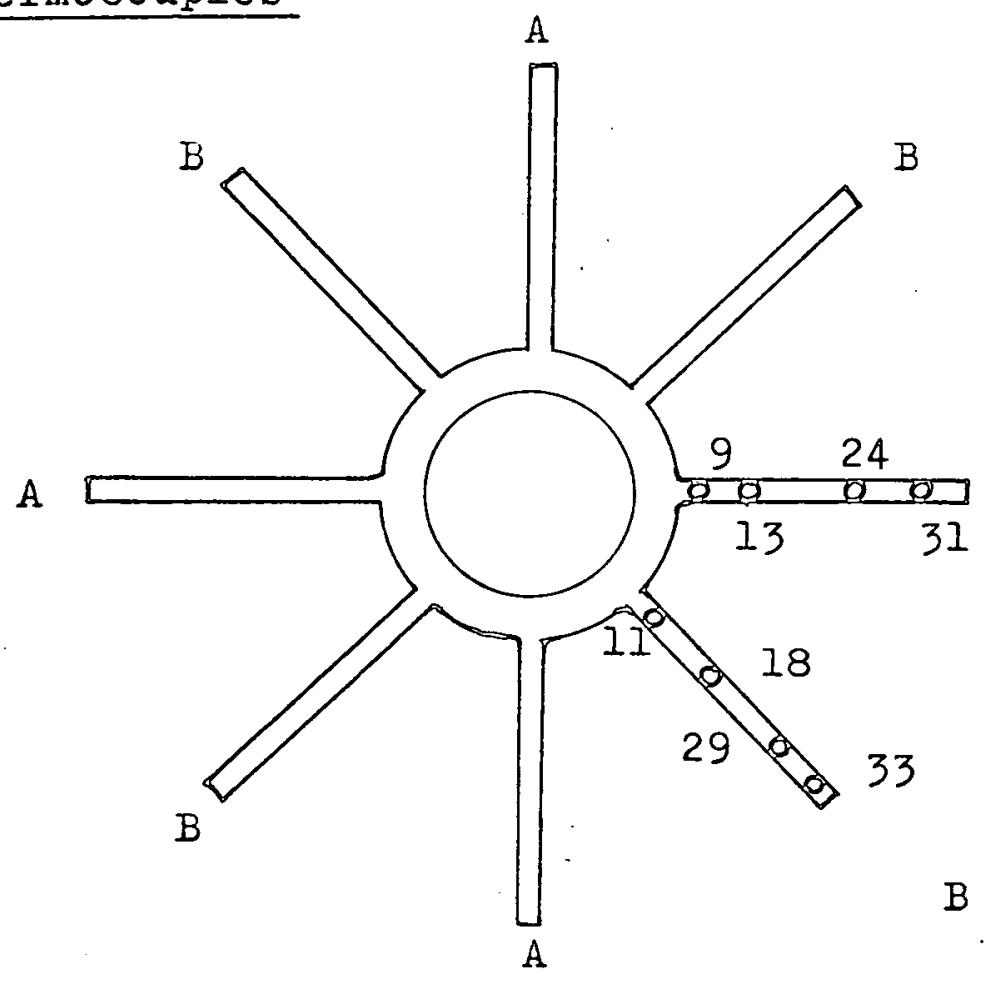

A

Entrance thermocouples

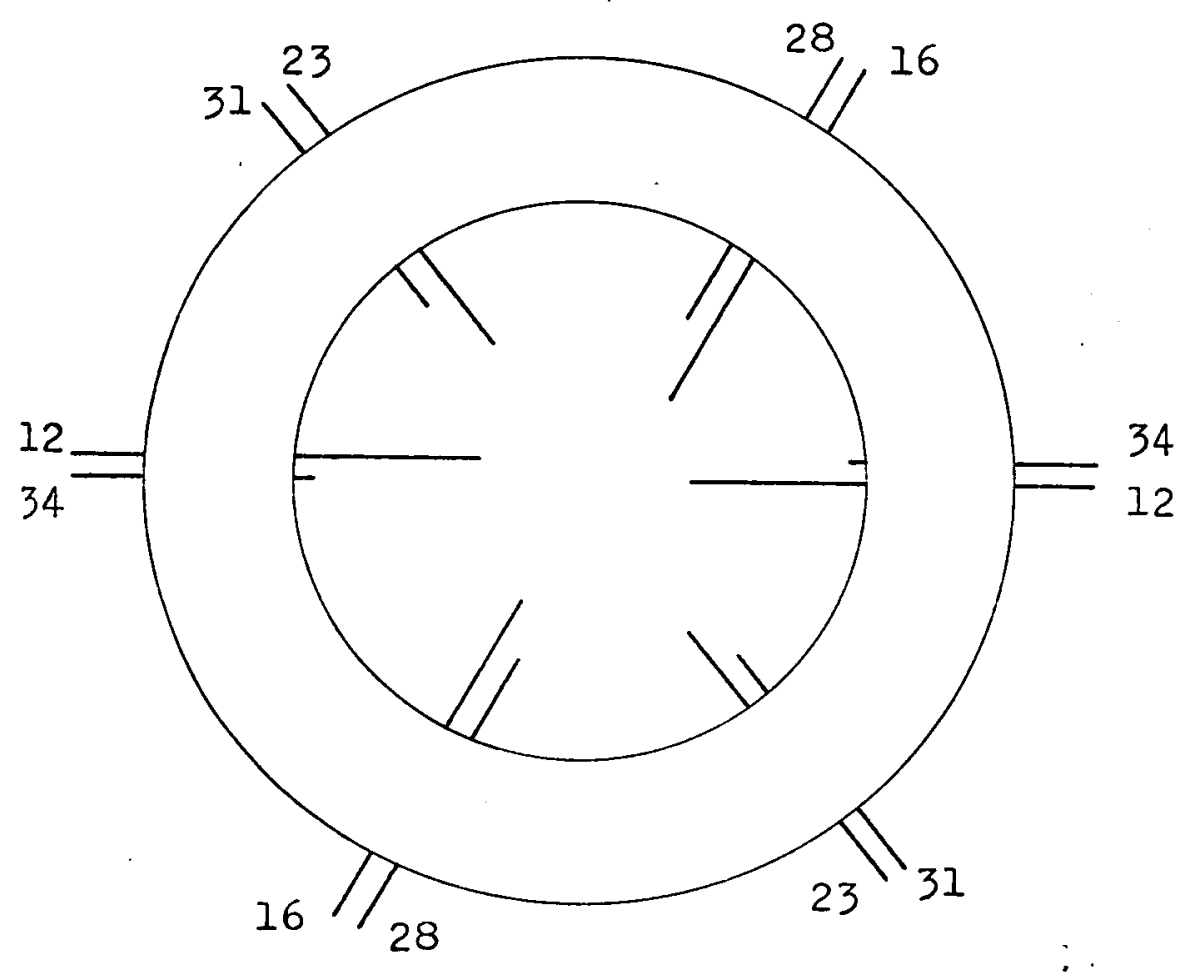

Figure 3 : Iocation of therinocouples 
(a) There was negligible heat conduction along the brass cross thermocouple wires.

(b) Immersion of the thermocouples in the bed gave the same results as location just above the surface of the bed。 except in the case of zero flow. This conclusion justifies measurement above the packing, since no stagnant bed measurements were made in the present work.

(c) Embedding of thermocouples was not considered as in beds of low $d_{t} / d_{p}$ measurements can then not be made near the wall, a severe restriction. Also the packing is distorted by the embedded thermocouples.

(d) Inserting thermocouples radially through the wall at different axial positions leads inevitably to large heat fluxes along the thermocouples and thus to inaccurate temperature measurement.

Before construction of the bed the thermocouples were calibrated against a $0.1^{\circ} \mathrm{C}$ standard reference mercury thermometer, in a thermostatic water bath, over the range $20-100^{\circ} \mathrm{C}$. Negligible difference was found between thermocouples on the same 'Comark' input, but different calibration curves were necessary for different inputs. The raw data obtained in the experiments were corrected by a computer program using cubic spline interpolation between the calibration points (ㅁ)

The positions of the thermocouples on the cross and in the bed were measured accurately and since they were 'araldited' firmly in position, and the cross fitted tightly in the bed, it was considered that there was no error in radial location of the thermocouples. The calming section was packed first, the gasket 'sandwich' placed in position, and finally the test section bolted on, for each repacking of the bed. This was to avoid dropping the packing past 
the entrance thermocouples, which might have damaged them. The rest of the packing was then trickled into the test section. The test section was taken to begin at the entrance thermocouples and the distance from these to the top of the bed measured. The distance from the top of the packing to the top of the bed was measured by a dipstick, at several positions, and the bed height found by subtraction. The average bed height was taken but the variation with position was small.

The thermocouple cross was then lowered into the bed until it rested just on or above the packing. The nuts on the screwed rods could be preset to achieve, this so that the notches on the arms engaged the tube top. The steam was then turned on and the walls allowed to reach a steady temperature, before the air feed began. The desired volumetric flow rate could be obtained on the appropriate rotameter using previously existing calibration charts to give the rotameter setting.

The bed was then allowed to reach steady-state, which took between $1 \frac{1}{2}$ and 3 hours, depending on its previous steady-state. Temperature measurements on representative thermocouples were made at regular intervals, and when these gave little or no change all the thermocouples were read. The flow rate was then adjusted or the bed repacked as appropriate and the procedure repeated.

In all, 4 different non-porous packings were used, at various bed depths and flow rates. For a given packing, the same flow rates were set at each bed depth. A set of tables showing the combinations of packing, flow rates, bed depths and run numbers giving the experimental order are presented in appendix B (tables Bl-B4). Re was calculated using the properties of air at $25^{\circ} \mathrm{C}$. The remainder of the appendix gives the corrected data obtained. The entrance and 
exit temperatures are given in full; however only the corrected average is given for wall temperature $\mathrm{T}_{\mathrm{w}}$ and feed temperature $\mathrm{T}_{0}$. Occasionally a thermocouple gave no reading due to a loose connection, thus some readings are missing.

All the measurements were originally taken by Dr.D.L.Cresswell over a period of $1 \frac{1}{2}$ years at various times. However for the $6.4 \mathrm{~mm}$ ceramic beads and the $9.5 \mathrm{~mm}$ steel balls the PVC entrance thermocouples gasket was removed, so that no entrance data were taken. The exit data obtained in these cases exhibited some peculiar behaviour, including some values in the bed less than the feed temperature $T_{0}$, clearly an impossibility. Accordingly the bed was dismantled, the thermoccuples re-calibrated and their positions checked. The entrance thermocouples were also restored. Quite different thermocouple calibration curves were obtained, for no obvious reason. Possibly long periods of non-use have some effect, either on the thermocouples or the 'Comark' thermometers.

As entrance data was required for these cases it was felt that the best course of action was to re-take the data for the two packings. This work and the re-calibration were carried out by the present writer. It is these runs which are given in appendix $B$ and show none of the peculiarities of the previous data.

A further set-back occurred with the runs for $\mathrm{Re}=109$ with $6.4 \mathrm{~mm}$ ceramic beads and $R e=146$ with $9.5 \mathrm{~mm}$ steel balls. These values required a setting at the upper limit of operation of the intermediate rotameter, which was found to be very hard to control accurately. The runs were repeated using an appropriate setting near the lower limit of the large rotameter, which gave much more consistent readings. Both sets of data are given in appendix $B$, the large rotameter runs being the last ones in each case. It was these latter which were used when the data were analysed. 
Discounting repeats, 107 runs were finally taken. For some combinations of flow rate and bed depth the temperature profile was virtually flat at bed exit. In such cases no measurements were taken, accounting for some of the gaps in tables $B I, B 2$ and $B 4$.

\subsection{Preliminary analysis of results}

For each run the wall temperature measurements showed a spread over the six readings of less than $0.5^{\circ} \mathrm{C}$ in virtually all cases; thus $T_{W}$ was taken as a constant and equal to the corrected average. Similarly the average of the two feed measurements was taken as $T_{0}$, as these rarely differed by more than $0.2^{\circ} \mathrm{C}$.

Typical bed exit profiles are shown in figure 4, taking the case $R e=120$ for $9.5 \mathrm{~mm}$ ceramic beads. The values of $T_{W}$ for each run are also shown.

The following may be noted:

(a) There is a significant, but apparently random, variation of temperature with angular position. For the longer bed depths this variation can be nearly as much as the total radial temperature change. No existing models account for this phenomenon.

(b) The angular average temperature appears to be a fairly smooth function of radial position, an encouraging sign for the applicability of dispersion models.

(c) There is a reproducible 'hump' in the radial temperature profile roughly $0.5 \mathrm{~d}$ from the wall. It is particularly noticeable in shallow beds, but is smoothed out with increasing depth. A similar hump, although at a greater distance from the wall, was observed by De Wasch and Froment (1). Paterson (1.3. ) observed two humps, also further from the walls, in his annular bed. By allowing $u$ and $k_{r}$ to be functions of radial position, Leroux and Froment 


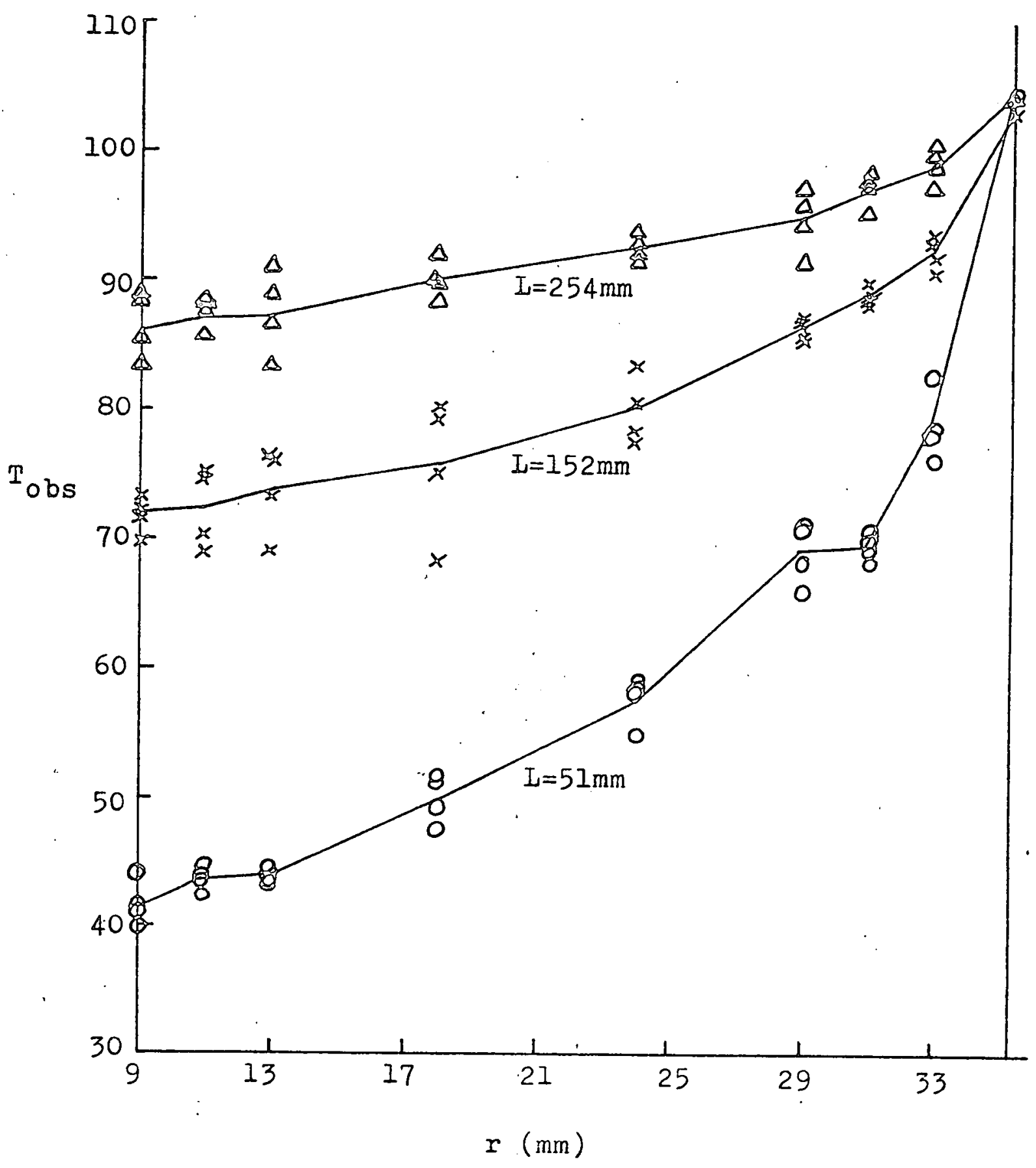

Figure 4 : Typical observed temperature profiles 
(1.16) have simulated these humps with the PF model, although at the cost of much computational complexity. Marivoet et al ( $\underline{3}$ ) have also simulated the hump. As the magnitude of these humps is small compared with the angular scatter, it is doubtful whether this feature is worth incorporating into a model.

An indication as to whether the IBC or FBC version of the ADPF model is the more appropriate may be obtained from examination of the entrance. profiles from each bed depth at a given flow rate. The infinite condition would be consistent with inlet profiles independent of bed length, whilst with the finite condition a systematic effect would be expected. The angular average inlet temperature profiles corresponding to $9.5 \mathrm{~mm}$ ceramic beads at $\mathrm{Re}=120$ are shown in

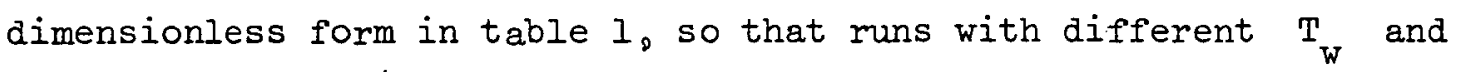
$\mathrm{T}_{\mathrm{O}}$ may be compared.

\begin{tabular}{|c|c|c|c|c|c|c|}
\hline \multirow[b]{2}{*}{$\underline{L(m)}$} & \multicolumn{6}{|c|}{$r(\mathrm{~mm})$} \\
\hline & 12 & 16 & 23 & 28 & 31 & 34 \\
\hline 51 & 0.04 & 0.06 & 0.06 & 0.14 & 0.20 & 0.25 \\
\hline 102 & 0.04 & 0.06 & 0.07 & 0.15 & 0.20 & 0.24 \\
\hline 152 & 0.04 & 0.06 & 0.08 & 0.16 & 0.20 & 0.24 \\
\hline 204 & 0.04 & 0.07 & 0.10 & 0.16 & 0.20 & 0.24 \\
\hline 254 & 0.04 & 0.06 & 0.08 & 0.16 & 0.20 & 0.25 \\
\hline
\end{tabular}

Table 1 : Dimensionless entrance profiles

No systematic trend is evident, which tends to support the IBC version; however the FBC model will be tested further in chapter 3 , as the above can hardly be termed conclusive. 


\subsection{Voidage studies}

Although the bed voidage $\varepsilon$ is not featured explicitly in the $\mathrm{PF}$ or $\mathrm{ADPF}$ models it is an important fundamental property of a packed bed, and is worth determining for later use.

The experimental method. adopted was again that of Paterson (1.3). PVC cylinders were packed with polystyrene balls, dyed candle wax was poured into the voids and left to set. The bed was then sawn into slices in the radial plane a sufficient distance above the base for the ordering effects to be negligible (about $5 a_{p}$ ). Photographs were taken of the surface of each slice and with suitable enlargement a transparency of polar graph paper could be superimposed, so that at any radial position the fraction of the circumference occupied by void could easily be measured. This determined the 'line voidage'. Blum and Wilhelm (4 4 ) have shown that area voidage and volume voidage are equal; and it may be assumed that all three are equal.

This procedure was followed for two values of $d_{t} / d_{p}$ and two slices of each. Figures 5 and 6 show a slice for each of the $d_{t} / d_{p}$ values. The line voidages at various dimensionless radial positions are given in table 2 for the four slices, and the average of the slices for each $d_{t} / d_{p}$ value is shown in figure 7 . 


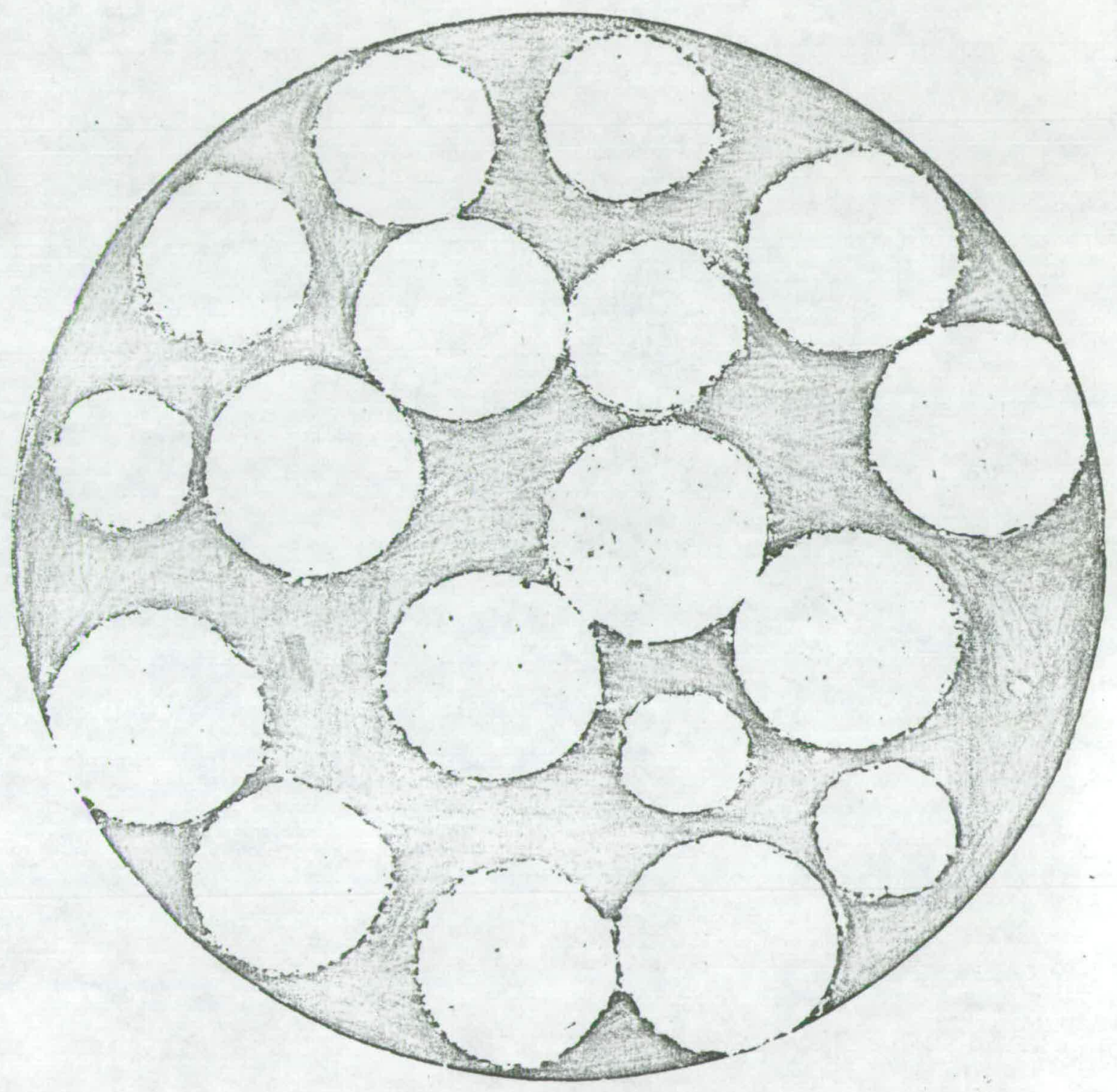

Figure 5 : Wax model slice, $\alpha_{t} / \alpha_{p}=5.58$ 


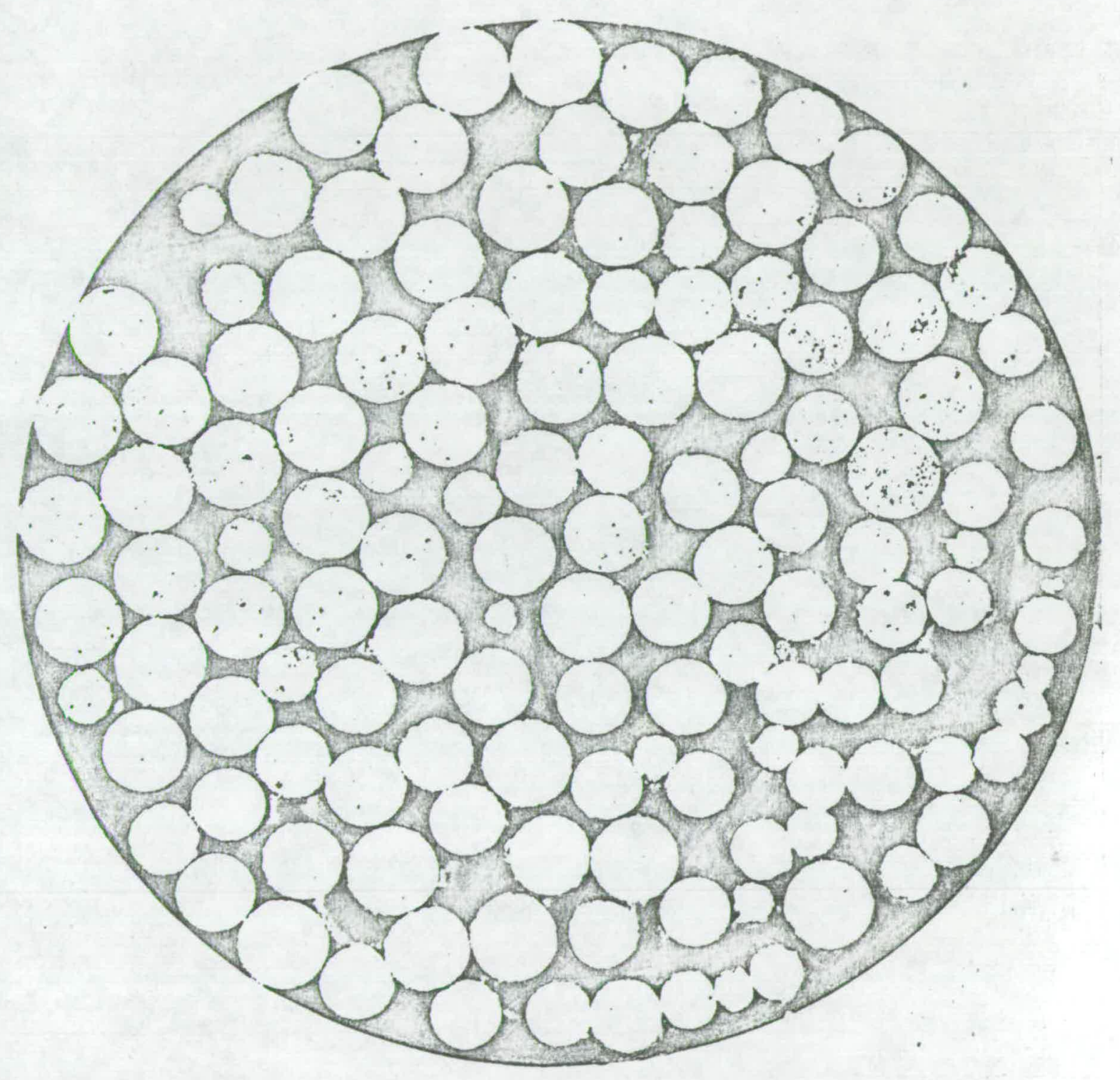

Figure 6 : Wax model slice, $d_{t} / d_{p}=11.81$ 


$$
\mathrm{d}_{t} / \mathrm{d}_{\mathrm{p}}=5.58 \quad \mathrm{~d}_{t} / \mathrm{d}_{p}=11.81
$$

\begin{tabular}{|c|c|c|c|c|}
\hline$\underline{\mathbf{y}}$ & $\varepsilon($ slice 1$)$ & $\varepsilon$ (slice 2) & $\varepsilon($ slice $I)$ & $\underline{\varepsilon(\text { slice 2) }}$ \\
\hline 0.07 & 0.44 & 0.33 & 0.39 & 0.19 \\
\hline 0.13 & 0.33 & 0.50 & 0.31 & 0.19 \\
\hline 0.20 & 0.40 & 0.62 & 0.52 & 0.41 \\
\hline 0.27 & 0.49 & 0.42 & 0.41 & 0.33 \\
\hline 0.33 & 0.28 & 0.35 & 0.30 & 0.32 \\
\hline 0.40 & 0.30 & 0.31 & 0.42 & 0.56 \\
\hline 0.46 & 0.43 & 0.30 & 0.26 & 0.32 \\
\hline 0.53 & 0.52 & 0.42 & 0.38 & 0.49 \\
\hline 0.60 & 0.62 & 0.70 & 0.31 & 0.42 \\
\hline 0.67 & 0.46 & 0.31 & 0.42 & 0.42 \\
\hline 0.74 & 0.23 & 0.19 & 0.24 & 0.28 \\
\hline 0.80 & 0.26 & 0.22 & 0.38 & 0.38 \\
\hline 0.86 & 0.35 & 0.26 & 0.33 & 0.38 \\
\hline 0.93 & 0.62 & 0.52 & 0.28 & 0.26 \\
\hline 1.00 & 0.96 & 0.86 & 0.92 & 0.92 \\
\hline
\end{tabular}

Table 2 : Voidage measurements

The oscillatory nature of the voidage, with maxima and minima approximately $d_{p}$ apart, confirms the results of other workers $(\underline{5}, \underline{6})$. The average voidages for the bed were determined from the curves in figure 7. It is also of interest to determine separately the 'centre-bed' $\left(\varepsilon_{c}\right)$ and 'wall-region' $\left(\varepsilon_{\mathrm{w}}\right)$ voidages, obtained by excluding the region within $0.5 d_{p}$ of the wall for $\varepsilon_{c}$, and taking only that region for $\varepsilon_{\mathrm{w}}$. The results are shown in table 3 . 


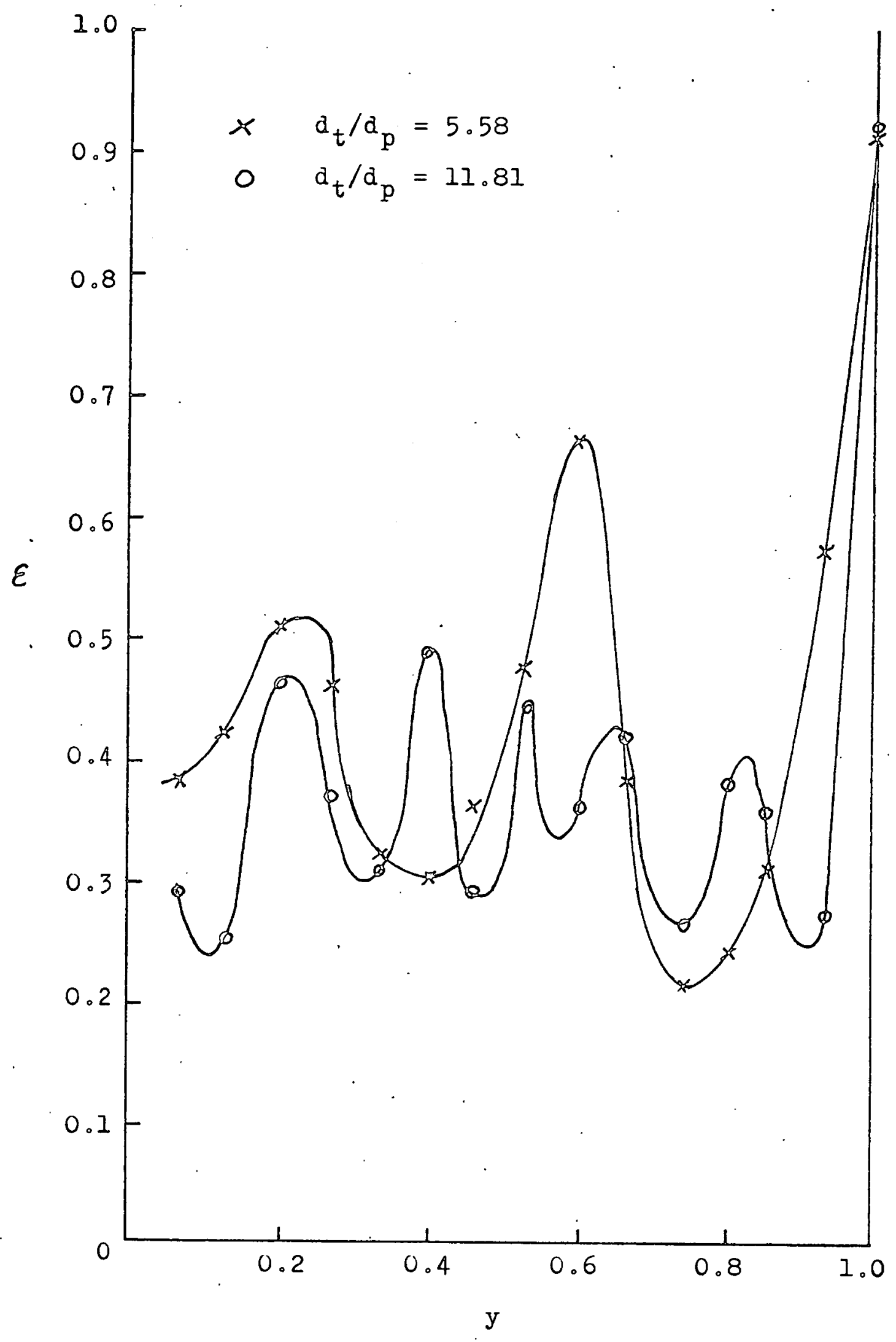

Figure 7 : Average void fractions 


$\begin{array}{cccc}\frac{d_{t} / d_{p}}{2} & \varepsilon & \varepsilon_{c} & \frac{\varepsilon_{w}}{2.58} \\ 5.81 & 0.42 & 0.39 & 0.50 \\ 11.81 & 0.38 & 0.36 & 0.51\end{array}$

\section{Table 3 : Various voidages}

The values of $d_{t} / d_{p}$ used correspond roughly to the two extreme values used experimentally, which were 5.57 and 11.15 . Previous studies of the variation of $\varepsilon$ with $d_{t} / d_{p}$ (I) indicate that the dependence is weak enough for the above correspondence to be good, and. interpolation to be used for the third experimental $d_{t} / d_{p}$ value which was $7.430^{\circ}$

\section{$\underline{\text { References }}$}

I) A.P.De Wasch and G.F.Froment, Heat transfer in packed beds, Chem. Eng.Sci. 27,567 (1972).

2) Subroutine $\mathrm{E}$ OI ADF, NAG Library, NAG Ltd., Oxford.

3) J.Marivoet, P.Teodoroiu and S.J.Wajc, Porosity, velocity and temperature profiles in cylindrical packed beds, Chem.Eng.Sci. 29, $1836(1974)$.

4) E.H.Blum and R.H.Wilhelm, A statistical geometric approach to random-packed beds, AIChE - Inst.Chem.Eng.Symp.Ser. 4, 21 (1965).

5) I.H.S.Roblee, R.M.Baird and J.W.Tierney, Radial porosity variations in packed beds, AIChE J 4, 460 (1958).

6) R.F.Benenati and C.B.Brosilow, Void fraction distribution in beds of spheres, AIChE J 8, 359 (1962).

7) D.P.Haughey and G.S.G.Beveridge, Structural properties of packed beds - a review, Can.J. Chem.Eng. 47, 130 (1969). 


\section{MODEL DISCRIMINATION AND PARAMETER ESTIMATION}

\subsection{Angular temperature measurements}

It has been pointed out in chapter two that considerable angular scatter exists in the bed exit temperature measurements. Since the magnitude of the scatter is much greater than can be attributed to experimental error, it must be concluded that non-homogeneity of the bed is the cause. It would be expected that a thermocouple positioned above a solid particle should give a different reading to one above a void space.

It is further remarked in chapter two that no existing model takes account of angular variation of temperature. It would thus appear that either the models presented in chapter one must be modified to include this phenomenon, or regarded as inadequate. The former alternative would probably involve stochastic modelling, a very underdeveloped area in heat transfer studies. The latter would cast doubt on any parameter estimates obtained with such a model.

The horns of this dilemma may be avoided, if not removed, by a point of view put forward by Paterson (1.3). In this approach the bed temperature $\mathrm{T}_{\mathrm{b}}$ is regarded as an angle-averaged temperature, and the angular temperatures as error-affected measurements of this average. If the 'errors' can be shown to behave like true measurement errors then standard estimation methods may be used.

Paterson found his 'errors' to be independent, normally-distributed with zero mean and to have constant variance. Since his measurements were made on much the same apparatus as those in the present work, it might be expected that the same conclusions should hold. An examination of the data in appendix $B$ indicates that this is the case, with the exception of constant variance. The variance decreases on 
longer beds since the temperatures are near wall temperature and must lie in a narrower range.

The consequence of this observation is that weighted least squares (WLS) appears to be more applicable in this case than the more common unweighted version (OLS), in order to estimate the parameters. However in long beds the profile is nearly flat and so. less sensitive to the parameters. Hence implementation of WLS leads to greatest weight being placed on those measurements which are least sensitive to the parameters, a situation which should be avoided.

For these reasons it was decided to employ OLS methods for parameter estimation.

\subsection{Least squares estimation}

The parameters are estimated by adjusting them so that the temperatures predicted by the model are in some sense 'close' to the observed temperatures. In least squares estimation the idea of 'closeness' is made more precise by requiring the sum of squares of the discrepancies between observed and predicted temperatures to be a minimum. Thus if there are a total of $m$ readings, the problem is to minimise

$$
S(\underline{x})=\sum_{i=1}^{m}\left(T_{b, i}(\underline{x})-T_{o b s, i}\right)^{2}=\sum_{i=1}^{m} f_{i}(\underline{x})^{2}
$$

with respect to $\underline{x}$, the vector of $p(\leq m)$ adjustable parameters. This involves searching through the allowed or feasible region of $x$ to find the point with the smallest value of $S(\underline{x})$. The search is carried out by starting from an initial guess point and forming a sequence of points tending to the minimum.

The least squares method has been described fully in the relevant literature (I, 2 ) and a comparison of search methods suitable for 
finding the minimum of a sum-of-squares function is made in the second reference. More general methods are described in the mathematics literature ( $(\underline{3})$. The specific methods used in this work are described in section 3.4 .

In appendix $B$ the data for a given packing are grouped by runs, each mun representing a different flow rate and bed depth combination. For parameter estimation the runs at different bed depths for the same flow rate (i.e. dimensionless Reynolds number $R e$ ) are considered together. This is termed "overall" analysis. If there are $\mathbb{N}$ bed depths associated with a given $R e$, and a total of $\mathrm{n}$ readings missing, then fitting to exit and entrance data simultaneously requires setting

$$
m=44 \mathrm{~N}-\mathrm{n}
$$

in equation (1). The PF model, however, cannot be fitted to entrance data as the profile at $z=0$ is specified as a boundary condition. The fact that the profiles in appendix $B$ are not flat, as predicted by the assumptions of this model, may be regarded as an indication of inadequacy. The bulk of the data collected is at bed exit, however, and overall analysis using this data alone may be achieved setting

$$
\mathrm{m}=32 \mathrm{~N}-\mathrm{n}
$$

The models may also be fitted to data at individual bed depths in order to detect any trend in the paremeters with bed depth. This only involves setting $N=1$ in (2) and (3), and is termed "depth-bydepth" analysis.

When estimates of the parameters are found, it is necessary to give some idea of how good these estimates are, by giving either the variances of the parameters or the associated confidence intervals at an appropriate level of significance.

The $m \times p$ matrix $J_{i j}(\underline{x})=\left[\frac{\partial f_{i}}{\partial x_{j}}\right]_{\underline{x}}$ is called the Jacobian matrix. 
If this is available as a by-product of minimisation, or can be calculated, then letting $H=\left[2 J^{T} J\right]^{-1}$ and $S$ be the sum of squares, both calculated at the solution $\underline{\hat{x}}$, an estimate of the variance of the $i^{\text {th }}$ parameter $x_{i}$ is.

$$
\operatorname{var}\left(x_{i}\right)=\frac{s}{m-p} H_{i i}
$$

and of the covariance of $x_{i}$ and $x_{j}$ is

$$
\operatorname{cov}\left(x_{i}, x_{j}\right)=\frac{s}{m-p} H_{i j}
$$

If $x^{\prime \prime}$ is the true solution then the $100(1-\beta)$ confidence interval on, $\underline{\hat{x}}$ is

$$
\begin{gathered}
x_{i}-\sqrt{\operatorname{var}\left(x_{i}\right)} t_{(\beta / 2, m-p)}<x_{i}^{*}<x_{i}+\sqrt{\operatorname{var}\left(x_{i}\right)} t_{(\beta / 2, m-p)} \\
i=1, . . p
\end{gathered}
$$

where $t_{(\beta / 2, m-p)}$ is the $100 \beta / 2$ percentage point of the $t$-distribution with $\mathrm{m}-\mathrm{p}$ degrees of freedom.

Hence the approximation to the Jacobian usually available after minimisation may be used to compute approximate confidence intervals, if the model used is adequate.

\subsection{Solution of model equations}

The analysis of the solutions to the model equations is facilitated if they are made dimensionless. Thus the equations for the ADPF models become

$$
\begin{aligned}
\frac{\partial \theta}{\partial x}= & \frac{1}{P e_{A}} \frac{\partial^{2} \theta}{\partial x^{2}}+\frac{1}{\mathrm{Pe}_{R}}\left(\frac{\partial^{2} \theta}{\partial y^{2}}+\frac{1}{y} \frac{\partial \theta}{\partial y}\right) \\
\text { for } 0<y<1 \text { and } & -\infty<x<\infty \quad \text { (IBC model) } \\
& -\infty<x<L / R \quad \text { (FBC model) }
\end{aligned}
$$

Centre-line boundary condition : $\quad \frac{\partial \theta}{\partial y}=0$ 
Well boundary condition: $\frac{\partial \theta}{\partial y}+B i \theta= \begin{cases}B i & x>0 \\ 0 & x<0\end{cases}$

Upstream boundary condition : $\theta=0$ at $x=-\infty$

Downstream boundary condition: $\theta=1$ at $x=\infty$ (IBC model)

$$
\frac{\partial \theta}{\partial x}=0 \text { at } x=L / R(F B C \text { model })
$$

The special case arising from neglect of axial dispersion, the PF model, is obtained from (7) by letting $\mathrm{Pe}_{\mathrm{A}} \rightarrow \infty$ :

$$
\begin{array}{r}
\frac{\partial \theta}{\partial x}=\frac{1}{P e_{R}}\left(\frac{\partial^{2} \theta}{\partial y^{2}}+\frac{1}{y} \frac{\partial \theta}{\partial y}\right) \\
\text { for } 0<y<1 \text { and } x>0
\end{array}
$$

The radial boundary conditions $(8)$ and (9) are unaltered apart from restriction to the range $x>0$. The downstream boundary condition may be dispensed with as the equation is now of parabolic type, and the upstream condition modified to be $\theta=0$ at $x=0$

It should be noted that $\mathrm{Pe}_{A}$ and $\mathrm{Pe}_{\mathrm{R}}$ are based on tube radius $R$ for convenience in these equations; later discussion uses $\mathrm{Pe}_{\mathrm{a}}$ and $P e_{r}$ based on particle diameter $d_{p}$, the more usual form.

The above model equations are easily solved by either Laplace transform or separation of variables technique to give:

(a) ADPF (IBC) model

$$
\theta(x, y)= \begin{cases}I-\sum_{n=1}^{\infty} \frac{B i\left(I+\beta_{n}\right) J_{0}\left(\lambda_{n} y\right)}{\left(B i^{2}+\lambda_{n}^{2}\right) B_{n} J_{0}\left(\lambda_{n}\right)} \exp \left\{\frac{P e_{A} x}{2}\left(I-B_{n}\right)\right\} & x>0 \\ \sum_{n=1}^{\infty} \frac{B i\left(B_{n}-1\right) J_{0}\left(\lambda_{n} y\right)}{\left(B i^{2}+\lambda_{n}^{2}\right) B_{n} J_{0}\left(\lambda_{n}\right)} \exp \left\{\frac{P e_{A} x}{2}\left(I+\beta_{n}\right)\right\} & x<0\end{cases}
$$


(b) ADPF (FBC) model

$$
\begin{aligned}
& \theta(x, y)=\int 1-\sum_{n=1}^{\infty} \frac{B i\left(1+\beta_{n}\right) J_{0}\left(\lambda_{n} y\right)}{\left(B i^{2}+\lambda_{n}^{2}\right) \beta_{n} J_{0}\left(\lambda_{n}\right)}\left[\exp \left\{\frac{P e_{A} x}{2}\left(1-\beta_{n}\right)\right\}\right. \\
& +\frac{\beta_{n}-1}{\beta_{n}+1} \exp \left\{\frac{P e_{A}}{2}\left(\beta_{n}(x-2 L / R)+x\right)\right\} \quad x>0 \\
& \sum_{n=1}^{\infty} \frac{B i\left(\beta_{n}-1\right) J_{0}\left(\lambda_{n} y\right)}{\left(B i^{2}+\lambda_{n}^{2}\right) \beta_{n} J_{0}\left(\lambda_{n}\right)}\left\{\exp \left\{\frac{P e_{A} x}{2}\left(1-\beta_{n}\right)\right\}\right. \\
& \left.-\exp \left\{\frac{P e_{A}}{2}\left(B_{n}(x-2 L / R)+x\right)\right\}\right] \quad x<0
\end{aligned}
$$

(c) PF model

$$
\theta(x, y)=1-\sum_{n=1}^{\infty} \frac{2 B i J_{0}\left(\lambda_{n} y\right)}{\left(B i^{2}+\lambda_{n}^{2}\right) J_{0}\left(\lambda_{n}\right)} \exp \left\{\frac{-\lambda_{n}^{2} x}{P e_{R}}\right\}
$$

The $\lambda_{n}$ are the roots of the characteristic equation

$$
\lambda_{n} J_{I}\left(\lambda_{n}\right)-\operatorname{Bi} J_{0}\left(\lambda_{n}\right)=0
$$

and $\beta_{n}=\sqrt{1+4 \lambda_{n}^{2} /\left(\mathrm{Pe}_{A} \mathrm{Pe}_{\mathrm{R}}\right)}$

For the PF model an alternative form of the solution may be obtained, useful for small values of $\mathrm{x}$ :

$$
\begin{aligned}
\theta(x, y) \simeq 1-\left(\frac{2 B i \sqrt{x}}{\sqrt{y \cdot P e_{R}}}\right. & i \operatorname{erfc}\left\{\frac{1-y}{2 \sqrt{x / P e_{R}}}\right\}+\frac{4 B i x}{\sqrt{y} P e_{R}} \times \\
& \left.i^{2} \operatorname{erfc}\left\{\frac{1-y}{2 \sqrt{x / P e_{R}}}\right\}\left(\frac{1}{8 y}+\frac{3}{8}-B i\right)+\ldots\right\}
\end{aligned}
$$

Similar expressions for the ADPF models are not easily obtained.

Bed exit profiles may be obtained from the truncated series solutions for $x>0$ in equations $(14),(15)$ and (16). It is not practicable to examine remainder terms from the truncated series due to the complexity of the expressions involved. It is easier to perform 
numerical experiments taking 'worst case' values of the parameters. It should be borne in mind that experimental variation in the temperatures measured is large, and hence high accuracy in the analytical solutions is unnecessary. Also the use of these solutions for parameter estimation, where they will be evaluated many times, indicates that as few terms as possible should be used.

It is easily shown that for all models the worst case of convergence occurs for high $\mathrm{Pe}_{\mathrm{R}}$ and low $\mathrm{x}$. For the ADPF models the worst case is also for low $\mathrm{Pe}_{\mathrm{A}}$. $\mathrm{Bi}$, however, influences $\lambda_{\mathrm{n}}$ through equation (17) and so affects each term in the series less straight-forwardly. Hence, it is not easy to determine worst-case values of $\mathrm{Bi}$ and a practical range must be covered, $0.5-10$ being taken in this work. Taking $\mathrm{Pe}_{\mathrm{R}}=200, \mathrm{Pe}_{\mathrm{A}}=0.5$ and $\mathrm{x}=0.3$ gives practical extremes for the experimentel conditions covered.

Each solution was evaluated at the 8 bed exit radial measurement points, using up to 50 terms, and examined after the addition of each term. A Newton-Raphson iteration was used to find the $\lambda_{n}$ from equation (17) to 6 decimal places. In all cases the solutions agreed to 4 decimal places $\left(0.01^{\circ} \mathrm{C}\right)$ well before the 50 th term was added, and this solution was taken to be 'exact'. An accuracy requirement of $0.1{ }^{\circ} \mathrm{C}$, or 3 decimal places in dimensionless solution, was taken as a reasonable compromise between speed and accuracy. This was achieved in all cases by taking 8 terms of equation (16) and 15 terms for each of equations (14) and (15).

A special case required for the ADPF models is $x=0$. In this case the solution was barely determined to $1^{\circ} \mathrm{C}$ ( 2 decimal places) by 50 terms, and was still not determined by 200 terms. This is due to the absence of the exponential term in $x$, which 'damps out' the Bessel function oscillations quickly for $x>0$. Since the only alternative 
is a numerical solution which would be slower and of probably no greater accuracy, a 50-term analytic solution may be regarded as a reasonable approximation to profiles at $\mathrm{x}=0$.

\subsection{Computation of parameter estimates}

The subroutine chosen from the Edinburgh Regional Computing Centre's NAG library (ㄴ) to minimise $S(\underline{x})$ in equation (I) takes advantage of the sum of squares form of $S(\underline{x})$. It is iterative and uses a strategy similar to that applied by Powell () to systems of nonlinear equations together with a version of the step selection procedure devised by Marquardt ( $\underline{6})$. Although the partial derivatives $\partial f_{i} / \partial x_{j}$ are not required to be supplied by the user, they are assumed to exist and be continuous, and are approximated by finite differences by the subroutine. On exit the sum of squares $S$ and the Jacobian $J$ are available, calculated at the best point.

The iteration is stopped when it is predicted that $S(\underline{x})$ is within "user-specified" accuracy of the minimum. This accuracy must be carefully chosen, since too large a value and the parameter estimates may be poor if $\underline{x}$ changes quickly near the minimum, too small a value and convergence to a minimum may not occur. In the latter case the parameter estimates over the last few iterations should be examined. If there is little change then it may not be necessary (or possible) to obtain the required accuracy, and the 'best' estimates accepted. For this reason it is advisable to print out the parameter values and $S(\underline{x})$ after each iteration.

An ever-present hazard in nonlinear minimisation is that the minimum found is local and not global. To guard against this, a preliminary examination of the sum-of-squares surface $S(\underline{x})$ was made for selected cases over a physically reasonable range of $\underline{x}$, where 
$\underline{x}=\left(\mathrm{Pe}_{r}, \mathrm{Bi}\right)$ for the $\mathrm{PF}$ model and $\underline{x}=\left(\mathrm{Pe}_{\mathrm{a}}, \mathrm{Pe}_{\mathrm{r}}, \mathrm{Bi}\right)$ for the ADPF models. Only two terms were used in the analytic series to keep the amount of computation practical.

The contours of the surface near the global minimum are shown in figure one for two cases of overall analysis with the PF model. Their shapes confirm those found by De Wasch and Froment (2.1) and Tsang et al (I). From these contours it appears that $\mathrm{Pe}_{\mathrm{r}}$ is best determined at lower $\operatorname{Re}$ and $\mathrm{Bi}$ at higher Re.

Although no other local minima were found on the sum-of-squares surface, there appear to be several near the global minimum. Accordingly several different starting points were taken within the innermost unbroken contour. As the same solution was reached in each case, it is concluded that the 'minima' in figure 1 are the result of misinterpretation of too coarse a mesh by the contour-drawing routine used.

As a final check, a conjugate-gradient method (ㅇ) devised by Powell (9) was used with widely scattered starting values for the PF model. It always confirmed the global minimum found by the main minimisation routine.

The starting-values yielded by the grid search proved to be good estimates of the solution point in all cases, and convergence was fairly rapid. For "depth-by-depth" analysis the "overall" analysis solutions were used as starting points. These were also used for the $A D P F$ models and an initial estimate for $\mathrm{Pe}_{\mathrm{a}}$ taken to be 0.1 , to prevent "overshoot" into $\mathrm{Pe}_{\mathrm{a}}<0$, where the analytic solution breaks down. However, some contours for these models are shown for interest in figures 2 and 3 , in the form of sections through the threedimensional surface. It is seen that the ADPF(IBC) model determines $\mathrm{Pe}_{\mathrm{a}}$ better than the ADPF(FBC) model. 

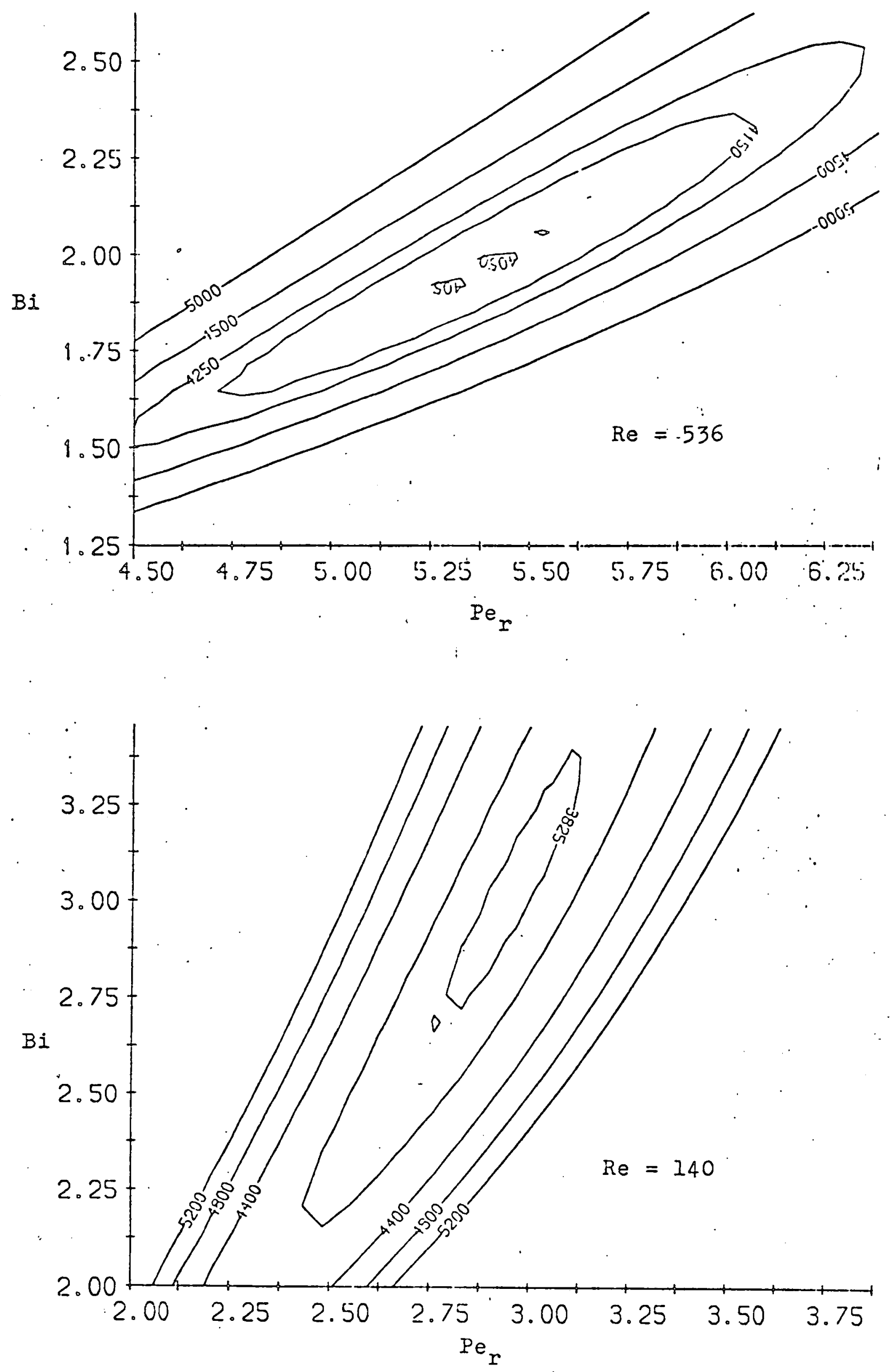

Figure 1 : $P F$ model contours, overall analysis $12.7 \mathrm{im}$ ceramic beads 

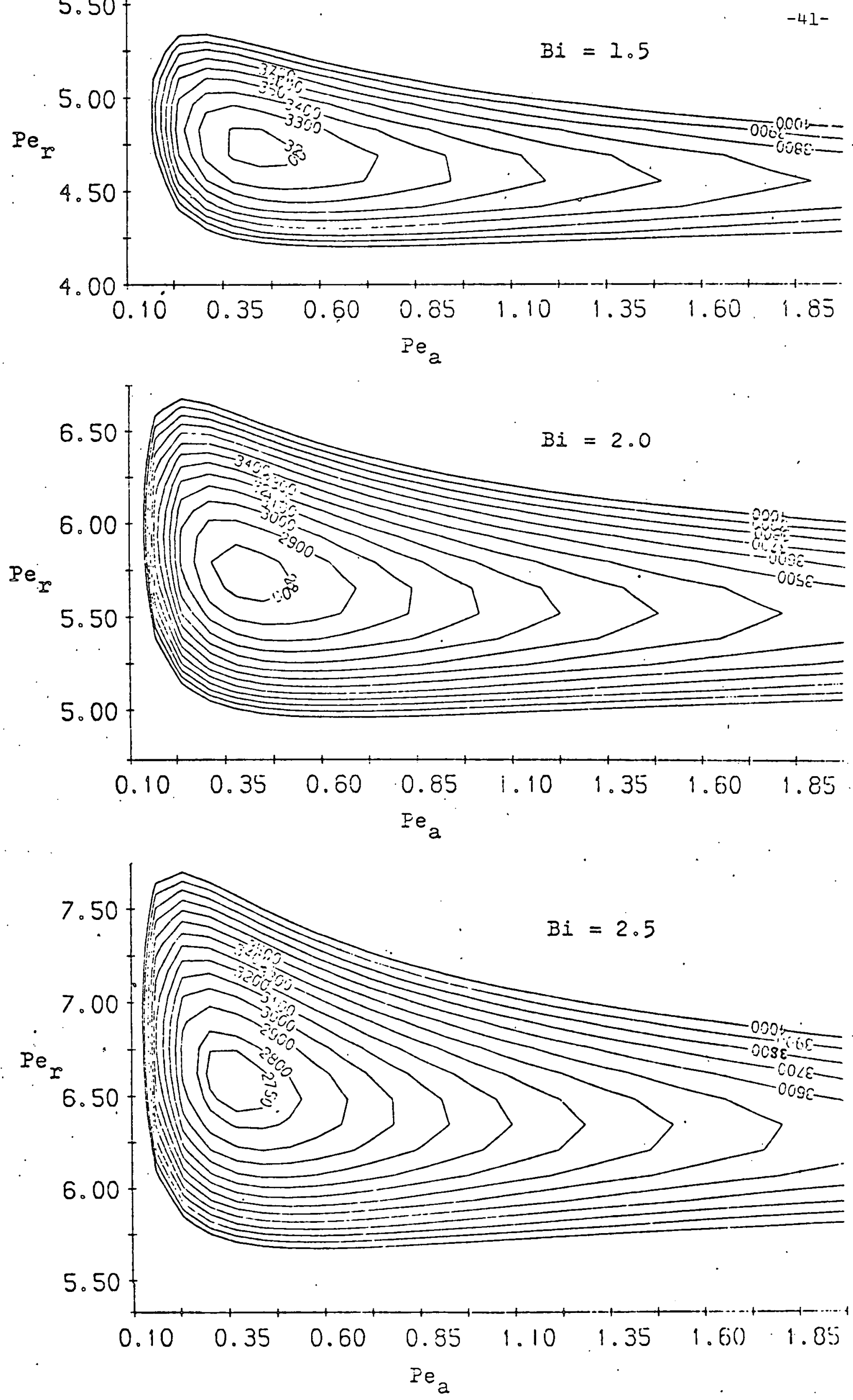

Figure 2 : $\mathrm{ADPF}(\mathrm{I} \mathrm{BC}$ ) model contours, overall analysis 

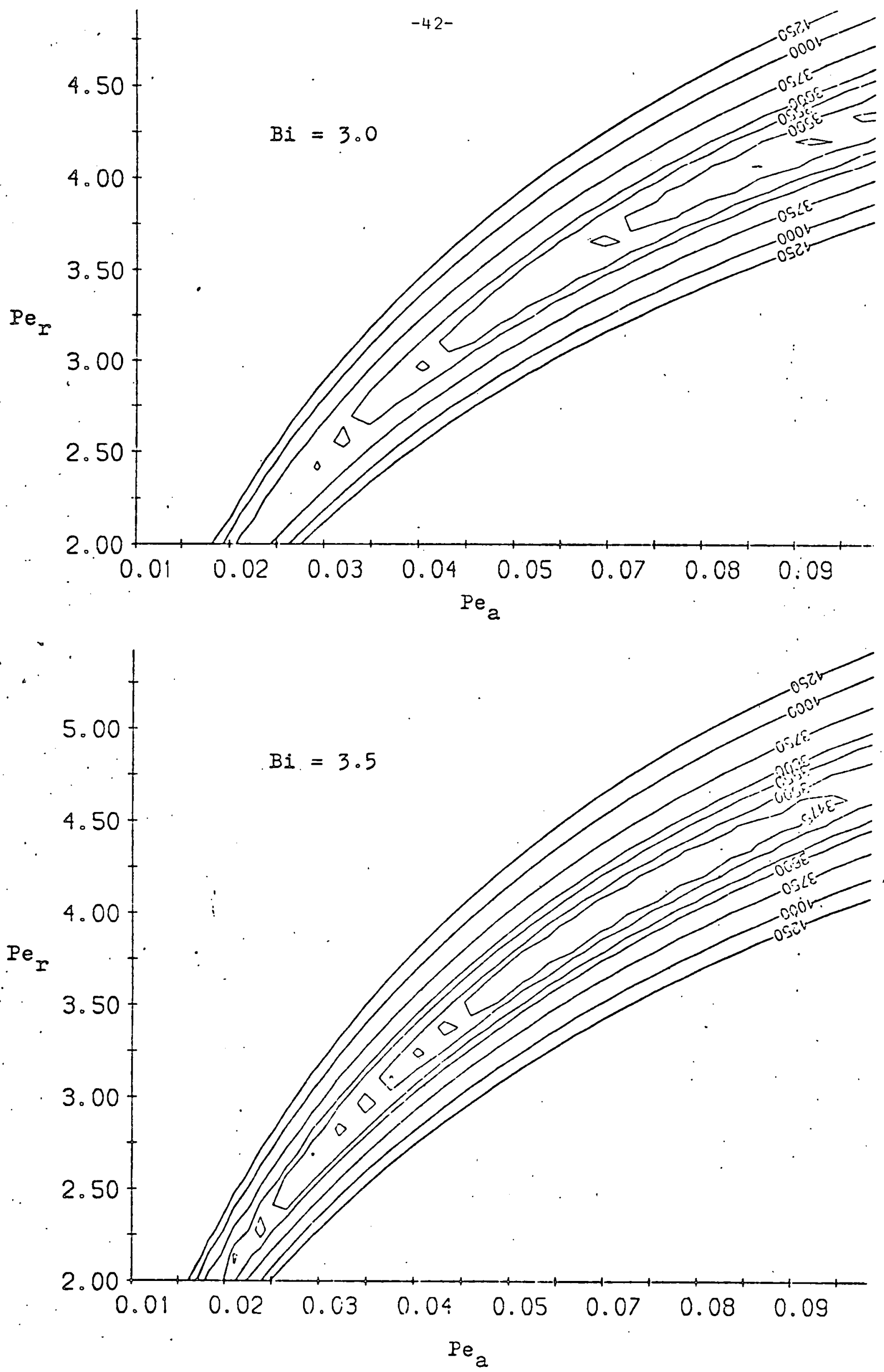

Figure 3 : ADPF(FBC) model contours, overall analysis $\operatorname{Re}=536,12.7 \mathrm{~mm}$ ceramic beads 
Due to the experimental difficulties described in chapter two, only the data for $12.7 \mathrm{~mm}$ and $9.5 \mathrm{~mm}$ ceramic beads were available for analysis for some time. The full range of proposed models (ADPF(IBC)。 $A D P F(F B C)$ and $P F)$ was therefore fitted to these data only. The model discrimination work described in section 3.5 was then carried out, and as a result of this only the $A D P F(I B C)$ model was fitted to the $6.4 \mathrm{~mm}$ ceramic beads and $9.5 \mathrm{~mm}$ steel balls data.

The results of the analysis are given in appendix $\mathrm{A}$ in tables A5-A37. The PF model was fitted in both "overall" and "depth-by-depth" modes to the exit data. The ADPF models were fitted both "overall" and "depth-by-depth" to the exit and entrance data simultaneously, and "overall" to the exit data alone. It proved impossible to obtain convergence when fitting a three-parameter model to exit data from a single bed depth. In some other cases, especially for long bed depths, no convergence was also obtained. In all these cases large. changes in the parameters produced little or no change in $S(\underline{x})$.

Since the ADPF(IBC) model gives one entrance profile regardless of bed depth, equation (I) was rewritten in terms of dimensionless temperatures so that runs of different $\mathrm{T}_{\mathrm{O}}$ and $\mathrm{T}_{\mathrm{w}}$ could be included in the "overall" analysis of this model with exit and entrance data. This has no effect on the parameter estimates obtained.

In the tables each parameter estimate is accompanied by a $95 \%$ confidence interval, calculated from equations. (4)-(6). The appropriate statistic for a single bed depth is

$$
t_{(0.025,30)}=2.04
$$

while for "overall" analysis $m-p$ may be taken as $\infty$

$$
t_{(0.025, \infty)}=1.96
$$


From this information the parameter variances are easily calculated from the confidence intervals and so are omitted from the tables.

The dimensionless parameters were actually the ones estimated; from these the physical parameters were easily obtained using the formulae

$$
\begin{aligned}
k_{r} & =(\operatorname{Re})(P r) k_{g} / P e_{r} \\
k_{a} & =(\operatorname{Re})(P r) k_{g} / P e_{a} \\
h_{w} & =k_{r} \mathrm{Bi} / \mathrm{R}
\end{aligned}
$$

where $\mathrm{k}_{\mathrm{g}}$ is conductivity of air at $25^{\circ} \mathrm{C}$, and $\mathrm{Pr}=0.72$.

To obtain their variances and covariances the formulae (2l) - (23) were expanded as Taylor series about the true parameter values, linearised, and the estimates substituted for the true values. This process leads to the formulae:

$$
\begin{aligned}
& \operatorname{var}\left(\mathrm{k}_{r}\right) \fallingdotseq\left(\mathrm{k}_{\mathrm{r}} / \mathrm{Pe}_{\mathrm{r}}\right)^{2} \operatorname{var}\left(\mathrm{Pe}_{r}\right) \\
& \operatorname{var}\left(\mathrm{k}_{\mathrm{a}}\right) \fallingdotseq\left(\mathrm{k}_{\mathrm{a}} / \mathrm{Pe}_{\mathrm{a}}\right)^{2} \operatorname{var}\left(\mathrm{Pe}_{\mathrm{a}}\right) \\
& \operatorname{var}\left(h_{w}\right) \fallingdotseq\left(k_{r} / R\right)^{2} \operatorname{var}(B i)+(B i / R)^{2} \operatorname{var}\left(k_{r}\right) \\
& -2 \mathrm{k}_{r} \mathrm{Bi} /\left(\mathrm{R}^{2} \mathrm{Pe} \mathrm{e}_{r}\right) \operatorname{cov}\left(\mathrm{Pe}_{r}, \mathrm{Bi}\right) \\
& \operatorname{cov}\left(\mathrm{k}_{a}, \mathrm{k}_{r}\right) \fallingdotseq\left(\mathrm{k}_{r} / \mathrm{Pe}_{\mathrm{a}}\right)^{2} \operatorname{cov}\left(\mathrm{Pe}_{\mathrm{a}}, \mathrm{Pe}_{r}\right) \\
& \operatorname{cov}\left(k_{r}, h_{W}\right) \fallingdotseq\left(B i / k_{r}\right) \operatorname{var}\left(k_{r}\right)-k_{r}^{2} /\left(R P e_{r}\right) \operatorname{cov}\left(P e_{r}, B i\right) \\
& \operatorname{cov}\left(k_{a}, h_{w}\right) \fallingdotseq(B i / R) \operatorname{cov}\left(k_{a}, k_{r}\right)-k_{a} k_{r} /\left(R P e_{a}\right) \operatorname{cov}\left(P_{a}, B i\right)
\end{aligned}
$$

From these the approximate $95 \%$ confidence intervals for the physical parameters were obtained.

Thus the physical parameters and confidence intervals are also given in appendix $A$.

Correlation coefficients between the parameters were also obtained from the covariances and a selection of these, in cases where the models were adequate, is also given in appendix $A$. 


\subsection{Model discrimination}

One consequence of the point of view adopted in section 3.1 is. that for each flow rate measurements made at the same radial and axial positions, but at different angular positions, may be regarded as 'replicates'. Thus the exit data at each depth give four replicate sets of eight measurements, and the entrance data give two replicate sets of six measurements.

Hence, a first test of model adequacy is to perform a conventional analysis of variance and F-test for each minimisation along the lines indicated by Kittrell (10). It should be noted, however, that the F-test applies strictly to the case of a model linear in its parameters only. For a nonlinear model it must be interpreted as an indication of the adequacy of fit, to be supported by other tests.

The pure-error sum of squares is calculated in general from

$$
\operatorname{SSPE}=\sum_{1}^{N}\left(\sum_{1}^{8} \sum_{1}^{4}\left(\mathrm{~T}_{\mathrm{obs}}-\mathrm{T}_{\mathrm{av}}\right)^{2}+\sum_{1}^{6} \sum_{1}^{2}\left(\mathrm{~T}_{\mathrm{obs}}-\mathrm{T}_{\mathrm{av}}\right)^{2}\right)
$$

where indices are omitted for clarity and the (different) averages are taken over each set of 4 and 2 replicate measurements respectively: For "depth-by-depth" analysis $\mathrm{N}=1$ and for entrance data omitted the second term is also omitted. For the $A D P F(I B C)$ model the $2 N$ entrance profiles are regarded as replicates, rather than $\mathrm{N}$ sets of 2 replicates as for the $A D P F(F B C)$ case. This requires a different formula:

$$
\operatorname{SSPE}=\sum_{1}^{N} \sum_{1}^{8} \sum_{1}^{4}\left(\theta_{o b s}-\theta_{a v}\right)^{2}+\sum_{i}^{6} \sum_{i}^{2 N}\left(\theta_{o b s}-\theta_{a v}\right)
$$

The mean square pure error is given by

$$
\mathrm{MSPE}=\mathrm{SSPE} / \mathrm{n}_{2}
$$

where

$$
n_{2}=m-\text { (no. of averages found) }
$$

MSPE is an unbiased estimate of the error variance; as this appears . to vary weakly with bed depth MSPE must be interpreted as 
estimating the depth-averaged error variance for the "overall" analysis case.

The mean lack-of-fit sum of squares is given by

$$
\text { MSLF }=(S-S S P E) / \mathrm{n}_{1}
$$

where $\quad n_{1}=m-p-n_{2}$

If the model is adequate and linear in the parameters then MSLF is an independent unbiased estimator of error variance; if the model is either inadequate or nonlinear then it is a biased estimator. Hence a test of model inadequacy may be stated

$$
F_{c}=\text { MSLF/MSPE }>F_{0.05}\left(n_{1}, n_{2}\right)
$$

The results of this test for each fit of a model to data are given in tables $\mathrm{Al}-\mathrm{A} 4$ of appendix $\mathrm{A}$.

The most stringent test of the models is provided by the case of : "overall" analysis, i.e. fitting to several bed depths simultaneously. The case of no entrance data is given in table Al. The PF model was clearly rejected in 10 out of 11 cases, with values of $F_{c} / F_{0.05}$ between 1.4 and 8 . The $A D P F(F B C)$ model gave similar results, also being clearly rejected 10 times. The $A D P F(I B C)$ model, however, was clearly rejected in only one case out of twenty-three, with typical ratio values of $0.4-1.0$. Hence little or no significant lack-of-fit was shown by this model.

The inclusion of entrance data, given in table $\mathrm{A} 2$, led to rejection of both $A D P F$ models in nearly all cases, except for the $9.5 \mathrm{~mm}$ ceramic beads data.

In the case of "depth-by-depth" analysis, the PF model fitted to exit data showed significant lack-of-fit in only two cases out of 47 . The corresponding analysis with ADPF models was not possible, entrance data had to be included. The models gave the same results, being rejected in 7 out of 47 cases; this was probably the result of the entrance data. 
In general, model fit was worst at low Re, probably due to the difficulty of measuring the development of the radial temperature profile, since at low Re the bed attained wall temperature within a few $d_{p}$ of the entrance.

Since all models exhibited no significant "lack-oif-fit" when fitted to individual bed depths, it would appear that radial profiles are adequately represented and that the overall lack-of-fit to bed exit data occurs in the axial direction. This is made clearer by plotting residuals against bed depth at the same radial position. An example for $9.5 \mathrm{~mm}$ ceramic beads at $R e=281$ and $r=9 \mathrm{~mm}$ is shown in figure 4. The inadequacy of the $P F$ and $A D P F(F B C)$ models is shown by the systematic trend of their residuals, indicating their inability to represent the axial profiles correctly. This is understandable in the case of the PF model, as axial dispersion is omitted; for the $A D P F(F B C)$ model it would appear that the finite boundary condition affects the axial profiles adversely, supporting the observations of section 2.3. There is no obvious trend in the ADPF(IBC) model residuals.

The inability of either ADPF model to fit most of the entrance data is not so easily explained. Examination of the profiles in appendix $B$ shows that in some cases there is great scatter in the 'replicates'; possibly one or two "wild" measurements are having an undue effect as only 12 measurements were taken. Also the disturbance in the packing due to the presence of the thermocouples may have adverse effects.

This first test of model adequacy points to the ADPF(IBC) model as being the only one capable of representing the data adequately. A typical fit of this model to the angular average bed exit data "overall" is shown in figure 5. 


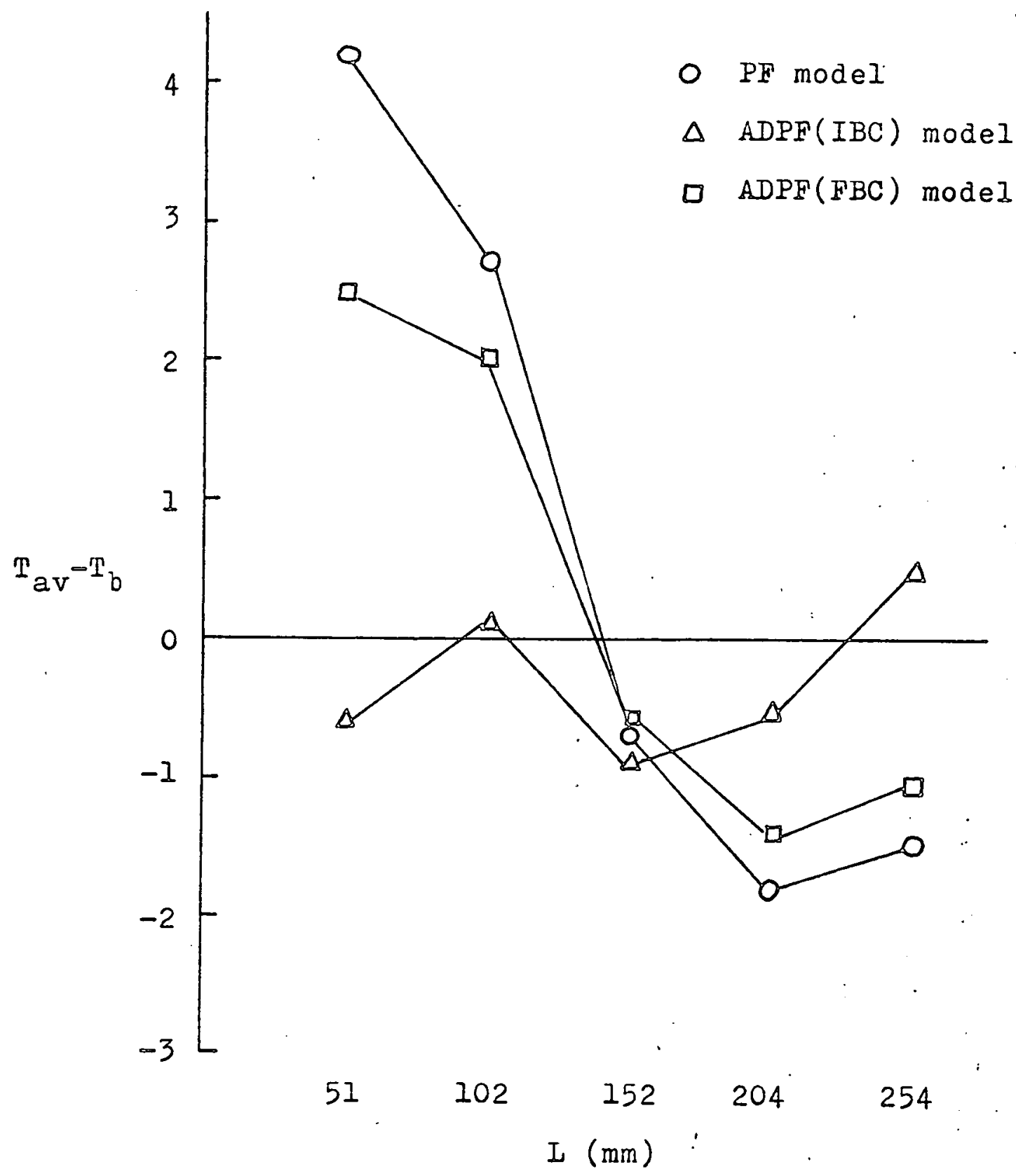

Figure 4 : Residual plot, $9.5 \mathrm{~mm}$ ceramic beads $\operatorname{Re}=281, r=9 \mathrm{~mm}$ 


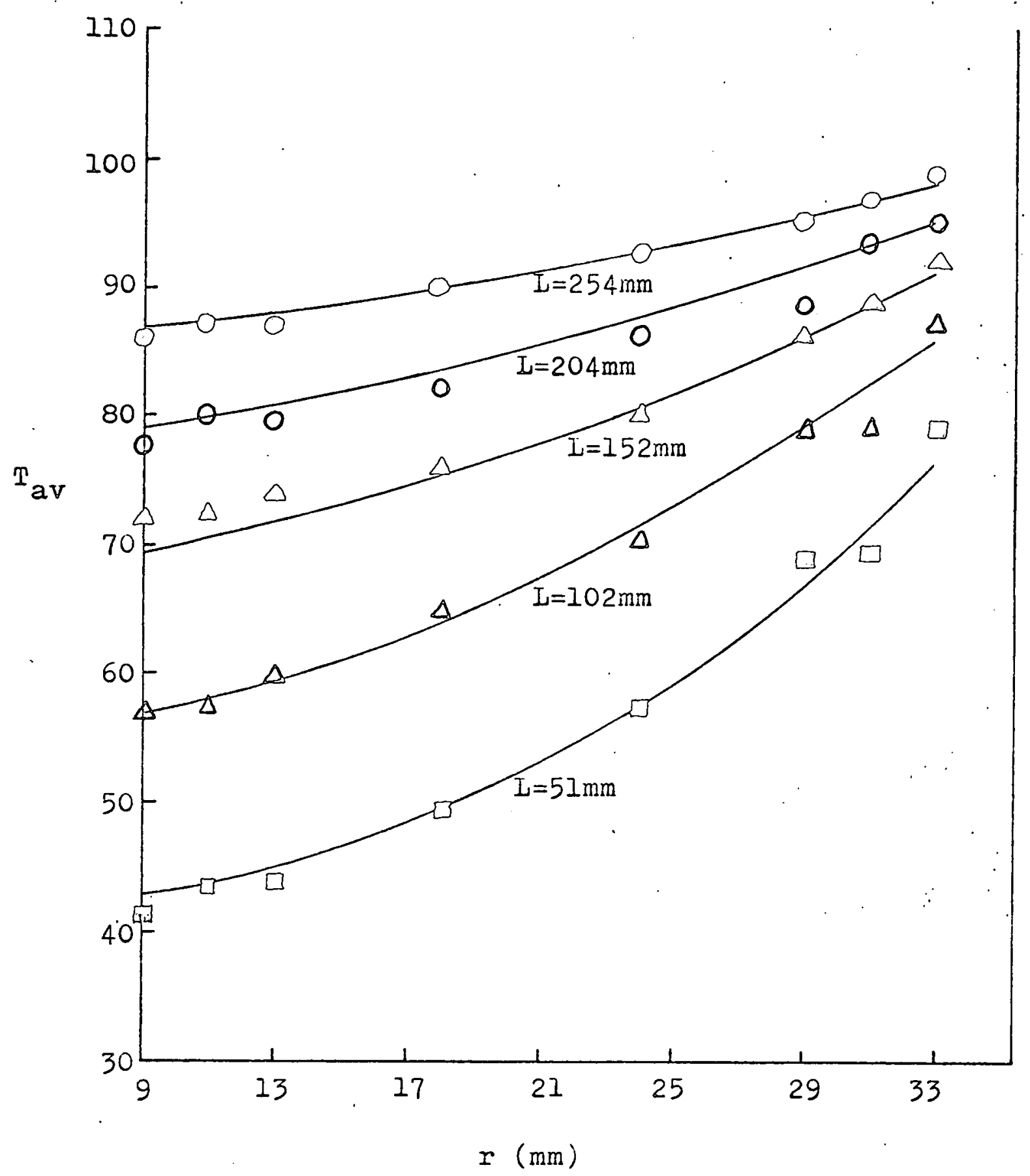

Figure 5.: Fit of $A D P F(I B C)$ model to angular average temperatures, $9.5 \mathrm{~mm}$ ceramic beads, $R e=120$ 
A second test of the models is provided by graphically examining the depth dependence of the parameters. This is done in figures 6-2I, where the results of tables A7-AIO and A26-A37 of appendix A are presented, to illustrate this dependence, when present. A key to the symbols used is given in table 1 :

\begin{tabular}{ccc} 
Symbol & $\frac{L(12.7 \mathrm{~mm} \text { ceramic })}{L(9.5 \mathrm{~mm} \text { ceramic })}$ \\
\hline & $51 \mathrm{~mm}$ & $51 \mathrm{~mm}$ \\
$\nabla$ & $102 \mathrm{~mm}$ & $102 \mathrm{~mm}$ \\
$\nabla$ & $178 \mathrm{~mm}$ & $152 \mathrm{~mm}$ \\
$\square$ & $204 \mathrm{~mm}$ & $204 \mathrm{~mm}$ \\
$Q$ & $356 \mathrm{~mm}$ & $254 \mathrm{~mm}$
\end{tabular}

Table 1 : Key to figures 6-21

In these figures parameter values corresponding to cases of nonfit by the models are omitted.

Figures 6 and 8 show that $\underline{k}_{r}$ decreases strongly with bed depth when the PF model is used. In figure 8 the $102 \mathrm{~mm}$ and $152 \mathrm{~mm}$ values are the same, as are the $204 \mathrm{~mm}$ and $254 \mathrm{~mm}$ data, hence only one set of symbols is shown in each case. The wall coefficient, $h_{\mathrm{w}}$, also appears to vary with depth and is shown in figures 7 and 9 to pass through a minimum. The depth-dependence of the parameters in the PF model was also noted by De Wasch and Froment (2.1)

When the $A D P F(I B C)$ model is used to analyse the data, figures 10 and 13 show that there is no dependence on bed depth of $k_{r}$. This is clearest in figure 13; all the cases of non-fit occurred for $12.7 \mathrm{~mm}$ ceramic beads, so there are few values in figure 10. The situation is not so clear-cut for $\mathrm{h}_{\mathrm{W}}$, there appears to be some weak dependence still in figure 14, with a shallow minimum; however this dependence is not significant within the scatter of the data. As a check figures 12 and 15 show there is no depth dependence of $\mathrm{k}_{\mathrm{a}}$. 


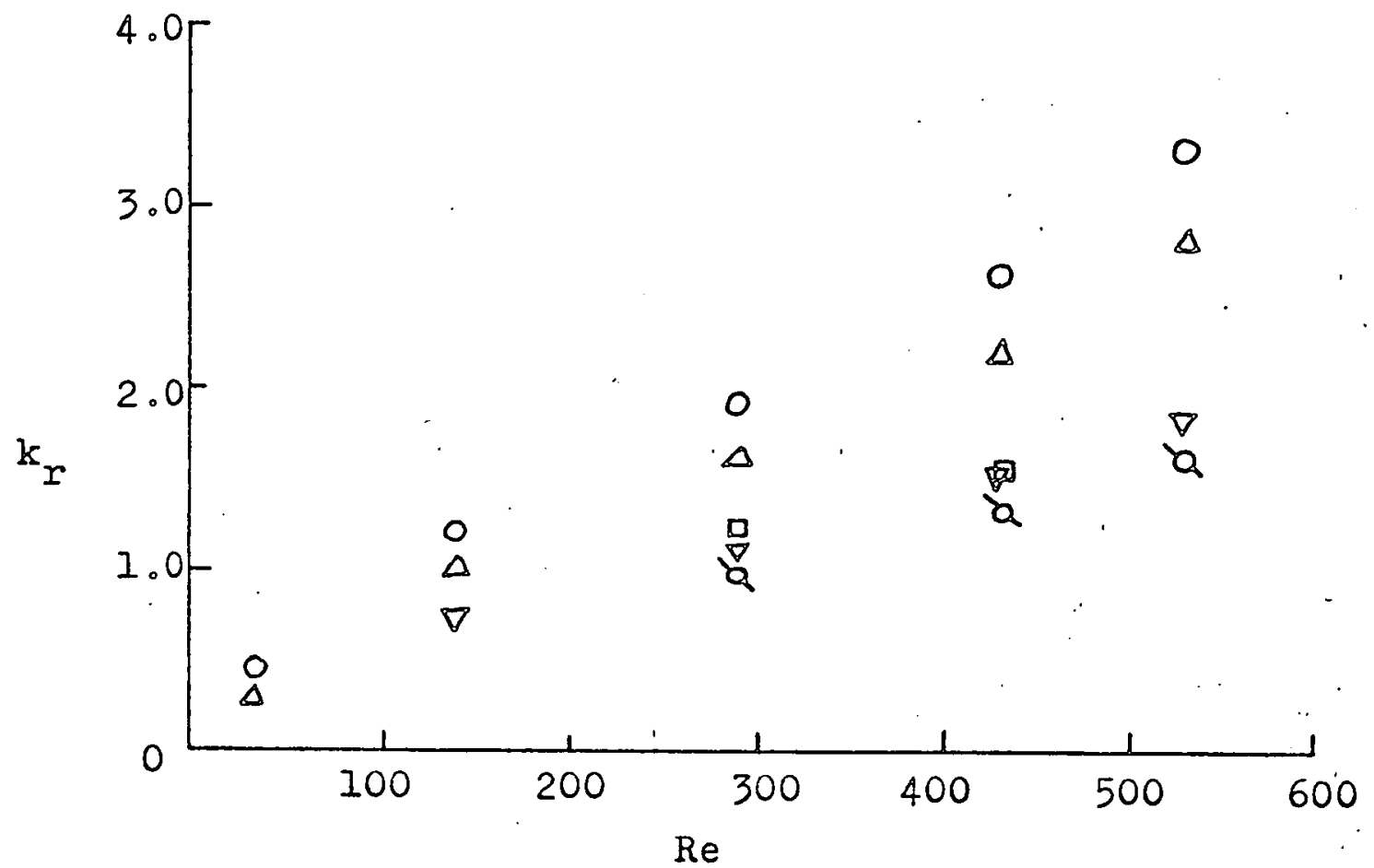

Figure 6 : Depth dependence of $\mathrm{k}_{\mathrm{r}}-12.7 \mathrm{~mm}$ ceramic beads, PF model

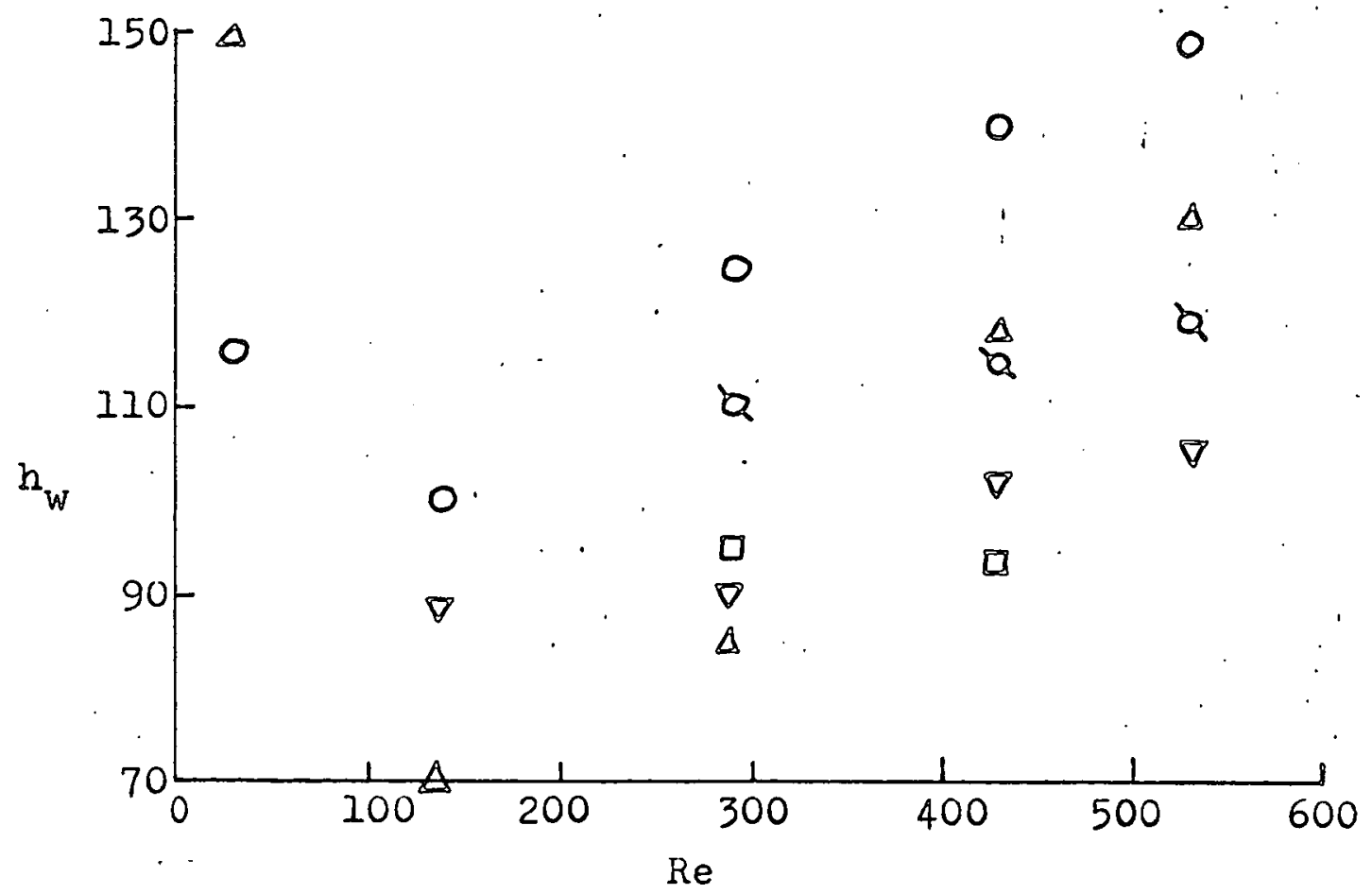

Figure 7 : Depth dependence of $\mathrm{h}_{\mathrm{w}}-12.7 \mathrm{~mm}$ ceramic beads, PF model 


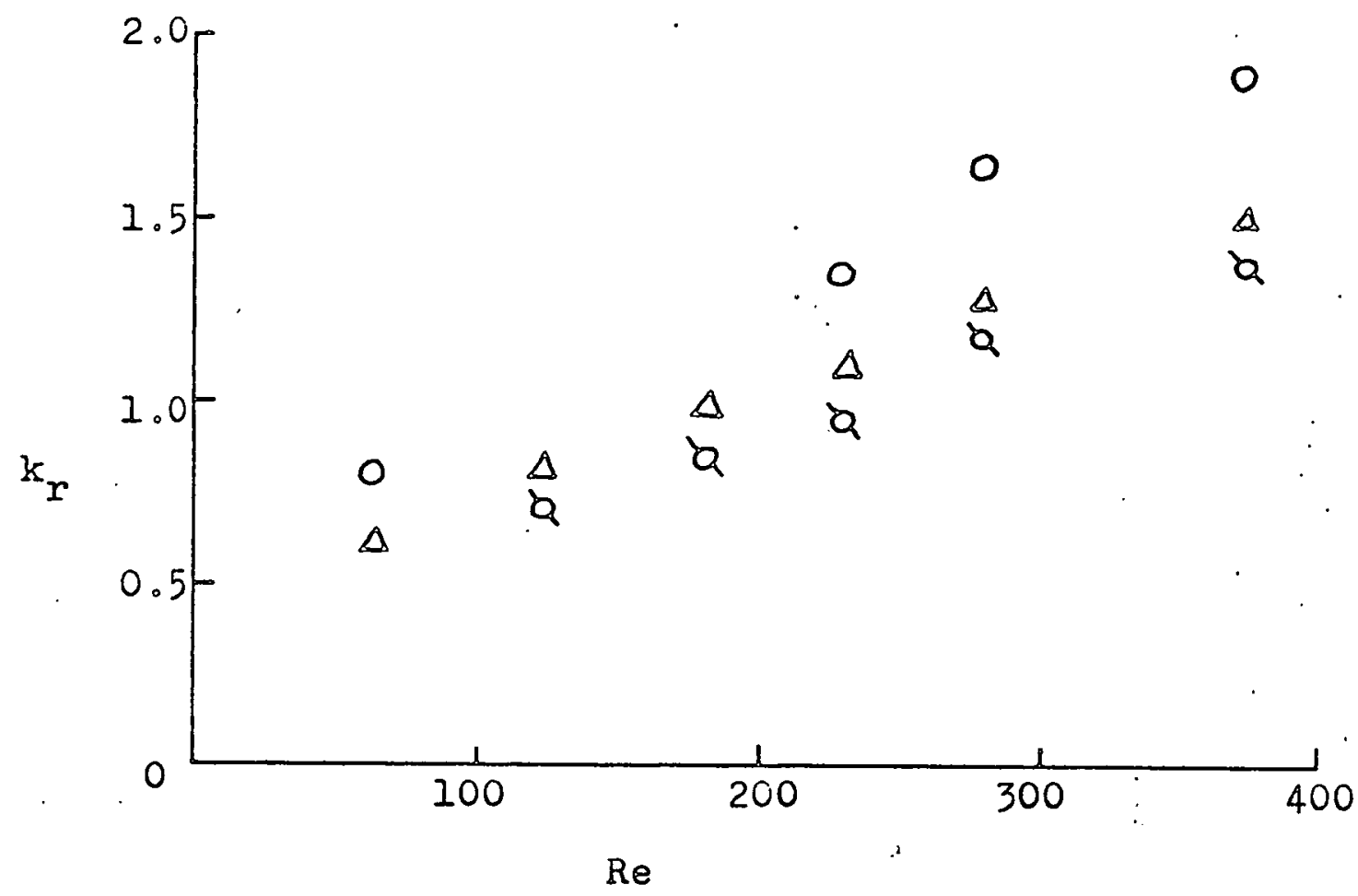

Figure 8 : Depth dependence of $k_{x}=9.5 \mathrm{~mm}$ ceramic beads, PF model

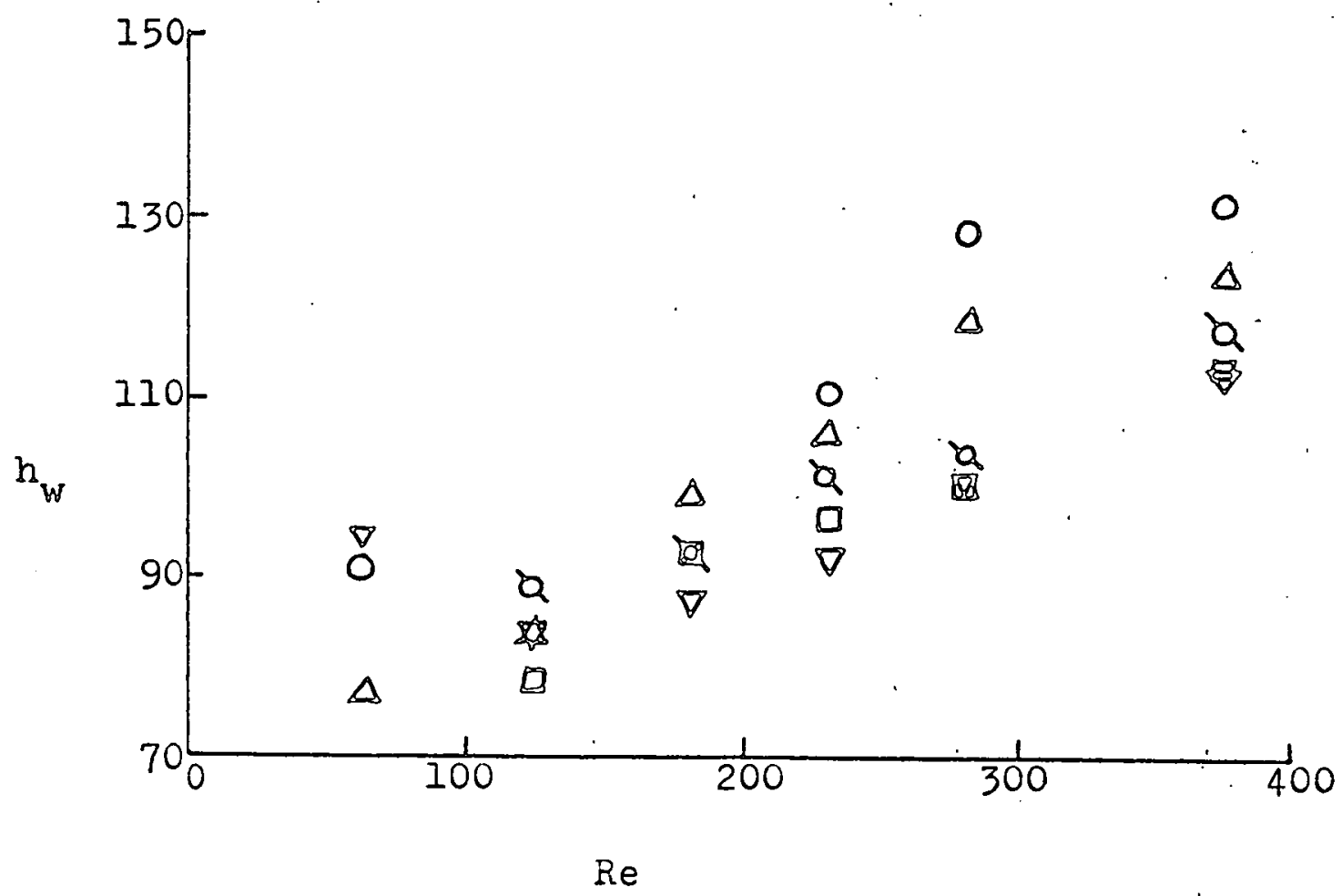

Figure 9 : Depth dependence of $\mathrm{h}_{\mathrm{w}}-9.5 \mathrm{~mm}$ ceramic beads, PF model 
$\Delta$

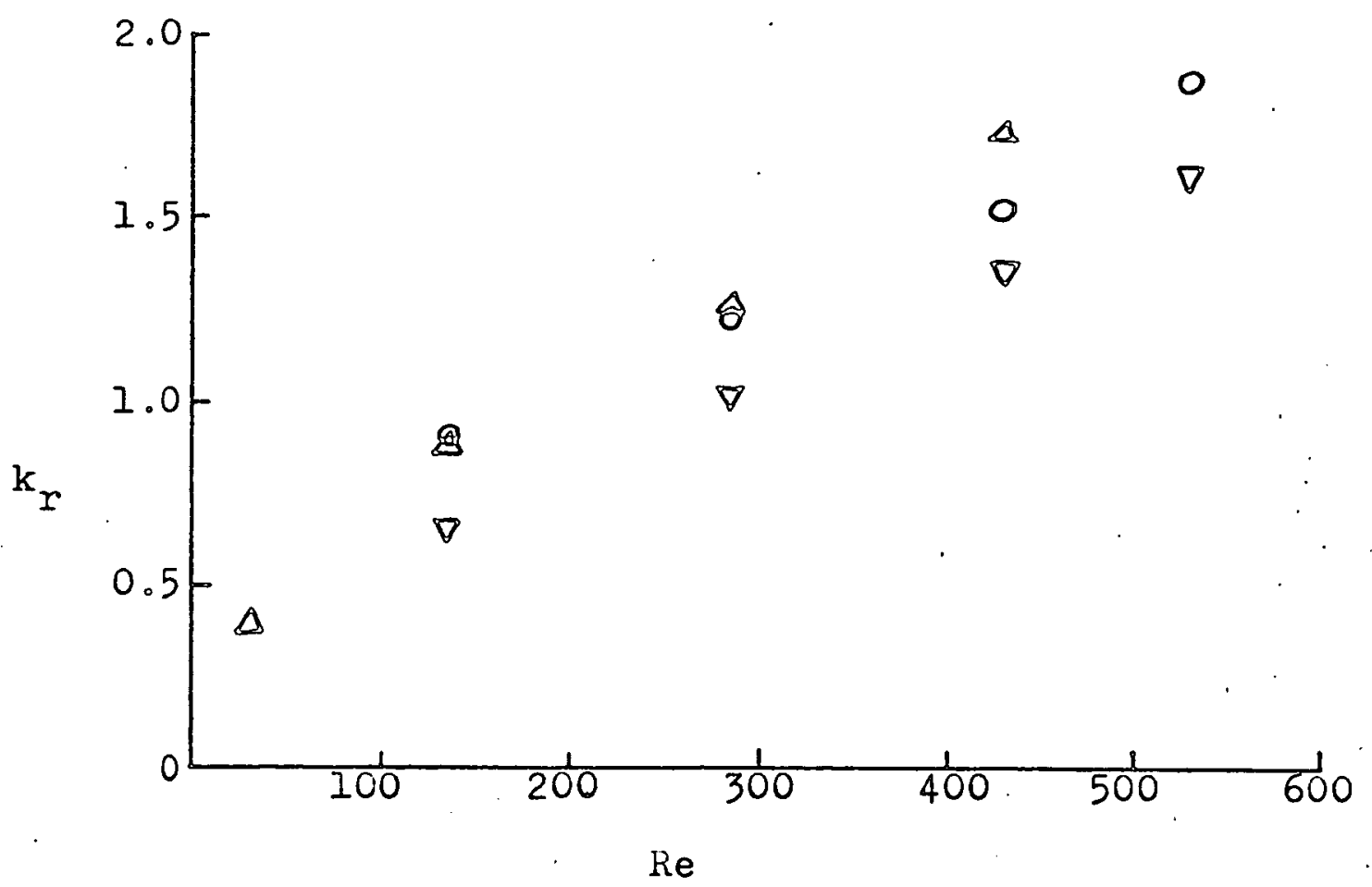

Figure 10: Depth dependence of $\mathrm{k}_{\mathrm{r}}-12.7 \mathrm{~mm}$ ceramic. beads, $A D P F(I B C)$ model

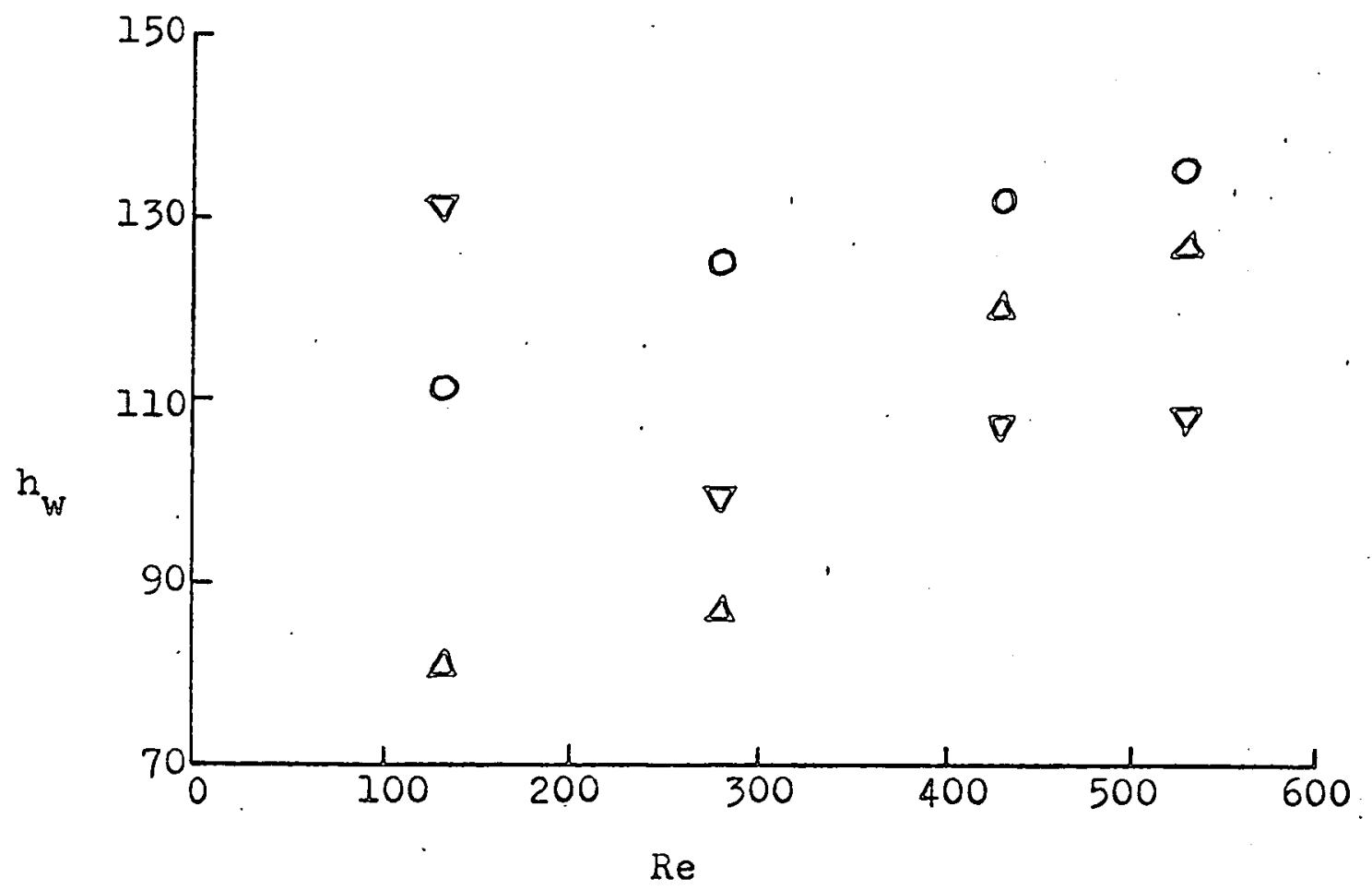

Figure 11: Depth dependence of $h_{w}-12.7 \mathrm{~mm}$ ceramic beads, $A D P F(I B C)$ model 


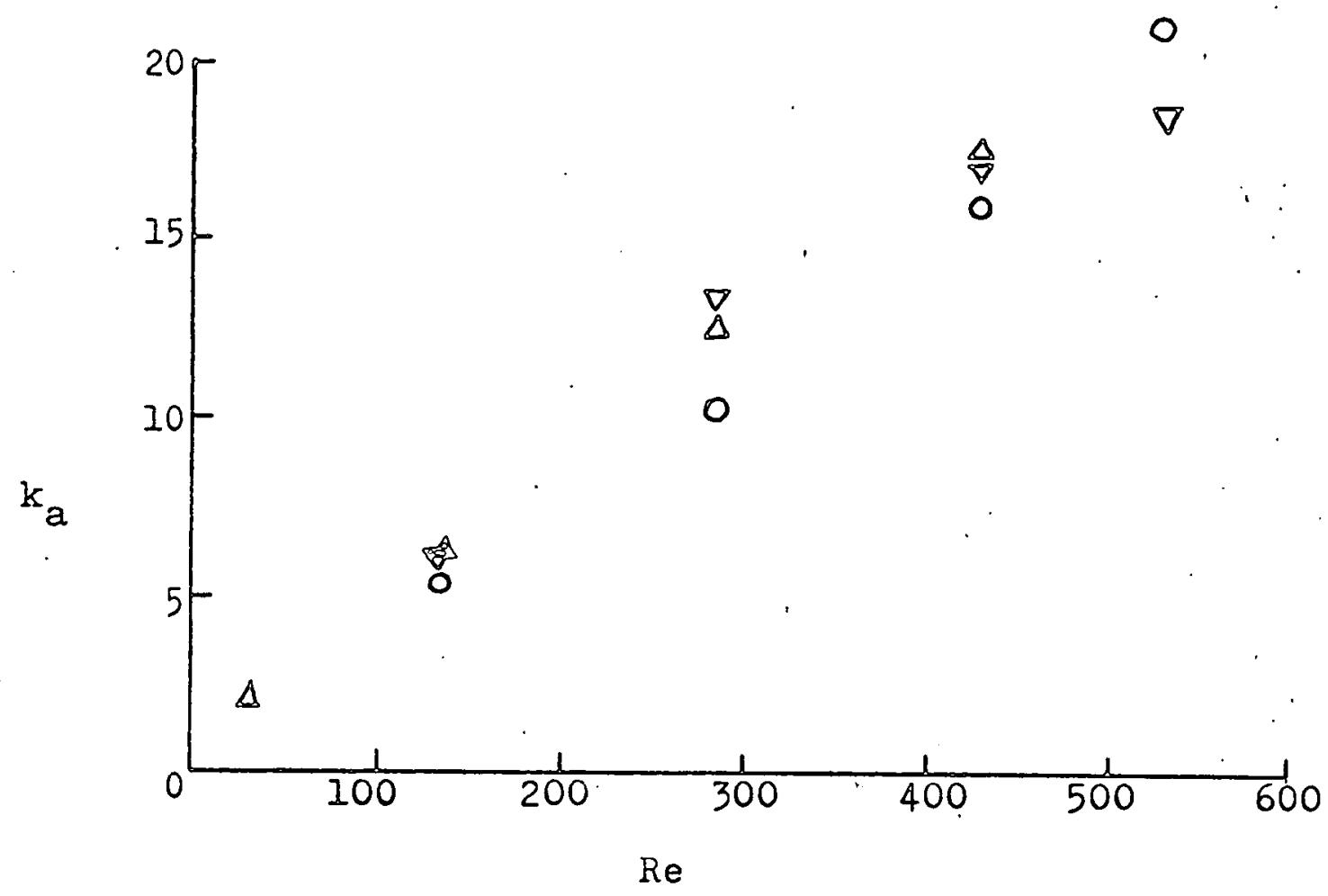

Figure 12 : Depth dependence of $\mathrm{k}_{\mathrm{a}}-12.7 \mathrm{~mm}$ ceramic beads, ADPF(IBC) model

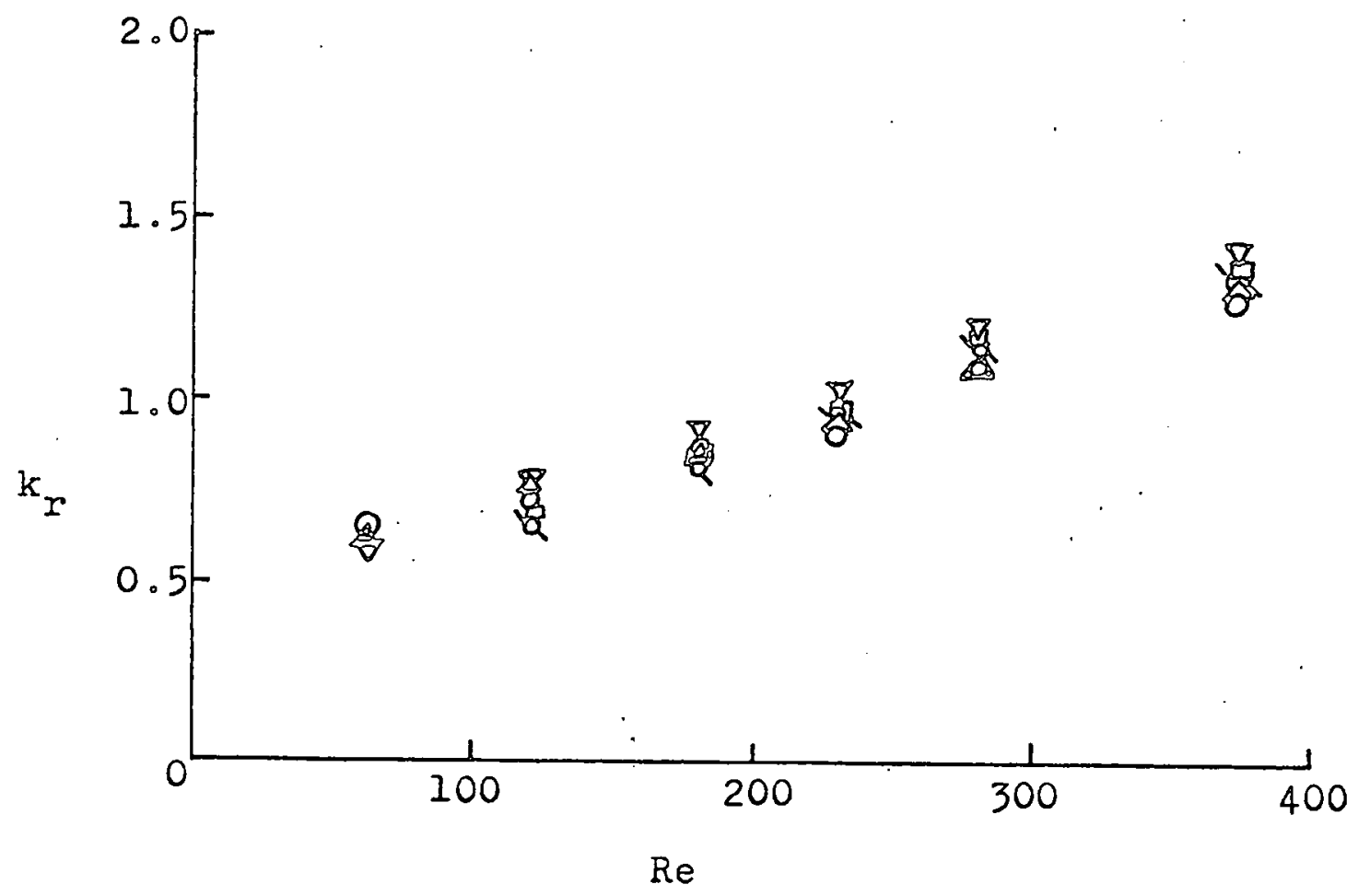

Figure 13 : Depth dependence of $\mathrm{k}_{\mathrm{r}}-9.5 \mathrm{~mm}$ ceramic beads, $A D P F(I B C)$ model 


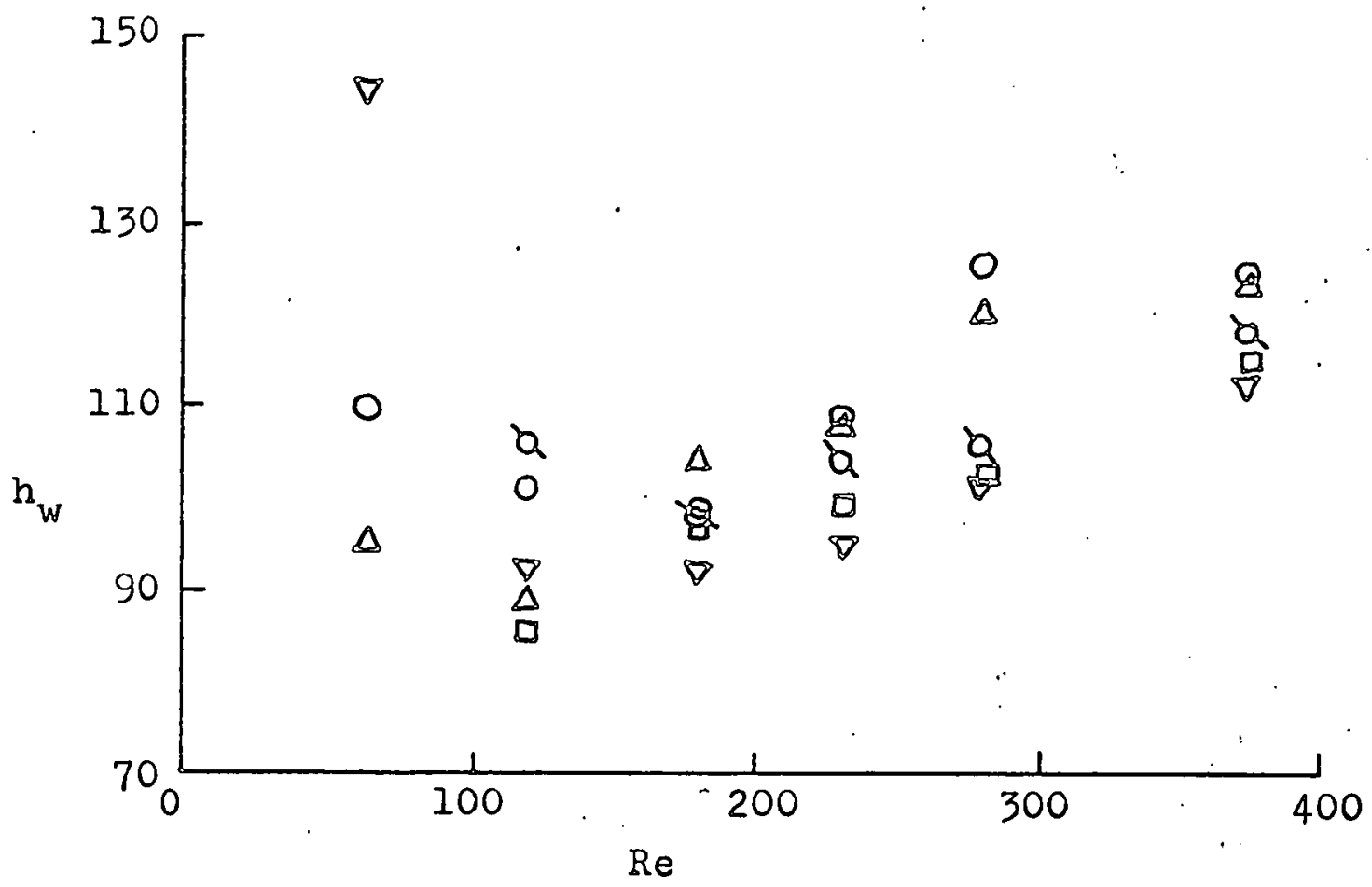

Figure $14:$ Depth dependence of $h_{w}-9.5 \mathrm{~mm}$ ceramic beads, AUPF (IBC) model

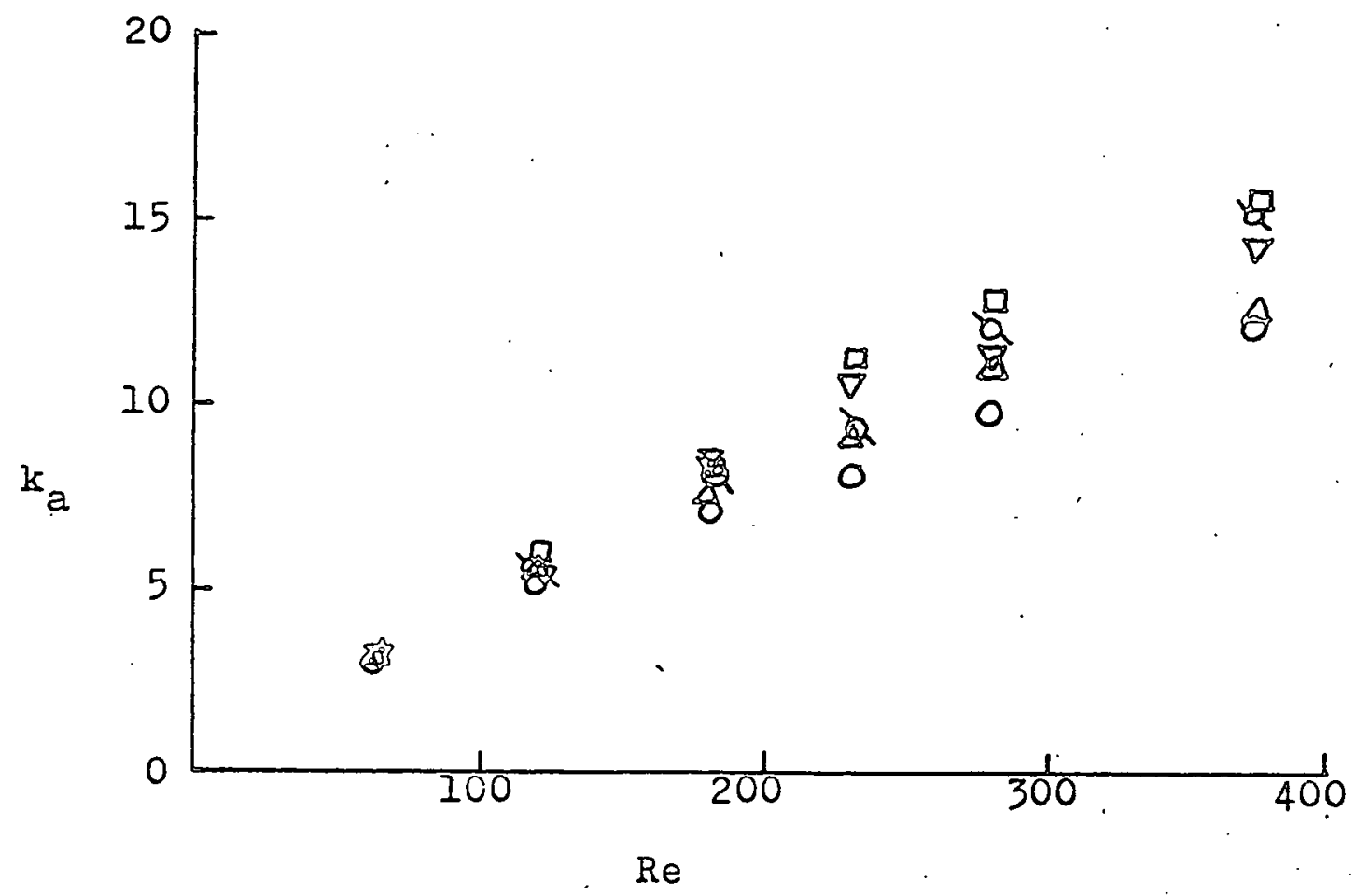

Figure 15: Depth dependence of $\mathrm{k}_{\mathrm{a}}-9.5 \mathrm{~mm}$ ceramic beads, $A D P F(I B C)$ model 


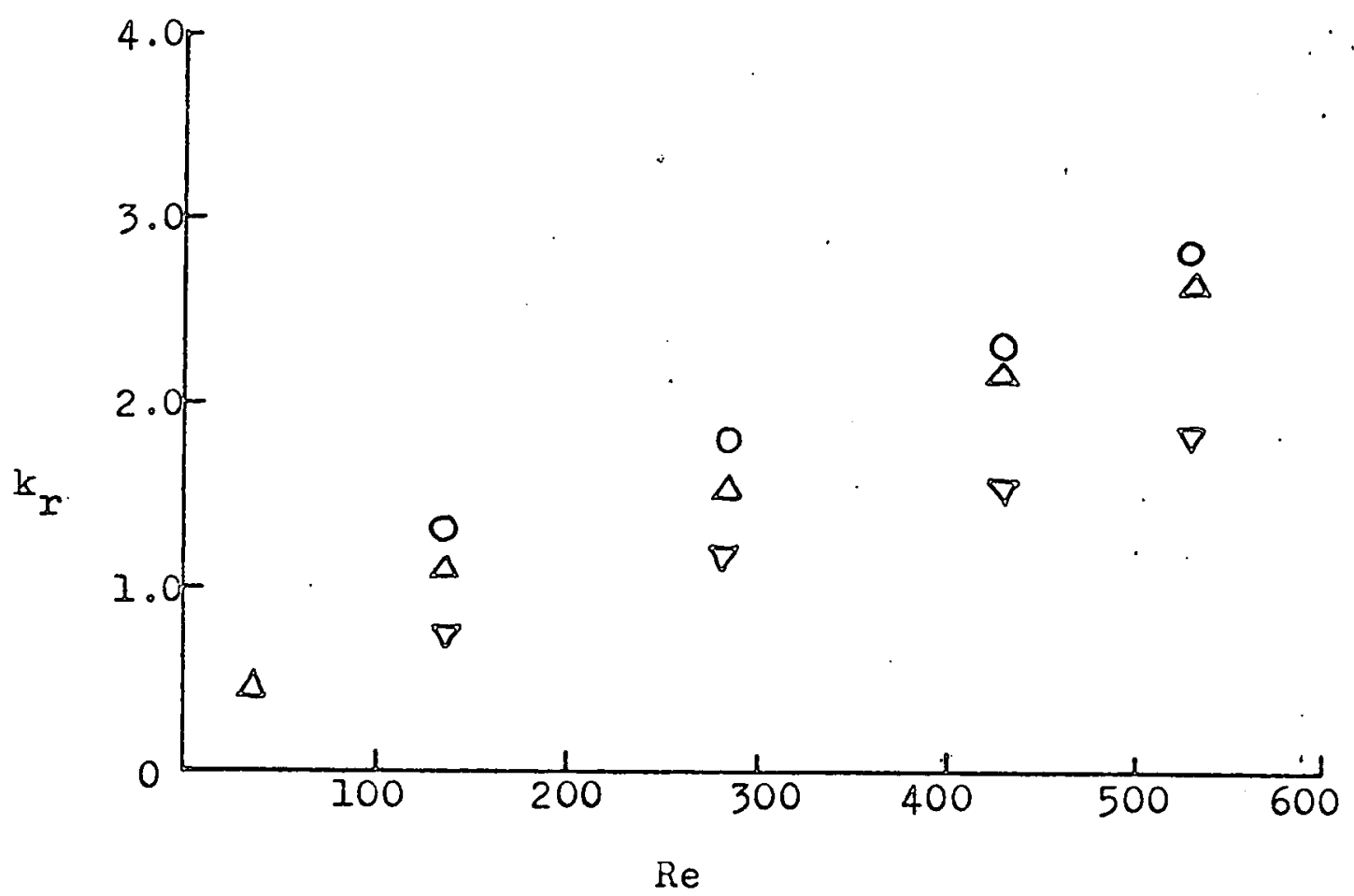

Figure 16 : Depth dependence of $\mathrm{k}_{\mathrm{r}}-12.7 \mathrm{~mm}$ ceramic beads, $A D P F(F B C)$ model

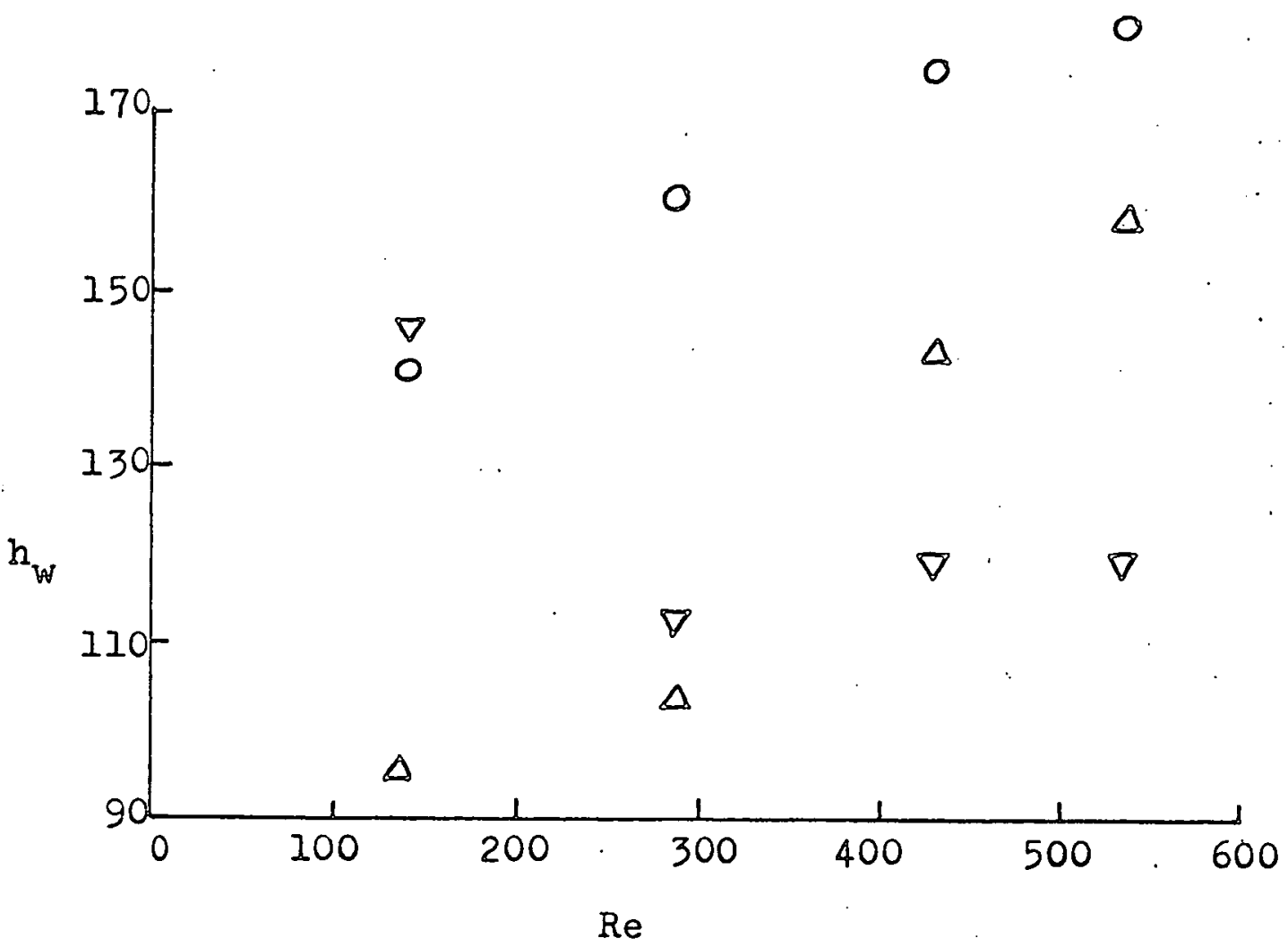

Figure 17 : Depth dependence of $h_{w}-12.7 \mathrm{~mm}$ ceramic beads, $A D P F(F B C)$ model 


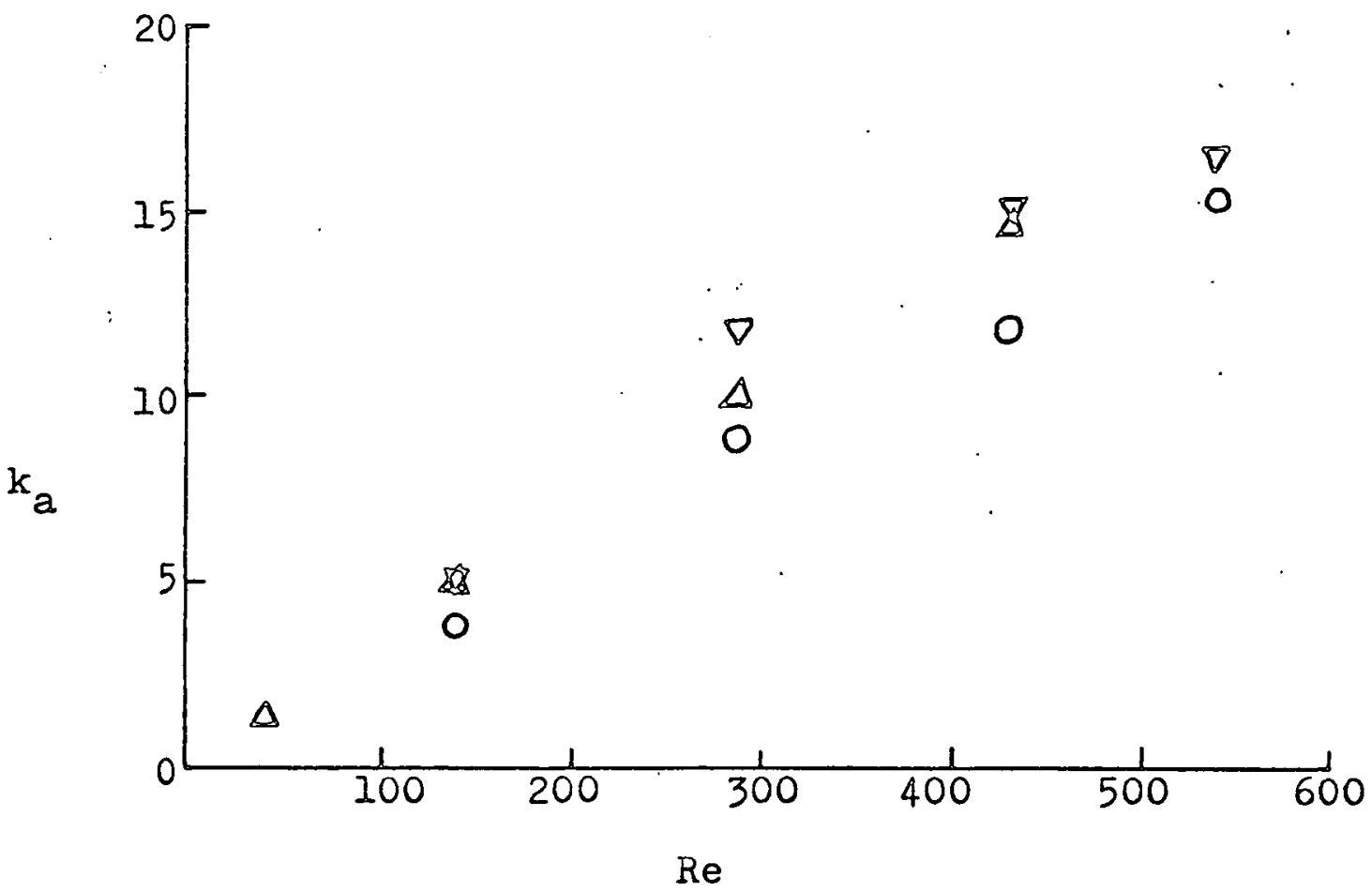

Figure 18 : Depth dependence of $\mathrm{k}_{a}-12.7 \mathrm{~mm}$ ceramic beads, ADPF(FBC) model

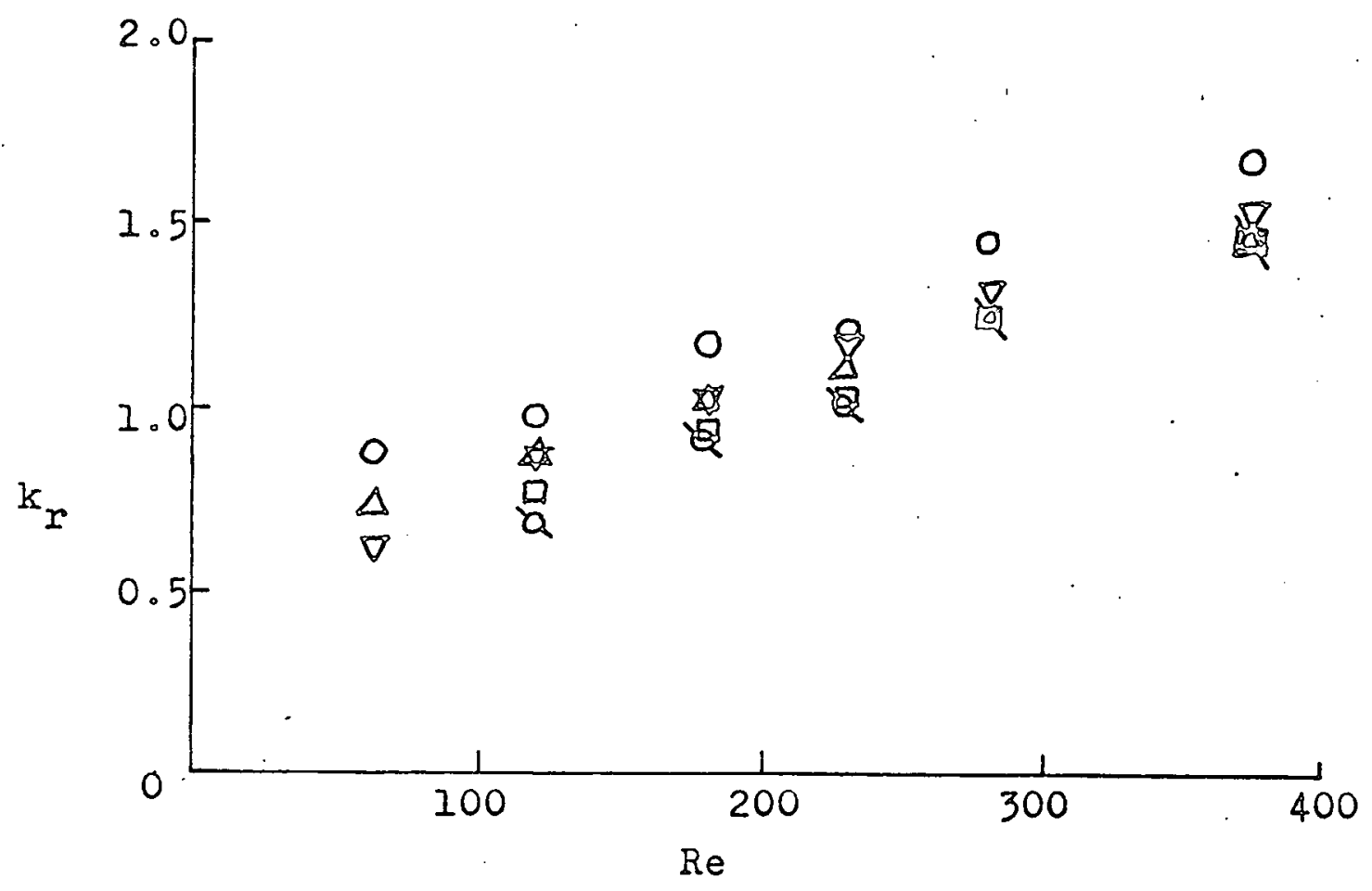

Figure 19 : Depth dependence of $\mathrm{k}_{\mathrm{r}}-9.5 \mathrm{~mm}$ ceramic beads, $A D P F(F B C)$ model 


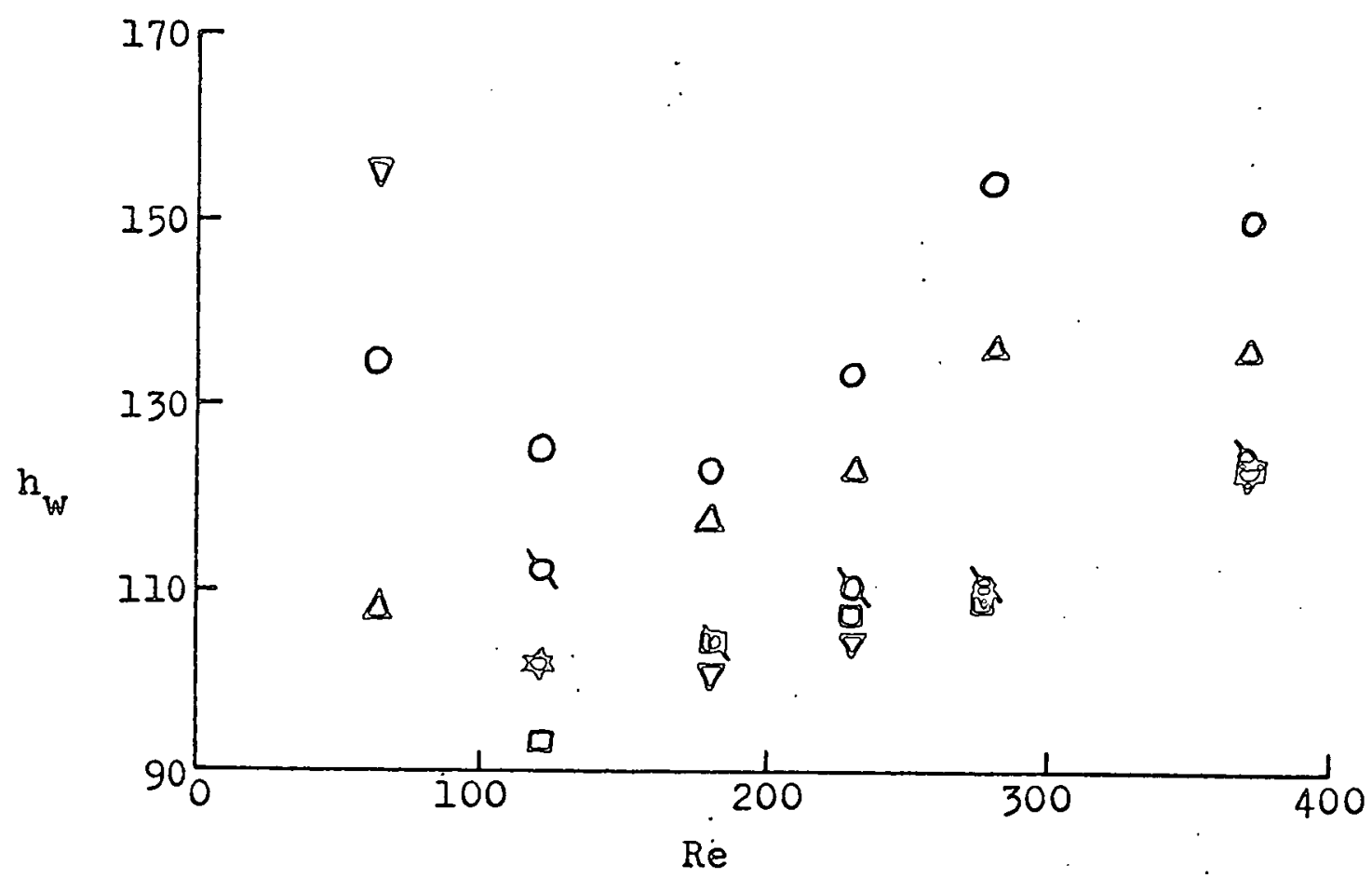

Figure 20 : Depth dependence of $h_{w}=9.5 \mathrm{~mm}$ ceramic beads, $A D P F(F B C)$ model

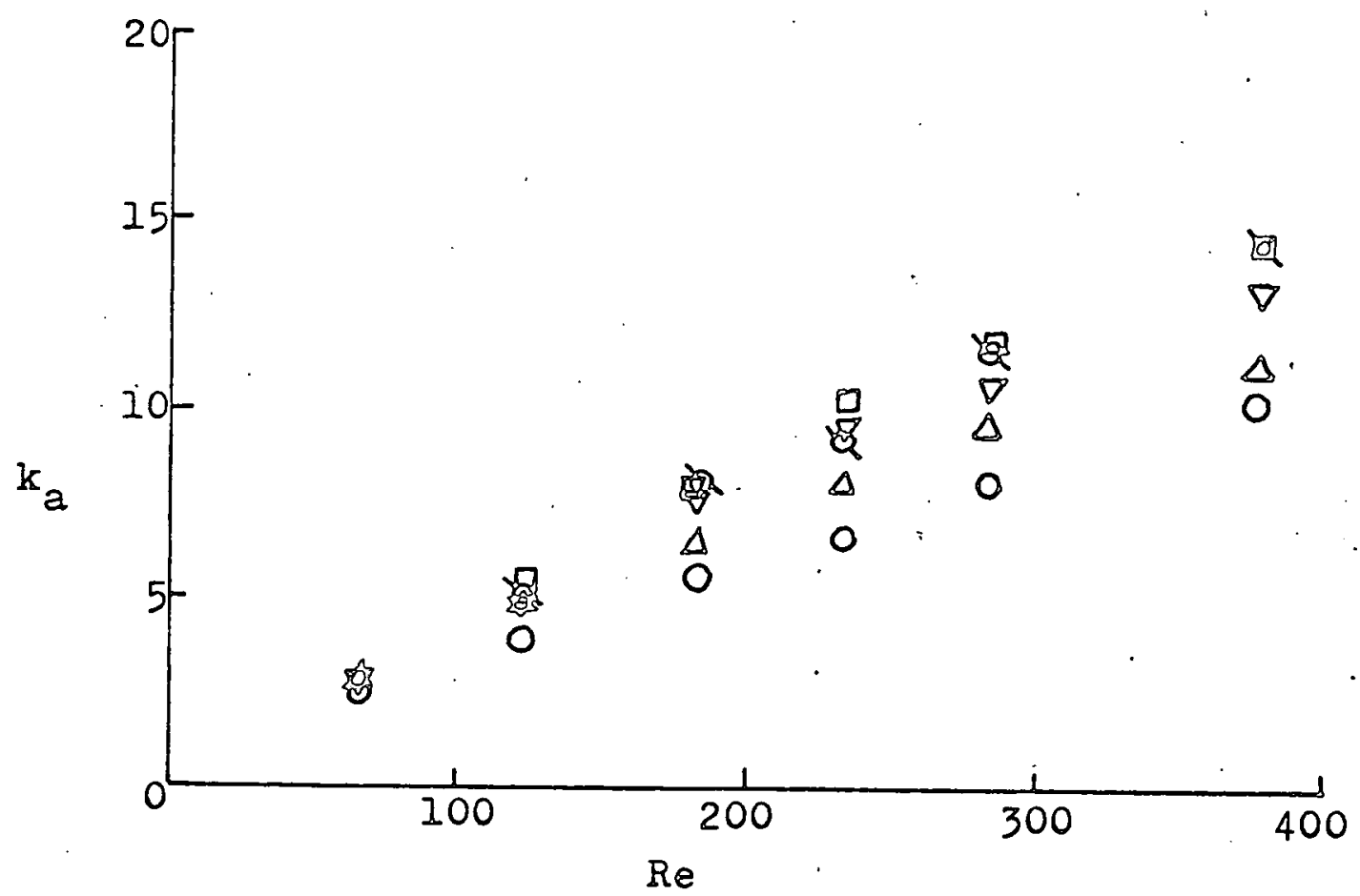

Figure 21 : Depth dependence of $k_{a}-9.5 \mathrm{~mm}$ ceramic beads, ADPF (FBC) model 
Virtually the same results hold for the ADPF(FBC) model. Figure 16 suggests that $k_{r}$ might be depth-dependent, but this is not supported by figure 19, although the values are spread more than for the IBC case. These observations support the idea that the omission of axial dispersion causes depth-dependence of parameters, but that the finite boundary condition is not realistic and causes lack-of-fit.

De Wasch and Froment correlated their data from the longest bed used, seeking to minimise axial dispersion effects. Comparison of figures 8 and 13 shows reasonable agreement for $k_{r}$; however the parameters become difficult to determine at longer bed depths and this procedure cannot be recommended.

Since the literature parameter values were all obtained using the PF model on beds of different lengths this behaviour of this model may be a significant factor in explaining some of the scatter in literature correlations.

From the above tests it is concluded that only the ADPF(IBC) model can be accepted as giving reasonable agreement with the bed exit data. Accordingly only the parameter estimates given by this model in "overall" analysis (tables Al3-Al6 in appendix A) are used in the rest of this work.

Finaliy it may be noted from tables All, Al2 and Al7 that there is a considerable degree of correlation between $k_{r}$ and $h_{w^{0}}$ whereas $k_{r}$ and $k_{a}$ appear to be independent, as do $k_{a}$ and $h_{w^{*}}$ This lends some weight to the idea that $h_{w}$ is no more than an empirical parameter needed in the model to account for a decreasing $k_{r}$ near the wall, and may have no real physical basis. 


\subsection{Empirical correlation of parameters}

The radial Peclet number $\mathrm{Pe}_{\mathrm{r}}$ and the Biot number $\mathrm{B} i$ were correlated out of curiosity against flow rate in the form of $R e$ 。 although it was felt that yet more empirical correlations would be of little use. The axial Peclet numbers were so scattered as to make correlation useless; they increased with Re in rough agreement with the values of Votruba et al. (14).

An idea of the spread in the literature data for $\mathrm{Pe}_{\mathrm{r}}$ may be obtained from table 2. In this table the results of each reference for packings nearest those of the present work are presented; the correlations have all been reduced to a common form, taking $P_{r}=0.72$ for air where necessary. Earlier authors used one correlation for all packings; later different conductivity packings were given separate correlations and more recently De Wasch and Froment included dependence on $d_{t} / d_{p}$.

The present data were correlated by standard linear regression methods (15) and gave the correlations:

$$
\begin{aligned}
& \left(\mathrm{Pe}_{r}\right)^{-1}=0.11+20.64(\mathrm{Re})^{-1} \text { for ceramic beads } \\
& \left(\mathrm{Pe}_{\mathrm{r}}\right)^{-1}=0.06+57.87(\mathrm{Re})^{-1} \text { for steel balls }
\end{aligned}
$$

All the ceramic beads data were well correlated by a single line as shown in figure 22; $95 \%$ confidence intervals are also shown.

Of more interest is the Biot number, since no literature correlations exist for this parameter. The effective wall heat transfer coefficient $h_{w}$ is invariably correlated in the form of a wall Nusselt number $\mathrm{Nu}_{\mathrm{w}}=\mathrm{h}_{\mathrm{w}} \mathrm{d}_{\mathrm{p}} / \mathrm{k}_{\mathrm{g}}{ } \quad$ The scatter of correlations for this parameter is vast, too vast to be presented here. Instead it is interesting to note that after some heuristic searching, all the present Biot number values were correlated by the single curve

$$
\operatorname{Bi}\left(d_{p} / a_{t}\right)^{\frac{1}{2}}=5.73(\operatorname{Re})^{-0.262}
$$

as shown in figure 23. 


\begin{tabular}{|c|c|c|c|c|c|c|}
\hline Authors : & Ref. & Packing_ & $d_{t} / d-$ & & Correlation & Re range \\
\hline Calderbank \& Pogorski & 11 & all & all & $\left(P e_{r}\right)^{-1}$ & $=0.15+15.6(\operatorname{Re})^{-1}$ & $50-2000$ \\
\hline Plautz \& Johnstone & 12 & all & all & $\left(P e_{r}\right)^{-1}$ & $=0.11+38.2(\operatorname{Re})^{-1}$ & $100-2000$ \\
\hline Yagi, Kunii \& Wakao & 13 & glass beads & 10 & $\left(\mathrm{Pe}_{\mathrm{r}}\right)^{-1}$ & $=0.08+11.1(\mathrm{Re})^{-1}$ & $0-800$ \\
\hline & & . & 4.8 & $\left(P e_{r}\right)^{-1}$ & $=0.06+11.1(\operatorname{Re})^{-1}$ & $0-800$ \\
\hline Agnew \& Potter & 1.1 & steel cylinders & 10 & $\left(\mathrm{Pe}_{\mathrm{r}}\right)^{-1}$ & $=0.19+20.8(\operatorname{Re})^{-1}$ & $25-350$ \\
\hline & & glass spheres. & 4.5 & $\left(\mathrm{Pe}_{r}\right)^{-1}$ & $=0.17+6.9(\operatorname{Re})^{-1}$ & $25-350$ \\
\hline De Wasch \& Froment & 2.1 & $\begin{array}{l}\text { iron oxide } \\
\text { cylinders }\end{array}$ & 10.14 & $\left(P e_{r}\right)^{-1}$ & $\begin{array}{l}=\frac{0.13}{1+40\left(d_{p} / d_{t}\right)^{2}} \\
+18.4(\operatorname{Re})^{-1}\end{array}$ & $200-900$ \\
\hline
\end{tabular}

Table 2 : Some literature correlations for effective radial thermal conductivity 


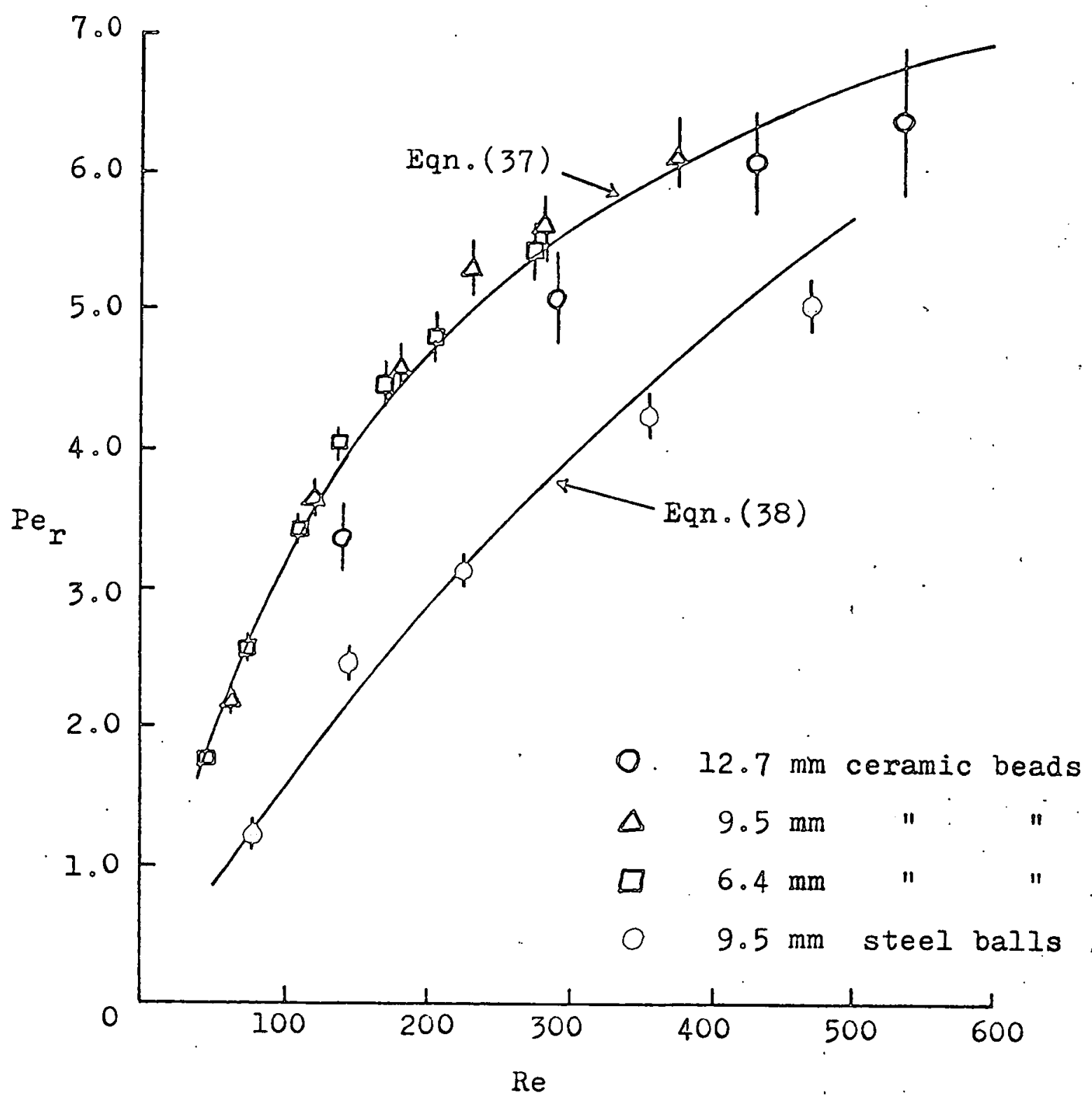

Figure 22 : Empirical correlation of radial Peclet numbers 


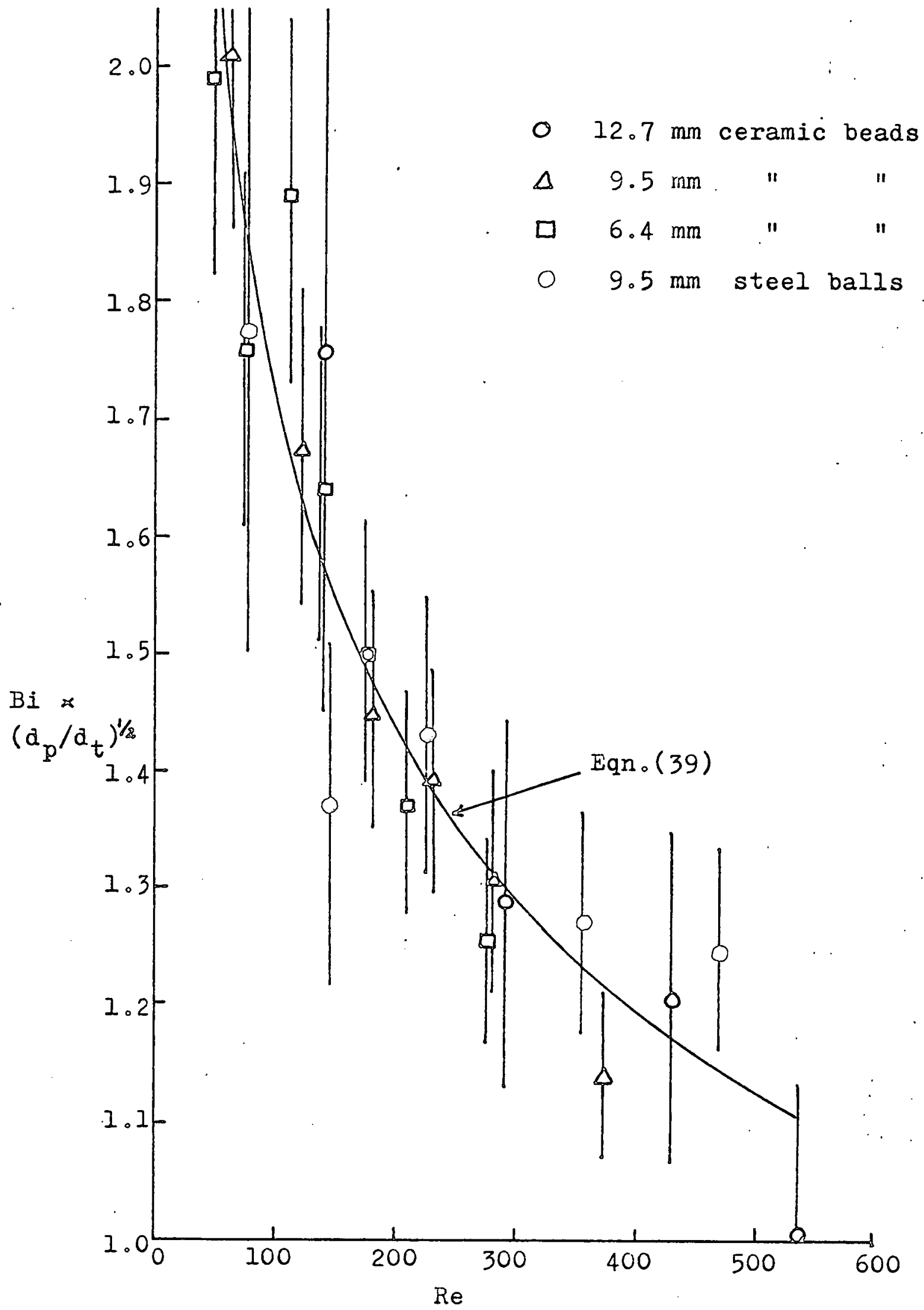

Figure 23 : Empirical correlation of Biot numbers 
Since Biot numbers for steel packing are similar to those for ceramic packing, yet $\mathrm{k}_{\mathrm{r}}$ is some $30-50 \%$ greater, these results show that $h_{w}$ is dependent on particle conductivity $k_{p}$. This implies a significant amount of heat transferred by wall-solid contacts. This could explain some of the scatter in published correlations for $h_{w}$ using packings of different conductivity.

\section{References}

1) J.R.Wolberg, Prediction Analysis, D.Van Nostrand Co.(1967).

2) J.V.Beck and K.J.Arnold, Parameter Estimation In Engineering and Science, Wiley Interscience, New York (1977).

3) W.Murray, (ed.), Numerical Methods for Unconstrained Optimization, Academic Press, London and New York, (1972).

4) Subroutine E O4 FBF, NAG Library, NAG Ltd., Oxford.

5) M.J.D. Powell, A Fortran subroutine for solving systems of nonIinear algebraic equations, Harwell report AERE - R5947。 H.M.Stationery office (1968).

6) D.W. Marquardt, An algorithm for least-squares estimation of nonlinear parameters, J.SIAM 11,431 (1963).

7) T.H.Tsang, T.F.Edgar and J.O.Hougen, Estimation of heat transfer parameters in a packed bed, Chem.Eng.J. 11,57 (1976).

8) Subroutine $\mathrm{E} 04 \mathrm{CAF}$, NAG Library, NAG Ltd., Oxford.

9) M.J.D.Powell, An efficient method for finding the minimum of a function of several variables without calculating derivatives。 Comp.J. T,155(1964).

10) J.R.Kittrell, Mathematical modelling of chemical reactions, Adv. Chem.Eng. 8,97 (1970).

1I) P.H.Calderbank and L.A.Pogorski, Heat transfer in packed beds, Trans.Inst.Chem.Engrs. 35,195(1957). 
12) D.A.Plautz and H.F.Johnstone, Heat and mass transfer in packed beds, AIChEJ I, 193 (1955).

13) S.Yagi, D.Kunii and N.Wakao, Radially effective thermal conductivities in packed beds, Int.Heat Transf. Develop. IV, 742 (1961).

14) J.Votruba, V.Hlavacek and M.Marek, Packed bed axial thermal conductivity, Chem.Eng.Sci. 27,1845 (1972).

15) C.Daniel and F.S.Wood, Fitting Equations To Data, Wiley-Interscience, New York, (1971). 


\subsection{Introduction}

It was suggested in section 1.1 and later in section 3.4 , that the empirical formulae usually obtained from studies of the present kind are rather unsatisfactory, due to the dangers of extrapolation outside the range of laboratory conditions, and also to the. great scatter in the results of different workers. In chapter three two possible explanations for this scatter were noted: (a) model inadequacy leading to systematic bias in the parameter estimates; (b) failure to include dependence on variables such as particle conductivity in the correlating formulae. The former cause may be eliminated by statistical testing of models fitted to the data; the latter cause is more difficult, as the "effective" parameters estimated "lump" together several processes, thus denying the engineer the use of physical intuition. A prohibitive amount of experimentation would be required to determine the effect of every variable.

For these reasons it is desirable to employ a theoretical approach which allows prediction of the effective parameters. By "theoretical approach" is meant the development of a model relating effective heat transfer parameters to the essential underlying and independently measurable heat transfer processes, so that no empirical or adjustable constants are involved. The remainder of the present work is concerned with such a development.

Previous work in this area is relatively scarce, and has for the most part followed the lines begun by Argo and Smith (l्) for the prediction of effective radial conductivity from a physical model of contacting spheres in the bed. This approach has been successful in 
predicting effective radial stagnant conductivity $\mathrm{k}_{\mathrm{r}}{ }^{0} \cdot\left(\underline{2}_{0} \underline{3}\right)$, and the extension to flow conditions, assuming additivity of static and dynamic contributions, has been successful for beds of reasonably large $a_{t} / a_{p}(\underline{3.13})$, although less so for beds of low $a_{t} / a_{p}(1.1)$. A general approach, applicable to all the parameters, is, however, lacking.

A different approach is proposed here, in which a two-phase diffusional model is considered, which contains many, if not all, of the basic heat transfer parameters which are believed to be effective and which can be determined experimentally. Relationships between the parameters of this model and those of the $A D P F(I B C)$ model are obtained by "matching" their solutions in a sense defined later. This procedure deals with all the effective parameters simultaneously; the relationships found are compared with experimental results in chapter 5 .

\subsection{Two-phase continuum model}

The two-phase model considered here is similar to that proposed by Olbrich (1.15) and considered briefly in section 1.3. It would appear to be the natural extension to two phases of homogeneous continuum models, in that each phase is regarded as a homogeneous continuum. Thus different temperature profiles in solid and fluid phases are allowed.

This approach may appear contradictory, in that the solid particles in the bed are essentially discrete, having, in the case of spheres, no more than negligibly small finite area contacts. However, if the "pockets" of stagnant fluid surrounding each contact are included as part of the "solid" phase, rather than the fluid, then it is possible to regard this "solid" phase as a continuum, with an 
effective solid conductivity. This conductivity is further interpreted in a later section.

The main reason for preferring this model is that it allows for particle-to-particle heat transfer, and also particle-to-wall heat transfer. These have been shown to be important, at least for beds of low $d_{t} / d_{p}$, both in the present work and by Paterson (1.3).

It should be noticed that the model presented here is more general than that of Olbrich, in that axial dispersion in both phases is included. The assumptions made in setting up the ADPF(IBC) model are retained. The resulting differential heat balances yield:

\section{Fluid phase}

$k_{r f}\left(\frac{\partial^{2} T}{\partial r^{2}} \& \frac{1}{r} \frac{\partial T}{\partial r}\right)+k_{a f} \frac{\partial^{2} T}{\partial z^{2}}-a h(T-t)=G c_{p} \frac{\partial T}{\partial z}$

\section{Solid phase}

$k_{r s}\left(\frac{\partial^{2} t}{\partial r^{2}}+\frac{1}{r} \frac{\partial t}{\partial r}\right)+k_{a s} \frac{\partial^{2} t}{\partial z^{2}}+$ ah $(T-t)=0$

with boundary conditions

$$
\begin{aligned}
& \frac{\partial T}{\partial r}=\frac{\partial t}{\partial r}=0 \text { at } r=0 \\
& -k_{r f} \frac{\partial T}{\partial r}=\left\{\begin{array}{ll}
h_{W f}\left(T-T_{W}\right) & z>0 \\
h_{W f}\left(T-T_{0}\right) & z<0
\end{array} \text { at } r=R\right. \\
& -k_{r s} \frac{\partial t}{\partial r}=\left\{\begin{array}{ll}
h_{W s}\left(t-T_{w}\right) & z>0 \\
h_{W S}\left(t-T_{0}\right) & z<0
\end{array} \text { at } r=R\right. \\
& t, T \rightarrow T_{0} \quad \text { as } \quad z \rightarrow-\infty \\
& t, T \rightarrow T_{W} \text { as } z \rightarrow \infty \\
& \mathrm{T}\left(0^{+}\right)=\mathrm{T}\left(0^{-}\right) ; t\left(0^{+}\right)=t\left(0^{-}\right) \\
& \frac{\partial T}{\partial z}\left(0^{+}\right)=\frac{\partial T}{\partial z}\left(0^{-}\right) ; \quad \frac{\partial t}{\partial z}\left(0^{\dagger}\right)=\frac{\partial t}{\partial z}\left(0^{-}\right)
\end{aligned}
$$


The boundary conditions for this model have been chosen to suit the bed geometry of the present study. The parameters in the model are interpreted and discussed in section 4.5. As usual it is convenient to render the equations dimensionless:

\section{Fluid phase}

$\frac{1}{P e_{R F}}\left(\frac{\partial^{2} T^{n}}{\partial y^{2}}+\frac{1}{y} \frac{\partial T^{n}}{\partial y}\right)+\frac{1}{P e_{A F}} \frac{\partial^{2} T^{n}}{\partial x^{2}}-\frac{N F}{P e_{R F}}\left(T^{n}-t^{n}\right)=\frac{\partial T^{n}}{\partial x}$

\section{Solid phase}

$$
\left(\frac{\partial^{2} t^{\prime \prime}}{\partial y^{2}}+\frac{1}{y} \frac{\partial t^{\prime \prime}}{\partial y}\right)+K \frac{\partial^{2} t^{n}}{\partial x^{2}}+N_{S}\left(T^{\prime \prime}-t^{\prime \prime}\right)=0
$$

and the boundary conditions become

$$
\begin{aligned}
& \frac{\partial T^{*}}{\partial y}=\frac{\partial t^{*}}{\partial y}=0 \text { at } y=0 \\
& \frac{\partial T^{*}}{\partial y}+B i_{f} T^{*}=\left\{\begin{array}{l}
B i_{f} x>0 \\
0 x<0
\end{array} \text { at } y=1\right. \\
& \frac{\partial t^{*}}{\partial \mathrm{y}} \& \mathrm{Bi}_{s} t^{*}=\left\{\begin{array}{ll}
\mathrm{Bi}_{\mathrm{s}} \mathrm{x}>0 \\
0 & \mathrm{x}<0
\end{array} \text { at } \mathrm{y}=1\right. \\
& t^{*}, T^{*} \rightarrow 0 \text { as } x \rightarrow-\infty \\
& t^{*}, T^{*} \rightarrow 1 \text { as } x \rightarrow \infty \\
& T^{n}\left(0^{+}\right)=T^{n}\left(0^{-}\right) ; t^{n}\left(0^{+}\right)=t^{n}\left(0^{-}\right) \\
& \frac{\partial T^{\ddot{n}}}{\partial \mathrm{x}}\left(0^{+}\right)=\frac{\partial \mathrm{T}^{\ddot{*}}}{\partial \mathrm{x}}\left(0^{-}\right) ; \frac{\partial t^{*}}{\partial \mathrm{x}}\left(0^{+}\right)=\frac{\partial t^{*}}{\partial \mathrm{x}}\left(0^{-}\right)
\end{aligned}
$$

It is the dimensionless equations (10) - (18) which are solved in 4.3.

\subsection{Approximate solutions}

Olbrich (1.15) obtained a (complicated) exact analytical solution of the two-phase model by neglecting axial conduction terms in both phases. This procedure cannot be followed here as matching with an 
axially-dispersed model is required. To date, a totally-determined analytic solution of the full model does not appear possible. Also, since matching of models usually means equating the first terms of respective infinite series solutions, itself an approximate procedure, it is preferable to derive approximate solutions of the models at the outset.

The radial derivatives in equations (10) - (18) are first discretised by a one-point collocation technique, as described by Villadsen and Michelson (4). The collocation point is chosen, after consideration of the form of the wall boundary conditions (13) and (14), to be the zero of the first degree symmetric Legendre polynomial

$$
P_{1}(0,0) \cdot\left(y^{2}\right)=2 y^{2}-1
$$

Denote this by $y_{1}(=1 / \sqrt{2})$ and further let $y_{2}=1$; then write

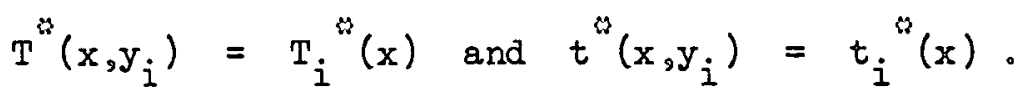

Then, suppressing arguments,

$$
\begin{aligned}
& \left(\frac{\partial^{2} \mathrm{~T}^{*}}{\partial \mathrm{y}^{2}}+\frac{1}{\mathrm{y}} \frac{\partial \mathrm{T}^{*}}{\partial \mathrm{y}}\right)_{\mathrm{y}=\mathrm{y}_{1}}=-8 \mathrm{~T}_{1}{ }^{\mu}+8 \mathrm{~T}_{2}{ }^{*} \\
& \left(\frac{\partial T^{*}}{\partial y}\right)_{y=1}=-4 T_{1}^{*}+4 T_{2}
\end{aligned}
$$

(20) is substituted into $(10)$, and $\mathrm{T}_{2}$ " eliminated via the wall boundary condition (13) and (21) to give

$$
\begin{array}{r}
\frac{1}{\mathrm{Pe}_{\mathrm{AF}}} \frac{\mathrm{d}^{2} \mathrm{~T}_{1}}{\mathrm{dx} \mathrm{x}^{2}}-\frac{\mathrm{dT} \mathrm{T}_{1}}{\mathrm{dx}}-\left(\gamma+\frac{\mathrm{N}_{\mathrm{F}}}{\mathrm{Pe}_{\mathrm{RF}}}\right) \mathrm{T}_{1}+\frac{\mathrm{N}_{\mathrm{F}}}{\mathrm{Pe}_{\mathrm{RF}}} \mathrm{t}_{1} \\
=\left\{\begin{array}{r}
-\gamma(\mathrm{x}>0) \\
0(\mathrm{x}<0)
\end{array}\right.
\end{array}
$$

where $r=8 \mathrm{Bi}_{\mathrm{f}} /\left(\mathrm{Pe}_{\mathrm{RF}}\left(B i_{f}+4\right)\right)$

Similarly equation (11) becomes 
$n \frac{d^{2} t_{1}^{*}}{d x^{2}}-\left(\alpha+\frac{N_{S}}{8}\right) t_{1}{ }^{\omega}+\frac{N_{S}}{8} T_{1}{ }^{n}=\left\{\begin{aligned}-\alpha & (x>0) \\ 0 & (x<0)\end{aligned}\right.$

where $\eta=K / 8$ and $\alpha=B i_{s} /\left(B i_{s}\right.$ \& 4)

The analytical solution of this pair of coupled boundary-value problems requires the roots of a 4 th order polynomial, which must be found numerically due to the complexity of the parameters. An exact solution to (22) and (24) is possible under certain restrictive assumptions

$$
\begin{aligned}
\text { (i) } \mathrm{T}_{1}^{*} & =t_{1}{ }^{*} \\
\text { or (ii) } K & =0
\end{aligned}
$$

Neither of these is acceptable, and it is preferable to develop an approximate solution via perturbation methods. The perturbation parameter is $\pi$, which is approximately 0.125 . Hence the solution is approximated by perturbing away from the solution obtained under as sumption (ii) above.

$$
\text { Let } t_{1}^{*}(x, n)=\sum_{m=0}^{\infty} n^{m} \psi_{m}(x)
$$

Substituting (26) into (24) and equating coefficients of like powers of $n$ yields

$$
\begin{aligned}
& \psi_{0}= \begin{cases}\left(\frac{N_{S}}{8} T_{1}^{*}+\alpha\right) /\left(\frac{N_{S}}{8}+\alpha\right) & x>0 \\
\frac{N_{S}}{8} T_{1}{ }^{*} /\left(\frac{N_{S}}{8}+\alpha\right) & x<0\end{cases} \\
& \psi_{\mathrm{m}}=\mathrm{w}_{\mathrm{m}-1}^{\prime \prime} /\left(\mathrm{N}_{\mathrm{S}} / 8+\alpha\right) \quad \mathrm{m} \geq 1 \\
& =\frac{N_{S}}{8} T_{1}^{*(2 m)} /\left(N_{S} / 8+\alpha\right)^{m+1}
\end{aligned}
$$

If (26) is truncated after $k+1$ terms and substituted into (22), an order $2 \mathrm{k}$ ODE in $\mathrm{T}_{1}$ " results. Hence, it is practical to consider only $k=1$, giving 


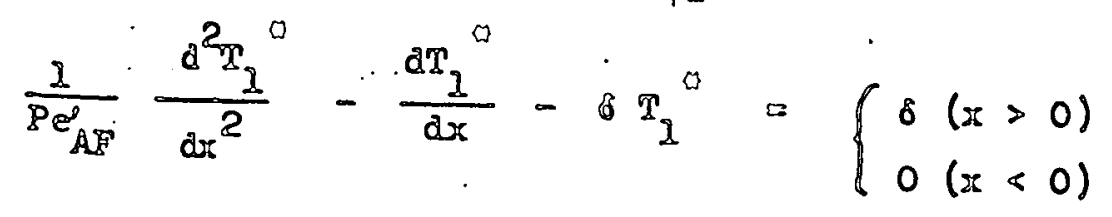

there

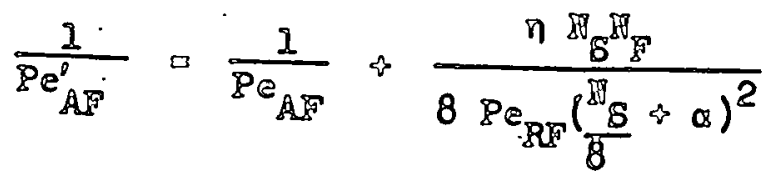

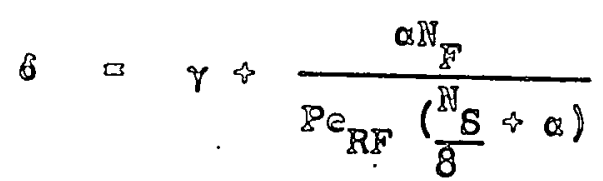

The solution of equation (29) is straightrorward: the conbiants of integration beizg obtained yis the boundary condition at $x$ s s c and the continuity conditions at st $=0$ :

$$
T_{1}^{g}(x)= \begin{cases}1-\frac{1+\Delta}{2 \Delta} \exp \left\{\frac{P e_{A F}^{a} x(1-\Delta)}{2}\right\} & x>0 \\ \frac{\Delta-1}{2 \Delta} \exp \left\{\frac{\left.P e_{A F x(1+\Delta)}^{a}\right\}}{2}\right. & x<0\end{cases}
$$

where $\Delta=\sqrt{1+\frac{4}{P e_{A F}^{\delta}} \delta}$

The fluid-phase approximate solution is found by isterpolation between $T_{1}$ and $T_{2}$ :

$$
\begin{aligned}
& \left.T^{a}(x, y)=2\left(1-y^{2}\right) T_{1}^{a} G\right)+\left(2 y^{2}-1\right) T_{2}^{0}(x) \\
& =\left\{\begin{array}{c}
1+\frac{\left\{i_{P} \cdot\left(y^{2}-1\right) \cdot-2\right\}}{B i_{P}+4} \frac{1+\Delta}{\Delta} \exp \left\{\frac{P e_{A F}^{a} x(1-\Delta)}{2}\right\} \\
(x>0)
\end{array}\right. \\
& \frac{\left\{B i_{P}\left(y^{2}-1\right)-2\right\}}{B i_{Y}+4} \cdot \frac{I-A}{\Delta} \exp \left\{\frac{P e_{A F}^{a} \cdot x(1+\Delta)}{2}\right\} \\
& (x<0)
\end{aligned}
$$

It is easy to obtain the solid-phase approximate solution, if desired, by back-substirution of (32) into the truncated (26).

A similar procedure is used to obtain an approximate solution to the ADPF (IBC) model, equations $(3.7)-(3.272)$. This time the application 
of the one-point collocation technique results in a single boundaryvalue problem, which is easily solved analytically. The procedure is routine, so only the solution is given here:

$$
\theta(x, y)=\left\{\begin{aligned}
& 1+\left\{\frac{B i\left(y^{2}-1\right)-2}{B i+4}\right\}\left(\frac{1+\beta}{\beta}\right)_{\exp }\left\{\frac{P A_{A} x(1-\beta)}{2}\right\} \\
&\left\{\frac{B i\left(y^{2}-1\right)-2}{B i+4}\right\}\left(\frac{1-\beta}{\beta}\right)_{\exp }\left\{\frac{P e_{A} x(1+B)}{2}\right\} \\
& x<0
\end{aligned}\right.
$$

where $\quad B=\sqrt{1+\frac{32 \mathrm{Bi} /(\mathrm{Bi}+4)}{\mathrm{Pe}_{\mathrm{A}} \mathrm{Pe}_{\mathrm{R}}}}$

\subsection{Model matching}

There are doubtless many ways in which the two approximate solutions found in section 4.3 may be matched. Possibly the best guide as to which to choose is to consider the experimental situation used to determine the parameters. In the present case ${ }_{0}$ as in many other studies, the radial temperature profile of the fluid leaving the bed was measured by an array of thermocouples suspended above the bed. This would seem to suggest a simple matching of the homogeneous model solution with that of the fluid phase in the two-phase model.

Some workers have measured the central axis temperature profile by inserting thermocouples radially through the wall ( $\left.\underline{5}_{0} \underline{I_{0}}\right)$. The exit and entrance mixing-cup temperatures were also measured. This suggests using some average temperature from the two-phase model。 although it is not clear how the averaging should be carried out. This is also the more dubious experimental procedure, as noted in section 2.2 .

The first procedure is employed here, and comparison of equations (34) and (35) shows that the two approximate solutions may be matched 
exactly at all points $(x, y)$ by the following relationships

$$
\begin{aligned}
\mathrm{Bi} & =\mathrm{Bi}_{f} \\
\mathrm{Pe}_{\mathrm{A}} & =\mathrm{Pe}_{\mathrm{AF}}^{\prime} \\
B & =\Delta
\end{aligned}
$$

Relationships (38) and (39) may be expanded in terms of the original dimensionless parameters and the more usually-defined Peclet numbers。 and after a little manipulation become

$$
\begin{aligned}
& \frac{1}{P e_{a}}=\frac{1}{P e_{\text {af }}}+\frac{K N_{F} / N_{S}}{P e_{r f}\left(1+\frac{8 B_{S}}{N_{S}\left(B i_{s}+4\right)}\right)^{2}} \\
& \frac{1}{P e_{r}}=\frac{1}{P e_{r f}}\left(1+\frac{N_{F}\left(\frac{B i_{f}+4}{B i_{f}}\right)}{8+N_{S}\left(\frac{B i_{s}+4}{B i_{S}}\right)}\right)
\end{aligned}
$$

These relationships are the most comprehensive so far derived for predicting the homogeneous continuum model parameters, and show how complicated is the synthesis of the effective parameters from the more basic ones. The terms on the right-hand sides of equations $(37),(40)$ and (41) can be estimated from existing correlations, a review of which is given in the next section, so that no adjustable constants are involved.

\subsection{Relevant heat transfer correlations}

The correlations available in the literature for estimation of the basic heat transfer parameters required in the above prediction formulae are reviewed in this section

(a) Fluid_phase radial Peclet_number_( $\left.\mathrm{Pe}_{\mathrm{re}}\right)$

This group can be estimated from radial mixing experiments, since a heat/mass analogy implies $\mathrm{Pe}_{\mathrm{rf}}=\mathrm{Pe}_{\mathrm{rm}}$. At low Re molecular 
diffusion dominates, while at higher values (say $\operatorname{Re}>40$ ) turbulent mixing is the dominant mechanism and $\mathrm{Pe}_{\mathrm{rm}^{\circ}}$ and hence $\mathrm{Pe}_{\mathrm{rf}^{\circ}}$ tends to a constant value $\mathrm{Pe}_{\mathrm{rm}}(\infty)$.

Gunn (6) suggests the interpolating correlation

$$
\frac{1}{\mathrm{Pe}_{\mathrm{rm}}}=\frac{1}{\mathrm{Pe}_{\mathrm{rm}}(\infty)}+\frac{0.67 \varepsilon}{(\mathrm{Re})(\mathrm{Sc})}
$$

based on the work of Pryce (I) in the range $I<$ Re $<420$. This also fits the results of Hiby (ㅇ) well, although it does not account for the rather weak maximum in the observed $\mathrm{Pe}_{\mathrm{rm}}$ vs. Re relationship.

Gunn takes $\mathrm{Pe}_{\mathrm{rm}}(\infty)=11$ in $(42)$, with no dependence on $\left(\mathrm{d}_{t} / \mathrm{d}_{\mathrm{p}}\right)$. Earlier work by Fahien and Smith (2), however finds a dependence given by

$$
\mathrm{Pe}_{\mathrm{rm}}(\infty)=A\left\{I+19.4\left(\mathrm{~d}_{\mathrm{p}} / \mathrm{d}_{\mathrm{t}}\right)^{2}\right\}
$$

with $8 \leq A \leq 10$. Olbrich and Potter (10) also use this form, but take $A=7$ for their experiments at low $d_{t} / d_{p} \cdot$ Closer examination of the results is required to resolve this disagreement.

Olbrich and Potter use the form (43) in imitation of the earlier work of Fahien and Smith; they present a graph justifying their decision and shown in figure 1.

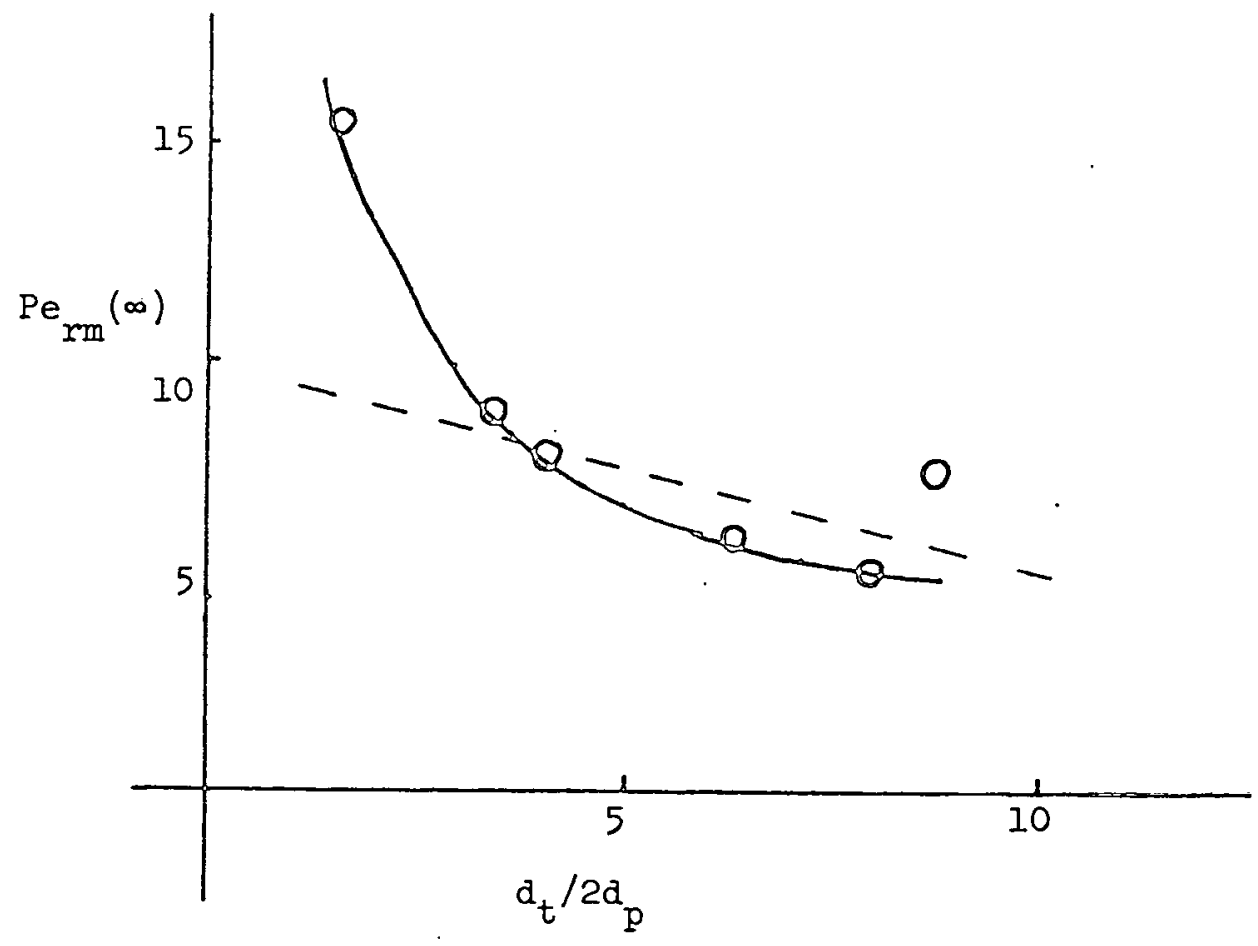

Figure 1 : Graph of Olbrich and Potter 
The curve they fitted is shown by the full line, and depends strongly on the point at $d_{t} / d_{p}=4 ;$ they give no confidence intervals and it is impossible to know if the strong upward trend is significanto possibly the weaker dependence shown by the dashed line is just as good a fit.

The greater part of the results of Fahien and Smith are point estimates of $\mathrm{Pe}_{\mathrm{rm}^{2}}$ which must be considered unreliable as they rely on differentiating the radial data twice. Examination of the average Peclet numbers presented in their paper shows (i) only one set of results is clearly separated from the others; (ii) the distinction between sets of data at different $d_{t} / d_{p}$ is less than a reasonable estimate of confidence intervals would be. Their results are also suspect in that axial dispersion was ignored; Roemer et al (II) found this neglect to result in over-estimation of $\mathrm{Pe}_{\mathrm{rm}}$ by $10-15 \%$ 。

Gunn and Pryce used acceptable statistical methods to analyse their data, and also included axial dispersion; however the ranges of Re covered by their different results at each $d_{t} / d_{p}$ do not overlap sufficiently for definite conclusions to be drawn.

It would appear that equation (43) must be regarded with suspicion; Fahien and Smith did not use $\left(d_{t} / d_{p}\right)$ ratios of sufficient severity to test their correlation adequately. It may be that there is a dependence of $\mathrm{Pe}_{\mathrm{rm}}(\infty)$ on $\mathrm{d}_{t} / \mathrm{d}_{\mathrm{p}}$, although a weaker one. As the majority of published data lies in the range $8-12$, the best that can be done at present is to take $\mathrm{Pe}_{\mathrm{rm}}(\infty)=10$ in equation (42).

\section{(b) Fluid phase axial Peclet number _ ( $\mathrm{Pe}$ af $)$}

Similarly to (a), this group can be estimated from axial mixing

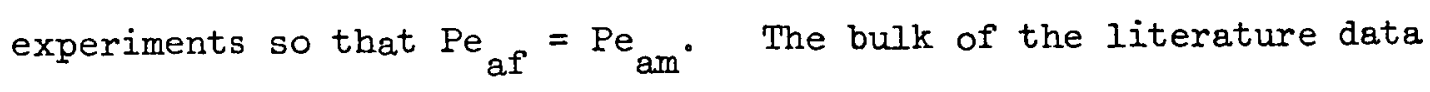
for axial mixing in gases lies in the region of $\left(d_{t} / d_{p}\right)>12$. For 
this range the semi-theoretical equation of Edwards and Richardson (12, 13) appears adequate

$$
\frac{1}{\mathrm{Pe}}=\frac{0.73 \varepsilon}{(\mathrm{Re})(\mathrm{Sc})}+\frac{0.5}{1+\varepsilon \beta /(\mathrm{Re} S \mathrm{c})}
$$

\section{$\beta$ is determined experimentally as $\beta=\left\{\begin{array}{cl}9.7 & \text { (air-argon) } \\ 14.1 & \text { (helium-nitrogen) }\end{array}\right.$}

A similar correlation is due to Hiby (ㅇ)

$$
\frac{1}{\mathrm{Pe}_{\mathrm{am}}}=\frac{0.67 \varepsilon}{(\mathrm{Re})(\mathrm{Sc})}+\frac{0.65}{1+7 \sqrt{\frac{\varepsilon}{\operatorname{ReSc}}}}
$$

which has been shown by Gunn (ㅁ) to give good agreement with the results of Pryce (1) and Evans and Kenney (14). However, (44) predicts $\mathrm{Pe}_{\mathrm{am}}(\infty)=2$, in agreement with the random walk theory of Aris and Amundson (15), in which the interstitial voids act as perfect mixers.

For $\left(d_{t} / d_{p}\right)<12$, however, this theory is not applicable, and recently Hsiang and Haynes (16) have presented results for $1.4 \leq\left(d_{t} / d_{p}\right)$ $\leq 8$ in which $\mathrm{Pe}_{\mathrm{am}}(\infty)$ appears to be in the region of $0.5-1.0$; however their experiments do not cover high enough flow rates in most cases to ensure that the limiting value has been reached. They explain this augmented axial dispersion by transfer to and from a fast moving wall stream, but can present only empirically fitted formulae for their data. Confirmation and extension of these results to higher Re will be necessary before reliable correlations can be developed for this $\left(d_{t} / d_{p}\right)$ range.

For $1 \leq\left(d_{t} / d_{p}\right) \leq 1.4$ the wall streams break down and the voids again behave like perfect mixers. In this region the results of scott et al (17), supported by some runs of Hsiang and Haynes, confirm that 
$\mathrm{Pe}_{\mathrm{rm}}(\infty)=2$ and that equation (44) may again be used.

(c) Effective solia phase conductivities_ $\left(\mathrm{k}_{\mathrm{rs}}{ }^{\circ} \mathrm{k}_{\mathrm{as}}\right)$

As noted in section 4.2 , the solid phase conductivities are not equal to the pellet conductivity $\left(\mathrm{k}_{p}\right)$ as the "solid" includes stagnant fluid.

Olbrich (1.15) reports work of Ikeda et al (18) which established that $\mathrm{k}_{\mathrm{aS}}=\mathrm{k}^{\circ}$, the stagnant bed conductivity. This is supported by Littmann and Sliva (19), who determined $\mathrm{k}_{\mathrm{as}}$ under flow conditions and found their average value to agree with static measurements by Preston (20). Kunii and Smith (ㅁ) and Yagi et al (2I) found $k_{r}{ }^{0}=k_{a}{ }^{0}=k^{0}$. Thus it seems reasonable to take $k_{r s}=k_{\text {as }}$ and to estimate this value by omitting the fluid phase conduction term from one of the many prediction formulae for $\mathrm{k}^{\circ}$.

A review of these formulae has been given by Zehner and Schlünder (22), and they also present their own, which appears to be more general than the others, as it is valid for $0<\varepsilon<1$. It also has various limiting properties, given in the paper, which are not all possessed by any other formula. They consider a unit cell in the bed divided into fluid and solid continuous phases based on voidage. rather than the usual "two--spheres" model of Kunii and Smith (ㅁ). This seems more appropriate for the present studies, and as Zehner and Schlünder correlate virtually all stagnant bed data to present to within $30 \%$ by their equation, it will be used here.

It shouid be noted that no formulae for $k^{0}$ are truly theoretical; all have at least one adjustable parameter to be determined from data. Most experiments on heat transfer are carried out under conditions of temperature and pressure which allow radiation and finite area contacts to be neglected. Then subtracting the fluid conduction term gives 
$k^{0}=\frac{2 \sqrt{1-\varepsilon}}{1-B\left(k_{g} / k_{p}\right)}\left[\frac{\left(1-k_{g} / k_{p}\right) B}{\left(1-B k_{g} / k_{p}\right)^{2}}\right.$ In $\left.\left(\frac{k_{p}}{B k_{g}}\right)-\frac{B+l}{2}-\frac{B-I}{1-B k_{g} / k_{p}}\right]$

where $B=C\left(\frac{1-\varepsilon}{\varepsilon}\right)^{10 / 9}$

and

$$
C= \begin{cases}1.25 & \text { (spheres) } \\ 1.4 & \text { (crushed particles) } \\ 2.5 & \text { (cylinders/Raschig rings) }\end{cases}
$$

[Note that for $\mathrm{Bk}_{\mathrm{g}} / \mathrm{K}_{\mathrm{p}}=1$ equation (46) is not defined;

$$
\mathrm{k}^{\circ}=\sqrt{1-\varepsilon}\left(\frac{1+2 B^{3}-3 B^{2}}{3(B-1)^{2}}\right)
$$

must be used instead.]

It is interesting to note that the fluid conduction term is given by Zehner and Schlünder by analogy from measured stagnant diffusivities as $(1-\sqrt{1-\varepsilon}) \mathrm{k}_{\mathrm{g}}\left(\fallingdotseq 0.23 \mathrm{k}_{\mathrm{g}}\right.$ for $\left.\varepsilon=0.4\right)$. This is less than the expected value of $\varepsilon k_{g}$ due to the fraction of fluid associated with the solid phase. This value, however compares closely with the values $0.67 \varepsilon \mathrm{kg}_{\mathrm{g}}\left(\fallingdotseq 0.27 \mathrm{k}_{\mathrm{g}}\right.$ for $\left.\varepsilon=0.4\right)$ and $0.73 \varepsilon \mathrm{k}_{\mathrm{g}}\left(\fallingdotseq 0.29 \mathrm{k}_{\mathrm{g}}\right.$ for $\varepsilon=0.4$ ) obtained by extrapolating equations (42) and (44) to stagnant conditions. It may be surmised that the factors 0.67 and 0.73. usually labelled "tortuousity factors", are no more than corrections for the intra-solid-phase fluid.

(d) Wall heat transfer coefficients $\left(h_{\text {wf }}, h_{\text {ws }}\right)$

The fluid-to-wall heat transfer coefficient $h_{w f}$ is obtained from mass transfer experiments using a heat and mass transfer analog:。 since direct determination from heat transfer experiments is made difficult due to simultaneous heat transfer between the wall and the solid. 
Yagi and Wakao (5) measured the dissolution rate of 2 - naphthol coated on the inner wall of the tube to water flowing through the bed. By analogy this gives

$$
N u_{w f}=\left\{\begin{array}{lll}
0.60(\mathrm{Pr})^{0.33} & (\mathrm{Re})^{0.5} & (1<\mathrm{Re}<40) \\
0.20(\mathrm{Pr})^{0.33} & (\mathrm{Re})^{0.8} & (40<\mathrm{Re}<2000)
\end{array}\right.
$$

The validity of this correlation for low Re must be in doubt as axial dispersion was neglected in analysing the data.

Kunii et al (23) report results of Kunii and Suzuki (24) giving

$$
N_{w f}=\frac{0.06}{\varepsilon_{w}^{2}}(\operatorname{Pr})^{0.33}(\operatorname{Re})^{0.75} \quad(\operatorname{Re}>100)
$$

where $\varepsilon_{W}$ is "near-wall" voidage, determined in section 2.4. No experimental details are reported.

Olbrich and Potter (10) measured the vapourisation of mercury into a nitrogen stream. They had to consider also simultaneous axial and radial gas mixing in the voids as well as accounting for the pressure drop across the bed, side-effects absent in the work of Yagi and Wakao. They obtained

$$
\mathrm{Nu}_{\mathrm{wf}}=8.9(\mathrm{Pr})^{0.33}(\mathrm{Re})^{0.34}(100<\mathrm{Re}<3000)
$$

substantially different from the other workers.

There is little, if any, published data on $\mathrm{h}_{\mathrm{ws}}{ }^{\circ}$ Olbrich (1.15) has given a theoretical lower bound by considering hexagonally closepacked spheres:

$$
\mathrm{Bi}_{\mathrm{s}} \geq 2.12 \mathrm{R} / \mathrm{d}_{\mathrm{p}}
$$

In practice $\mathrm{Bi}_{\mathrm{s}}$ has little effect on the equations when greater than 10 , so unless $R / d_{p}$ is very small it is permissible to set $\mathrm{Bi}_{\mathrm{s}}=\infty$. 
(e) Interphase heat transfer coefficient (h)

The more commonly correlated interphase heat transfer coefficient $\mathrm{h}_{\mathrm{fs}}$ is related to particle surface temperature, whereas the smoothing of solid temperature variations in the present two-phase model requires that $\mathrm{h}$ be related to average particle temperature, and is consequently a lumping of transfer across a film and conduction through the pellet.

The appropriate lumping was first shown by Stuke (25):

$$
\frac{I}{h}=\frac{I}{h_{f s}}+\frac{d_{p} / \beta}{k_{p}}
$$

where $\beta=10,8$ and 6 for spheres, cylinders and slabs respectively, and $d_{p}$ is the sphere or cylinder diameter or slab thickness. This lumping has been confirmed by later work (26).

The available correlations for $h_{f s}$ may conveniently be considered in two groups

\section{(i) High Re_correlations}

For a moderate to hich Reynolds number the results of many studies are in approximate agreement and several correlations averaging a lot of data have been presented. Some are given in table 1 ; that of Handley and Heggs is widely-used and is therefore adopted in this work.

Author(s) Ref. $\quad$ Correlation range

$\begin{array}{lllll}\text { Handley \& Heggs } & 27 & N u_{\text {fs }}=\frac{0.255}{\varepsilon}(\operatorname{Pr})^{0.33}(\mathrm{Re})^{0.665} & 100-6000 \\ \text { Thodos } & 28 & N u_{f s}=\frac{0.357}{\varepsilon}(\operatorname{Pr})^{0.33}(\mathrm{Re})^{0.641} & 3-1000 \\ \text { Aerov \& Umnik } & 29 \quad N u_{f s}=\frac{0.395}{\varepsilon}(\operatorname{Pr})^{0.33}(\operatorname{Re})^{0.64} & 30-10^{5} \\ \text { Vortmeyer } & 30 \quad N u_{f s}=\frac{0.288}{\varepsilon} \frac{R e}{1.22 \operatorname{Re}^{0.35}-1.9} & >60\end{array}$


(ii) Low Re correlations

There is considerable disagreement in the literature over the values of $\mathrm{Nu}_{f s}$ in the range $\mathrm{Re}<10$, with estimates from both theory and experiment differing by up to two orders of magnitude. In particular, the limiting value as $R e \rightarrow 0$ is in dispute. A summary of the results available is given by Nelson and Galloway (31), who also present a theory predicting $\mathrm{Nu}_{f s} \rightarrow 0$ as $\mathrm{Re} \rightarrow 0$. The most recent paper at the time of writing is by Gunn (32)。 which updates this summary, and also uses his probabilistic model to give $\mathrm{Nu}_{f s} \rightarrow 3.54$ as $\operatorname{Re} \rightarrow \mathrm{O}_{2}$ in reasonable agreement with the numerical results of Sorensen and stewart ( $\underline{33})$, giving $\mathrm{Nu}_{\mathrm{fs}} \rightarrow 3.9$ as $\mathrm{Re} \rightarrow 0$.

Experimental results range from $\mathrm{Nu}_{f s} \rightarrow \mathrm{O}$ from Kunii and Suzuki (34), to $\mathrm{Nu}_{f s} \rightarrow 12.4$, inferred from the mass transfer work of Miyauchi et al ( $\underline{35})$. There is some doubt about the results giving $\mathrm{Nu}_{f s} \rightarrow \mathrm{O}$ as axial dispersion was omitted from the analysis of results $(\underline{36})$. Any choice of correlation is clearly arbitrary; however Littman and Sliva (19) did careful heat transfer experiments using the two-phase quasi-continuum model to analyse their results, and give a correlation which appears to extend the Handley-Heggs correlation to lower Re.

$$
\mathrm{Nu}_{f S}=0.42+0.35(\operatorname{Re})^{0.8}(0.6<\operatorname{Re}<13)
$$

This equation is used when needed in the present work.

\subsection{Accuracy of approximate solutions}

The validity of the parameter relationships (37), (40) and (41) must ultimately stand or fall by their agreement with reliable experimental results. However some indirect indications may be obtained by examining whether the approximate solutions used are close to the exact solution of the two-phase model, and by comparison of 
the exact solutions of the one-and two-phase plug-flow models.

It is convenient to examine the approximate solution to the axially-dispersed two-phase model in two stages:

(i) collocation approximation to radial derivatives

(ii) perturbation solution of collocated equations

\section{(i) Collocation approximation}

This can be studied in isolation by considering the one-phase model and comparing the approximate solution (35) with the exact analytic solution (3.14). This is done for a typical case in figure 2; 50 terms of (3.14) were used in all cases. It is clear that the approximate solution is poor at bed entrance but improves rapidly with increasing bed depth, being within $2 \%$ of the exact solution at a depth of $10 \mathrm{~d}_{\mathrm{p}}$.

The poor approximation at bed entrance is due to the quicklychanging profile near the wall, caused by the discontinuous wall temperature. The Biot number is critical for determining this effect, and for larger $B i$ the poor approximation will persist for larger values of $x$.

Villadsen and Michelson (4) have proposed a one-point "optimal" method based on choosing the collocation point as a function of $\mathrm{Bi}_{0}$ to allow for the change in type of the wall boundary condition (3.9) with varying $B i$. In the present case this involves setting $y_{I}=\sqrt{\frac{1}{3} \frac{B i+6}{B i+4}}$. Repeating the analysis leads to much more complicated parameter relationships for the effective Peclet numbers:

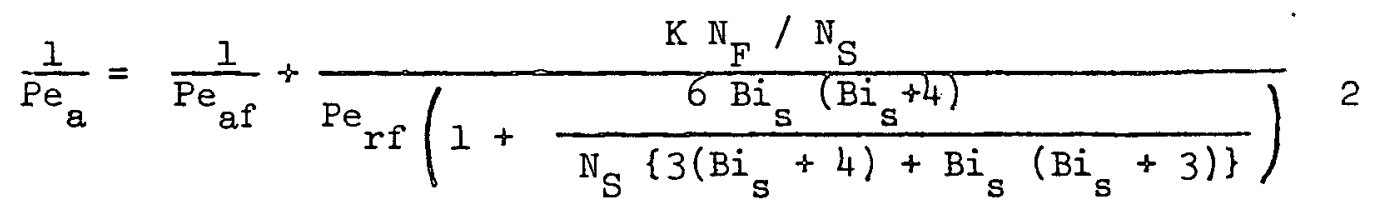




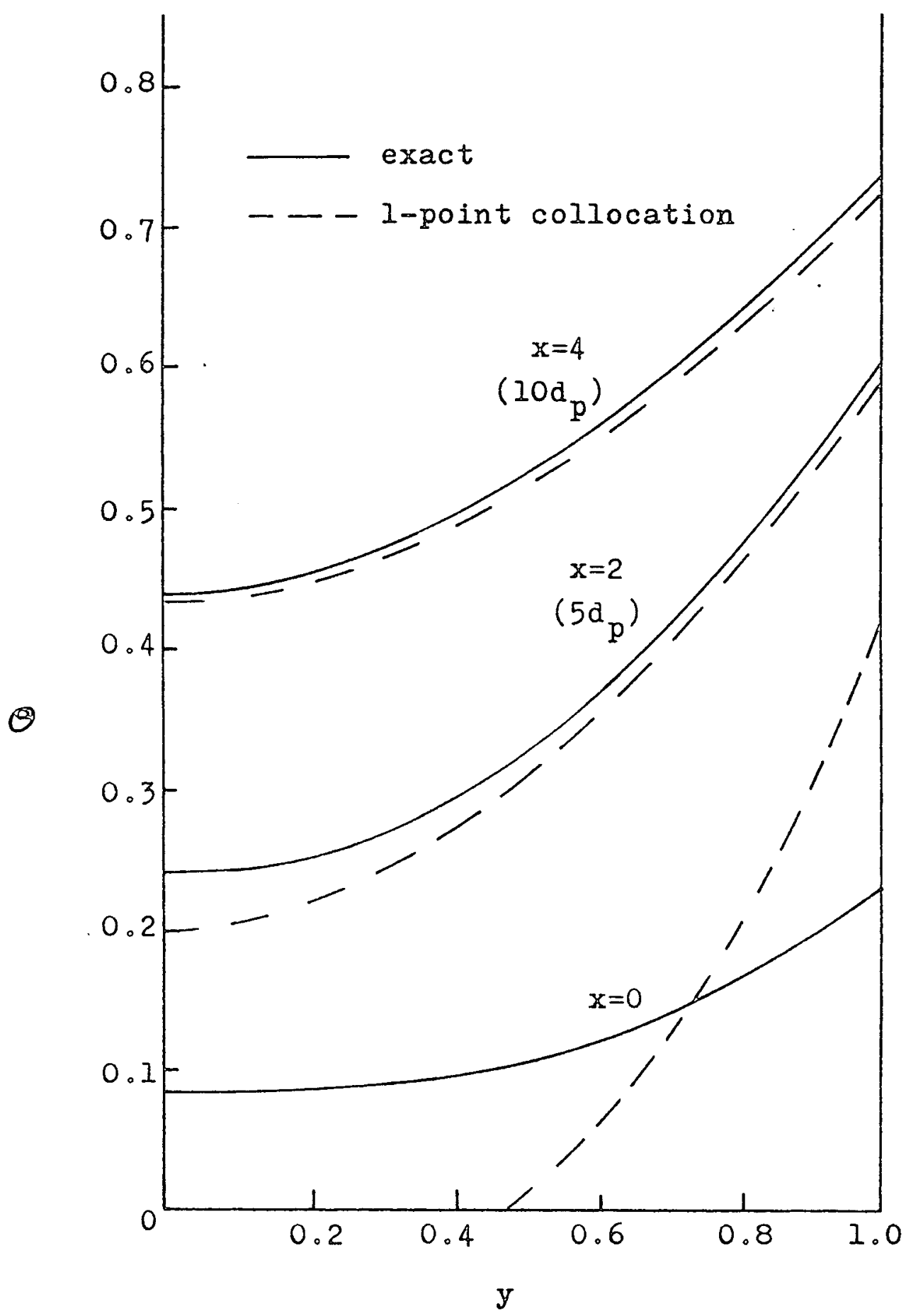

Figure 2 : Comparison of 1-point collocation and exact solutions of one-phase model 


$$
\begin{aligned}
& -85- \\
& \frac{1}{P e_{r}}=\frac{1}{P e_{r f}}\left[1+\frac{N_{F}\left(\frac{3(B i+4)+B i(B i+3)}{B i+(B i+4)}\right)}{6+N_{S}\left(\frac{3\left(B i_{S}+4\right)+B i_{S}\left(B i_{S}+3\right)}{B i_{S}\left(B i_{S}+4\right)}\right)}\right]
\end{aligned}
$$

There is little difference numerically between these and (40) and (41); the improvement to the radial approximation is also small. The refinement does not justify the extra complication for this case.

\section{(ii) Perturbation solution}

An analysis of the truncation error in the perturbation expansion solution of equations (22) and (24) would be extremely difficult. However these equations may be solved for specific values of the parameters by finding the roots of their characteristic equation numerically. This solution may then be compared with that given by the perturbation technique.

By examining the truncated series for $t_{1}{ }^{*}$ "worst-case" conditions regarding accuracy are anticipated for small $\mathrm{N}_{\mathrm{S}}{ }$. This occurs for

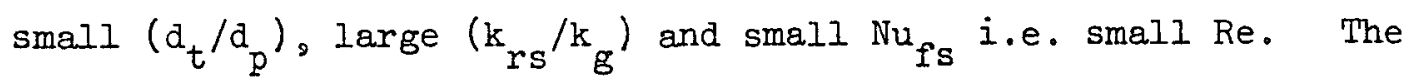
values taken are therefore $\left(k_{r s} / k_{g}\right)=18$ and $\left(d_{t} / d_{p}\right)=7.5 ;$ Re is varied.

Equations (22) and (24) may be combined to give

$$
\begin{aligned}
& \frac{K}{P e_{A F}} \frac{d^{4} T_{I}^{*}}{d x^{4}}-K \frac{d^{3} T_{I}^{*}}{d x^{3}}-\left[\frac{N_{S}+8}{P e_{A F}}+\frac{K}{P e_{R F}}\left(N_{F}+\frac{8 \mathrm{Bi}_{f}}{B i_{f}+4}\right)\right] \frac{d^{2} T_{I}^{*}}{d x^{2}}
\end{aligned}
$$

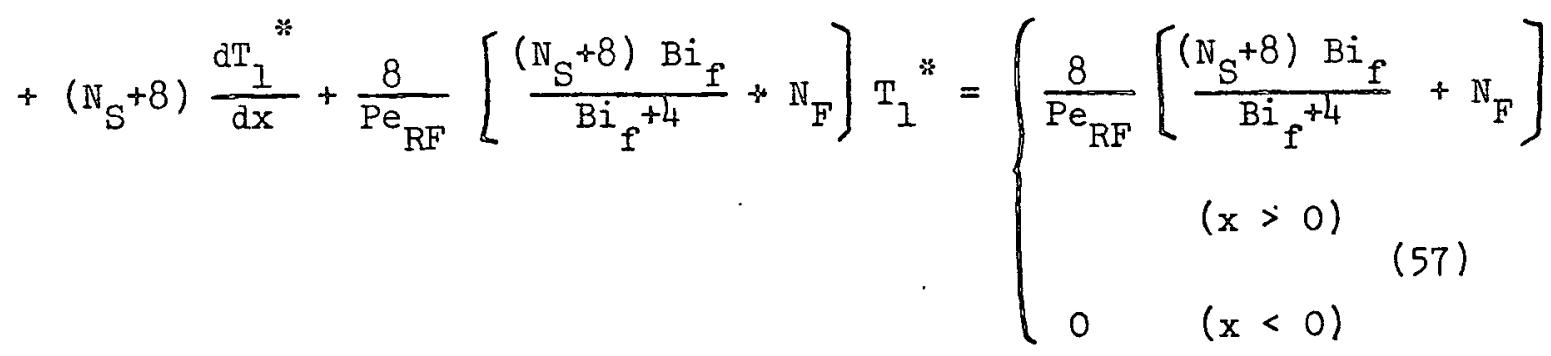

where $\mathrm{Bi}_{\mathrm{s}}$ is taken as $\infty$. 
Case (a) $\mathrm{Re}=50$

From the correlations of section 4.5: $\mathrm{Pe}_{\mathrm{RF}}=34.9, \mathrm{Pe}_{\mathrm{AF}}=8.18$ 。 $B i_{f}=3.97$ and extending the Handley-Heggs correlation slightly $N_{S}=21.94, N_{F}=102.1$

The characteristic equation is

$$
0.12 D^{4}-D^{3}-6.70 D^{2}+29.94 D+26.82=0
$$

The roots are found graphically and after some algebra the solution is

$$
\begin{aligned}
& \mathrm{T}_{I}^{*}= \begin{cases}1+0.033 \mathrm{e}^{-6.2 x}-0.89 \mathrm{e}^{-0.8 \mathrm{x}} & \mathrm{x}>0 \\
0.15 \mathrm{e}^{4.1 \mathrm{x}}-0.0085 \mathrm{e}^{11.1 \mathrm{x}} & \mathrm{x}<0\end{cases} \\
& t_{I}^{*}= \begin{cases}1-0.088 \mathrm{e}^{-6.2 x}-0.662 e^{-0.8 x} & \mathrm{x}>0 \\
0.259 \mathrm{e}^{4.1 \mathrm{x}}+0.002 \mathrm{e}^{11.1 x} & \mathrm{x}<0\end{cases}
\end{aligned}
$$

The perturbation solution gives, for $\mathrm{T}_{1}$ * and $\mathrm{x}>0$,

$$
\mathrm{T}_{1}{ }^{*}=1-0.88 \mathrm{e}^{-0.77 \mathrm{x}}
$$

Comparison of relevant expressions for $\mathrm{T}_{1}{ }^{*}$ shows extremely good agreement, shown in figure 3 . It is interesting to note that the solid and fluid phase temperatures given in equations (59) and (60) from the "exact" solution are significantly different.

Case (bL $\operatorname{Re}=1$

It is unlikely that heat transfer parameters will be examined using the relationships in this work at $\mathrm{Re}<1$.

The characteristic equation is

$$
0.13 D^{4}-D^{3}-16.31 D^{2}+10.16 D+121.23=0
$$

and the solutions are:

$$
\mathrm{T}_{1}^{*}= \begin{cases}1+0.062 \mathrm{e}^{-7.7 x}-0.64 \mathrm{e}^{-2.7 x} & \mathrm{x}>0 \\ 0.416 \mathrm{e}^{2.9 \mathrm{x}}+0.0036 \mathrm{e}^{15.6 \mathrm{x}} & \mathrm{x}<0\end{cases}
$$




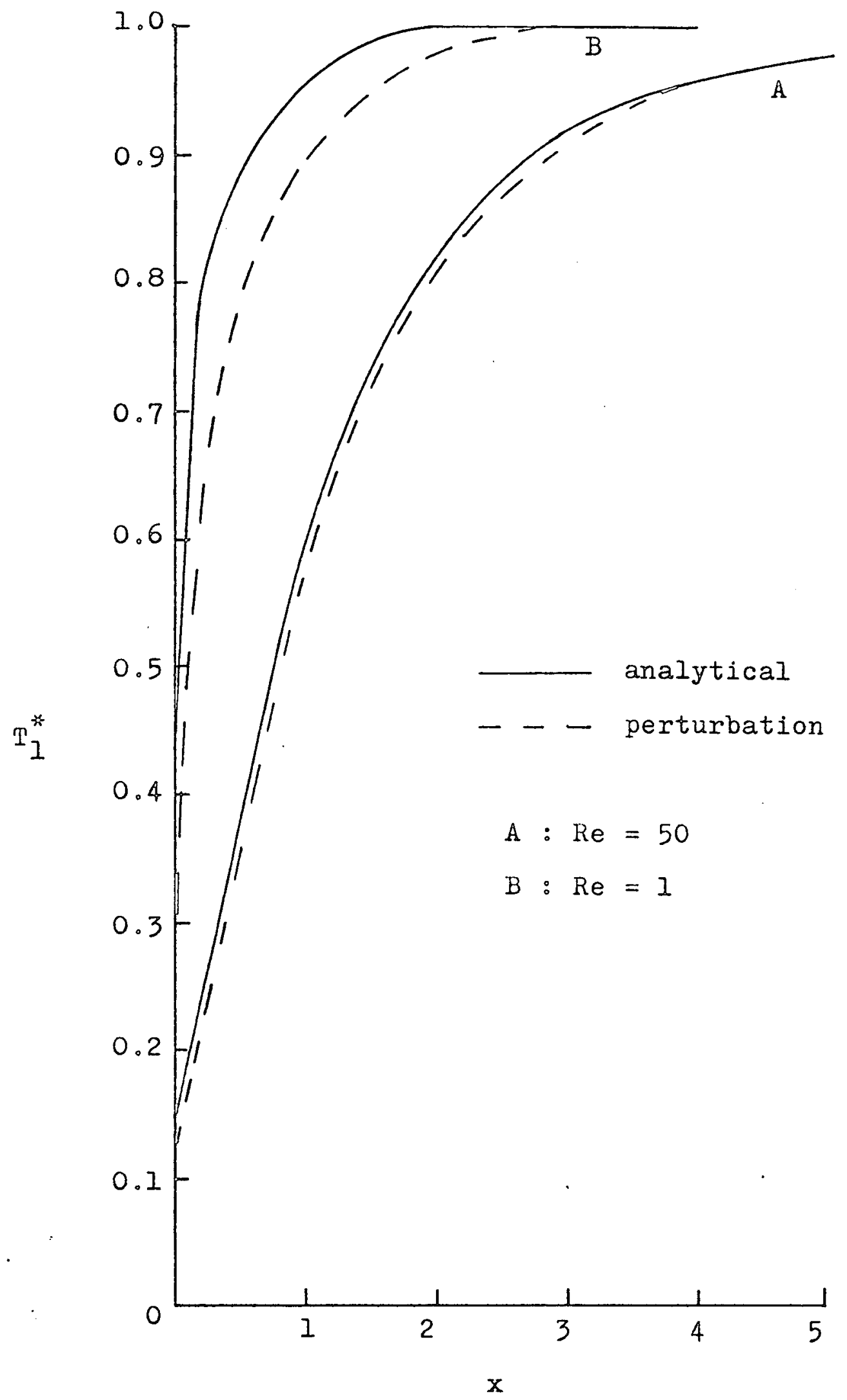

Figure 3 : Comparison of perturbation and analytical solutions of the collocated two-phase model equations 


$$
t_{I}^{*}= \begin{cases}1-0.002 e^{-7.7 x}-0.505 e^{-2.7 x} & x>0 \\ 0.487 e^{2.9 x}+0.0003 e^{15.6 x} & x<0\end{cases}
$$

and the perturbation solution is

$$
\mathrm{T}_{1}^{*}=1-0.69 \mathrm{e}^{-1.95 \mathrm{x}} \quad \mathrm{x}<0
$$

This comparison is also shown in figure 3. Agreement is not so good in this case, for small $x_{0}$ but is still reasonable. It should be noted that the correlation used for $\mathrm{Nu}_{\text {fs }}$ has a large effect at such low $\mathrm{Re}_{0}$ the larger the value taken as the asymptotic limit of $\mathrm{Nu}_{\text {fs }}$ as $\mathrm{Re} \rightarrow \mathrm{O}_{0}$ the better the approximation.

\section{PF models}

As it is observed (37) that equations (37) and (41) are unchanged if axial dispersion is omitted from the models matched in section 4.4 . a test of these relationships is provided by choosing values of the two-phase plug-flow model parameters, using (37) and (41) to obtain the effective (PF model) parameters from them, and comparing the radial profiles predicted by each model. Analytical solutions are available for both one-phase (equation 3.16) and two-phase (1.15) models, and comparisons may be made at bed depths such that the first term of the series solutions suffices.

This is shown in figure 4 for the parameter values given there; agreement is reasonable, the gradient near the wall in the fluid phase is especially well matched by the one-phase model. It is interesting to note a slight inflection in the fluid-phase profile。 which a one-point collocation could not reproduce.

\section{$\underline{\text { References }}$}

1) W.B.Argo and J.M.Smith, Heat transfer in packed beds, Chem. Eng. Prog. 49, 443 (1953). 


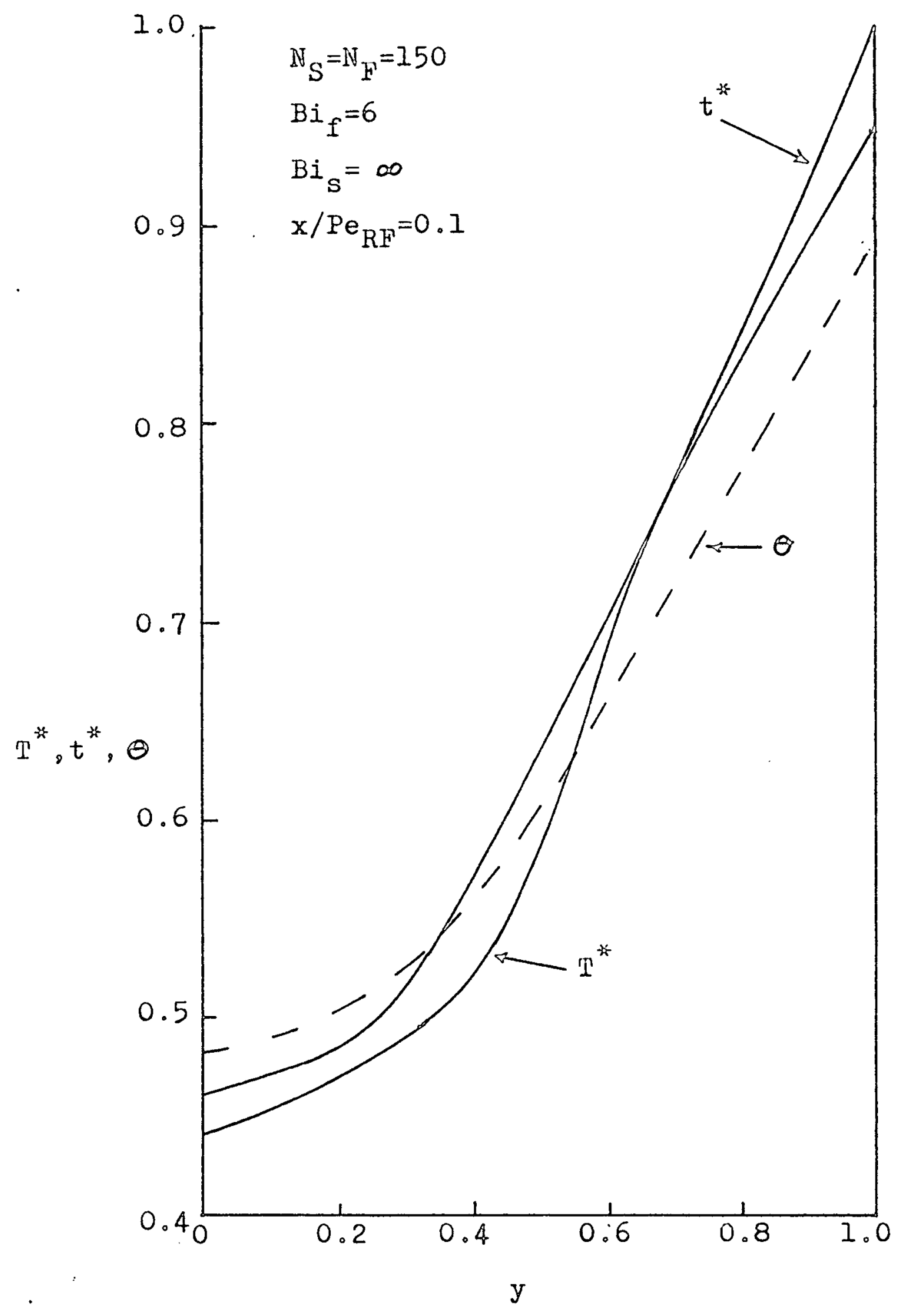

Figure 4 : Comparison of one- and two-phase PF model, profiles, using equations (37) and (41) to obtain effective parameters 
2) D.Kunii and J.M.Smith, Heat transfer characteristics of porous rocks o AIChEJ 6,71 (1960).

3) G.P.Willhite, D.Kunii and J.M.Smith, Heat transfer in beds of fine particles (Heat transfer perpendicular to flow)。AIChEJ 8, $340(1962)$.

4) J. Villadsen and M.L.Michelson, Solution of Differential Equation Models by Polynomial Approximation, Prentice-Hall。 Englewood Cliffs N.J.。 (1978).

5) S.Yagi and N.Wakao, Heat and mass transfer from wall to fluid in packed beds。AIChEJ 5,79 (1959).

6) D.J.Gunn, Mixing in packed and fluidised beds, Chemical Engineer 219。CE 153 (1968).

7) D.J.Gunn and C.Pryce, Dispersion in packed beds, Trans.Inst. Chem.Eng. 47, T341 (1969).

8) J.W.Hiby, Longitudinal and transverse mixing during single-phase flow through granular beds, Inst.Chem.Eng.Symp.Ser. No.9 (1962).

9) R.W.Fahien and J.M.Smith, Mass transfer in packed beds, AIChEJ $1,28(1955)$.

10) W.E.Olbrich and O.E.Potter, Mass transfer from the wall in small diameter packed beds, Chem.Eng.Sci. 27, 1733 (1972).

11) G. Roemer, J.S.Dranoff and J.M.Smith, Diffusion in packed beds at low flow rates, I.E.C. Fund. 1,284 (1962).

12) M.F.Edwards and J.F.Richardson, Gas dispersion in packed beds, Chem. Eng.Sci. 23,109 (1968).

13) M.F.Edwards and J.F.Richardson, The correlation of axial dispersion data, Can.J.Chem.Eng. 48 , 466 (1970).

14) E.V.Evans and C.N.Kenney, Gaseous dispersion in packed beds at low Reynolds numbers, Trans.Inst.Chem. Eng. 44,T189 (1966). 
15) R.Aris and N.R.Amundson, Some remarks on longitudinal mixing or diffusion in packed beds, AIChEJ 3,280 (1957).

16) T.C.Hsiang and H.W.Haynes, Jnr. A Axial dispersion in small diameter beds of large spherical particles, Chem.Eng.Sci.32,678 (1977).

17) D.S.Scott, Wey Lee and J.Papa, The measurement of transport coefficients in gas-solid heterogeneous reactions, Chem. Eng.Sci. $29,2155(1974)$.

18) M.Ikeda, Y.Nishimura and M.Kubota, Mechanism of heat transfer in packed beds, Kagaku Kogaku (Abr.English Edn.) 2,213 (1964).

19) H.Littman and D.E.Sliva, Gas-particle heat transfer coefficients in packed beds at low Reynolds numbers, 4th Int.Heat Trans. Conf. Paris-Versailles 1970, Vol.7 CT 1.4.

20) F.W.Preston, _Ph.D.Thesis ${ }_{0}$ Pennsylvania State Univ., State College。 Pennsylvania (1957) [given in 3 ]

21) S.Yagi, D。Kunii and N.Wakao, Studies on axial effective thermal conductivities in packed beds, AIChEJ 6,543 (1960).

22) P.Zehner and E.U.Schlünder, Wärmeleitfahigkeit von Schüttungen bei mässigen Temperaturen, Chemie-Ing,-Techn. 42,933 (1970).

23) D.Kunii, M.Suzuki and N.Ono, Heat transfer from wall surface to packed beds at high Reynolds number, J.Chem.Eng.Japan 1,21 (1968).

24) D.Kunii and M.Suzuki, , Symp.Heat Mass Transfer, Minsk (1968).

25) B.Stuke, Berechnung des Wärmeaustausches in Regeneratoren mit zylindrichem und kugelförmigem Füllmạterial, Angew.Chemie B, $20,262(1948)$.

26) K.W.Hansen and S.B.Jorgensen, Dynamic analysis of fixed bed chemical reactor, section J3 4th CHISA congr., Prague (1972).

27) D.Handley and P.J.Heggs, Momentum and heat transfer mechanisms in regular shaped packings, Trans.Inst.Chem.Eng. 46, T251 (1968). 
28) L.J.Petrovic and G.Thodos, Mass transfer in the flow of gases through packed beds, IEC Fund: 7,274 (1968).

29) M.E.Aerov and O.M.Todes, Hydraulic and Thermal Basis of the Operation of Packed and Fluidized Bed Equipment, Chimija, Leningrad (1968).

30). D. Vortmeyer, Axial heat dispersion in packed beds, Chem.Eng. Sci. 30, 999 (1975).

31) P.A.Nelson and T.R.Galloway, Particle-to-fluid heat and mass transfer in dense systems of fine particles, Chem.Eng.Sci. 30, $1(1975)$.

32) D.J.Gunn, Transfer of heat or mass to particles in fixed and fluidised beds, Int.J.Heat Mass Transfer 21, 467 (1978).

33) J. Spprensen and W.E.Stewart, Computation of forced convection in slow flow through ducts and packed beds - III. Heat and mass transfer in a simple cubic array of spheres, Chem. Eng. Sci. 29, $827(1974)$.

34) D. Kunii and M.Suzuki, Particle to fluid heat and mass transfer in packed beds of fine particles, Int.J.Heat Mass Transfer 10, 845 (1967).

35) T.Miyauchi, H.Kataoka and T.Kikuchi, Gas film coefficients of mass transfer in low Peclet number region for sphere packed beds, Chem.Eng.Sci. 31,9 (1976).

36) D.J.Gunn and J.F.C. de Souza, Heat transfer and axial dispersion in packed beds, Chem.Eng.Sci. 29,1363 (1974).

37) D.L.Cresswell, Private communication (1978). 


\section{COMPARISON OF THEORY WITH EXPERIMENTAL RESULTS}

\section{I Selection of data}

As was shown in chapter three, model inadequacy may lead to an artificial spread in the data. When possible experimental inadequacies are added to this, it is clear that to expect the relationships developed in chapter four to predict all current literature data would be unreasonable; some selection procedure must be implemented.

Ideally the following criteria should be met by acceptable data:

(a) The data should be obtained through experimentation suitably designed to reliably determine the parameters to be estimated.

(b) A statistically adequate model should be employed in the analysis of the data.

(c) Parameter estimation methods which are statistically sound in the face of experimental error should be used.

Unfortunately the rigorous application of these criteria would often result in the only acceptable data being that of the present work. To avoid this undesirable situation a more detailed inspection of the literature is required, and results will often be included where the effects of violation of one or more of the above criteria are judged to be minimal. One conclusion reached during this selection is that the effective radial Peclet number appears to be "robust", in that reasonable estimates are obtained even under highly unfavourable experimental conditions. The apparent wall Biot number and the effective axial Peclet number are, on the other hand, "sensitive" to experimental conditions.

For effective radial Peclet numbers, the results of Gunn and Khalid (1.4), which include axial conduction effects, supply sufficient 
reliable data on which to examine the theory at low and intermediate $\mathrm{Re}_{0}$ in spite of their estimating three parameters at a single bed depth, which was not found possible in the present work. These are supplemented by the present results, and at high $R e$ the results of Kunii et al ( $\underline{4.23}$ ) may be taken,as axial conduction effects can be neglected (this is verified by the improved fit of the PF model at higher Re in table Al).

Measurement of effective axial Peclet numbers has usually proceeded in one of two ways:

(i) experiments in adiabatic packed beds i.e. no radial conduction present

(ii) joint estimation with $\mathrm{Pe}_{\mathrm{r}}$ and $\mathrm{Bi}$ from radial temperature profiles at bed exit.

The latter method, used in the present work and by Gunn and Khalid, tends to give unreliable estimates of $\mathrm{Pe}_{\mathrm{a}}$, as this parameter has little effect on exit profiles. Hence only data obtained by the former method are accepted (3.14, $\underline{4.21}$ and $\underline{4.36}$ ).

The wall heat transfer coefficient $h_{w}$ is commonly used in the formation of two dimensionless groups. It appears in dispersion models in the form of the Biot number $B i\left(=h_{W} R / k_{r}\right)$ representing the ratio of resistance inside the bed to that at the wall. In spite of appearing naturally in this form $\mathrm{h}_{\mathrm{w}}$ has been presented by most workers in the form of the Nusselt number $\mathrm{Nu}_{w}\left(=h_{w} d_{p} / k_{g}\right)$. Li and Finlayson ( 1 ) have recently presented a comprehensive review of the literature data on $\mathrm{Nu}_{\mathrm{w}{ }^{\circ}}$ and have shown a large amount of scatter particularly at low-to-moderate Re.

Since the PF model, used in all the studies cited in ( 1 ), leads to depth-dependent estimates of $h_{w^{2}} \mathrm{Li}$ and Finlayson postulate a "length effect" as being responsible for this scatter. They then 
accept or reject data according to whether the method of analysis used jields "asymptotic" values of $h_{w^{\circ}}$ or not. As a result they only accept data determined from measurements made at the exit of long tubes, as in the method of Yagi and Wakao (‥5).

The results of chapter three, however, have shown the depthdependency of $h_{w}$ to be due to the use of an inadequate model, in which axial conduction is neglected. Since Li and Finlayson present no evidence for the existence of a "length effect" in packed beds, but invoke this entity in order to be able to reject unwanted data, their analysis cannot be considered valid, and a fresh examination must be made.

First note that the data of some workers $(\underline{2}, \underline{3})$ is difficult to obtain other than in the review of $\mathrm{Li}$ and Finlayson, from which Biot numbers could not be obtained, or experimental procedure examined; this data is not considered here.

The results of Hawthorn et al (1.10) are for chemical reaction taking place on the wall; unfortunately, since this is the only data available with a reaction present, no thermal conductivities were measured and Biot numbers were not obtainable.

of the remaining work a substantial body may be criticised on the adequacy of experimental procedure and the techniques used for analysis. It is shown in section 5.3 that in the range $40 \leq$ Re $\leq 400$ the group $B i\left(d_{p} / R\right)$ is in the range $0.7-1.2$. Since the results of chapter three show that Biot numbers greater than 10 cannot be reliably estimated using the PF model (a conclusion supported by Li and Finlayson), data in this Re range for which $\left(d_{t} / d_{p}\right)>20$ must be excluded.

A method of data analysis used by earlier workers (e.g. Plautz and Johnstone ( $3: 12)$, Coberley and Marshall (4)) involved numerical 
differentiation of data to obtain approximations to the derivatives appearing in the model equations. This method is notoriously unreliable, especially for estimating second derivatives. In addition it produces biased parameter estimates, since systematic truncation errors are introduced into the approximation of derivatives .

A further widely-used method of analysis is that of Yagi and Wakao $(\underline{4.5})$, which was also used by Agnew and Potter (1.1). They took several measurements of bed temperature along the central axis at different positions $\left(\mathrm{T}_{\mathrm{bc}}\right)$, and also measured mean exit gas temperature. They assumed $\mathrm{T}_{\mathrm{w}}=100^{\circ} \mathrm{C}$ and did not actually measure it. Taking the first term of (3.16) gives

$$
\frac{T_{w}-T_{b c}}{T_{w}-T_{O}}=\frac{2 B i \exp \left\{-z d_{p} \lambda_{1}{ }^{2} / R^{2} P e_{r}\right\}}{\left(B i^{2}+\lambda_{l}{ }^{2}\right) J_{0}\left(\lambda_{1}\right)}
$$

$\mathrm{Bi}$ and $\mathrm{Pe}_{\mathrm{r}}$ may be calculated simultaneously from the slope of the straight-line portion of the semi-log plot of $T_{W}-T_{b c}$ versus $z$ 。 together with the ratio of temperature differences at bed exit

$$
\frac{T_{w}-T_{e m}}{T_{w}-T_{e c}}=2 \frac{J_{I}\left(\lambda_{I}\right)}{\lambda_{I}}
$$

and the characteristic equation

$$
\lambda_{1} J_{1}\left(\lambda_{1}\right)=\operatorname{Bi} J_{0}\left(\lambda_{1}\right)
$$

However $\mathrm{Bi}$ alone may be obtained from (2) and (3) only, requiring mean and centre-line bed exit temperatures. Thus this method may be applied to data in the present work, if the exit profiles are plotted graphically and extrapolated to wall and centre-line, giving $\mathrm{T}_{\mathrm{ec}}$ directly and $\mathrm{T}_{\mathrm{em}}$ by numerical integration. A comparison may then be, effected with the results of the non-linear least squares method 


\begin{tabular}{|c|c|c|c|c|c|c|c|c|c|}
\hline Packing_ & $\underline{\mathrm{Re}}$ & $\begin{array}{c}\mathrm{L} \\
(\mathrm{mm}) \\
\end{array}$ & $T_{W}$ & $\underline{\mathrm{T}_{\text {ec }}}$ & $\underline{T}_{\text {em }}$ & $\left.\frac{T_{w}-T_{e m}}{T_{w}-T_{e c}}\right)$ & $\underline{\lambda_{1}}$ & $\begin{array}{c}\mathrm{Bi} \\
(\mathrm{Y}-\mathrm{W}) \\
\end{array}$ & $\begin{array}{c}B i \\
\text { (NLLS) } \\
\end{array}$ \\
\hline $12.7 \mathrm{~mm}$ & & 51 & 106.6 & 32.0 & 42.3 & 0.8619 & 1.075 & 0.681 & 1.599 \\
\hline \multirow[t]{5}{*}{ ceramic beads } & 536 & 178 & 107.0 & 53.2 & 64.0 & 0.7992 & 1.310 & 1.116 & 2.132 \\
\hline & & 356 & 105.9 & 80.5 & 85.8 & 0.7913 & 1.340 & 1.186 & 2.606 \\
\hline & 429 & 178 & 106.8 & 57.0 & 68.1 & 0.7930 & 1.333 & 1.170 & 2.453 \\
\hline & 291 & $"$ & 106.9 & 64.0 & 73.8 & 0.7716 & 1.408 & 1.360 & 2.874 \\
\hline & 140 & " & 106.4 & 83.5 & 88.2 & 0.7948 & 1.326 & 1.153 & 4.614 \\
\hline $9.5 \mathrm{~mm}$ & 373 & 204 & 103.6 & 53.5 & 65.1 & 0.7685 & 1.427 & 1.384 & 2.878 \\
\hline \multirow[t]{4}{*}{ ceramic beads } & 281 & $"$ & 103.8 & 58.5 & 69.7 & 0.7528 & 1.469 & 1.535 & 3.253 \\
\hline & 231 & " & 104.3 & 60.5 & 72.0 & 0.7374 & 1.520 & 1.702 & 3.379 \\
\hline & 181 & " & 104.0 & 67.0 & 77.1 & 0.7270 & 1.552 & 1.814 & 3.576 \\
\hline & 120 & $"$ & 104.4 & 76.0 & 83.5 & 0.7359 & 1.525 & 1.719 & 3.572 \\
\hline
\end{tabular}

Table 1 : Comparison of Yagi and Waka 's estimation method and nonlinear least squares. 
(NLLS) used with the PF model; this is shown in Table 1. From this it appears that the appealingly simple procedure of Yagi and Wakao gives estimates of $\mathrm{Bi}$ with a large negative bias. Clearly criterion (c) is being violated, and results obtained using this method should be rejected.

Results obtained by Ziolkowski'() are also rejected, although least squares estimation was used, on consideration of experimental procedure. The thermocouples were inserted vertically into the bed; which disturbs the packing and can lead to channelling. Quinton and Storrow (6) determined their parameters from typical radial temperature profiles of $3^{\circ} \mathrm{C}$ temperature rise, which can be regarded as flat within the scatter of the data.

The results of Gunn and Khalid, when re-computed, give the only Biot numbers which increase with Re. Why this should be is not clear, and their data is suspended pending further elucidation; possibly the effects which prevented three-parameter minimisation from a single bed depth in chapter three are here making themselves felt.

The acceptable data is considered to be that of Kunii et al (․․23) since at such high Re virtually all resistance in the bed will be at the wall, allowing good determination of $\mathrm{Bi}$. Also the "non-homogeneity" of the bed will have small effect and more accurate measurements may be made, thus minimising the bias due to the method of estimation used. The only objection to the data of De Wasch and Froment (2.1) is the use of the PF model; however, if the results from all the bed depths are used, they should span the "correct" results and at least give an idea of the qualitative trend of the data. 
5.2 Effective radial Peclet number

The vast bulk of the literature data on this parameter concerns heat transfer experiments carried out in large diameter beds of small particles, for which $\left(d_{t} / d_{p}\right) \rightarrow \infty$. The case of heat transfer in relatively narrow tubes, for which typically $4 \leq\left(d_{t} / d_{p}\right) \leq 12$, which is one of considerable practical importance, has received insufficient attention.

The relationship for $\mathrm{Pe}_{r}$ may be written in the form

$$
\begin{aligned}
& \frac{1}{P e_{r}}=\frac{1}{P e_{r f}}+\frac{k_{r s}}{k_{g}}(R e P r)^{-1}\left(\frac{B i_{f}+4}{B i_{f}}\right)\left[\frac{8}{N_{S}}+\frac{B i_{s}+4}{B i_{s}}\right]^{-1} \\
& \text { where } \quad N_{S}=\frac{1.5(1-\varepsilon)\left(d_{t} / d_{p}\right)^{2}}{\frac{k_{r s}}{k_{g}}\left\{\frac{1}{N u_{f s}}+\frac{0.1}{k_{p} / k_{g}}\right\}}
\end{aligned}
$$

Note first that as $\left(d_{t} / d_{p}\right) \rightarrow \infty, N_{S} \rightarrow \infty$ and it may be deduced from equations (4.10) $-(4.18)$ that $\mathrm{Bi}_{f}=\mathrm{Bi}$ in this limit. Thus (4) reduces to the familiar limiting form

$$
\frac{l}{\mathrm{Pe}_{r}}=\frac{1}{\mathrm{Pe}_{\mathrm{rf}}}+\frac{\mathrm{k}_{\mathrm{rS}}}{\mathrm{k}_{\mathrm{g}}}(\operatorname{Re} \operatorname{Pr})^{-1}
$$

This form of correlation has been used with considerable success (3.13). Figure 1 shows the data of Kunii et al and Gunn and Khalid; a key to symbols is given in table 2. Equation 6 is shown to predict the Peclet numbers to within $25 \%$ for non-metallic packings such as glass and celite, having an average $\left(\mathrm{k}_{\mathrm{rs}} / \mathrm{k}_{\mathrm{g}}\right)=7$, and using $\mathrm{Pe} \mathrm{rm}_{\mathrm{rm}}$ $(\infty)=10$. This is to be expected for the results of Gunn and Khalid (1.4) since most of their data involves high $\left(a_{t} / d_{p}\right)$. The data of Kunii et al (4.23) was taken at high Re so that the second terms of equations (4) and (6) are dominated by the first, which ensures a. reasonable fit. Equation (6) is less successful for metallic packings. In these cases $\left(k_{r s} / k_{g}\right)$ is larger, perhaps $15-18$, and to 


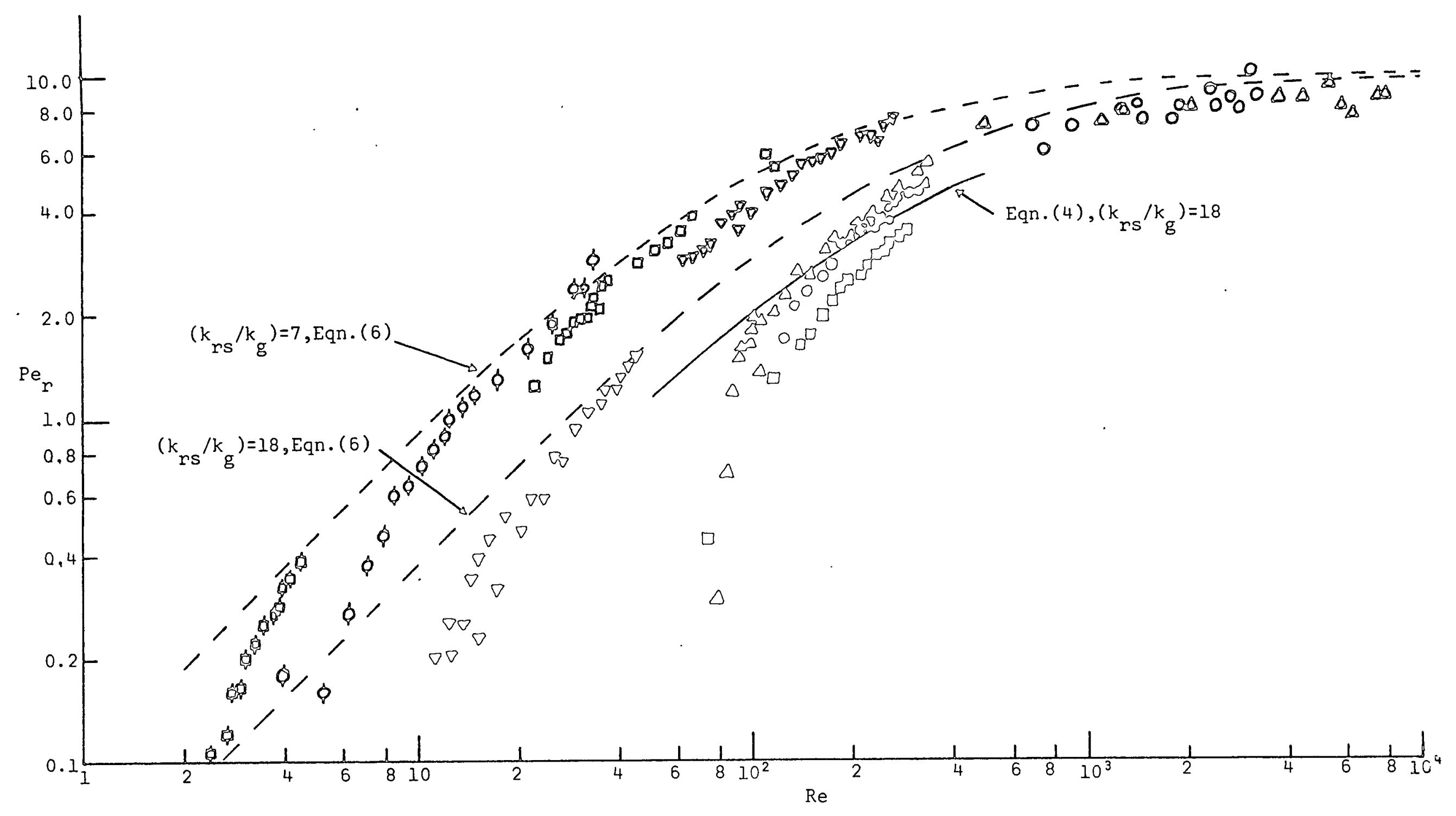

Figure 1 : Comparison of prediction formulae for $\mathrm{Pe}_{r}$ 
maintain a large $N_{S}$ requires increased $\left(d_{t} / d_{p}\right)$ or very much increased Re.

\begin{tabular}{|c|c|c|c|}
\hline Symbol & Packing & $\mathrm{d}_{\mathrm{t}} \stackrel{/ \mathrm{d}}{\mathrm{p}}-$ & Workers \\
\hline 0 & $6.8 \mathrm{~mm}$ Nickel & 14.0 & Gunn \& Khalid \\
\hline$\square$ & $6.4 \mathrm{~mm}$ Steel & 14.9 & $"$ \\
\hline$\nabla$ & 1. Omm Lead & 95.2 & $"$ \\
\hline$\Delta$ & 7. Omm Lead & 13.6 & $"$ \\
\hline$\nabla$ & $6.0 \mathrm{~mm}$ Glass & 15.9 & $"$ \\
\hline ه & $0.5 \mathrm{~mm} \quad "$ & 190.5 & $"$ \\
\hline$\phi$ & $1.15 \mathrm{~mm} \quad "$ & 82.8 & $"$ \\
\hline 口 & $3.0 \mathrm{~mm} \quad "$ & 31.8 & $"$ \\
\hline 0 & 28mm Celite & 5.0 & Kunii et al \\
\hline$\Delta$ & $42 m$ & 3.3 & $"$ \\
\hline
\end{tabular}

For the present data, at low $\left(d_{t} / d_{p}\right)$ and moderate flow rate, equation (6) would not be expected to be so successful, and this is confirmed in figures 2 and 3. The 95\% confidence intervals are shown for this data and the symbols are the same as for figure 4. For data at such $\left(d_{t} / d_{p}\right)$ ratios (in range 5-12) the general equation (4) must be used. The best agreement with the data is found for $\mathrm{Bi}_{\mathrm{S}}=\infty_{\text {, and }}$ in the absence of data on $\mathrm{h}_{\mathrm{ws}}$. it is recomended that this value be used in computing $\mathrm{Pe}_{r} \cdot \quad$ The data in figure 2 indicates that particle diameter has only a weak effect on $\mathrm{Pe}_{r}$ and the data can be adequately predicted by a single curve for the intermediate $\left(d_{t} / d_{p}\right)$ ratio $(=7.5)$ and taking $\mathrm{Pe}_{\mathrm{rm}}(\infty)=10$. For the ceramics $\left(\mathrm{k}_{\mathrm{rs}} / \mathrm{k}_{\mathrm{g}}\right)$. $=8.2$ and was measured directly using Sehr's method $(\underline{7}, \underline{8})$. For steel balls a value of $k_{p}$ was taken from standard tables ( $(2)$ and equation (4.46) used. $\quad B i_{f}$ was calculated using equations (12) and $(4.37)$ 


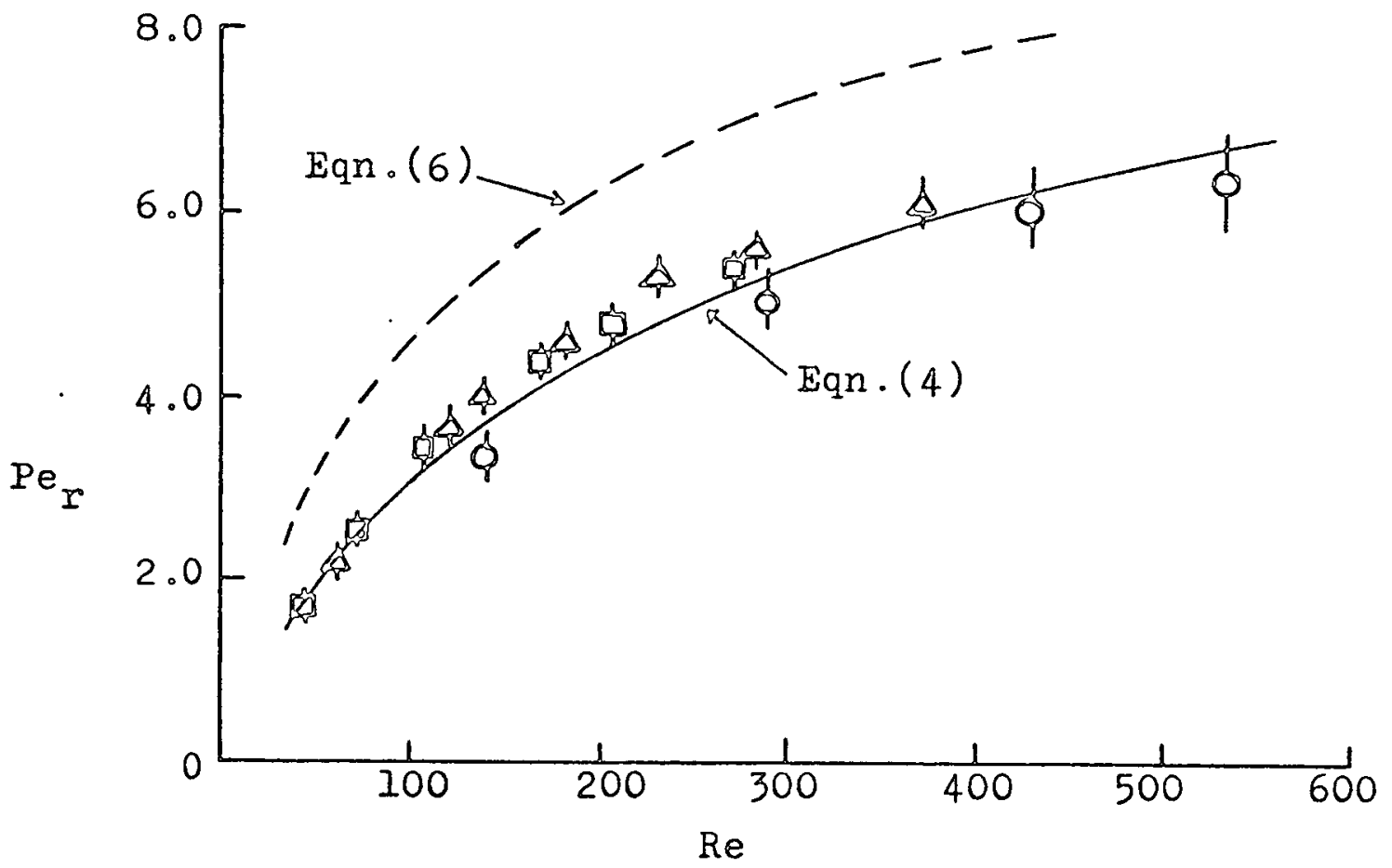

Figure 2 : Comparison of prediction formulae for $\mathrm{Pe}_{\mathrm{r}}$ nonmetallic packing

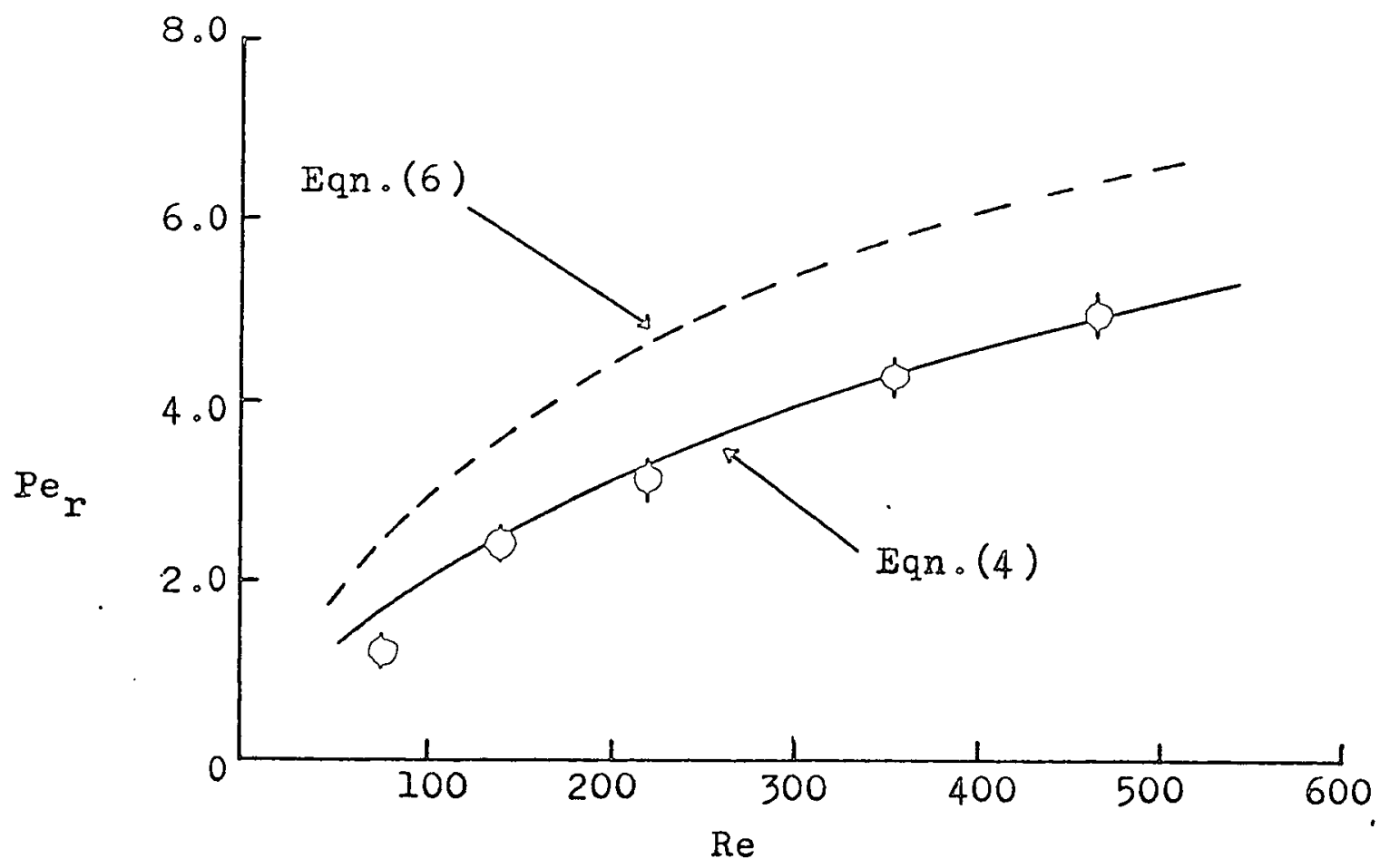

Figure 3 : Comparison of prediction formulae for $\mathrm{Pe}_{r}$ metallic packing 
In figure 1 is also shown the prediction of equation (4) for the metallic packings at lower $\left(d_{t} / d_{p}\right)(13.6-14.9)$ and moderate $\operatorname{Re}(50-400)$. The deviation of this data from the prediction of equation (6) was particularly bad. The values $\left(d_{t} / d_{p}\right)=14$ and $\left(\mathrm{k}_{\mathrm{rs}} / \mathrm{k}_{\mathrm{g}}\right)=18$ were taken. The prediction now lies within the data; however the data has a greater slope, as is the case with virtually all Gunn and Khalid's data. It is not clear why this should be; it is encouraging, however, that equation (4) predicts the magnitude of the data well, and is a definite improvement over equation (6).

Finally, note that as $\mathrm{Re}^{\rightarrow} \mathrm{O}$ equation (6) becomes

$$
\frac{k_{r}^{\circ}}{k_{g}}=0.67 \varepsilon+\frac{k_{r s}}{k_{g}}
$$

the familiar form for stagnant conductivity. The behaviour of equation (4), however, hinges directly on the behaviour of $\mathrm{Nu}_{\text {fs }}$ and $N u_{w f}$ as $\operatorname{Re} \rightarrow 0$. Since this is far from well-established, no conclusion can be reached about equation (4).

\subsection{Apparent wall Biot number}

From equation ( 3.37$)$ :

$$
\begin{aligned}
B i & ={ }_{i f}=\frac{h_{w f} R}{k_{r f}} \\
& \left.=\left(\frac{h_{w f} d_{p}}{k_{g}}\right)\left(\frac{R}{d_{p}}\right) \frac{P e_{r f}}{(\operatorname{Re} P r}\right) \\
& \left.=N u_{w f}\left(\frac{R}{d_{p}}\right) \frac{P e_{r f}}{(\operatorname{Re} P r}\right)
\end{aligned}
$$

Now for $\mathrm{Re}>40 \mathrm{Pe}_{\mathrm{rf}}=\mathrm{Pe}_{\mathrm{rm}}(\infty)$ and a constant value of $\mathrm{Pe}_{\mathrm{rm}}(\infty)=10$, was found to be adequate for prediction of $\mathrm{Pe}_{\mathrm{r}}$ in section 5.2 . Further, present correlations for $\mathrm{Nu}_{\mathrm{wf}}$ involve only $\mathrm{Re}$ and $\mathrm{Pr}$. Hence, 
for a given fluid, data plotted as $B i\left(d_{p} / R\right)$ versus Re should fall onto a single line for $\mathrm{Re}>40$. This is in agreement with $\mathrm{Li}$ and Finlayson (1), although they found empirically

$$
B i\left(a_{p} / R\right)=\text { const. }
$$

There are three choices of correlation for $\mathrm{Nu}_{\mathrm{wf}}$ given in section 4.5: Substituting $(4.49)-(4.51)$ into equation (9) and taking $\operatorname{Pr}=0.72, \varepsilon_{\mathrm{w}}=0.5$ and $\mathrm{Pe}_{\mathrm{rm}}(\infty)=10$ gives, respectively

$$
\begin{aligned}
& \operatorname{Bi}\left(d_{p} / R\right)=\left\{\begin{array}{lll}
7.48 & R e^{-0.5} & (\operatorname{Re}<40) \\
2.49 & \operatorname{Re}^{-0.2} & (\operatorname{Re}>40)
\end{array}\right. \\
& \mathrm{Bi}\left(d_{p} / R\right)=3.00 R e^{-0.25}(\operatorname{Re}>100) \\
& \operatorname{Bi}\left(d_{p} / R\right)=110.91 \operatorname{Re}^{-0.66}(100<\operatorname{Re}<3000)
\end{aligned}
$$

Figure 4 shows equations (11) - (13) compared with the data from the present work. Clearly there is little to choose between (II) and (12), both lying a little below the data; equation (13) does not appear to give reasonable estimates and can be rejected. It is interesting to note the similarity of Re dependence between equation (12) and the empirical correlation found in section 3.6, equation $(3.39):$

$$
\operatorname{Bi}\left(\mathrm{d}_{\mathrm{p}} / \mathrm{d}_{\mathrm{t}}\right)^{\frac{1}{2}}=5.73 \mathrm{Re}^{-0.26}
$$

Although equation (II) appears to fit the data in figure 4 a little better than equation (12), the latter gives a better fit to all the acceptable data, and is therefore the equation used in figure 5 where this data is shown. A key is given in table 3 . It is seen that equation (12) gives a good prediction at moderate and high $R e$, and that the data do indeed fall onto one line. 


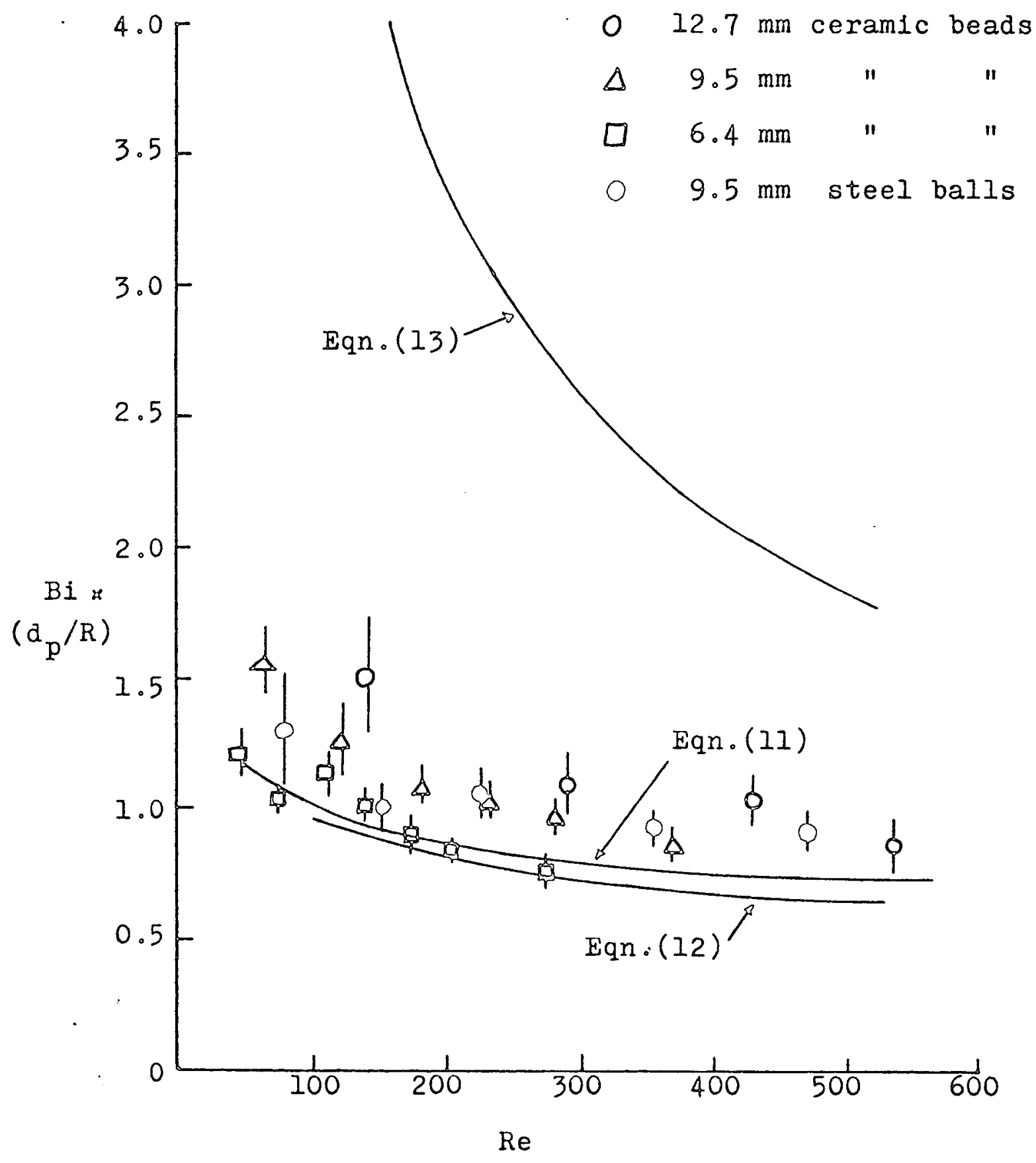

Figure 4 : Comparison of predictions for Bi using different correlations for $N u_{W f}$ 


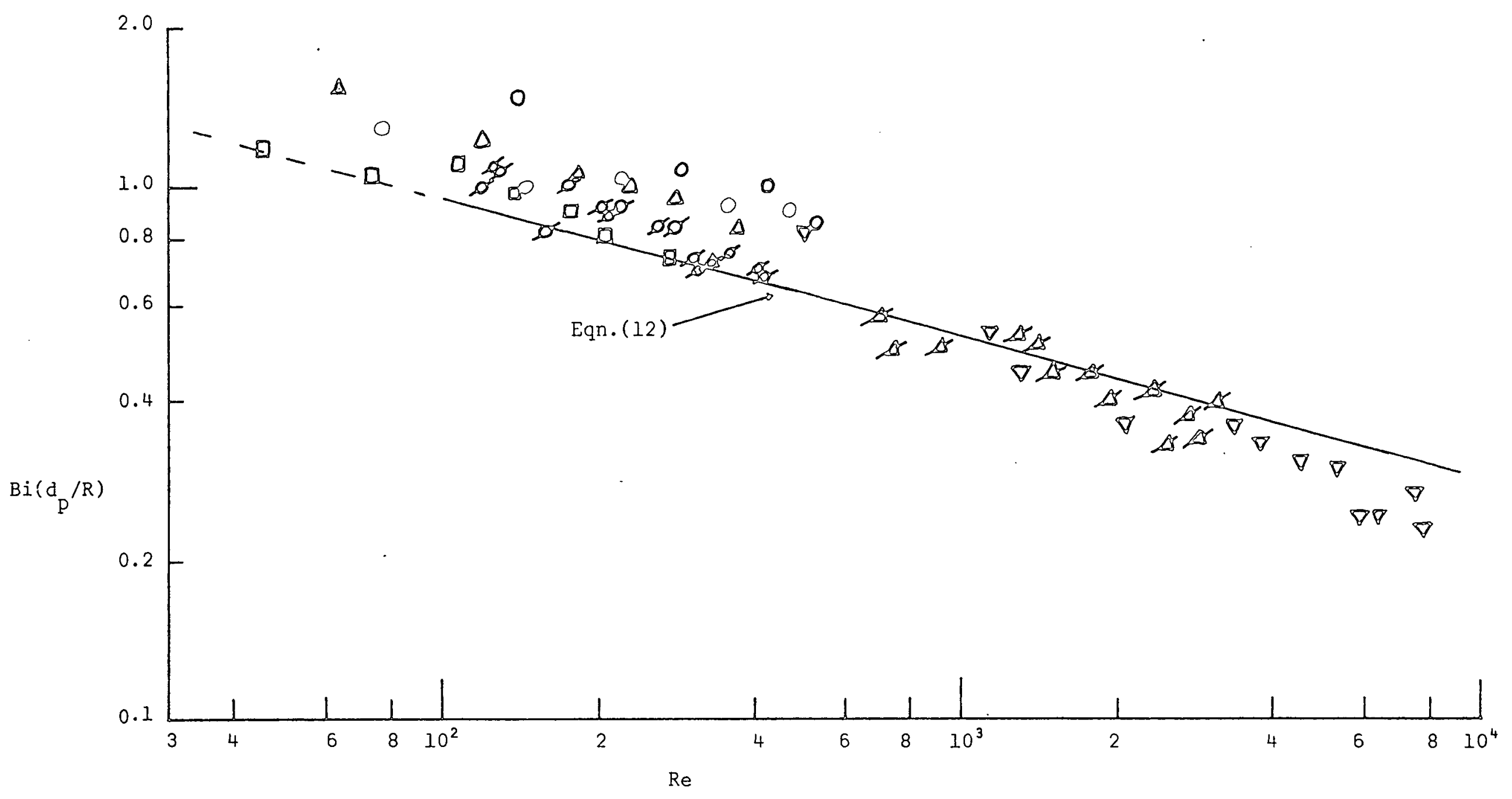

Figure 5 : Comparison of Biot number predictions with experimental results 


\begin{tabular}{|c|c|c|c|}
\hline Symbol & Packing & $d_{t} \underline{d}_{p}-$ & Workers \\
\hline$\Delta$ & Celite spheres & 5.00 & Kunii et al (4.23) \\
\hline$\nabla$ & $"$ & 3.33 & $"$ \\
\hline$\sigma$ & $\mathrm{v}_{2} \mathrm{O}_{5}$ cylinders & 17.24 & De Wasch \& Froment (‥1) \\
\hline 0 & ceramic spheres & 5.57 & Present work \\
\hline$\Delta$ & $"$ & 7.43 & $"$ \\
\hline$\square$ & $"$ & 11.15 & $"$ \\
\hline 0 & steel balls & 7.43 & $"$ \\
\hline
\end{tabular}

At low $\operatorname{Re}(<40)$ nothing definite can be said as only one correlation for $h_{w f}$ is available, that of Yagi and Wakao (ㄴ.5). Their analysis omitted axial dispersion, which has been shown by Gunn and de Souza (3.36) to be important at low $R e$ in the analagous problem of determining $h_{f s}$. Experimental data on $B i$ at low Re will be difficult to obtain as short bed depths must be used to give significant radial profiles, leading to difficulties, not the least of which is which downstream boundary condition to use in the axial dispersion model, a decision which becomes important for short beds.

If the data in figure 5 are re-plotted as Nusselt numbers $\left(N u_{w}\right)_{0}$ as shown in figure 6 , the spread noticed by $L i$ and Finlayson is again present. This may be accounted for as follows:

$$
\begin{aligned}
\mathrm{Nu}_{w} & =\frac{h_{w}{ } p}{k_{g}}=\left(\frac{h_{w} R}{k_{r}}\right)\left(\frac{d_{p}}{R}\right)\left(\frac{R e P r}{P e_{r}}\right) \\
& =B i\left(\frac{d_{p}}{R}\right)\left(\frac{\operatorname{Re} P r}{P e_{r}}\right)
\end{aligned}
$$

Substituting for $\mathrm{Bi}$ from equation (9) gives

$$
N u_{w}=\frac{N u_{w f} P_{r f}}{\mathrm{Pe}_{r}}
$$




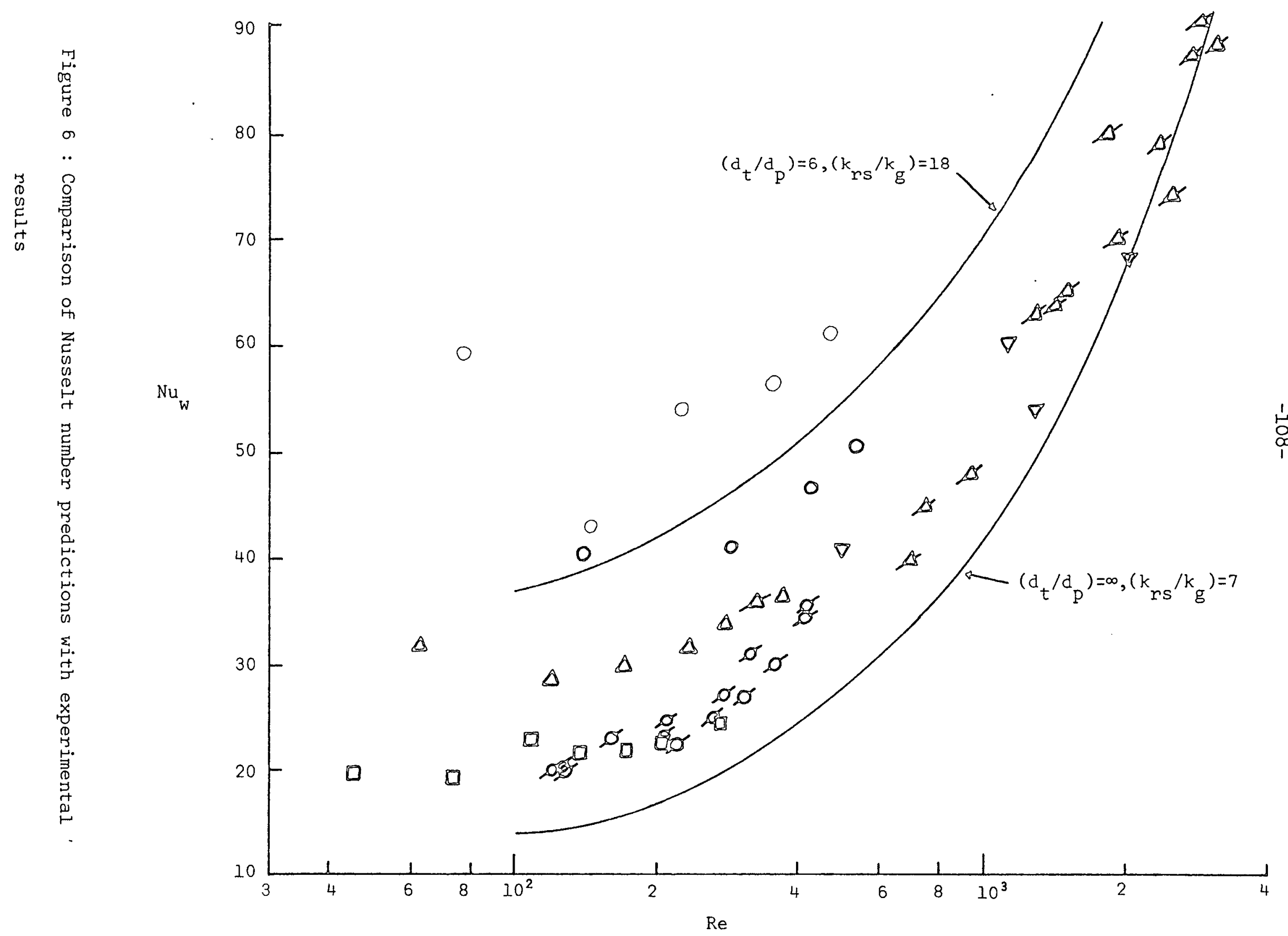


Now $\mathrm{Nu}_{w f}$ depends only on $\mathrm{Re}$ and $\mathrm{Pr}$, and $\mathrm{Pe}{ }_{\text {rf }}$ may be taken as constant. In section 5.2 it was shown that $\mathrm{Pe}_{r}$ depends on $\mathrm{Bi}_{f}$, $B i_{s}, N u_{f s},\left(d_{t} / d_{p}\right),\left(k_{r s} / k_{g}\right)$ and Re. Hence $N u_{w}$ must also depend on these variables, and it shourd be expected that data plotted as $\mathrm{Nu} u_{\mathrm{w}}$ vs. Re will be scattered, if they involve different packings and tube sizes. The apparent "scatter" is no more than a failure to take these variables into account, as hinted in section 3.6 .

In figure 6 curves are shown corresponding to the cases of $a_{t} / d_{p}=\infty$ with low conductivity packing, and $d_{t} / d_{p}=6$ with metallic packing. These reproduce the trend of the data well, and account for almost all the spread. In figures 4 to 6 the predictions appear consistently slightly below the data at low and moderate Re; possibly the correlation used is a little inaccurate in this region.

\subsection{Effective axial Peclet number}

The data indicated as acceptable in section 5.1 are presented in figure 7 ; a key is given in table 4. The results show considerable scatter, typically of an order of magnitude, at all Re. There is no clear distinction between metallic and non-metallic packings; however, the results of Votruba et al (3.14), in all but two cases having $4 \leq\left(a_{t} / a_{p}\right) \leq 12$, lie fairly consistently beneath the rest, which were mostly in the range $d_{t} / d_{p}>20$. 


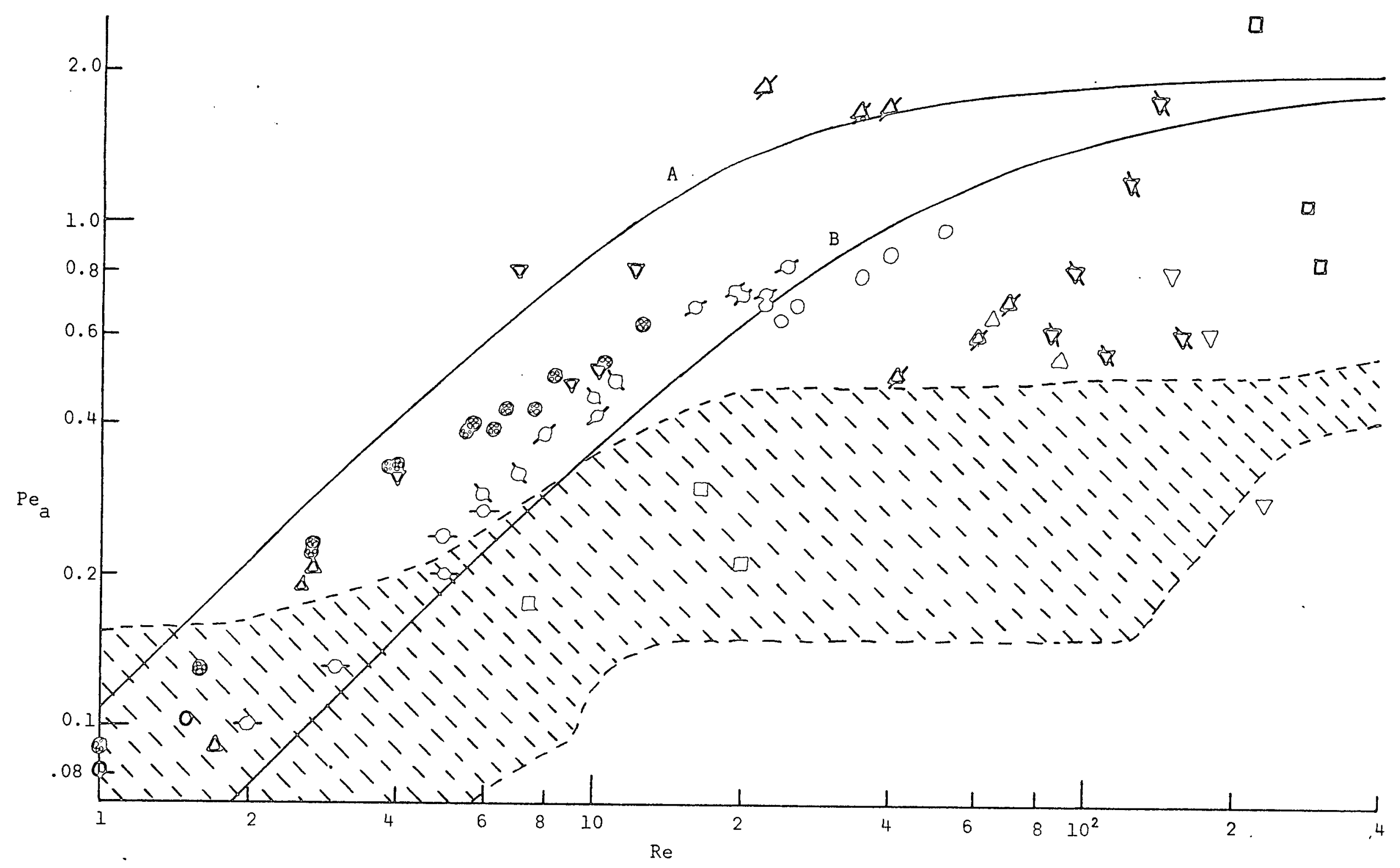

Figure 7 : Axial Peclet number data 


\begin{tabular}{|c|c|c|c|}
\hline Symbol & Packing & $-\mathrm{d} t \frac{\mathrm{d}}{-\mathrm{p}-}$ & Workers \\
\hline 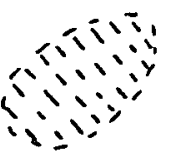 & Various & $\begin{array}{r}3.8-12 \\
19.7,57.8\end{array}$ & Votruba et al. (3.14) \\
\hline$\otimes$ & 6. Omm Glass & 8.3 & Yagi et al (4.21) \\
\hline 68 & $2.6 \mathrm{~mm} . "$ & 19.2 & $" 1$ \\
\hline 0 & $0.9 \mathrm{~mm} \quad "$ & 55.6 & $"$ \\
\hline 0 & 4.8mm Steel & 10.4 & $"$ \\
\hline$\sigma$ & $4.8 \mathrm{rm} \quad "$ & 14.2 & $"$ \\
\hline 2 & $3.0 \mathrm{~mm} \quad "$ & 22.7 & 11 \\
\hline$\alpha$ & $1.5 \mathrm{~mm}$ Lead & 45.3 & $"$ \\
\hline$\Delta$ & $0.5 \mathrm{~mm}$ Glass & 190.0 & Gunn \& de Souza (‥36) \\
\hline$\nabla$ & $1.2 \mathrm{~mm} \quad "$ & 79.0 & $"$ \\
\hline$\Delta$ & $2.2 \mathrm{~mm} \quad "$ & 43.3 & $"$ \\
\hline \& & $3.0 \mathrm{~mm} "$ & 31.8 & $"$ \\
\hline$\square$ & $6.0 \mathrm{~mm} "$ & 15.9 & $"$ \\
\hline$\Delta$ & $3.2 \mathrm{~mm}$ Steel & 29.8 & $"$ \\
\hline$\nabla$ & $6.3 \mathrm{~mm} " 1$ & 15.1 & " \\
\hline$\square$ & $0.8 \mathrm{~mm}$ Lead & 119.1 & " \\
\hline
\end{tabular}

After some re-arrangement the relationship for axial Peclet numbers is

$$
\frac{1}{P e_{a}}=\frac{1}{P e_{a f}}+\frac{k_{a s}}{k_{g}}(\operatorname{Re} \operatorname{Pr})^{-1}\left(1+\frac{8 B i_{s}}{N_{S}\left(B i_{s}+4\right)}\right)^{-2}
$$

where $\mathrm{N}_{\mathrm{S}}$ is given in equation (5).

(a) Large $\left(\mathrm{d}_{t} / \mathrm{d}_{\mathrm{p}}\right)_{-}$

In the limit $a_{t} / d_{p} \rightarrow \infty, N_{S} \rightarrow \infty$ and the limiting form of the equation is 


$$
\frac{1}{\mathrm{Pe}_{\mathrm{a}}}=\frac{1}{\mathrm{Pe}_{\mathrm{af}}}+\frac{\mathrm{k}_{\mathrm{as}}}{\mathrm{k}_{\mathrm{g}}}(\mathrm{Re} \mathrm{Pr})^{-1}
$$

If equation (4.44) for $\mathrm{Pe}_{\text {am }}$ is used and substituted into (17):

$$
\frac{1}{P e_{a}}=\frac{0.73 \varepsilon}{\operatorname{Re} \operatorname{Pr}}+\frac{0.5}{1+\varepsilon \beta /(\operatorname{Re} \operatorname{Pr})}+\frac{k_{\text {as }}}{k_{g}}(\operatorname{Re} \operatorname{Pr})^{-1}
$$

and $\beta=9.7$ for air as fluid.

Note that as a consequence of the choice of correlation for $\mathrm{Pe}$ am the following limiting relationships hold:

$$
\begin{aligned}
& \mathrm{Pe}_{\mathrm{a}} \rightarrow 2 \text { as } \mathrm{Re} \rightarrow \infty \\
& \mathrm{k}^{\circ} / \mathrm{k}_{\mathrm{g}}=0.73 \varepsilon+\mathrm{k}_{\text {as }} / \mathrm{k}_{\mathrm{g}}
\end{aligned}
$$

If the alternative equation $(4.45)$ is used for $\mathrm{Pe}_{\mathrm{rm}}$ the limits are

$$
\begin{aligned}
& \mathrm{Pe}_{\mathrm{a}} \rightarrow 1.54 \text { as } \mathrm{Re} \rightarrow \infty \\
& \mathrm{k}^{\circ} / \mathrm{k}_{\mathrm{g}}=0.67 \varepsilon+\mathrm{k}_{a s} / \mathrm{k}_{g}
\end{aligned}
$$

Taking an average $\varepsilon=0.4$, a band is formed in figure 7 by the

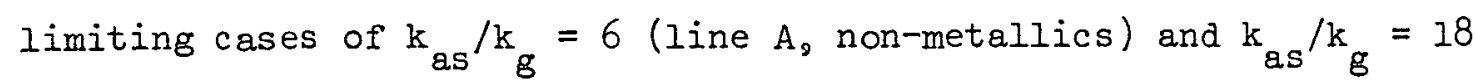
(line $\mathrm{B}_{2}$ metallics); the majority of the data of Yagi et al and Gunn and de Souza lie within this band, which uses equation (18). This is as expected, as this data mainly represents high $\left(d_{t} / \alpha_{p}\right)$ values. There is, however, some deviation from the band at higher Re. The results of Gunn and de Souza are very scattered in this area; the results of Yagi et al, on the other hand, appear to systematically deviate, in particular the $4.8 \mathrm{~mm}$ steel spheres, with $\left(\mathrm{d}_{t} / \mathrm{d}_{\mathrm{p}}\right)=10.4$. The. Iow $\left(a_{t} / \alpha_{p}\right)$ results of Votruba et al lie beneath the band, and appear to have a slower increase with increasing Re.

Within the band the data for metallic packings lie on or near line $B_{0}$ while those for non-metallic lie nearer line A. Hence particle conductivity would appear to produce a secondary ordering on the data. 
(b) Small_ $\left(d_{t} / d_{p}\right)_{-}$

In this case $\mathrm{N}_{\mathrm{S}}$ may not be large and the general equation (16) may have to be used. For this general formula, which is simpler than that for $\mathrm{Pe}_{r}$ it is possible to work out the conditions in terms of $\operatorname{Re},\left(d_{t} / d_{p}\right)$ and $\left(k_{p} / k_{g}\right)$ under which the simplified form (17) gives unacceptable errors. This has been done for experiments using air as fluid ( $\operatorname{Pr}=0.72$ ), taking an average $\varepsilon=0.4$ and setting an error tolerance of $5 \%$ in an estimate of magnitude 2 . The results are shown in figure 8 , taking $B i_{S}=\infty$ (worst-case) and using the Handley-Heggs correlation (4.27) for $\mathrm{Nu}_{f s^{2}}$ supplemented by that of Littman \& Sliva (4.19) at low Re.

To use figure 8 , the line applicable to particle/fluid conductivity ratio $\left(\mathrm{k}_{\mathrm{p}} / \mathrm{k}_{\mathrm{g}}\right)$ should be chosen. Then with one of $\mathrm{Re}$, $\left(d_{t} / d_{p}\right)$ given, the range of the other for which (17) may be used with less than $5 \%$ error is that which gives points above and to the right of the $\left(k_{p} / k_{g}\right)$ line.

From figure 8 , it is seen that the discrepancies between the predictions of equation (17) and the data of Votruba et al for low $\left(d_{t} / d_{p}\right)$ in figure 7 cannot be accounted for by using equation (16) instead of equation (17).

The explanation for the discrepancies is readily provided by the results of Hsiang and Haynes (4.16) as discussed in section 4.5 . Their anomalous decreases in $\mathrm{Pe}$ am as Re increases, for $1.4<\left(\mathrm{d}_{t} / \mathrm{d}_{\mathrm{p}}\right)$ < 8. suggest that the commonly taken constant asymptote $\mathrm{Pe}_{\text {am }}(\infty)$ should be regarded as a function of $\left(a_{t} / d_{p}\right)$. Unfortunately their experiments were not conducted at high enough Re to allow definite conclusions as to the form of the function; indeed they were able to fit an empirical correlation giving $\mathrm{Pe}_{a m} \rightarrow \mathrm{O}$ for some finite $\mathrm{Re}$. 


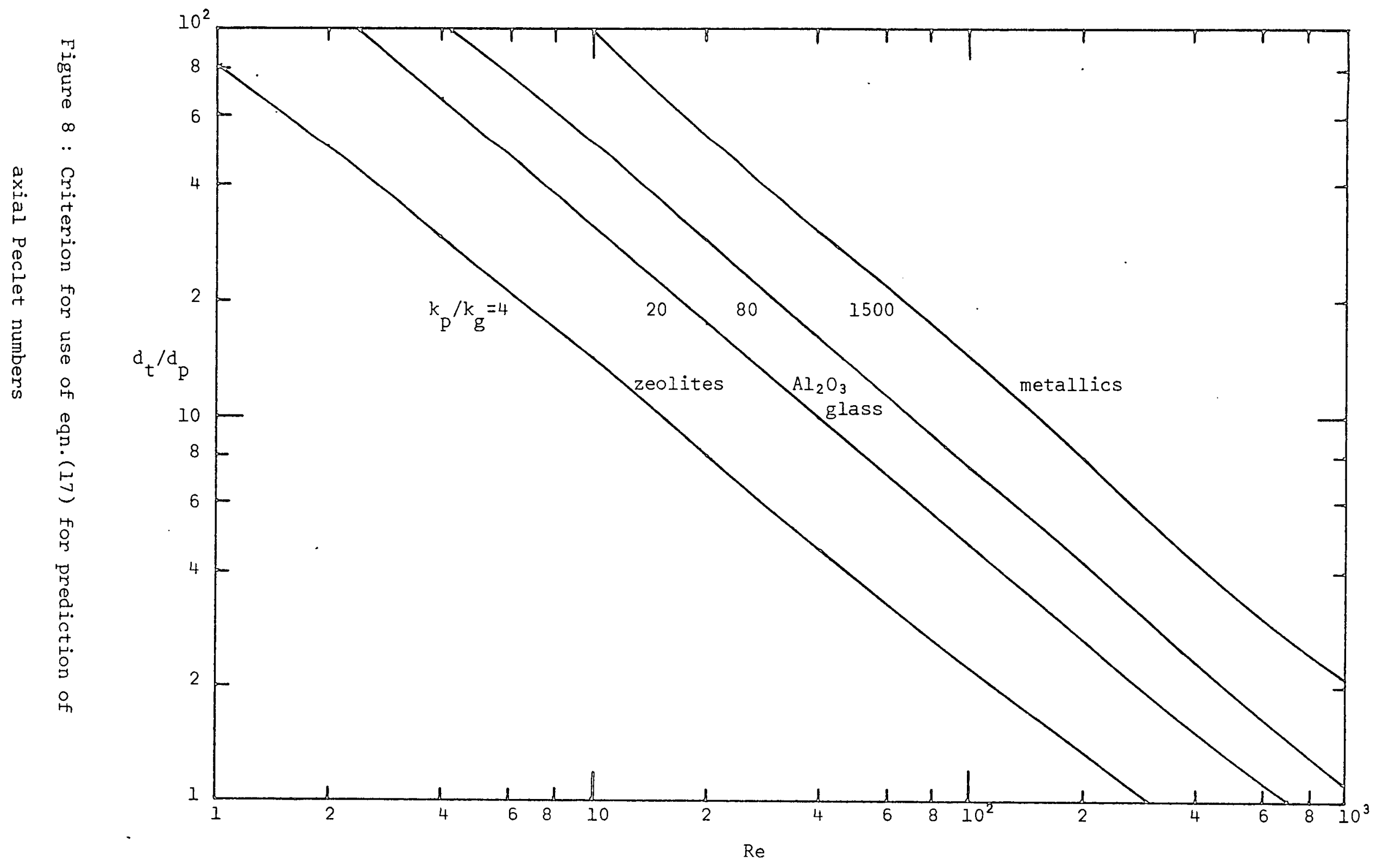


Inspection of the literature reveals an acute shortage of work in the Re and $\left(a_{t} / d_{p}\right)$ ranges of interest here $e_{0}$ and the work of Hsiang and Haynes remains uncorroborated.

Indirect support, however, comes from consideration of the empirical formulae employed by heat transfer workers. The results of Gunn and de Souza (4.36) were too scattered to permit correlation. however Yagi et al (4.21) fitted their results well with a formula which may be written in the present notation after some re-arrangement as

$$
\frac{1}{P e_{a}}=\frac{0.73 \varepsilon}{\operatorname{Re} \operatorname{Pr}}+\frac{1}{P_{a}^{(\infty)}}+\frac{k_{a s}}{k_{g}}(\operatorname{Pr} R e)^{-1}
$$

where their average value of $\mathrm{Pe}_{\mathrm{a}}(\infty)$ is 1.33 .

Votruba et al ( 3.14$)$ arrived at the empirical correlation

$$
\frac{1}{P e_{a}}=\frac{0.73 \varepsilon}{\operatorname{Re} \operatorname{Pr}}+\frac{k_{\text {es }}}{k_{g}}(\operatorname{Re} \operatorname{Pr})^{-1}+\frac{14.5 / d_{p}}{\left(1+\frac{C_{3}}{(\operatorname{Re} P r)}\right)}
$$

where $d_{p}$ is in $\mathrm{mm}$ and the dependence of $\mathrm{Pe}_{a}(\infty)$ upon $\left(d_{t} / d_{p}\right)$ is evident. Using these results a speculative relationship is shown in figure 9.

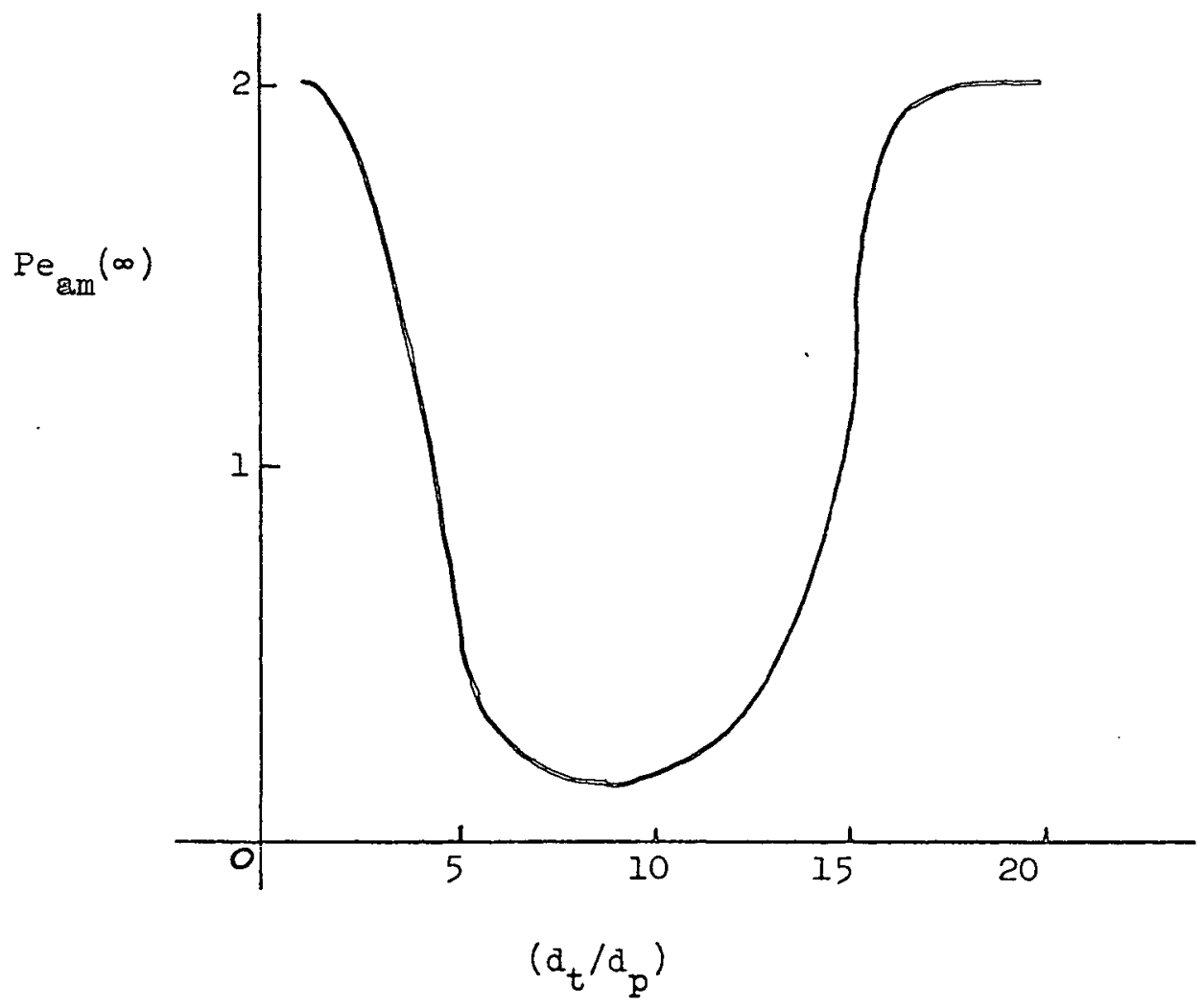

Figure $9:$ Speculative $\left(\mathrm{d}_{t} / \mathrm{d}_{\mathrm{p}}\right)$ dependence of $\mathrm{Pe} \mathrm{am}(\infty)$ 
However this relationship cannot be recomended, and reliable prediction of $\mathrm{Pe}_{\mathrm{a}}$ at high Re must await further work on $\mathrm{Pe}_{\mathrm{am}}$.

\section{(c) Prediction of Pe Pe $_{\text {at }}$ low Re}

The previous discussion is possibly of more academic than practical interest, however, as axial conduction is more important at low Re. Unfortunately another area of doubt arises here, since figure 8 usually requires that the general equation (16) be used, and there is no definitive correlation for $\mathrm{Nu}_{\text {fs }}$ available at low $\mathrm{Re}$.

To show the influence of this parameter, the data of Votruba et al for $1<\operatorname{Re}<10$ and low $\left(d_{t} / d_{p}\right)$ is plotted in figure 10 , making no distinction between different particle sizes. Two extreme cases of correlation for $\mathrm{Nu}_{f s}$ are considered.

$$
\begin{aligned}
\text { (i) } N u_{f s}= & 12 \quad \begin{array}{c}
\text { (determined experimentally by } \\
\text { Miyauchi et al }(\underline{4.35}))
\end{array} \\
\text { (ii) } N u_{f s}= & 0.032 \mathrm{Re}\left(\begin{array}{r}
\text { theoretical prediction } \\
\text { Nelson and Galloway }(\underline{4.31}))
\end{array}\right.
\end{aligned}
$$

For case (i) extremes of particle conductivity are taken as for figure 7 to give a band (curves $A$ and $B$ ). For each of $A$ and $B$ there are two lines, the full line representing equation (16) and the dotted line equation (17).

Since the data represented asymptote to values of $\mathrm{Pe}_{\mathrm{a}}(\infty)$ between 0.15 and 0.5 , an average $\mathrm{Pe}_{\mathrm{a}}(\infty)=0.3$ was taken and $\mathrm{Pe}_{\mathrm{am}}$ obtained from an appropriately modified version of equation (4.44).

.It is seen that either band represents the data reasonably, and that the differences between equations (16) and (17) under case (i) are not large; possibly they may be regarded as giving the same results.

Under case (ii), however, equation (16) becomes $\mathrm{Pe}_{\mathrm{a}}=\mathrm{Pe}_{\text {af }}$ as shown by curve $C_{0}$ which is clearly unrealistic. 


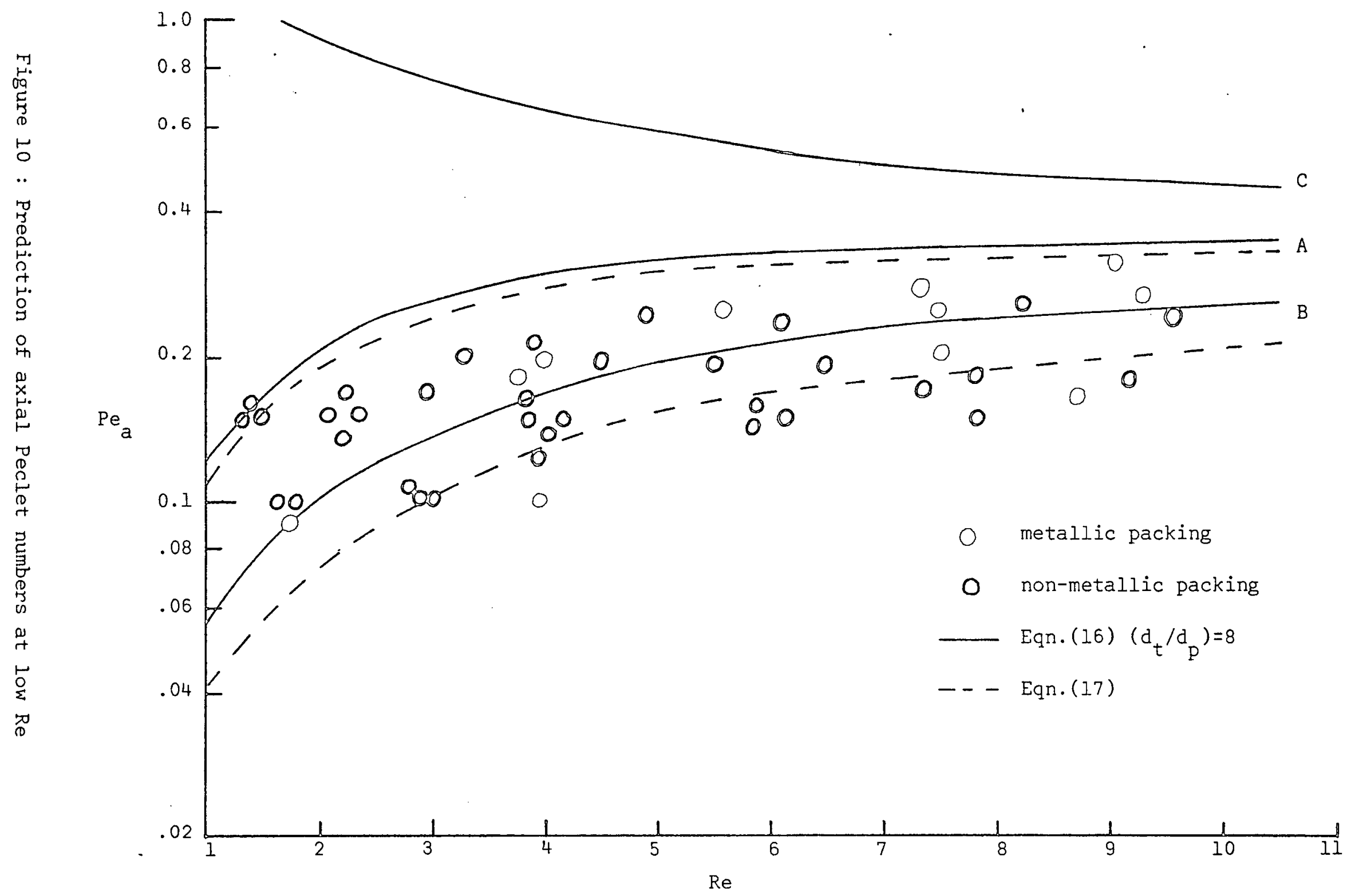


Possibly the best choice for predicting $\mathrm{Pe}_{\mathrm{a}}$ at low $\mathrm{Re}$ is to use equation (17), as the errors involved are small compared with those made if an inappropriate choice for $\mathrm{Nu}_{f s}$ is used.

(d) Theoretical model of Vortmeyer and Schaeffer

An alternative theoretical prediction formula has been obtained by Vortmeyer and Schaeffer (10). They matched one-and two-phase models of adiabatic beds, assuming equality of second axial temperature derivatives in the two phases. It is easy to show that this implies equality of temperature in the two phases using the present boundary conditions, which is an unjustifiable result.

Vortmeyer and Schaeffer obtained the result

$$
\frac{1}{\mathrm{Pe}_{a}}=\frac{\mathrm{k}_{\mathrm{as}}}{\mathrm{k}_{\mathrm{g}}}(\operatorname{Re} \operatorname{Pr})^{-1}+\frac{\operatorname{Re} \operatorname{Pr}}{6(1-\varepsilon) \mathrm{Nu} \mathrm{fs}_{\mathrm{s}}}
$$

In a further paper by Vortmeyer $(\underline{4.30})$ this was shown to predict the data of Gunn and de Souza at lower Re. However at low Re the first term in equation (25) dominates and good agreement is guaranteed。 providing the appropriate $\left(\mathrm{k}_{\mathrm{as}} / \mathrm{k}_{\mathrm{g}}\right)$ value is chosen. On the other hand, as $\mathrm{Re} \rightarrow \infty$ equation (25) gives $\mathrm{Pe}_{\mathrm{a}} \rightarrow 0$ which does not agree with experimental data. Equation (25) cannot be regarded as a reliable prediction formula.

\section{$\underline{\text { References }}$}

1) Chi-Hsiung Li and B.A.Finlayson, Heat transfer in packed beds a reevaluation, Chem.Eng.Sci. 32,1055 (1977).
2) J.M.Valstar,
- Ph.D.Thesis, Delft, Netherlands (1969).
3) T.R.Felix, - Ph.D.Thesis, University of Wisconsin (1951). 
4) C.A.Coberley and W.R.Marshall, Temperature gradients in gas streams flowing through fixed granular beds, Chem.Eng.Prog. $47.141(1951)$

5) D.Ziolkowski, A new method for simultaneous estimation of the effective thermal conductivity and the wall heat transfer coefficient in a tube packed with granular material, Bull. Acad.Pol.Sci., Ser.Sci.Chem. 18,221 (1970).

6) J.H.Quinton and J.A.Storrow, Heat transfer to air flowing through packed tubes。Chem.Eng.Sci. 5,245 (1956).

7) Undergraduate project under the direction of Dr.D.L.Cresswell。 University of Edinburgh.

8) R.A.Sehr, The thermal conductivity of catalyst particles, Chem. Eng.Sci. 9.145 (1958).

9) R.H.Perry and C.H.Chilton, Chemical Engineers' Handbook, 5th edn., McGraw-Hill Kogakusha, Tokyo (1973).

10) D.Vortmeyer and R.J.Schaefer, Equivalence of one-and two-phase models for heat transfer processes in packed beds: one dimensional theory, Chem.Eng.Sci. 29,485 (1974). 
The work presented in this thesis may conveniently be divided into two parts : (i) model testing and parameter estimation (chapters 1 to 3); (ii) theoretical prediction of effective heat transfer parameters (chapters 4 and 5).

In the first part of the thesis, statistical methods were applied to the analysis, via homogeneous continuum models, of experimental data obtained from a low $d_{t} / d_{p}$ packed bed heat exchanger. These statistical methods discriminated clearly amongst the models, showing that the omission of axial conduction in such models leads to a systematic lack-of-fit of the model and to biased parameter estimates. The 'depth-dependence' of the effective heat transfer parameters was shown to be due to this omission, rather than other physical effects, as suggested in the literature (5.1).

The above results show that while physical intuition must be used to determine and simplify engineering models, it is essential that these are then justified by statistical analysis. If this step is omitted, as is usually the case in chemical engineering studies, the parameter estimates obtained from an inadequate model may be at best biased, at worst meaningless. The need for rigorous analysis is highlighted by the fact that the inclusion of axial conduction changes the magnitude of predicted bed exit temperature profiles very littie, as shown by the difficulty in estimating effective axial Peclet numbers. This observation is often used to justify the omission of axial conduction; however, only statistical analysis can detect the small but systematic changes in profile. It is a matter of conjecture in how many other areas inadequate models are being used; the parameters. may not always show such convenient 'symptoms' of bias. 
As a corollary to the above, it must also be emphasised that parameter estimates, even if obtained from an adequate model, should always be accompanied by estimates of variance or confidence intervals. Without these it is impossible to know if trends in the parameters are significant. This is again rarely done in chemical engineering literature.

It was also shown in this part of the work that the choice of boundary conditions is as important to a model as the main equation. The inclusion of axial conduction effects leads to the problem of choosing a simplified downstream boundary condition. The assumption of plug-flow in the space above the packing was shown to be inadequate both by statistical rejection of the model and by a separate test for any change in entrance profile with different bed lengths. A boundary condition placed at infinity was compatible with the observed lack of change.

Finally, in this part of the work, it should be stressed that the model which passed the statistical tests predicts only angle-averaged temperatures. The inclusion of angular dependence is a task for the future; at present only probabilistic models appear to show any hope in this direction.

In the second part of the work a new theory for prediction of the effective heat transfer parameters appearing in homogeneous continuum models was presented. This theory relates the effective parameters to more basic underlying heat transfer processes which may be independently measured and thus estimated from literature correlations.

The development of this theory required the solution to a two-phase quasi-continuum model containing the basic heat transfer parameters. Previous solutions to this model had involved finding at least the eigenvalues of the model equations numerically, so that 
no totally-determined analytic solution existed. In this work an approximate analytic solution was found, using a one-point collocation-perturbation method, which was shown to give accurate fluid-phase temperatures away from bed entrance. In particular the perturbation method gave pleasing results. The collocation method is a familiar numerical tool; this application shows its versatility in deriving qualitative aspects of a solution, often more important in engineering situations than precise numerical answers.

The effective parameters were then related to the basic ones by matching one-phase and fluid-phase approximate solutions to the respective models. The relationships found were complex, especially for the effective Peclet numbers. The assumption of additivity of 'fluid and solid phase conductivities, until now a standard one in the literature, was shown to be a special case applicable only in the case of large $d_{t} / d_{p}$ beds; for small $d_{t} / d_{p}$ beds, as in the present study, wall and interphase effects must be included.

Besides showing the correct 'Iumping' procedures for the effective parameters, the relationships also do much to explain the scattered Iiterature data. In particular, the scatter in the correlation of the wall heat transfer coefficient, in the form of a Nusselt number versus Reynolds number, was explained as a failure to include other influencing factors. A simpler correlation in the form of a Biot number was shown by the theory to be preferable.

Although the parameter estimates of this work, and certain of the literature data, were predicted accurately by the theory, final testing has not yet been possible due to two factors. The first is the regrettable conclusion that much literature data is unreliable, due either to poor experimental design or poor analysis of results. 
The latter reason is the chief cause; much data has been analysed using inadequate models or poor parameter estimation techniques. The 'short-cut' methods used in the pre-computer era are not rigorous in the face of experimental errors; the safest course is to discard all data obtained using them. As good experimental data are costly and time-consuming to obtain, more thought should be given to their analysis.

The second factor is the necessity of awaiting further work on the basic heat transfer correlations. For some of these the situation is less certain than could be wished, for others it is not at all certain. It is appropriate to conclude this study by mentioning the most urgent areas requiring clarification:
(a) axial mass transfer at low $a_{t} / a_{p}(3-12)$; corroboration of the work of Hsiang and.Haynes $(\underline{4.16}$ ) and extension to larger Re to determine limiting values.
(b) interphase heat or mass transfer at low Re (<10)
(c) wall-to-fluid mass transfer at low $\operatorname{Re}(<100)$ for gases.
(d) wall-to-solid heat transfer. 


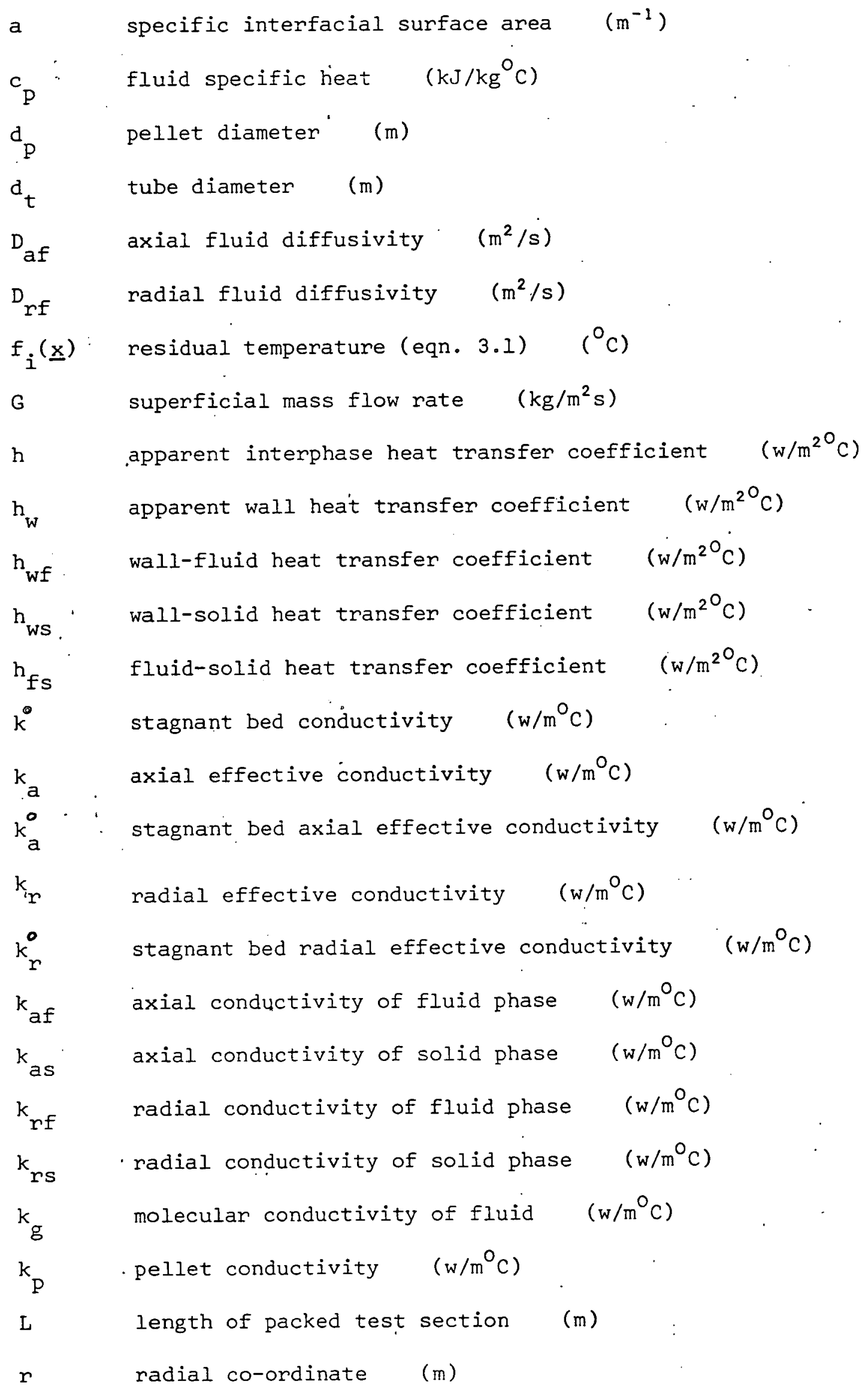




\begin{tabular}{|c|c|}
\hline $\mathrm{R}$ & tube radius \\
\hline$S$ & sum-of-squares at 'solution' $\left({ }^{0} \mathrm{C}\right)^{2}$ \\
\hline$S(\underline{x})$ & sum-of-squares at $\underline{x} \quad\left({ }^{O} \mathrm{C}\right)^{2}$ \\
\hline$t$ & solid phase temperature $\quad\left({ }^{\circ} \mathrm{C}\right)$ \\
\hline$\Gamma$ & fluid phase temperature $\quad\left({ }^{\circ} \mathrm{C}\right)$ \\
\hline $\mathrm{b}$ & bed temperature (in one-phase models) \\
\hline 0 & temperature of calming section. wall \\
\hline r w & temperature of test section wall \\
\hline$r_{b c}$ & bed temperature at $r=0 \quad\left({ }^{\circ} \mathrm{C}\right)$ \\
\hline [ec & bed exit temperature at $r=0 \quad\left({ }^{0} \mathrm{C}\right)$ \\
\hline Tem & mixing-cup temperature at bed exit \\
\hline Tav & average replicate temperature \\
\hline Tobs & experimentally measured temperature \\
\hline $\mathrm{u}$ & superficial fluid velocity. $(\mathrm{m} / \mathrm{s})$ \\
\hline & axial co-ordinate (m) \\
\hline
\end{tabular}

\section{Dimensionless parameters}

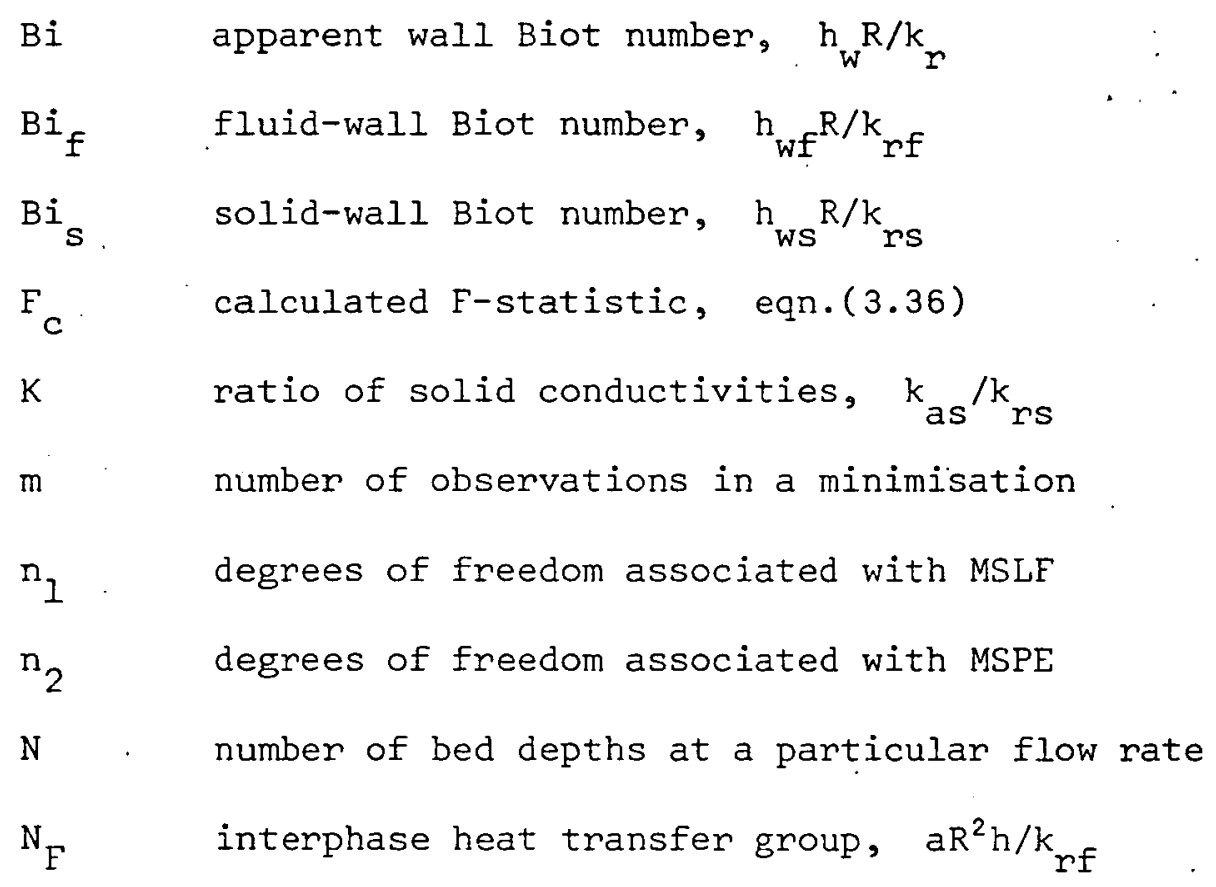


$\mathrm{N}_{\mathrm{S}}$. interphase heat transfer group, $\mathrm{aR}^{2} \mathrm{~h} / \mathrm{k}$ rs

$\mathrm{Nu}_{\mathrm{w}} \quad$ apparent wall Nusselt number, $\mathrm{h}_{\mathrm{w}} \mathrm{d} / \mathrm{k}_{\mathrm{g}}$

$\mathrm{Nu}_{\text {fs }}$. fluid-solid Nusselt number, $\mathrm{h}_{f s} \mathrm{~d}_{\mathrm{p}} / \mathrm{k}_{\mathrm{g}}$

$\mathrm{Nu}_{\text {wf }}$ fluid-wall Nusselt number, $\mathrm{h}_{\mathrm{wf}} \mathrm{d}_{\mathrm{p}} / \mathrm{k}_{\mathrm{g}}$

$\mathrm{P} \quad$ number of parameters estimated in a minimisation.

$\mathrm{Pe}_{\mathrm{a}}$ effective axial Peclet number, ${ }^{\mathrm{G}} \mathrm{c}_{\mathrm{p}} \mathrm{d}_{\mathrm{p}} / \mathrm{k}_{\mathrm{a}}$

$\mathrm{Pe}_{\mathrm{A}} \quad$ effective axial Peclet number (based on $\mathrm{R}$ ), $G_{\mathrm{P}} \mathrm{R} / \mathrm{k}_{a}$

$\mathrm{Pe}_{\mathrm{r}} \quad$ effective radial Peclet number, $G c_{\mathrm{p} . \mathrm{p}} / \mathrm{k}_{\mathrm{r}}$

$\mathrm{Pe}_{\mathrm{R}} \quad$ effective radial Peclet number (based on $R$ ), ${ }^{G} c_{P} R / k_{r}$

$\mathrm{Pe}_{\text {af }}$ axial fluid Peclet number, $G c_{\mathrm{p}} \mathrm{d}_{\mathrm{p}} / \mathrm{k}_{\mathrm{af}}$

$\mathrm{Pe}_{\mathrm{AF}}$ axial fluid Peclet number (based on $R$ ), $G_{p} R / k_{a f}$

$\mathrm{Pe}_{\mathrm{AF}}$ modified axial fluid Peclet number, eqn.(4.30)

$\mathrm{Pe}_{\mathrm{rf}} \quad$ radial fluid Peclet number, $\mathrm{Gc}_{\mathrm{p}} \mathrm{d} / \mathrm{k}_{\mathrm{rf}}$

$\mathrm{Pe}_{\mathrm{RF}} \quad$ radial fluid Peclet number (based on $\mathrm{R}$ ), $\mathrm{Gc}_{\mathrm{p}} \mathrm{R} / \mathrm{k}_{\mathrm{rf}}^{\prime}$

$\mathrm{Pe}_{\mathrm{am}}$ axial mass Peclet number, $\mathrm{ud}_{\mathrm{p}} / \mathrm{D}_{\text {af }}$

$\mathrm{Pe}_{\mathrm{rm}} \quad$ radial mass Peclet number, $\mathrm{ud}_{\mathrm{P}} / \mathrm{D}_{\mathrm{rf}}$

Pr Prandtl number, $\mu c_{\mathrm{p}} / \mathrm{k}_{\mathrm{g}}$

$\operatorname{Re} \quad$ Reynolds number, $\mathrm{Gd}_{\mathrm{p}} / \mu$

Sc Schmidt number, $\mu / \rho D$

$t *$ dimensionless solid temperature, $\left(t-T_{0}\right) /\left(T_{w}-T_{0}\right)$

$t_{1}^{*}, t_{2}^{*}$ values of $t *$ at collocation points $y_{1}, y_{2}$

$\mathrm{T} *$ dimensionless fluid temperature, $\left(\mathrm{T}-\mathrm{T}_{0}\right) /\left(\mathrm{T}_{\mathrm{W}}-\mathrm{T}_{0}\right)$.

$\mathrm{T}{ }_{1}^{*}, \mathrm{~T}_{2}^{*} \quad$ values of $\mathrm{T} *$ at collocation points $\mathrm{y}_{1}, \mathrm{y}_{2}$

$x$ normalised axial co-ordinate, $z / R$

y normalised radial co-ordinate, $r / R$

$y_{1}, y_{2} \quad$ collocation points $\left(y_{2}=1\right)$ 


\section{Greek symbols.}

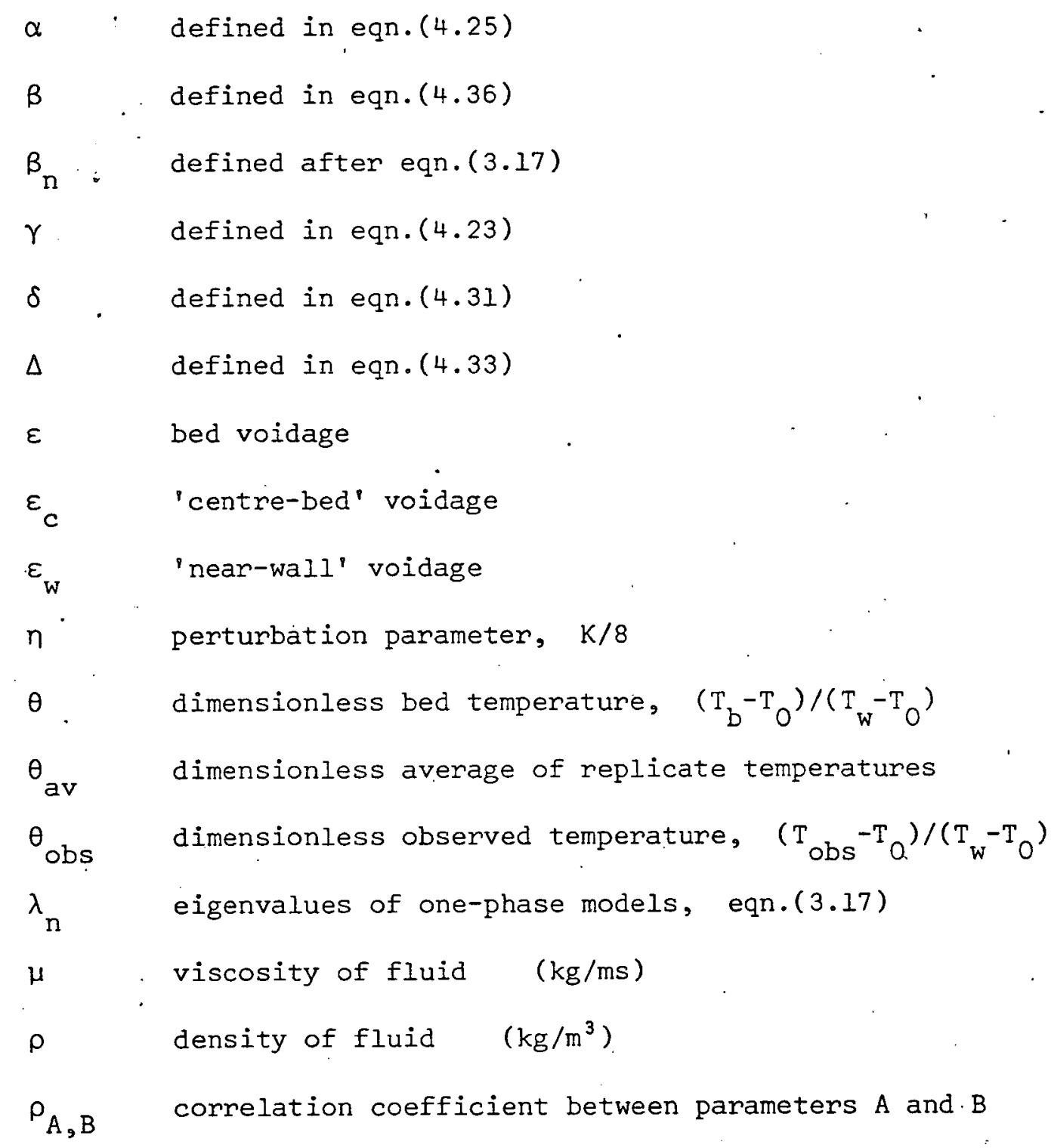

\section{Abbreviations}

ADPF(IBC) axially-dispersed plug-flow model (infinite boundary condition)

$A D P F(F B C)$ axially-dispersed plug-flow model (finite boundary condition)

MSLF mean lack-of-fit sum-of-squares

MSPE mean pure error sum-of-squares

NLLS nonlinear least squares

OLS ordinary (i.e. unweighted) least squares

PF plug-flow model 
SSPE pure error sum-of-squares

WLS weighted least squares

\section{Vectors and matrices}

$\mathrm{H} \quad$ approximation to inverse Hessian of $S(\underline{x})$

$\mathrm{J}_{i j}(\underline{x}), \mathrm{J}$ approximation to Jacobian of $\mathrm{S}(\underline{x})$

$\underline{x} \quad$ vector of parameters to be estimated

Symbols' which are standard mathematical notation (e.g. ' Jo $(x)$, $j_{1}(x)$ the Bessel functions of order 0,1 ) have been omitted from this list. Also some symbols which appear only once and are defined on their appearance are omitted; this latter allows some 'general-purpose' symbols to be used more than once in different contexts. 
APPENDIX A

Tables of F-tests and parameter estimates 


\section{ADEQUACY OF HODELS}

\section{Overall Analysis}

Iable Al

$\mathrm{F}_{\mathrm{C}} / \mathrm{F}_{0} 0.05$

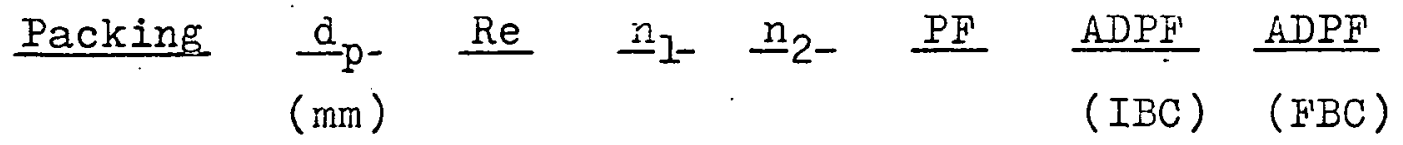

$\begin{array}{llllllll}\text { Ceramic } & 12.7 & 536 & 29 & 93 & 1.57 & 0.42 & 1.15\end{array}$

$\begin{array}{llllll}430 & 37 & 117 & 2.61 & 0.48 & 2.03\end{array}$

$290 \cdot 37 \quad 118 \quad 2.40 \quad 0.67 \quad 1.86$

$\begin{array}{llllll}140 & 29 & 94 & 2.61 & 0.68 & 2.05\end{array}$

$\begin{array}{llllll}36 & 29 & 94 & 8.01 & 5.81 & 8.19\end{array}$

$\begin{array}{llllllll}\text { Ceramic } & 9.5 & 373 & 37 & 119 & 0.92 & 0.50 & 0.87\end{array}$

$\begin{array}{llllll}281 & 37 & 120 & 1.54 & 0.64 & 1.47\end{array}$

$\begin{array}{llllll}231 & 37 & 120 & 1.43 & 0.53 & 1.25\end{array}$

$\begin{array}{llllll}181 & 37 & 120 & 2.04 & 0.51 & 1.55\end{array}$

$\begin{array}{llllll}120 & 37 & 120 & 3.40 & 0.78 & 2.64\end{array}$

$\begin{array}{llllll}63 & 21 & 72 & 5.17 & 1.03 & 3.79\end{array}$

$\begin{array}{llllllllll}\text { Ceramic } & 6.4 & 274 & 37 & 119 & - & 0.89 & \text { - }\end{array}$

\begin{tabular}{|c|c|c|c|c|c|c|c|}
\hline & & 206 & 37 & 119 & - & 0.81 & - \\
\hline & & 171 & 37 & 119 & - & 0.91 & - \\
\hline & & 138 & 37 & 118 & - & 0.91 & . \\
\hline & & 109 & 37 & 118 & - & 0.57 & - \\
\hline & & 73 & 37 & 118 & - & 1.05 & . \\
\hline & & 45 & 37 & 118 & - & 0.26 & . \\
\hline eel & 9.5 & 468 & 37 & 119 & - & 0.82 & . \\
\hline & & 356 & 37 & 119 & - & 0.74 & . \\
\hline & & 224 & 37 & 119 & - & 0.70 & . \\
\hline & & 146 & 29 & 95 & - & 0.82 & . \\
\hline & & 77 & 21 & 71 & - & 0.46 & . \\
\hline
\end{tabular}


ADEQUACY OF ADPF MODELS

Overall Analysis

Table A2

Entrance Data Included

$$
\mathrm{F}_{\mathrm{c}} / \mathrm{F}_{0.05} \quad \mathrm{~F}_{\mathrm{c}} / \mathrm{F}_{0.05}
$$

$\underline{\text { Packing }} \underset{(\mathrm{mm})}{\frac{\mathrm{d}}{\mathrm{p}}-} \stackrel{\mathrm{Re}}{\underline{n_{1}}} \underline{\underline{n}}_{2-} \frac{\underline{\mathrm{ADPF}}}{(\mathrm{IBC})} \underline{\mathrm{n}}_{1-} \underline{\mathrm{n}}_{2}-\frac{\mathrm{ADPF}}{(\mathrm{FBC})}$

$\begin{array}{llllllllll}\text { Ceramic } & 12.7 & 536 & 35 & 130 & 0.97 & 53 & 112 & 1.26\end{array}$

$\begin{array}{lllllll}430 & 43 & 165 & 1.53 & 67 & 141 & 2.01\end{array}$

$\begin{array}{lllllll}290 & 43 & 167 & 1.84 & 67 & 143 & 2.00\end{array}$

$\begin{array}{lllllll}140 & 35 & 132 & 1.86 & 53 & 114 & 2.26\end{array}$

$\begin{array}{lllllll}36 & 35 & 132 & 4.91 & 53 & 114 & 6.62\end{array}$

$\begin{array}{lllllllll}\text { Ceramic } & 9.5 & 373 & 43 & 172 & 0.58 & 67 & 149 & 0.59\end{array}$

$\begin{array}{lllllll}281 & 43 & 174 & 0.69 & 67 & 150 & 0.92\end{array}$

$\begin{array}{lllllll}231 & 43 & 174 & 0.57 & 67 & 150 & 0.77\end{array}$

$\begin{array}{lllllll}181 & 43 & 174 & 0.58 & 67 & 150 & 0.96\end{array}$

$\begin{array}{lllllll}120 & \cdot 43 & 174 & 0.94 & 67 & 150 & 1.56\end{array}$

$\begin{array}{lllllll}63 & 27 & 102 & 1.39 & 39 & 90 & 2.20\end{array}$

$\begin{array}{llllllllllll}\text { Ceramic } & 6.4 & 274 & 43 & 173 & 3.20 & \text { - }\end{array}$

$20643 \cdot 173 \quad 3.36 \quad-\infty$

$\begin{array}{llllllll}171 & 43 & 173 & 3.62 & - & -\end{array}$

$\begin{array}{lllllll}138 & 43 & 172 & 3.51 & - & -\end{array}$

$\begin{array}{lllllll}109 & 43 & 168 & 3.48 \quad- & -\end{array}$

$7343 \quad 1723.96$ - - -

$45 \quad 43 \quad 172 \quad 3.23$ -

Steel $9.5 \quad 468 \quad 43 \quad 173 \quad 1.74 \quad-\ldots$

$\begin{array}{llllllll}356 & 43 & 173 & .1 .92 & - & -\end{array}$

$\begin{array}{lllllll}224 & 43 & 173 & 1.76 \quad- & -\end{array}$

$\begin{array}{lllllll}146 & 35 & 133 & 2.62 & - & -\end{array}$

$\begin{array}{llllllll}77 & 27 & 101 & 0.71 & - & - & -\end{array}$ 
ADEQUACY OF MODELS

Depth-by-depth Analysis

Table A3

Entrance Data Included In ADPF Models

$12.7 \mathrm{~mm}$ Ceramic Beads

$$
\mathrm{F}_{\mathrm{C}} / \mathrm{F}_{0.05} \quad \mathrm{~F}_{\mathrm{c}} / \mathrm{F}_{0.05}
$$

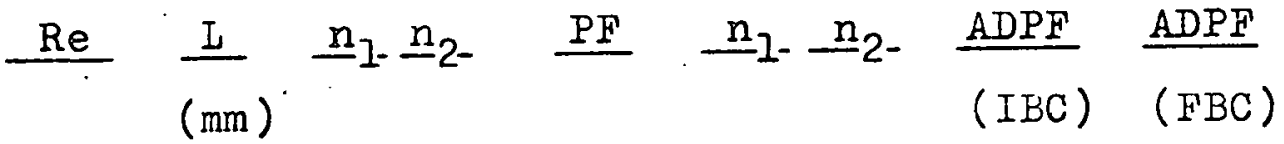

$\begin{array}{lllllllll}536 & 51 & 6 & 23 & 0.23 & 11 & 28 & 0.27 & 0.32\end{array}$ $\begin{array}{llllllll}102 & 6 & 23 & 0.24 & 11 & 28 & 0.38 & 0.40\end{array}$ $\begin{array}{llllllll}178 & 6 & 23 & 0.14 & 11 & 27 & 0.26 & 0.26\end{array}$ $\begin{array}{llllllll}356 & 6 & 24 & 0.27 & 11 & 29 & 1.12 & 1.13\end{array}$ $\begin{array}{lllllllll}430 & 51 & 6 & 23 & 0.18 & 11 & 28 & 0.24 & 0.29\end{array}$ $\begin{array}{llllllll}102 & 6 & 23 & 0.25 & 11 & 28 & 0.44 & 0.46\end{array}$ $\begin{array}{llllllll}178 & 6 & 23 & 0.15 & 11 & 27 & 0.32 & 0.32\end{array}$ $\begin{array}{llllllll}254 & 6 & 24 & 0.09 & 11 & 29 & 1.57 & 1.58\end{array}$ $\begin{array}{llllllll}356 & 6 & 24 & 0.37 & 11 & 29 & 2.07 & 2.09\end{array}$ $\begin{array}{lllllllll}290 & 51 & 6 & 23 & 0.21 & 11 & 28 & 0.29 & 0.34\end{array}$ $\begin{array}{llllllll}102 & 6 & 23 & 0.28 & 11 & 28 & 0.51 & 0.53\end{array}$ $\begin{array}{llllllll}178 & 6 & 24 & 0.10 & 11 & 29 & 0.41 & 0.42\end{array}$ $\begin{array}{llllllll}254 & 6 & 24 & 0.25 & 11 & 29 & 3.44 & 3.48\end{array}$ $\begin{array}{llllllll}356 & 6 & 24 & 0.43 & 11 & 29 & 3.31 & 3.32\end{array}$ $\begin{array}{lllllllll}140 & 51 & 6 & 23 & 0.23 & \text {.11 } & 28 & 0.39 & 0.44\end{array}$ $\begin{array}{llllllll}102 & 6 & 23 & 0.15 & 11 & 27 & 0.61 & 0.72\end{array}$ $\begin{array}{llllllll}178 & 6 & 24 & 0.12 & 11 & 29 & 0.45 & 0.46\end{array}$ 356 - - - 1129.2 .412 .33 $\begin{array}{lllllllll}36 & 51 & 6 & 23 & 0.72 & 11 & 28 & 1.43 & 1.58\end{array}$ $\begin{array}{llllllll}102 & 6 & 23 & 0.52 & 11 & .28 & 0.87 & 0.77\end{array}$ $178-\quad-\quad-\quad-\quad-$ $356-$ 
Depth-by-depth Analysis

Table A4.

Entrance Data Included In ADPF Models

$9.5 \mathrm{~mm}$ Ceramic Beads

$$
\mathrm{F}_{\mathrm{c}} / \mathrm{F}_{0.05} \quad \mathrm{~F}_{\mathrm{c}} / \mathrm{F}_{0.05}
$$

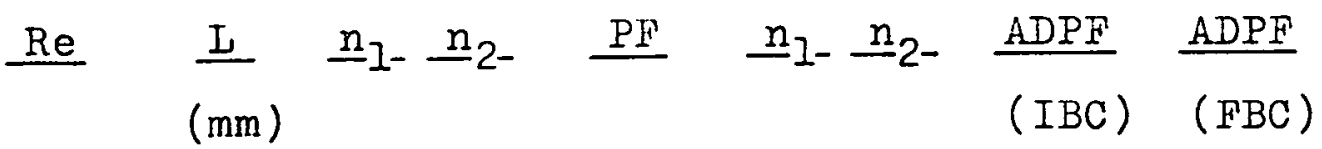

$\begin{array}{lllllllll}373 & 51 & 6 & 24 & 0.80 & 11 & 30 & 0.31 & 0.33\end{array}$

$\begin{array}{llllllll}102 & 6 & 23 & 0.08 & 11 & 29 & 0.10 & 0.10\end{array}$

$\begin{array}{llllllll}152 & 6 & 24 & 0.44 & 11 & 30 & 0.32 & 0.32\end{array}$

$\begin{array}{llllllll}204 & 0 & 24 & 0.39 & 11 & 30 & 0.28 & 0.28\end{array}$

$\begin{array}{llllllll}254 & 6 & 24 & 0.34 & 11 & 30 & 0.26 & 0.26\end{array}$

281. $51 \quad \begin{array}{lllllll}51 & 64 & 0.84 & 11 & 30 & 0.34 & 0.36\end{array}$

$\begin{array}{llllllll}102 & 6 & 24 & 0.19 & 11 & 30 & 0.13 & 0.13\end{array}$

$\begin{array}{llllllll}152 & 6 & 24 & 0.41 & 11 & 30 & 0.30 & 0.30\end{array}$

$\begin{array}{llllllll}204 & 6 & 24 & 0.36 & 11 & 30 & 0.25 & 0.25\end{array}$

$\begin{array}{llllllll}254 & 6 & 24 & 0.28 & 11 & 30 & 0.21 & 0.21\end{array}$

$\begin{array}{lllllllll}231 & 51 & 6 & 24 & 0.84 & 11 & 30 & 0.37 & 0.39\end{array}$

102. $\begin{array}{lllllll}6 & 24 & 0.21 & 11 & 30 & 0.15 & 0.15\end{array}$

$\begin{array}{llllllll}152 & 6 & 24 & 0.26 & 11 & 30 & 0.20 & 0.20\end{array}$

$\begin{array}{llllllll}204 & 6 & 24 & 0.44 & 11 & 30 & 0.29 & 0.29\end{array}$

$\begin{array}{llllllll}254 & 6 & 24 & 0.10 & 11 & 30 & 0.09 & 0.09\end{array}$

$\begin{array}{lllllllll}181 & 51 & 6 & 24 & 1.12 & 11 & 30 & 0.58 & 0.63\end{array}$

$\begin{array}{llllllll}102 & 6 & 24 & 0.15 & 11 & 30 & 0.13 & 0.14\end{array}$

$\begin{array}{llllllll}152 & 6 & 24 & 0.35 & 11 & 30 & 0.28 & 0.28\end{array}$

204. $\quad \begin{array}{lllllll}6 & 24 & 0.51 & 11 & 30 & 0.32 & 0.32\end{array}$

$\begin{array}{llllllll}254 & 6 & 64 & 0.14 & 11 & 30 & 0.13 & 0.13\end{array}$ 
Table A4 (contd。)

$$
\mathrm{F}_{\mathrm{c}} / \mathrm{F}_{0.05} \quad \mathrm{~F}_{\mathrm{c}} / \mathrm{F}_{0.05}
$$

$\underline{\operatorname{Re}} \quad \frac{\mathrm{L}}{(\mathrm{mm})} \underline{\mathrm{n}}_{1-} \underline{n}_{2} \quad \underline{\mathrm{PF}} \quad \underline{n}_{1-} \underline{n}_{2}-\frac{\mathrm{ADPF}}{(\mathrm{IBC})} \frac{\mathrm{ADPF}}{(\mathrm{FBC})}$

$\begin{array}{lllllllll}120 & 51 & 6 & 24 & 1.57 & 11 & 30 & 0.86 & 0.92\end{array}$

$\begin{array}{llllllll}102 & 6 & 24 & 0.49 & 11 & 30 & 0.42 & 0.44\end{array}$

$\begin{array}{llllllll}152 & 6.24 & 0.24 & 11 & 30 & 0.25 & 0.25\end{array}$

$\begin{array}{llllllll}204 & 6 & 24 & 0.27 & 11 & 30 & 0.19 & 0.19\end{array}$

$\begin{array}{llllllll}254 & 6 & 24 & 0.16 & 11 & 30 & 0.21 & 0.22\end{array}$

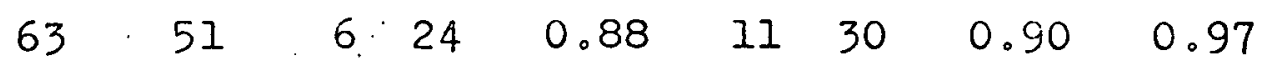

$\begin{array}{llllllll}102 & 6 & 24 & 0.49 & 11 & 30 & 0.71 & 0.73\end{array}$

$\begin{array}{llllllll}152 & 6 & 24 & 0.16 & 11 & 30 & 0.32 & 0.33\end{array}$ 
PF NODEL PARAMETERS

\section{Overall Analysis \\ $12.7 \mathrm{~mm}$ Ceramic Beads}

irable A5

\begin{tabular}{|c|c|c|c|c|}
\hline $\mathrm{Re}$ & Pe $_{r-}$ & $95 \%$ Conf. Int. & $\underline{k}_{r-}$ & $95 \%$ Conf. Int. \\
\hline 536 & 5.38 & $4.88-5.89$ & 2.19 & $1.98-2.39$ \\
\hline 430 & 5.28 & $4.84-5.72$ & 1.63 & $1.50-1.77$ \\
\hline 290 & 4.56 & $4.20=4.91$ & 1.30 & $1.20-1.40$ \\
\hline 140 & 2.95 & $2.67-3.23$ & 0.96 & $0.87-1.06$ \\
\hline 36 & 1.72 & $1.59-1.84$ & 0.43 & $0.40=0.46$ \\
\hline
\end{tabular}

Re $\mathrm{Bi}$ 95\% Conf。Int。 $\mathrm{h}_{\mathrm{w}}$ - $95 \%$ Conf。Into

$\begin{array}{rrrrr}536 & 1.97 & 1.69-2.25 & 121.9 & 114.5-129.4 \\ 430 & 2.34 & 2.02-2.66 & 107.8 & 101.0-114.6 \\ 290 & 2.54 & 2.20-2.89 & 93.4 & 87.4-99.5 \\ 140 & 3.01 & 2.47-3.55 & 82.2 & 74.4-89.9 \\ 36 & 10.27 & 6.72-13.83 & 124.2 & 89.9-158.5\end{array}$


PF HODEL PARAIVETERS

Overall Analysis

Table A6

$9.5 \mathrm{~mm}$ Ceramic Beads

Re Per- $\underline{9 \% \text { Conf。Int。 }} \underline{k}_{r}-\underline{95 \% \text { Conf。Int。 }}$

$3735.76 \quad 5.54-5.99 \quad 1.42 \quad 1.36-1.48$

$281 \quad 5.19 \quad 4.98-5.41 \quad 1.19 \quad 1.14-1.24$

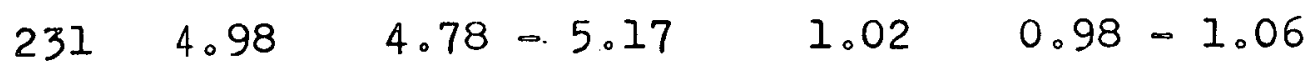

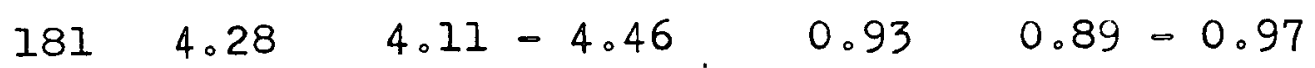

$120 \quad 3.43 \quad 3.27-3.58 \quad 0.77 \quad 0.73-0.80$

$\begin{array}{llllll}63 & 2.09 \quad 1.96-2.21 .0 .63-0.71\end{array}$

Re $\mathrm{Bi}$ 95\% Conf。Int。 $\mathrm{h}_{\mathrm{w}}$ 95\% Conf。Int。

$\begin{array}{lllll}373 & 2.94 & 2.73-3.14 & 117.8 & 113.6-122.1\end{array}$

281. $3.26 \quad 3.00-3.51 \quad 109.5 \quad 104.8-114.1$

$2313.48 \quad 3.22-3.75 \quad 100.2 \quad 96.0=104.4$

$181 \quad 3.55 \quad 3.26-3.84 \quad 93.1 \quad 88.9=97.4$

$\begin{array}{lllll}120 & 3.95 & 3.57-4.34 & 85.8 & 80.9\end{array}$

$63 \quad 4.55 \quad 3.90-5.22 \quad 86.0 \quad 78.3-93.7$ 


\section{PF MODEL PARAMETERS}

Depth-by-depth Analysis

Table A7

\section{$12.7 \mathrm{~mm}$ Ceramic Beads}

$\underline{\mathrm{Re}} \quad \mathrm{L} \quad \mathrm{Pe}_{\mathrm{r}} \quad \underline{95 \% \text { Conf。Int。 }} \underline{\mathrm{k}}_{\mathrm{r}} \quad \underline{95 \% \text { Conf。Int。 }}$ (mm)

$\begin{array}{llll}536 & 51 \quad 3.55 \quad 3.07-4.04\end{array}$

$3.32 \quad 2.86-3.77$

$102 \quad 4.24 \quad 3.50=4.98$

$2.762 .28-3.25$

$\begin{array}{lll}178 & 6.23 & 5.27-7.18\end{array}$

$1.76 \quad 1.49-2.04$

$3566.80,6.13=7.48$

$1.61-1.45-1.78$

430

$51 \quad 3.31 \cdot 2.88-3.73$

$2: 60$

$2.27-2.94$

$102 \quad 3.97 \quad 3.31-4.63$

2.17

$1.81-2.53$

$178 \quad 5.85 \quad 4.97-6.73$

1.47

$1.25-1.69$

$2545.645 .18=6.10$

1.53

$1.40-1.65$

$356 \quad 6.55$

$5.95-7.14$

1.31

$1.19-1.43$

290

$513.06 \quad 2.68-3.44$

1.93

$1.69-2.17$

$1023.82 \quad 3.22-4.41$

1.55

$1.31-1.80$

$178 \quad 5.37$

$4.61-6.13$

1.10

$0.95-1.26$

$254 \quad 4.90$

$4.50-5.29$

1.21

$1.11-1.31$

3566.06

$5.55-6.57$

0.98

$0.90-1.06$

140

$51 \quad 2.32$

$2.04-2.59$

1.23

$1.08-1.37$

$102 \quad 2.88$

$2.45=3.30$

0.99

$0.84=1.044$

$178 \cdot 4.19$

$3.49^{\circ}-4.88$

0.68

$0.57-0.79$

356

36

511.60

$102 \quad 2.22$

$1.48-1.71$

0.46

$0.43-0.49$

178

$1.98-2.45$

0.33

$0.30-0.37$ 


\section{PF MODEL PARAMETERS}

Depth-by-depth Analysis

$12.7 \mathrm{~mm}$ Ceramic Beads

Table A8

Re I $\quad$ Bi $95 \%$ Conf。Int。 $h_{W-95 \% \text { Conf。Int。 }}$ $(\mathrm{mm})$

536

$51 \quad 1.60 \quad 1.31-1.88 \quad 149.7 \quad 138.0-161.4$ $1021.67 \quad 1.25-2.09 \quad 130.4 \quad 116.9-143.9$

$\begin{array}{lllll}178 & 2.13 & 1.60-2.66 & 106.3 \quad 94.5-118.0\end{array}$

$\begin{array}{llllll}356 & 2.61 & 2.12-3.09 & 118.8 \quad 108.3-129.3\end{array}$

$430 \quad 51 \quad i .90 \quad 1.56-2.24 \quad 139.6 \quad 127.9-151.4$

$\begin{array}{llllll}102 & 1.92 \quad 1.43-2.41 & 117.8 \quad 104.6 & -130.9\end{array}$

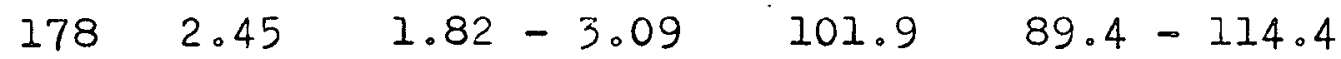

$\begin{array}{lllll}254 & 2.18 \quad 1.88-2.48 \quad 94.0 \quad 88.4-99.7\end{array}$

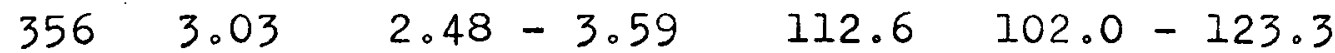

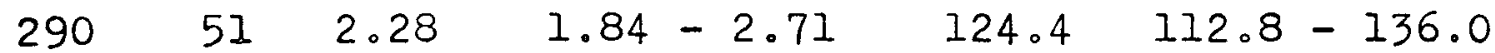

$\begin{array}{llllll}102 & 1.93 & 1.47-2.40 & 84.8 & 75.9 & -93.7\end{array}$

$\begin{array}{llllll}178 & 2.87 & 2.10 & -3.64 & 89.5 & 77.2-101.8\end{array}$

$254 \quad 2.78 \quad 2.35-3.20 \quad 94.9 \quad 87.7-102.2$

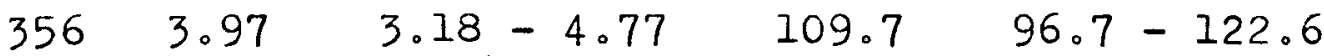

$\begin{array}{lllllll}140 & 51 & 2.87 & 2.26 & -3.49 & 99.6 & 88.2\end{array}-110.9$

$\begin{array}{llllll}102 & 2.52 \quad 1.85-3.18 & 70.3 \quad 61.4 & -79.2\end{array}$

$\begin{array}{lllll}178 & 4.61 \quad 2.64-6.59 & 88.6 \quad 64.7-112.4\end{array}$

356

$\begin{array}{llllll}36 & 51 & 8.94 & 6.25-11.63 \quad 116.0 \quad 89.0-143.0\end{array}$ $102 \quad 16.05 \quad 3.55=28.54 \quad 150.4 \quad 48.5-252.2$ $178 \quad-$

$356-$ 


\section{PF MODEL PARAMETERS}

Depth-by-depth Arialysis

Table A9

$9.5 \mathrm{~mm}$ Ceramic Beads

$\underline{\text { Re }} \quad \underline{\mathrm{Pe}} \mathrm{r}$ $\underline{95 \% \text { Conf。Into }} \underline{\mathrm{k}}_{\mathrm{r}}$ $\underline{95 \% \text { Conf。Int。 }}$ (mm)

373

51

4.28

$3.90-4.65$

1.91

$1.75-2.08$

$102 \quad 5.42$

$4.92-5.92$

1.51

$1.38-1.65$

$152 \quad 5.46$

$4.96-5.96$

1.50

$1.36-1.64$

$204 \quad 5.88$

$5.31-6.46$

1.39

$1.26=1.53$

$254 \quad 5.98$

$5.59-6.38$

1.37

$1.28-1.46$

281

$51 \quad 3.78$

$3.50-4.06$

1.64

$1.52-1.76$

1024.82

$4.45-5.20$

1.28

$1.18-1.38$

1524.86

$4.42-5.31$

1.27

$1.16-1.39$

2045.23

$4.70-5.76$

1.18

$1.06-1.30$

$254 \quad 5.27$

$4.85-5.69$

1.17

$1.08-1.27$

$23 i$

$51 \quad 3.76$

$3.48-4.03$

1.35

$1.25-1.45$

1024.56

$4.20=4.92$

1.11

$1.02-1.20$

1524.59

$4.21-4.97$

1.10

$1.01-1.20$

$204 \quad 5.25$

$4.75-5.75$

0.96

$0.87-1.06$

$.254 \quad 5.39$

$5.03-5.76$

0.94

$0.88-1.00$

181

$\begin{array}{rrr}51 & 3.07 & 2.91-3.23 \\ 102 & 4.03 & 3.72-4.34 \\ 152 & 4.08 & 3.73-4.42 \\ 204 & 4.60 & 4.18--5.03 \\ 254 & 4.86 & 4.48-5.24\end{array}$

1.29

$1.23-1.36$

0.98

$0.91-1.06$

0.97

$0.89-1.06$

0.86

$0.78=0.94$

0.82

$0.75-0.88$ 


\section{Table A9 (contd。)}

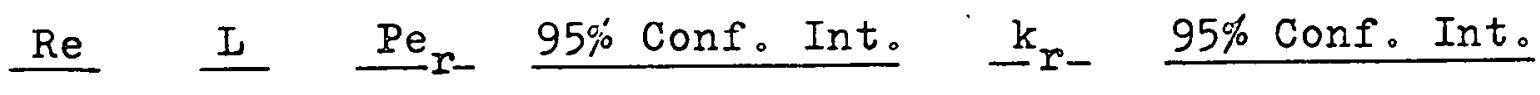
( $\mathrm{mm}$ )

$\begin{array}{lllllll}120 & 51 & 2.57 & 2.44 & -2.71 & 1.02 & 0.97-1.08\end{array}$

$\begin{array}{llllll}102 & 3.18 & 2.95 & -3.42 & 0.83 & 0.77-0.89\end{array}$

$152 \quad 3.37, \quad 3.08-3.66 \quad 0.78 \quad 0.71=0.85$

$2043.78 \quad 3.37-4.20 \quad 0.70 \quad 0.64-0.77$

$254 \quad 4.05 \quad 3.65-4.46 \quad 0.65 \quad 0.58-0.72$

63

$\begin{array}{rllll}51 & 1.75 & 1.66-1.83 & 0.80 & 0.76-0.83 \\ 102 & 2.25 & 2.08-2.42 & 0.62 & 0.57-0.66 \\ 152 & 2.45 & 2.20-2.71 & 0.57 & 0.51-0.63\end{array}$




\section{PF MODEL PARAMETERS}

Depth-by-depth Analysis

Table AlO

$9.5 \mathrm{~mm}$ Ceramic Beads

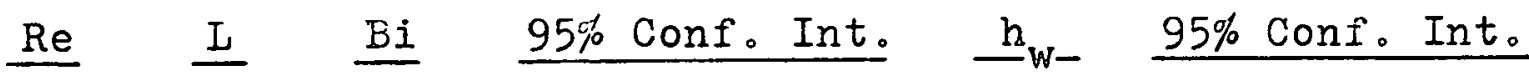
$(\mathrm{mm})$

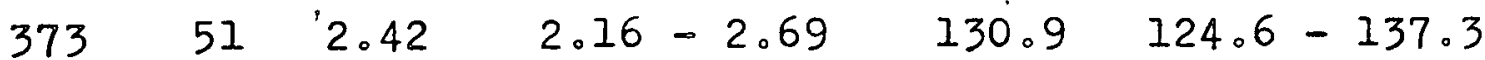

$102 \cdot 2.89 \quad 2.48-3.30 \quad 123.4 \quad 114.4-132.3$

$\begin{array}{llllll}152 & 2.65 \quad 2.23-3.06 \quad 112.2 \quad 103.3-121.2\end{array}$

$2042.88 \quad 2.36-3.40 \quad 113.2 \quad 102.4-123.8$

$\begin{array}{llllll}254 & 3.03 \quad 2.64-3.41 & 117.1 & 109.2-124.9\end{array}$

$\begin{array}{llllllll}281 & 51 & 2.77 & 2.49 & -3.04 & 127.7 & 121.5 & -133.9\end{array}$

$1023.25 \quad 2.81-3.70 \quad 117.8 \quad 109.0=126.5$

$152 \quad 2.79 \quad 2.33-3.24 \quad 100.1 \quad 91.6-108.5$

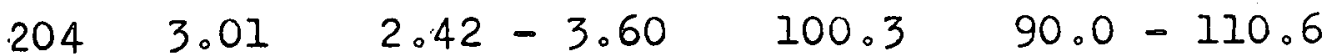

$2543.11 \quad 2.62-3.61 \quad 103.1 \quad 94.3-111.8$

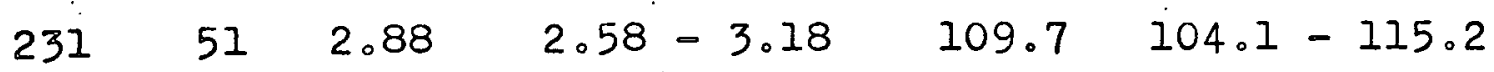

$\begin{array}{lllll}102 & 3.38 & 2.90-3.86 & 105.9 \quad 97.6-114.2\end{array}$

$152 \quad 2.95 \cdot 2.49-3.40 \quad 91.9 \quad 84.4-99.4$

$2043.53 \quad 2.82=4.24 \quad 96.1 \quad 85.2-107.0$

$254 \quad 3.80 \quad 3.23-4.38 \quad 100.9 \quad 92.0-109.7$

$\begin{array}{lllllll}181 & 51 & 2.71 & 2.50-2.92 & 99.0 & 95.2 & -102.8\end{array}$

$\begin{array}{lllll}102 & 3.58 & 3.04-4.11 \quad 99.5 & 90.9-108.1\end{array}$

$\begin{array}{llllll}152 & 3.19 & 2.65 & -3.72 & 87.7 & 79.7\end{array}$

$204^{\cdot} 3.79 \quad 3.00-4.58 \quad 92.4 \quad 81.2-103.5$

$254 \quad 3.99 \quad 3.26-4.72 \quad 92.2 \quad 82.2-102.2$ 
i'able AlO (contd。)

\begin{tabular}{|c|c|c|c|c|c|}
\hline $\mathrm{Re}$ & $\underline{I}$ & $\underline{B i}$ & $95 \%$ Conf。Int。 & $h_{w-}$ & $95 \%$ Conf. Int \\
\hline & $(\mathrm{mm})$ & & & & \\
\hline \multirow[t]{5}{*}{120} & 51 & 3.30 & $3.00-3.59$ & 95.2 & $90.6-99.9$ \\
\hline & 102 & 3.57 & $3.04-4.10$ & 83.4 & $76.3-90.4$ \\
\hline & 152 & 3.81 & $3.08-4.55$ & 84.1 & $74.7-93.6$ \\
\hline & 204 & 3.97 & $2.95-4.98$ & 78.0 & $66.2-89.8$ \\
\hline & 254 & 4.86 & $3.55-6.17$ & 89.1 & $73.7-104.5$ \\
\hline \multirow[t]{3}{*}{63} & 51 & 4.07 & $3.65-4.49$ & 91.4 & $85.7-97.0$ \\
\hline & 102 & 4.45 & $3.63-5.28$ & 77.7 & $68.7-86.6$ \\
\hline & 152 & 5.92 & $3.97-7.87$ & 94.7 & $73.2-116.3$ \\
\hline
\end{tabular}




\begin{tabular}{|c|c|c|c|}
\hline Re & $\frac{\mathrm{L}}{(\mathrm{mm})}$ & $P_{P e}, \mathrm{Bj}$ & $f_{k_{r}}, h_{W}$ \\
\hline \multirow[t]{4}{*}{536} & 51 & 0.91 & -0.33 \\
\hline & 102 & 0.94 & -0.61 \\
\hline & 178 & 0.95 & $\infty 0.74$ \\
\hline & $356^{\circ}$ & 0.98 & -0.93 \\
\hline \multirow[t]{5}{*}{430} & 51 & 0.91 & -0.42 \\
\hline & 102 & 0.95 & -0.67 \\
\hline & 178 & 0.96 & -0.79 \\
\hline & 254 & 0.98 & -0.88 \\
\hline & 356 & 0.98 & -0.94 \\
\hline \multirow[t]{5}{*}{290} & 51 & 0.91 & -0.52 \\
\hline & 102 & 0.95 & -0.69 \\
\hline & 178 & 0.96 & -0.85 \\
\hline & 254 & 0.98 & -0.93 \\
\hline & 356 & 0.99 & -0.96 \\
\hline \multirow[t]{4}{*}{140} & 51 & 0.93 & -0.72 \\
\hline & 102 & 0.97 & -0.84 \\
\hline & 178 & 0.98 & -0.94 \\
\hline & $356^{\circ}$ & - & - \\
\hline \multirow[t]{4}{*}{36.} & 51 & 0.96 & -0.93 \\
\hline & 102 & 0.98 & -0.97 \\
\hline & 178 & - & - \\
\hline & 56 & - & - \\
\hline
\end{tabular}


PF WODEL CORRELATIOH COEFFICIENTS

Depth-by-depth Analysis

Table A12

$9.5 \mathrm{~mm}$ Ceramic Beads

\begin{tabular}{|c|c|c|c|}
\hline$\underline{\text { Re }}$ & $\frac{\mathrm{L}}{(\mathrm{mm})}$ & $\rho_{P e, B i-}$ & $f_{k_{r}, h_{W}}$ \\
\hline \multirow[t]{5}{*}{$i^{373}$} & 51 & 0.90 & -0.23 \\
\hline & 102 & 0.90 & $=0.50$ \\
\hline & 152 & 0.93 & -0.67 \\
\hline & 204 & 0.94 & -0.77 \\
\hline & 254. & 0.96 & -0.85 \\
\hline \multirow[t]{5}{*}{281} & 51 & 0.89 & -0.34 \\
\hline & 102 & 0.90 & -0.61 \\
\hline & 152 & 0.94 & -0.73 \\
\hline & 204 & 0.96 & -0.84 \\
\hline & 254 & 0.97 & -0.88 \\
\hline \multirow[t]{5}{*}{231} & 51 & 0.89 & -0.36 \\
\hline & 102 & 0.90 & -0.64 \\
\hline & 152 & 0.94 & -0.76 \\
\hline & 204 & 0.95 & $=0.84$ \\
\hline & 254 & 0.97 & -0.90 \\
\hline \multirow[t]{5}{*}{181} & 51 & 0.89 & -0.43 \\
\hline & 102 & 0.91 & -0.70 \\
\hline & 152 & 0.95 & -0.82 \\
\hline & 204 & 0.97 & -0.90 \\
\hline & 254 & 0.97 & -0.92 \\
\hline
\end{tabular}


Table Al2 (contd.)

$\begin{array}{cccc}\text { Re } & \frac{I}{(\mathrm{~mm})} & \rho_{\mathrm{Pe}, \mathrm{Bi}} & \rho_{\mathrm{k}_{\mathrm{r}}, \mathrm{h}_{\mathrm{W}}} \\ 120 & 51 & 0.89 & -0.67 \\ & 102 & 0.94 & -0.80 \\ 152 & 0.96 & -0.89 \\ & 204 & 0.97 & -0.92 \\ 63 & 254 & 0.98 & -0.95 \\ 51 & 0.92 & -0.77 \\ 102 & 0.96 & -0.90 \\ 152 & 0.98 & -0.96\end{array}$


ADPF (IBC) WODEL PARAMETERS

Overall Analysis

Table Al3

$12.7 \mathrm{~mm}$ Ceranic Beads

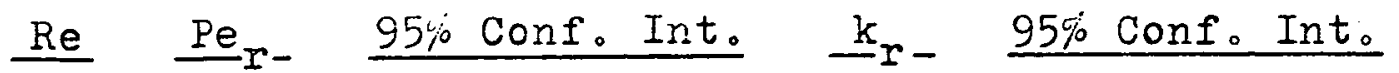

$536 \quad 6.37 \quad 5.83-6.90 \quad 1.85 . \quad 1.69=2.01$

$430 \quad 6.06 \quad 5.66-6.46 \quad 1.42 \quad 1.32-1.52$

$290 \quad 5.07 \quad 4.74-5.41 \quad 1.17 \quad 1.09-1.24$

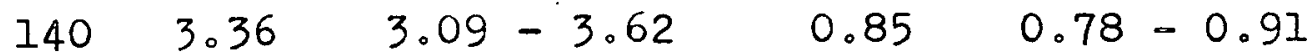

$\begin{array}{lllll}36 & 1.28,1.10-1.47 & 0.57 & 0.49-0.66\end{array}$

Re $\quad \underline{B} \quad \underline{9 \%}$ Conf. Int。 $h_{w}-95 \%$ Conf。 Int。

$5362.37 \quad 2.06-2.68 \quad 123.9 \quad 116.6-131.2$

$\begin{array}{lllll}430 & 2.85 & 2.51-3.18 & 114.2 & 107.5-120.9\end{array}$

$\begin{array}{llllll}290 & 3.04 & 2.67-3.41 & 100.4 \quad 94.1 & -106.6\end{array}$

$\begin{array}{lllll}140 & 4.15 \quad 3.43-4.88 \quad 99.4 & 88.8-110.0\end{array}$

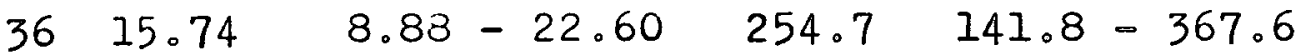

$\frac{\text { Re }}{536} \quad \frac{\text { Pe }}{0.38} \frac{95 \% \text { Conf。Int。 }}{0.28-0.47} \quad \frac{\mathrm{k}_{\mathrm{a}}}{31.4} \frac{.95 \% \text { Conf. Int. }}{23.1-39.7}$

$\begin{array}{llllll}430 & 0.28 & 0.22 & -0.33 & 30.9 & 25.0\end{array}$

$\begin{array}{llllll}290 & 0.38 & 0.30-0.46 & 15.8 & 12.4-19.2\end{array}$

$\begin{array}{lllll}140 & 0.30 & 0.22-0.38 & 9.5 & 7.0-12.0\end{array}$

$\begin{array}{lllllll}36 & 0.29 & 0.14 & -0.43 & 2.5 & 1.3 & -3.8\end{array}$ 
ADPF (IBC) MODEI PARAIIETERS

Overall Analysis

Table Al4

$9.5 \mathrm{~mm}$ Ceramic Beads

Re $\quad \mathrm{Pe}_{\mathrm{r}}$ $\underline{95 \% \text { Conf. Int。 }} \mathrm{k}_{\mathrm{r}}$ $95 \%$ Conf。Int.

$\begin{array}{lllll}373 \quad 6.12 & 5.87-6.37 \quad 1.34 & 1.28=1.39\end{array}$

$2815.59 \quad 5.36-5.81 \quad 1.11 \quad 1.06=1.15$

$2315.30 \quad 5.11-5.50 \quad 0.95 \quad 0.92-0.99$

$\begin{array}{llllll}181 & 4.58 & 4.43-4.74 & 0.87 & 0.84-0.90\end{array}$

$\begin{array}{llllll}120 & 3.64 & 3.52-3.77 & 0.72 & 0.70-0.75\end{array}$

$\begin{array}{lllll}63 & 2.17 \quad 2.08-2.26 & 0.64 & 0.61-0.67\end{array}$

Re $\quad$ Bi $95 \%$ Conf。 Int。 $h_{w}$ 95\% Conf。Int。

$373 \quad 3.12 \quad 2.91-3.34 \quad 118.1 \quad 114.0-122.1$

$2813.56 \quad 3.29-3.82 \quad 111.2 \quad 106.7-115.6$

$231 \quad 3.80 \quad 3.53-4.06 \quad 102.4 \quad 98.4-106.4$

$\begin{array}{lllll}181 & 3.96 \quad 3.68-4.24 & 96.9 & 93.0-100.9\end{array}$

$\begin{array}{lllll}120 & 4.57 \quad 4.20-4.93 \quad 93.2 \quad 88.6-97.8\end{array}$

$\begin{array}{lllll}63 & 5.73 \quad 5.08-6.38 \quad 103.6 \quad 95.3-111.9\end{array}$

Re Pe $a-$ 95\% Conf。Int。 $k_{a}-\underline{95 \% \text { Conf. Int. }}$

$3730.70 \quad 0.48-0.93 \quad 11.6 \quad 7.9-15.3$

$\begin{array}{llllll}281 & 0.51 & 0.38-0.64 & 12.1 & 9.3-15.0\end{array}$

$\begin{array}{llllll}231 & 0.58 & 0.45-0.72 & 8.7 & 6.6 & -10.7\end{array}$

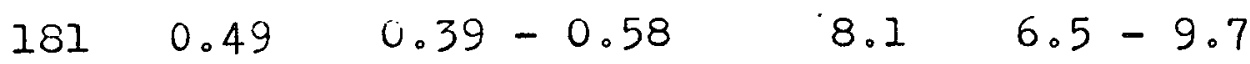

$120 \quad 0.40 \quad 0.34-0.47 \quad 6.5 \quad 5.4-7.5$

$\begin{array}{lllll}63 & 0.35 & 0.28-0.42 & 4.0 & 3.2-4.8\end{array}$ 
ADPF (IBC) MIODEI PARAMIETERS

Overall Analysis

Table A15

$6.4 \mathrm{~mm}$ Ceramic Beads

$\underline{\mathrm{Re}} \quad \underline{P e}_{\mathrm{r}}-\underline{95 \% \text { Conf。Int。 }} \underline{k}_{\mathrm{r}}-\underline{95 \% \text { Conf。Int。 }}$

$\begin{array}{llllll}274 & 5.42 & 5.20-5.64^{\circ} & 1.01 & 0.97-1.05\end{array}$

$\begin{array}{llllll}206 & 4.81 & 4.63-4.99 & 0.86 & 0.82 & -0.89\end{array}$

$171 \quad 4.47 \quad 4.31-4.63 \quad 0.76 \quad 0.74-0.79$

$\begin{array}{llllll}138 & 4.03 & 3.88-4.17 & 0.68 & 0.66-0.71\end{array}$

$109 \quad 3.43 \quad 3.32-3.54 \quad 0.63 \quad 0.61-0.65$

$732.55 \cdot 2.46-2.63 \quad 0.57 \quad 0.55-0.59$

$45 \quad 1.74 \quad 1.70=1.80 \quad 0.51 \quad 0.50-0.53$

$\frac{\text { Re }}{274} \quad \frac{\mathrm{Bi}}{4.19} \quad \frac{95 \% \text { Conf。Int。 }}{3.89-4.50} \quad \frac{\mathrm{h}}{\mathrm{w}}-\frac{95 \% \text { Conf。Int。 }}{119.3}$

$206 \quad 4.58 \quad 4.25-4.91 \quad 110.9 \quad 106.2-115.6$

$1715.02 \quad 4.64-5.39 \quad 108.2 \quad 103.2-115.1$

$138 \quad 5.48 \quad 5.04-5.92 \quad 105.6 \quad 100.2-110.9$

$\begin{array}{llllll}109 & 6.29 & 5.77-0.81 & 112.3 \quad 106.1 & -118.6\end{array}$

$.73 \quad 5.85 \quad 5.35-6.35 \quad 94.6 \quad 89.2-99.9$

$45 \quad 6.62 \quad 6.08-7.15 \quad 95.7 \quad 90.2-101.1$

Re Pe ${ }_{a}-95 \%$ Conf。Int。 $\mathrm{k}_{\mathrm{a}}-\underline{95 \% \text { Conf。Int。 }}$

$\begin{array}{rllll}274 & 1.00 & 0.46-1.54 & 5.5 & 2.5-8.4 \\ 206 & 0.55 & 0.39-0.71 & 7.5 & 5.3-9.7 \\ 171 & 0.46 & 0.36-0.56 & 7.4 & 5.8-9.1 \\ 138 & 0.36 & 0.29-0.42 & 7.7 & 6.2-9.2 \\ 109 & 0.27 & 0.23=0.30 & 8.1 & 7.0-9.1 \\ 73 & 0.30 & 0.26-0.35 & 4.8 & 4.1-5.5 \\ 45 & 0.27 & 0.24-0.30 & 3.3 & 3.0-3.6\end{array}$


ADPF (IBC) HODEL PARAHETERS

Overall Analysis

Table A16

$9.5 \mathrm{~mm}$ Steel Balls

Re $\quad \underline{P e}_{\mathrm{r}}$ 95\% Conf。Into $\underline{\mathrm{k}}_{\mathrm{r}}$

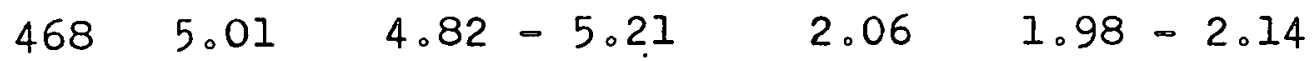

$\begin{array}{lllll}356 & 4.23 & 4.07-4.39 & 1.86 & 1.79-1.93\end{array}$

$\begin{array}{llllll}224 & 3.11 & 2.98 & -3.23 & 1.59 & 1.53-1.65\end{array}$

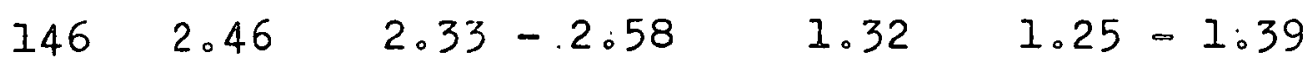

$\begin{array}{lllll}77 \quad 1.20 & 1.10-1.30 \quad 1.41 & 1.30-1.53\end{array}$

$\begin{array}{rrrrr}\frac{\mathrm{Re}}{468} & \frac{\mathrm{Bi}}{3.40} & \frac{95 \% \text { Conf. Int. }}{3.15-3.64} & \frac{\mathrm{h}_{\mathrm{w}}}{197.7} & \frac{95 \% \text { Conf。 Int。 }}{190.0-205.4} \\ 356 & 3.47 & 3.21-3.72 & 181.9 & 174.5-189.3 \\ 224 & 3.90 & 3.57-4.23 & 175.1 & 166.4-183.9 \\ 146 & 3.72 & 3.31-4.12 & 138.5 & 129.8-147.2 \\ 77 & 4.84 & 4.09-5.59 & 193.2 & 168.3-218.0\end{array}$

Re Pe ${ }_{a}$ 95\% Conf。Int。 $\mathrm{k}_{\mathrm{a}}$ 95\% Conf。Int。

$\begin{array}{lllll}468 & 0.73 & 0.52-0.94 & 14.2 & 10.1-18.3\end{array}$

$\begin{array}{lllll}356 & 0.77 & 0.55-0.98 & 10.3 & 7.4-13.2\end{array}$

$\begin{array}{lllll}224 & 0.51 & 0.41-0.62 & 9.7 & 7.7-11.6\end{array}$

$\begin{array}{lllll}146 & 0.95 & 0.62-1.28 & 3.4 & 2.2-4.6\end{array}$

$\begin{array}{lllll}77 & 0.22 & 0.16-0.28 & 7.6 & 5.5-9.8\end{array}$ 
Packing $\underset{(\mathrm{mm})}{\stackrel{d}{p-}} \cdot \stackrel{\text { Re }}{\rho_{k_{a}, k_{\bar{r}}}}{\stackrel{\rho}{k_{a}, h_{\bar{w}}}}_{\rho_{k_{r}, h_{W}}}$ Ceramic

12.7

$\begin{array}{rrrr}536 & -0.34 & 0.04 & -0.68 \\ 430 & -0.22 & 0.15 & -0.76 \\ 290 & -0.18 & 0.18 & -0.80 \\ 140 & -0.11 & 0.38 & -0.77 \\ 36 & 0.88 & 0.62 & 0.21\end{array}$

Ceramic

9.5

37

$-0.44$

$0.03-0.64$

$281:-0.41$

$0.12-0.70$

$231-0.34$

$0.12 \quad-0.71$

$181-0.28$

$0.17-0.78$

$120-0.14$

$0.24 \quad-0.81$

$63 \quad-0.01$

$0.42 \quad-0.75$

Ceramic

6.4

27

$-0.51$

0.07

$-0.58$

$206 \quad-0.36$

$0.01 \cdot-0.64$

$171-0.35$

$0.13-0.70$

$138 \quad-0.34$

$0.13 \quad-0.72$

$109-0.24$

$0.14 \quad-0.78$

$73 \quad-0.14$

$0.15-0.79$

$45 \quad-0.05$

$0.21 \quad-0.79$

Steel

9.5

$468 \quad-0.31$

$0.09 \quad-0.74$

$356-0.24$

$0.15 \quad-0.79$

$224-0.09$

$0.26 \quad-0.82$

$146-0.12$

$0.27-0.84$

$77 \quad 0.60$

$0.70 . \quad-0.06$ 
ADPF (FBC) HODEL PARAIETERS

Overall Analysis

Table A18

$12.7 \mathrm{~mm}$ Ceramic Beads

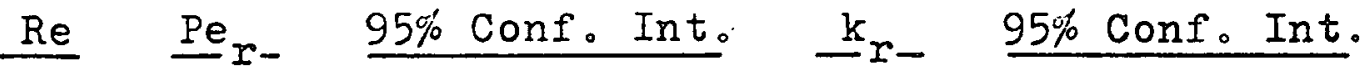

$536 \quad 4.25 \quad 2.60-5.90 \quad 2.77 \quad 1.69-3.85$

$430 \quad 3.45 \quad 1.59=5.30 \quad 2.50 \quad 1.15=3.84$

$290 \quad 2.89 \quad 1.34=4.44 \quad 2.05 \quad 0.95=3.14$

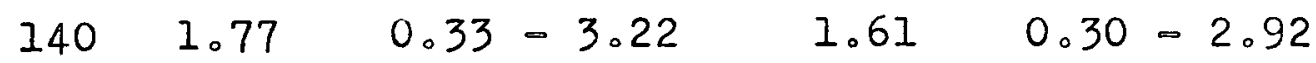

$36 \quad 0.08 \quad-1.98-2.15 \quad 8.66:-201-219$

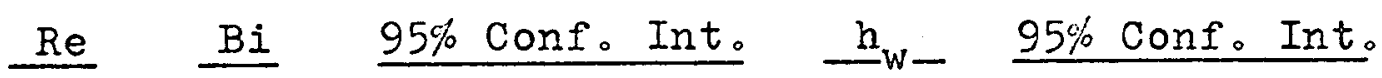

$\begin{array}{llllll}536 & 3.89 & 2.60-5.17 & 304.2 & 103.2 & -505.2\end{array}$

$430 \quad 4.77 \quad 3.25-6.30 \quad 336.4 \quad 66.0-606.9$

$290 \quad 5.06 \quad 3.48-6.63 \quad 292.6 \quad 60.5-524.7$

$\begin{array}{lllll}140 & 6.06 \quad 3.44-8.67 & 274.8 & -50.7-600.3\end{array}$

$368.502 .90-14.1 \quad 2079^{\circ}-5_{10} 4-5_{10} 4$

Re Pe ${ }_{a-} \underline{95 \% \text { Conf。Int。 } k_{a}}$ 95\%.Conf。Int。

$\begin{array}{lllll}536 & 0.07 & -0.01-0.15 & 171.0 & -19.6-361.5\end{array}$

$\begin{array}{lllll}430 & 0.06 & -0.01-0.12 & 154.5 & -29.3-338.3\end{array}$

$\begin{array}{lllll}290 & 0.07 & -0.01-0.15 & 88.2 \quad-14.6-190.9\end{array}$

$\begin{array}{lllll}140 & 0.10 & -0.07-0.28 & 27.3 \quad-18.4-73.0\end{array}$

$\begin{array}{lllll}36 & 0.02 & -0.47-0.51 \quad 38.5 & -954-1032\end{array}$ 
ADPF ( FBC ) NODEL PARAWETERS

Overall Analysis

Table Al9

$9.5 \mathrm{~mm}$ Ceranic Beads

Re Pe ${ }_{r-} \underline{95 \% \text { Conf。Int。 }} \mathrm{k}_{\mathrm{r}}-\underline{95 \% \text { Conf。 Int。 }}$

$\begin{array}{lllll}373 & 5.78 \quad 5.56-6.01 & 1.42 & 1.36-1.47\end{array}$

$281 \quad 5.18 \quad 4.97-5.40 \quad 1.19 \quad 1.14-1.24$

$\begin{array}{llllll}.231 & 4.93 \quad 4.73-5.13 & 1.03 & 0.98 & -1.07\end{array}$

$\begin{array}{lllll}181 & 4.04 & 3.79-4.29 & 0.98 & 0.92=1.04\end{array}$

$120 \quad 2.78 \quad 2.35-3.20 \quad 0.95 \quad 0.80-1.09$

$\begin{array}{llllll}63 & 0.77 & -0.08 & -1.62 & 1.81 & -0.19-3.81\end{array}$

Re $\quad$ Bi $95 \%$ Conf。Int。 $h_{w}$ 95\% Conf。Int。

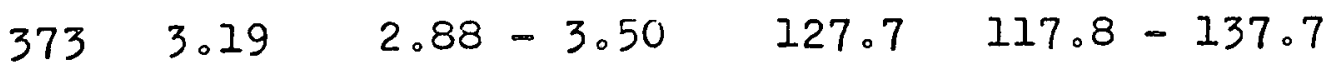

$281 \quad 3.63 \quad 3.23-4.04 \quad 122.3 \quad 110.4=134.2$

$231 \quad 4.13 \quad 3.66-4.60 \quad 119.7 \quad 106.8-132.7$

$1814.76 \quad 4.12=5.40 \quad 132.3 \quad 111.1=153.5$

$120 \quad 6.38 \quad 5.16-7.59 \quad 170.7 \cdot 118.2-223.2$

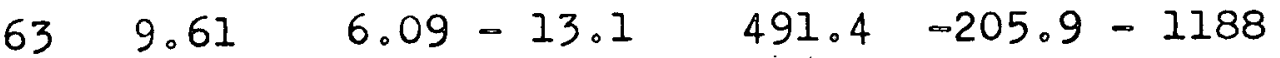

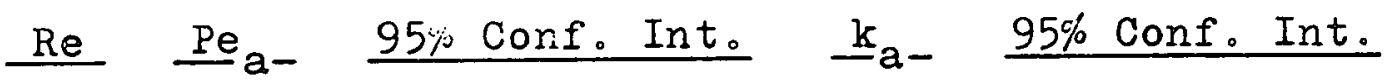

$\begin{array}{lllll}373 & 0.95 & 0.08-1.82 & 8.6 & 0.7-16.5\end{array}$

$2810.80 \quad 0.11=1.49 \quad 7.7 \quad 1.1-14.3$

$231 \quad 0.53 \quad 0.20-0.87 \quad 9.5 \quad 3.5-15.4$

$181 \quad 0.28 \quad 0.13=0.42 \quad 14.4 \quad 6.8-22.1$

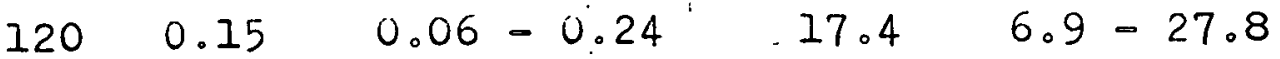

$63 \cdot 0.05-0.03-0.14 \quad 27.1-18.1-72.4$ 
ADPF (IBC) MIODEL PARAFIETERS

Overall Analysis

$12.7 \mathrm{~mm}$ Ceramic Beads
Table A20

Entrance Data Included

Re Pe ${ }_{r-}$ 95\% Conf. Int. $\mathrm{k}_{\mathrm{r}}-$ 95\% Conf.Int.

$\begin{array}{llllll}536 & 6.50 & 6.03-6.96 & 1.81 & 1.68-1.94\end{array}$

$430 \quad 6.15 \quad 5.79-6.51 \quad 1.40 \quad 1.32-1.48$

$290 \quad 5.34 \quad 5.04-5.65 \quad 1.11 \quad 1.04=1.17$

$140 \quad 3.61$

$3.36-3.85$

0.79

$0.74-0.84$

361.63

$1.54-1.73$

0.45

$0.42-0.48$

Re Bi $95 \%$ Conf. Int $h_{w-19}$ 95\% Conf. Int.

$5362.48 \quad 2.20-2.76 \quad 127.1 \quad 120.3-133.9$

$\begin{array}{lllll}430 & 2.93 \quad 2.63-3.24 & 115.9 & 109.9 & -121.9\end{array}$

$290 \quad 3.36 \quad 2.99-3.74 \quad 105.3 \quad 98.8=111.8$

$\begin{array}{lllll}140 & 4.70 \quad 3.97-5.42 & 104.8 & 94.8 & -114.7\end{array}$

$\begin{array}{lllll}36 & 50.03 \quad 5.98-94.1 & 635.9 & 109.6 & -1162\end{array}$

Re $\underline{P e}_{\mathrm{a}}-\underline{95 \% \text { Conf。Int。 }} \underline{\mathrm{k}}_{\mathrm{a}}$ - $95 \%$ Conf。Int。

$\begin{array}{llllll}536 & 0.49 & 0.42 & -0.56 & 24.2 & 20.8\end{array}$

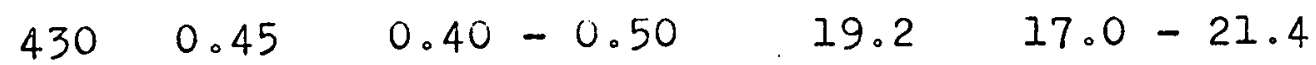

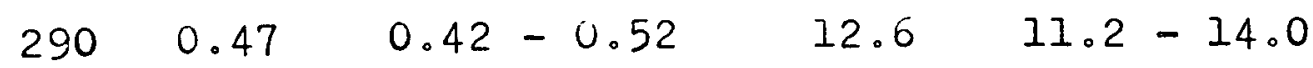

$\begin{array}{llllll}140 & 0.47 & 0.42 & -0.52 & 6.1 & 5.4\end{array}$

$\begin{array}{llllll}36 & 0.49 & 0.46-0.52 & 1.5 & 1.4-1.6\end{array}$ 


\section{ADPF ( IBC ) IVIVDEL PARAIIETERS}

Overall Analysis

$9.5 \mathrm{~mm}$ Ceramic Beads
Table A2I

Entrance Data Included

Re Pe $\underline{r}_{\mathrm{r}}$ 95,0 Conf. Int. $\mathrm{k}_{\mathrm{r}}$ $95 \%$ Conf. Int.

$3736.216 .00-6.42 \quad 1.32 \quad 1.28-1.36$

$2815.60 \quad 5.41-5.79 \quad 1.10 \quad 1.07-1.14$

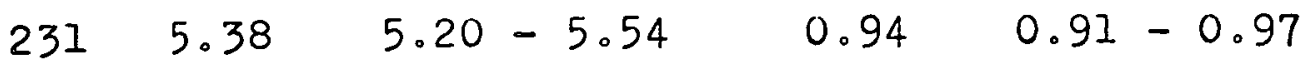

$181 \quad 4.60 \quad 4.46-4.75 \quad 0.86 \quad 0.84-0.89$

$\begin{array}{llllll}120 & 3.69 & 3.57-3.81 & 0.71 & 0.69-0.74\end{array}$

632.26

$2.16-2.36$

0.62

$0.59-0.64$

Re $\quad$ Bi $95 \%$ Conf. Int. ${ }_{w}-95 \%$ Conf. Int.

$\begin{array}{llllll}373 & 3.19 & 3.00-3.38 & 118.8 & 115.0 & -122.6\end{array}$

$281 \quad 3.60 \quad 3.37=3.83 \quad 112.2 \quad 108.2-116.2$

$2313.90 \quad 3.65=4.14 \quad 103.6 \quad 99.9=107.4$

$1814.01 \quad 3.75-4.27 \quad 97.6 \quad 93.9-101.3$

$120 \quad 4.70 \quad 4.35=5.05 \quad 94.6 \quad 90.3=99.0$

$\begin{array}{lllll}63 & 6.20 & 5.45-6.96 & 107.8 & 99.0\end{array}$

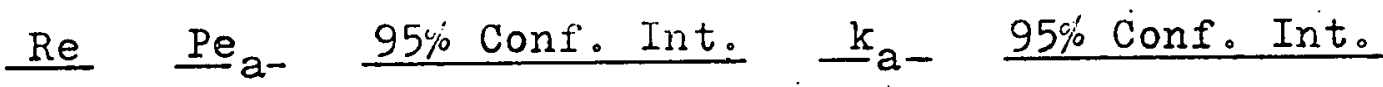

$\begin{array}{lllll}373 & 0.61 \quad 0.54-0.68 & 13.5 & 12.0-15.0\end{array}$

$281 \cdot 0.54 \quad 0.48-0.60 \quad 11.4 \quad 10.3-12.6$

$2310.54 \quad 0.49=0.59 \quad 9.4 \quad 8.5=10.2$

$1810.50 \quad 0.46-0.54 \quad 7.9 \quad 7.3-8.6$

$120 \quad 0.47 \quad 0.44-0.51$

$5.6 \quad 5.2-6.0$

$63 \quad 0.44 \quad 0.41=0.48$

$3.1 \quad 2.9-3.4$. 
ADPF (IBC) VNODEL PARAMETERS

Overall Analysis

$6.4 \mathrm{~mm}$ Ceramic Beads
Table 122

Entrance Data Included

$\begin{array}{rrrrr}\text { Re } & \text { Pe } & \text { 95\% Conf。Int. } & \underline{k} r- & \text { 95\% Conf。Int. } \\ 274 & 6.12 & 5.78-6.46 & 0.89 & 0.84-0.94 \\ 206 & 5.32 & 5.04-5.60 & 0.77 & 0.73-0.82 \\ 171 & 4.90 & 4.64-5.15 & 0.70 & 0.66-0.73 \\ 138 & 4.34 & 4.12-4.56 & 0.63 & 0.60-0.66 \\ 109 & 3.58 & 3.45-3.72 & 0.60 & 0.58-0.62 \\ 73 & 2.69 & 2.54-2.83 & 0.54 & 0.51-0.57 \\ 45 & 1.82 & 1.73-1.92 & 0.49 & 0.46-0.52\end{array}$

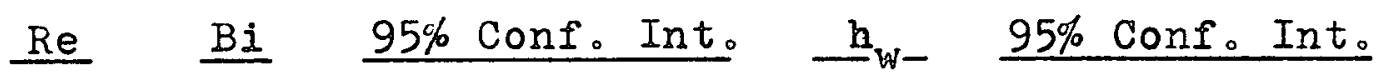

$\begin{array}{rllll}274 & 4.84 & 4.33-5.36 & 122.0 & 114.2=129.8 \\ 206 & 5.30 & 4.70-5.89 & 115.8 & 107.7-123.9 \\ 171 & 5.86 & 5.17-6.56 & 115.3 & 106.4-124.1 \\ 138 & 6.44 & 5.64-7.25 & 115.2 & 105.6=124.8 \\ 109 & 7.17 & 6.44-7.90 & 121.5 & 112.8-130.2 \\ 73 & 7.36 & 6.26-8.46 & 112.7 & 100.8-124.5 \\ 45 & 9.47 & 7.76-11.2 & 131.0 & 113.3=148.7\end{array}$

\begin{tabular}{|c|c|c|c|c|}
\hline e & $\underline{P e}{ }_{a-}$ & $95 \%$ Conf. Int。 & $\underline{k}_{a-}$ & $95 \%$ Conf。 Int \\
\hline 274 & 0.18 & $0.15-0.20$ & $30.6^{\circ}$ & $26.2-35.1$ \\
\hline 206 & 0.16 & $0.14-0.18$ & 25.8 & $22.6-29.0$ \\
\hline 171 & 0.15 & $0.13-0.17$ & 22.2 & $19.4-25.0$ \\
\hline 138 & 0.14 & $0.13-0.16$ & 19.0. & $16.9-21.2$ \\
\hline 109 & 0.16 & $0.14-0.17$ & 13.7 & $12.6-14.9$ \\
\hline 73 & 0.14 & $0.13-0.15$ & 10.6 & $9.7-11.5$ \\
\hline 45 & 0.13 & $0.12-0.14$ & 7.1 & $6.5=7.7$ \\
\hline
\end{tabular}


ADPF (IBC) IODEL PARAMETERS

Overall Analysis

$9.5 \mathrm{~mm}$ Steel Balls
Table A23

Entrance Data Included

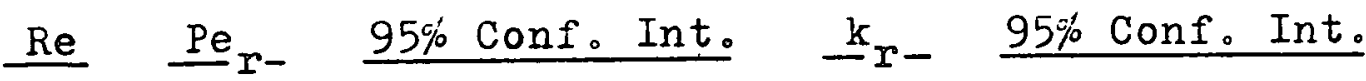

$\begin{array}{rllll}468 & 5.19 & 4.94=5.43 & 1.99 & 1.90=2.09 \\ 356 & 4.38 & 4.16=4.59 & 1.80 & 1.71=1.88 \\ 224 & 3.12 & 2.97=3.28 & 1.58 & 1.50=1.66 \\ 146 & 2.50 & 2.36=2.63 & 1.30 & 1.23-1.37 \\ 77 & 1.21 & 1.12=1.31 & 1.40 & 1.29=1.51\end{array}$

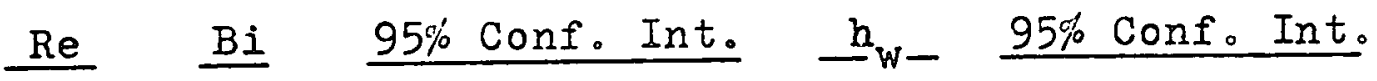

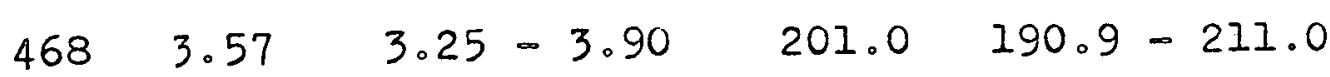

$\begin{array}{lllll}356 & 3.71 \quad 3.56-4.07 \quad 188.3 \quad 178.1=198.4\end{array}$

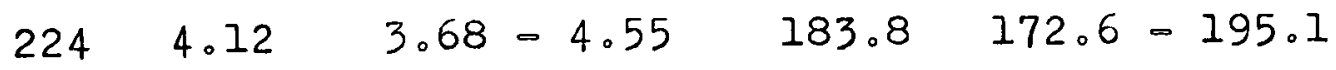

$146 \quad 4.10 \quad 3.62-4.58 \quad 150.6 \quad 140.2-161.0$

$\begin{array}{llllll}77 & 5.17 & 4.20-6.14 & 204.3 & 179.9 & -228.7\end{array}$

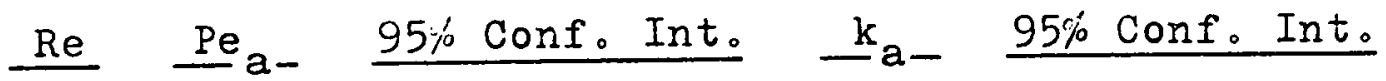

$\begin{array}{lllll}468 & 0.34 & 0.31-0.38 & 30.2 & 27.2-33.2\end{array}$

$\begin{array}{lllll}356 & 0.32 & 0.29-0.35 & 24.3 & 22.1-26.6\end{array}$

$2240.30 \quad 0.28-0.33 \quad 16.2 \quad 15.0-17.5$

$\begin{array}{llllll}146 & 0.36 & 0.32-0.39 & 9.1 & 8.3-9.9\end{array}$

$\begin{array}{llllll}77 & 0.21 & 0.19-0.22 & 0.2 & 7.5-8.8\end{array}$ 
Overall Analysis

$12.7 \mathrm{~mm}$ Ceramic beads
Table A24

Entrance Data Included

Re $\underline{P e}_{r-}$ 95\% Conf. Int. $\underline{k}_{r}-95 \%$ Conf. Int.

$\begin{array}{llllll}536 & 5.81 & 5.35-6.26 & 1.94 & 1.78-2.09\end{array}$

$430 \quad 5.62 \quad 5.23=6.00 \quad 1.53 \quad 1.43=1.64$

$290 \quad 4.82 \quad 4.50-5.13 \quad 1.23 \quad 1.15=1.31$

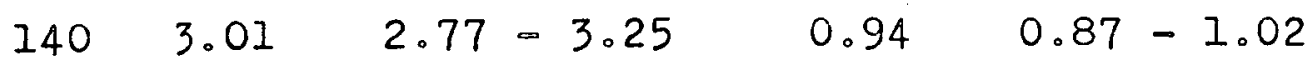

$\begin{array}{llllll}36 & 1.33 & 1.27-1.39 & 0.55 & 0.53-0.58\end{array}$

Re $\quad \underline{B} \quad 95 \%$ Conf. Int. $\underline{h}_{w-95 \% \text { Conf. Int. }}$

$\begin{array}{lllll}536 & 2.62 \quad 2.28-2.96 \quad 143.3 \quad 134.1-152.5\end{array}$

$\begin{array}{llllll}430 & 3.20 & 2.80-3.60 & 138.5 & 129.2 & -147.8\end{array}$

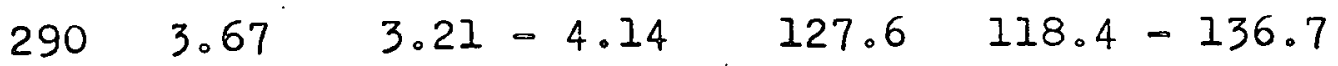

$140 \quad 4.91 \quad 4.04-5.78 \quad 131.0 \quad 116.4-145.6$

$\begin{array}{lllll}36 & 63.20 \quad 19.18-107.2 \quad 988.4 \quad 333.2-1643\end{array}$

Re Pe ${ }_{a-} \underline{95 \% \text { Conf。Int。 }} \mathrm{k}_{\mathrm{a}}-\underline{95 \% \text { Conf。 Int。 }}$

$\begin{array}{lllll}536 & 0.58 & 0.47-0.68 & 19.5 & 16.0-23.1\end{array}$

$\begin{array}{llllll}430 & 0.57 \quad 0.48-0.66 & 15.1 & 12.8-17.4\end{array}$

$290 \quad 0.55 \quad 0.48-0.62 \quad 10.7 \quad 9.4-12.1$

$\begin{array}{lllll}140 & 0.59 & 0.52-0.66 & 4.8 & 4.2-5.4\end{array}$

$360.620 .58-0.66 \cdot 1.2 \quad 1.1-1.3$ 


\section{ADPF ( $F B C)$ IIODEL FARAHETERS}

Overall Analysis

$9.5 \mathrm{~mm}$ Ceramic Beads
Table A25

Entrance Data Included

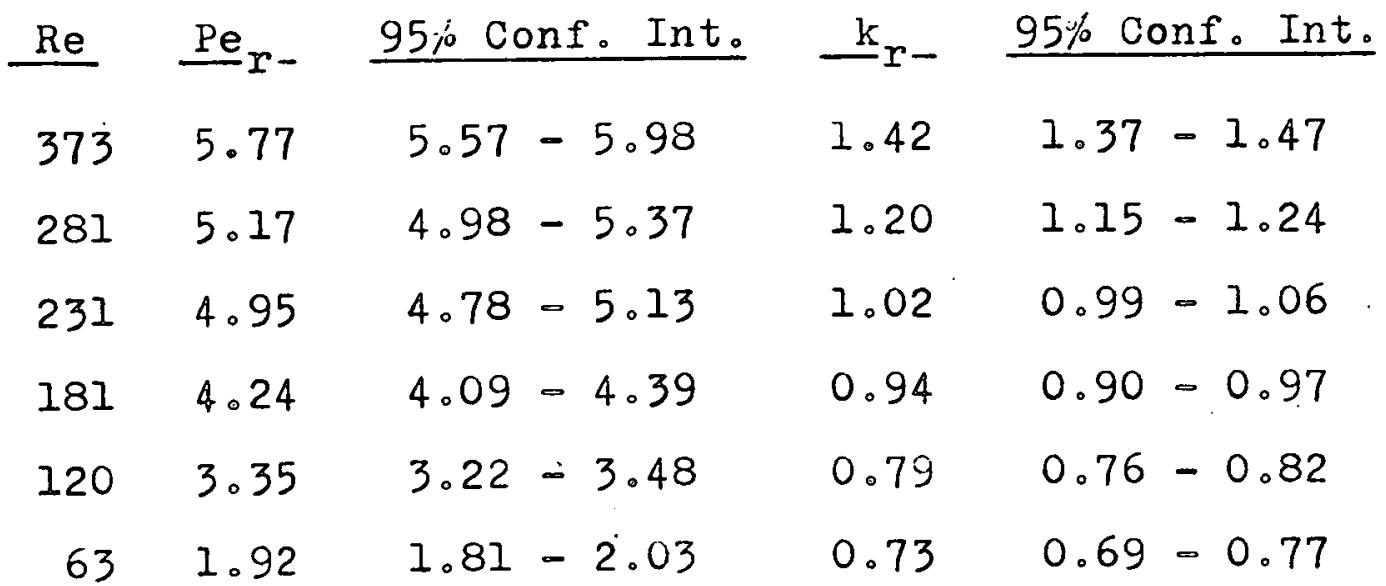

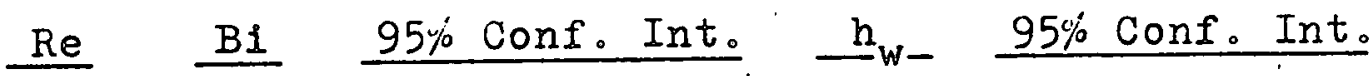

$373 \quad 3.29 \quad 3.08-3.50 \quad 131.9 \quad 127.4-136.5$

$2813.74 \quad 3.47-4.01 \quad 126.3 \quad 121.1-131.4$

$2314.09 \quad 3.81-4.38 \quad 118.2 \quad 113.4=123.1$

181. $4.30 \quad 3.98-4.62 \quad 113.9 \quad 108.9-119.0$

$120 \quad 5.06 \quad 4.60-5.52 \quad 112.4 \quad 106.1-119.0$

$63 \quad 6.48 \quad 5.50-7.46 \quad 133.2 \quad 119.5=147.0$

Re Pea- 95\% Conf。. Int $\underline{\mathrm{k}}_{\mathrm{a}}-\underline{95 \% \text { Conf。 Into }}$

$3730.66 \quad 0.58-0.74 \quad 12.4 \quad 10.9=14.0$

$\begin{array}{llllll}281 & 0.61 & 0.54 & -0.68 & 10.1 & 8.9-11.2\end{array}$

$\begin{array}{llllll}231 & 0.59 & 0.53 .-0.66 & 8.5 & 7.6 & -9.4\end{array}$

$1810.56 \quad 0.50 .-0.61 \quad 7.1 \quad 6.5-7.8$

$120 \quad 0.550 .50-0.60$

$4.8 \quad 4.4-5.2$

$\begin{array}{lll}63 & 0.54 & 0.48-0.59\end{array}$

$2.6 \quad 2.4-2.9$ 
ADPF (IBC) MODEL PARAMETERS

Depth-by-depth Analysis

Table A26

$12.7 \mathrm{~mm}$ Ceramic Beads

Entrance Data Included

Re $\quad$ L Per- $95 \%$ Conf. Int。 $\underline{k}_{r}-95 \%$ Conf。Int。 ( $\mathrm{nm}$ )

536

51

6.30

$4.98-7.63$

1.87

$1.48-2.26$

1025.43

$5.43-5.43$

2.16

$2.16-2.16$

178

6.79

$5.81=7.77$

1.62

$1.38-1.85$

356

7.18

$6.47-7.88$

1.53

$1.38-1.68$

430

$51 \quad 5.66$

$4.58-6.74$

1.52

$1.23-1.81$

102

4.93

$4.07-5.79$

1.75

$1.44=2.05$

178

6.37

$5.47-7.27$

1.35

$1.16=1.54$

254

5.94

$5.37-6.51$

1.45

$1.31=1.59$

356

7.17

$6.48-7.86$

1.20

$1.08-1.32$

290

51

$$
4.82
$$

$4.00-5.63$

1.23

$1.02=1.44$

$102 \quad 4.72 \quad 3.94-5.49$

1.26

$1.05-1.46$

$178 \quad 5.79$

$5.02-6.56$

1.02

$0.89-1.16$

$254 \quad 5.38$

$4.81-5.94$

1.10

$0.99-1.22$

3567.30

$6.70-7.90$

0.81

$0.74-0.88$

140

$51 \quad 3.16$

$2.74-3.58$

0.90

$0.78-1.02$

1023.20

$2.72-3.67$

0.89

$0.76-1.02$

$178 \quad 4.42$

$3.81-5.04$

0.64

$0.55-0.73$

$356 \quad 4.33$

$3.95-4.70$

0.66

$0.60-0.72$

36

51

$$
1.51
$$

$1.39-1.62$

0.49

$0.45-0.52$

$102 \quad 1.82$

$1.65-1.99$

0.40

$0.37-0.44$

178

356 


\section{ADPF (IBC) HODEI PARAMETERS}

Depth-by-depth Analysis

Pable A27

$12.7 \mathrm{~mm}$ Ceramic Beads

Entrance Data Included

\begin{tabular}{|c|c|c|c|c|c|c|c|}
\hline $\mathrm{Re}$ & I & $\mathrm{Bi}$ & $95 \% \mathrm{Co}$ & onf. Int & $\underline{n}_{w-}$ & \multicolumn{2}{|c|}{$95 \%$ Conf。Int。 } \\
\hline & $(\mathrm{mm})$ & & & & & & \\
\hline \multirow[t]{4}{*}{536} & 51 & 2.56 & 1.98 & -3.14 & 135.3 & 122.4 & -148.2 \\
\hline & 102 & 2.09 & 2.09 & -2.09 & 127.3 & 127.3 & -127.3 \\
\hline & 178 & 2.37 & 1.81 & -2.93 & 108.3 & 96.4 & -120.2 \\
\hline & 356 & 3.10 & 2.50 & -3.70 & 133.9 & 120.4 & -147.5 \\
\hline \multirow[t]{5}{*}{430} & 51 & 3.08 & 2.37 & -3.78 & 132.0 & 119.0 & $=145.0$ \\
\hline & 102 & 2.43 & 1.78 & -3.07 & 119.7 & 105.0 & -134.4 \\
\hline & 178 & 2.81 & 2.11 & -3.51 & 107.1 & 93.8 & -120.4 \\
\hline & 254 & 2.49 & 2.07 & -2.92 & 101.8 & 93.6 & -110.1 \\
\hline & 356 & 4.13 & 3.20 & -5.07 & 140.1 & 121.3 & -158.8 \\
\hline \multirow[t]{5}{*}{290} & 51 & 3.59 & 2.74 & -4.43 & 124.5 & 110.8 & -138.3 \\
\hline & 102 & 2.45 & 1.82 & -3.07 & 86.8 & 76.6 & -97.0 \\
\hline & 178 & 3.43 & 2.52 & -4.35 & 99.2 & 84.6 & -113.8 \\
\hline & 254 & 3.82 & 2.93 & -4.71 & 118.9 & 103.0 & -134.8 \\
\hline & 356 & 8.99 & 6.00 & -12.0 & 206.0 & 153.7 & -258.4 \\
\hline \multirow[t]{4}{*}{140} & 51 & 4.38 & 3.27 & $=5.50$ & 111.5 & 95.3 & -127.6 \\
\hline & 102 & 3.22 & 2.31 & -4.13 & 81.0 & 68.8 & $=93.1$ \\
\hline & 178 & 7.21 & 3.92 & -10.5 & 131.0 & 88.1 & -174.0 \\
\hline & 356 & 87.9 & -104 & -280 & 1633 & -1837 & -5103 \\
\hline \multirow[t]{4}{*}{36} & 51 & 18.4 & 9.40 & -27.5 & 254.2 & 146.6 & -361.8 \\
\hline & 102 & 68.5 & -80.4 & -217 & 780.4 & -850 & -2410 \\
\hline & 178 & - & & - & - & & - \\
\hline & 356 & - & & - & - & & - \\
\hline
\end{tabular}


Re $\quad \underline{\mathrm{Pe}} \mathrm{a}-\underline{95 \% \text { Conf. Into }} \mathrm{k}_{\mathrm{a}}$ 95\% Conf。Int。 (mm)

536

$$
51
$$$$
0.57
$$$$
0.36-0.77
$$

20.8

$13.3-28.3$

102$$
0.44-0.44
$$

26.4

$$
26.4-26.4
$$

$178 \quad 0.60$

$0.30=0.89$

18.5

356

0.59

$0.48=0.70$

18.6

$$
9.4-27.5
$$

430$$
0.54
$$

$0.36-0.72$

15.9

$15.3-22.0$

102

0.49

$0.29-0.68$

17.6

$10.5-21.3$ :

$178 \quad 0.51$

$0.31-0.71$

16.9

$10.5-24.8$

$254 \quad 0.56$

$$
0.45=0.68
$$

15.3

$10.2-23.7$

356

$0.48=0.67$

15.0

$12.2-18.3$

290

51

0.57

$0.38=0.78$

10.2

$12.6-17.4$

$102 \quad 0.47$

$$
0.030-0.64
$$

12.6

$6.8-13.6$

$178 \quad 0.44$

$0.31-0.58$

13.3

$8.0-17.3$

$254 \quad 0.54$

$0.45-0.63$

10.9

$9.3-17.3$

$356 \quad 0.59$

$0.51-0.66$

10.1

$9.1-12.8$

140

$51 \quad 0.55$

$$
0.39-0.71
$$

5.2

$8.7=11.5$.

1020.46

$0.34-0.58$

6.2

$3.7-6.7$

178

0.50

$0.39-0.60$

5.8

$4.5=7.8$

356

0.90

$0.80-1.00$

3.2

$4.5-7.0$

36

51

0.57

$0.50-0.64$

1.3

$2.8-3.5$

102

0.46

$0.42-0.51$

1.6

$$
1.1=1.4
$$

178

356 


\section{ADPF (IBC) HODEI PARAMETERS}

Depth-by-depth Analysis

$9.5 \mathrm{~mm}$ Ceramic Beads
Table A29

Entrance Data Inclúded

Re $\frac{I}{(\mathrm{~mm})}$

373

$$
51
$$$$
6.48
$$$$
5.78-7.18
$$

1.26

$1.13-1.40$

102

6.41

$5.78-7.04$

1.28

$1.15-1.40$

152

5.94

$5.37-6.50$

1.38

$1.25-1.51$

2046.12

$5.57-6.67$

1.34

$1.22-1.46$

2546.00

$5.58-6.43$

1.36

$1.27-1.46$

281

$51 \quad 5.68$

$5.13-6.22$

1.09

$0.98-1.19$

102

5.73

$5.25-6.20$

1.03

$0.99-1.17$

1525.23

$4.77-5.68$

1.18

$1.08-1.28$

$204 \quad 5.37$

$4.88-5.87$

1.15

$1.04-1.26$

254

5.25

$4.80-5.70$

1.18

$1.08-1.28$

231

51

5.62

$5.08-6.17$

0.90

$0.81-0.99$

$102 \quad 5.37$

$4.93-5.81$

0.94

$0.86-1.02$

1524.91

$4.52-5.30$

1.03

$0.95-1.11$

$204 \quad 5.36$

$4.87-5.84$

0.94

$0.86-1.03$

254

5.34

$4.95-5.72$

0.95

$0.88-1.02$

181

$\begin{array}{rll}51 & 4.64 & 4.27-5.00 \\ 102 & 4.63 & 4.25-5.00 \\ 152 & 4.28 & 3.93-4.64 \\ 204 & 4.60 & 4.18-5.02 \\ 254 & 4.78 & 4.38-5.19\end{array}$

0.86

$0.79=0.92$

0.86

$0.79-0.93$

0.93

$0.85-1.00$

0.86

$0.78-0.94$

0.83

$0.76-0.90$ 


\section{Table A29 (contd。)}

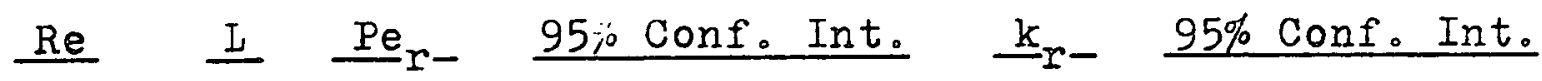

(mm)

120

$\begin{array}{rllll}51 & 3.67 & 3.39-3.95 & 0.72 & 0.66-0.77 \\ 102 & 3.52 & 3.26-3.78 & 0.75 & 0.69-0.80 \\ 152 & 3.43 & 3.13-3.73 & 0.77 & 0.70=0.83 \\ 204 & 3.72 & 3.32-4.12 & 0.71 & 0.63-0.78 \\ 254 & 4.02 & 3.64-4.41 & 0.65 & 0.59-0.72 \\ 51 & 2.15 & 2.02-2.29 & 0.65 & 0.60-0.69 \\ 102 & 2.29 & 2.09-2.48 & 0.61 & 0.56-0.66 .\end{array}$

$\begin{array}{llllll}152 & 2.43 & 2.16-2.71 & 0.57 & 0.51-0.64\end{array}$ 


\section{ADPF (IBC) NODEL PARANETERS}

Depth-by-depth Analysis

$9.5 \mathrm{~mm}$ Ceramic Beads
Table A30

Entrance Data Included

$\underline{\operatorname{Re}} \quad \underline{\mathrm{I}} \quad \underline{\mathrm{Bi}} \quad \underline{95 \% \text { Conf. Int }} \underline{h}_{\mathrm{w}} \underline{95 \% \text { Conf。 Into }_{0}}$

(mm)

373

$\begin{array}{rllll}51 & 3.49 & 3.06-3.92 & 124.7 & 118.2=131.1 \\ 102 & 3.41 & 2.92=3.90 & 123.2 & 113.7=132.6 \\ 152 & 2.88 & 2.50=3.26 & 112.1 & 105.0-119.2 \\ 204 & 3.02 & 2.51-3.53 & 114.0 & 103.1=125.0 \\ 254 & 3.07 & 2.65=3.48 & 118.2 & 109.6=126.8\end{array}$

281

514.08

$3.58-4.58$

$125.4 \cdot 118.4-132.4$

1023.94

$3.39-4.48$

120.0

$110.7-129.2$

$152 \quad 3.02$

$2.55-3.49$

100.9

$92.6-109.2$

$204 \quad 3.15$

$2.58-3.71$

102.2

$92.4-112.1$

2543.18 .

$2.64-3.72$

105.7

$96.1-115.3$

231 .

514.28

$3.75-4.81$

108.8

$102.8-114.7$

1024.08

$3.49-4.67$

108.7

$99.6-117.8$

$152 \quad 3.22$

$2.76-3.68$

93.8

$86.6-101.0$

$204 \quad 3.71$

$3.00-4.42$

99.0

$88.0-109.9$

$254 \quad 3.88$

$3.27-4.50$

104.1

$94.5=113.7$

181

514.08

$3.66-4.51$

98.8

$93.9-103.8$

102

4.27

$3.62-4.91$

103.5

$94.1-112.8$

1523.50

$2.92-4.07$

91.5

$83.1-99.9$

$204 \quad 3.97$

$3.17-4.78$

96.8

$85.3-108.3$

$254 \quad 4.18$

$3.36-5.01$

.98 .1

$86.6-109.6$ 
Table A30 (contd。)

Re $\underline{\mathrm{I}} \underline{\mathrm{Bi}} \underline{\mathrm{g5} \% \text { Conf.Int。 }} \mathrm{h}_{\mathrm{w}}$ 95\% Conf。Int。 (mm)

$\begin{array}{llllll}120 & 51 \quad 5.00 \quad 4.38-5.62 \quad 101.3 \quad 94.4-108.2\end{array}$

$102 \quad 4.22 \quad 3.58-4.87 \quad 89.2 \quad 81.0-97.3$

$152 \quad 4.28 \quad 3.43-5.13 \quad 92.7 \cdot 81.5-103.8$

$204 \quad 4.32 \quad 3.23-5.40 \quad 86.2 \quad 73.0=99.3$

$2545.74 \quad 4.18-7.30 \quad 106.0 \quad 86.7-125.3$

$\begin{array}{llllll}63 & 51 & 6.01 & 5.10 & -6.91 \quad 109.6 \quad 98.9-120.3\end{array}$

$\begin{array}{lllll}102 & 5.52 \quad 4.22-6.83 \quad 94.8 \quad 79.7-109.8\end{array}$

$\begin{array}{lllll}152 & 8.91 \quad 5.08-12.7 & 143.7 & 96.9 & -190.5\end{array}$ 
Depth-by-depth Analysis

$9.5 \mathrm{mri}$ Ceramic Deads

\section{Table A3I}

Entrance Data Included

Re. $\quad$ L $\quad \mathrm{Pe}_{\mathrm{a}}$ 95\% Conf。Int。 $\mathbf{k}_{\mathrm{a}}$ 95\% Conf。Int ( $\mathrm{nm}$ )

373

$51 \quad 0.67 \quad 0.53-0.82$

$102 \cdot 0.66$

$0.44-0.89$

12.1

$9.5-14.8$

$152 \quad 0.57$

$0.38=0.77$

12.4

$8.1-16.6$

204

0.53

$0.35=0.71$

14.3

$9.4-19.2$

254

0.54

$0.39-0.69$

15.5

$10.2-20.7$

281

$51 \quad 0.64$

$0.51-0.76$

15.2

$11.0-19.5$

$102 \quad 0.56$

$0.41=0.72$

9.7

$7.8-11.6$

152

0.53

$0.37-0.69$

11.0

$8.0-14.0$

2040.49

$0.35-0.63$

11.6

$8.2-15.1$

$254 \quad 0.52$

$0.40=0.63$

12.7

$9.1-16.4$

12.0

$9.3=14.7$

231

51

0.64

$0.50-0.77$

8.0

$6.3=9.6$

102

0.55

$0.40=0.70$

9.2

$6.7-11.6$

1520.48

$0.36=0.60$

10.5

$7.9-13.1$

$204 \quad 0.46$

$0.33-0.59$

11.0

$7.9-14.1$

254

0.54

$0.43-0.64$

9.4

$7.6-11.3$

181

$51 \quad 0.56$

$0.47-0.66$

7.0

$5.9-8.2$

102

0.53

$0.40-0.65$

7.5

$5.8-9.3$

$\begin{array}{ll}152 & 0.47\end{array}$

$0.36-0.57$

8.5

$6.6-10.4$

204

0.48

$0.37-0.58$

8.4

$6.5-10.2$

$254 \cdot 0.48$

$0.40-0.56$

8.3

$6.8-9.7$ 
Table A3I (contd。)

Re $\quad \underline{\mathrm{I}} \underline{\mathrm{Pe}}_{\mathrm{a}}$ 95\% Conf。Int。 $\mathrm{k}_{\mathrm{a}}$ 95\% Conf. Into (mm)

120

$510.53 \quad 0.44-0.62$

$102 \quad 0.49 \quad 0.39=0.58$

$5.0 \quad 4.2-5.8$

$1520.490 .40=0.58$

$5.4 \quad 4.3-6.5$

$204 \quad 0.45 \quad 0.36=0.54$

$5.4 \quad 4.4-6.4$

$254 \quad 0.49 \quad 0.42-0.57$

$5.9 \quad 4.7-7.0$

$51 \quad 0.46 \quad 0.39-0.52$

$5.4 \quad 4.5-6.2$

63

102

0.45

$0.38-0.53$

3.0

$2.6-3.5$

$152 \quad 0.48$

$0.40-0.55$

$3.12 .6-3.6$

$2.92 .4-3.4$ 


\section{ADPF (FBC) HODEL PARAMETERS}

Depth-byodepth Analysis

Table A32

$12.7 \mathrm{~mm}$ Ceramic Beads

Entrance Data Included.

Re $\quad \underline{\mathrm{L}} \underline{\mathrm{Pe}}_{\mathrm{r}}-\underline{95 \% \text { Conf.Into }} \underline{\mathrm{k}}_{\mathrm{r}}-\underline{95 \% \text { Conf. Int }}$ (mm)

536

$51 \quad 4.14 \quad 3.55-4.73 \quad 2.84 \quad 2.44-3.25$

$\begin{array}{lllll}102 & 4.40 \quad 3.65 & -5.15 & 2.66 \quad 2.21-3.12\end{array}$

$178 \quad 6.10 \quad 5.21-6.99 \quad 1.80 \quad 1.54-2.06$

$\begin{array}{llllll}356 & 6.81 & 6.13-7.50 & 1.61 & 1.45-1.77\end{array}$

$\begin{array}{lllllll}430 & 51 & 3.71 & 3.20 & -4.21 & 2.32 & 2.01\end{array}-2.64$

$\begin{array}{llllll}102 & 3.95 & 3.30-4.60^{\circ} & 2.18 & 1.82 & -2.54\end{array}$

$\begin{array}{llllll}178 & 5.65 & 4.84-6.46 & 1.52 & 1.30-1.74\end{array}$

$254 \quad 5.51 \quad 4.97-6.06 \quad 1.56 \quad 1.41-1.71$

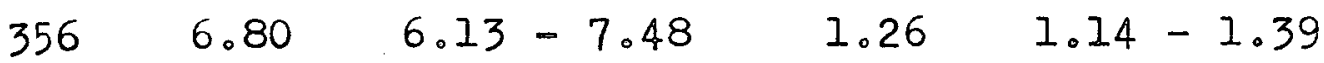

$\begin{array}{llllll}290 \quad 51 \quad 3.29 & 2.87-3.70 \quad 1.80 & 1.58-2.03\end{array}$

$\begin{array}{lllll}102 & 3.76 \quad 3.17-4.36 & 1.57 \quad 1.33-1.82\end{array}$

$\begin{array}{lllll}178 \quad 5.08 & 4.38-5.78 \quad .1 .16 \quad 1.00-1.32\end{array}$

$254 \quad 4.99 \quad 4.46-5.53 \quad 1.19 \quad 1.06-1.31$

$\begin{array}{lllll}356 & 6.95 & 6.37-7.54 & 0.85 & 0.78-0.92\end{array}$

$\begin{array}{llllll}140 & 51 & 2.21 & 1.94-2.48 & 1.29 & 1.13-1.44\end{array}$

$\begin{array}{lllll}102 & 2.61 & 2.21-3.01 & 1.09 & 0.92-1.26\end{array}$

$178 \quad 3.98 \quad 3.40-4.56 \quad 0.72 \quad 0.61-0.82$

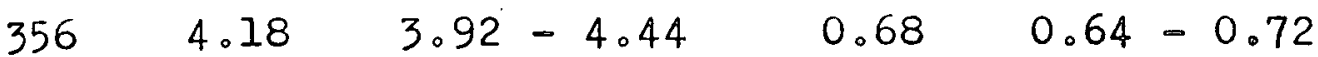

$\begin{array}{lllllll}36 & 51 \quad 1.18 & 1.08 & -1.27 & 0.62 & 0.57-0.68\end{array}$

$102 \quad 1.61 \quad 1.52-1.69 \quad 0.46 \cdot 0.43=0.48$

178

356 


\section{ADPF ( HBC ) HODEL PARA IETERS}

Depthoby-depth Analysis

Table A33

$12.7 \mathrm{~mm}$ Cerainic Beads

Entrance Data Included

\begin{tabular}{|c|c|c|c|c|c|c|}
\hline $\mathrm{Re}$ & $\mathrm{I}$ & $\mathrm{Bi}$ & $95 ; \mathrm{Co}^{2}$ & nf. Int. & $\underline{h}_{w-}$ & $95 \%$ Conf. Int. \\
\hline & $(\mathrm{mm})$ & & & & & \\
\hline \multirow[t]{4}{*}{536} & 51 & 2.24 & 1.80 & -2.68 & 179.9 & $163.6-196.2$ \\
\hline & 102 & 2.10 & 1.57 & -2.64 & 158.1 & $139.2-176.9$ \\
\hline & 178 & 2.35 & 1.80 & -2.90 & 119.4 & $105.8-133.1$ \\
\hline & 356 & 3.10 & 2.50 & -3.70 & 141.1 & $127.0=155.2$ \\
\hline \multirow[t]{5}{*}{430} & 51 & 2.67 & 2.13 & -3.21 & 175.1 & $155.6-194.6$ \\
\hline & 102 & 2.33 & 1.72 & -2.93 & 143.4 & $124.4-162.3$ \\
\hline & 178 & 2.78 & 2.09 & -3.46 & 119.4 & $104.1-134.6$ \\
\hline & 254. & 2.49 & 2.07 & -2.91 & 109.6 & $100.9=118.4$ \\
\hline & 356 & 4.13 & 3.20 & -5.06 & 147.6 & $128.2-167.0$ \\
\hline \multirow[t]{5}{*}{290} & 51 & 3.15 & 2.49 & $=3.81$ & 160.4 & $141.9-179.0$ \\
\hline & 102 & 2.34 & 1.76 & -2.92 & 103.9 & $91.4-116.5$ \\
\hline & 178 & 3.39 & 2.49 & -4.29 & 111.6 & $95.1-128.0$ \\
\hline & 254 & 3.82 & 2.94 & -4.71 & 128.1 & $111.2-145.1$ \\
\hline & $356^{\circ}$ & 9.04 & 6.07 & -12.0 & 217.6 & $163.4-271.8$ \\
\hline \multirow[t]{4}{*}{140} & 51 & 3.88 & 2.97 & -4.79 & 141.0 & $121.1-161.0$ \\
\hline & 102 & 3.11 & 2.27 & -3.95 & 95.6 & $82.5-108.7$ \\
\hline & 178 & 7.17 & 3.91 & -10.4 & 144.8 & $98.3-191.2$ \\
\hline & 356 & 78.5 & $32: 3$ & -124 & 1509 & $648.8-2370$ \\
\hline \multirow[t]{4}{*}{36} & 51 & 16.1 & 8.82 & -23.3 & 283.6 & $176.1-391.1$ \\
\hline & 102 & 88.7 & 3.25 & -174 & 1146 & $82.0-2210$ \\
\hline & 178 & - & & - & - & $=$ \\
\hline & 356 & - & & - & - & - \\
\hline
\end{tabular}


Re $\quad \underline{\mathrm{L}} \quad \mathrm{Pe} a-\underline{95 \% \text { Conf。Int。 } \mathrm{k}} \mathrm{a}-\underline{95 \% \text { Conf: Into }}$

( $\mathrm{mm})$

536

$51 \quad 0.78 \quad 0.54-1.02 \quad 15.2 \quad 10.4=20.0$

$\begin{array}{llllll}102 & 0.54 & 0.34-0.74 & 21.7 & 13.6 & -29.9\end{array}$

$\begin{array}{lllll}178 & 0.66 \quad 0.37-0.95 & 16.6 \quad 9.3-23.9\end{array}$

$\begin{array}{lllll}356 & 0.62 \quad 0.52=0.73 \quad 17.7 \quad 14.6-20.7\end{array}$

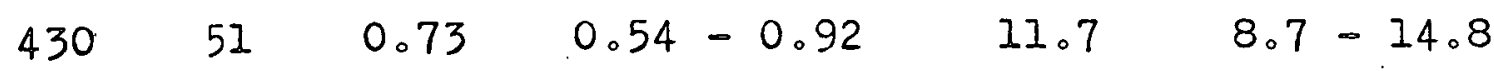

$\begin{array}{lllll}102 & 0.59 \quad 0.33-0.85 \quad 14.6 \quad 8.1-21.1\end{array}$

$\begin{array}{lllll}178 & 0.57 \quad 0.37-0.78 & 15.0 \quad 9.6=20.5\end{array}$

$2540.61 \quad 0.49-0.72 \quad 14.2 \quad 11.5=16.8$

$3560.060 .51-0.70$

$14.2 \quad 12.0=16.4$

290

$510.780 .55-1.00$

7.6

$5.4=9.8$

1020.58

$0.39=0.76$

10.2

$6.9-13.6$

$178 \quad 0.50$

$0.37-0.64$

11.7

$8.6-14.9$

$254 \quad 0.58$

$0.49=0.68$

10.2

$8.6-11.8$

356

0.62

$0.54=0.70$

9.6

$8.4-10.8$

140

51

0.73

$0.55-0.91$

3.9

$2.9 \cdot 4.9$

102

0.56

$0.42=0.70$

5.1

$3.8-6.4$

178

0.55

$0.44-0.66$

5.2

$4: 1-6.2$

356

0.94

$0.85=1.03$

3.0

$2.7-3.3$

36

51

0.70

$0.63-0.78$

1.0

$0.9-1.2$

102

0.54

$0.49-0.59$

1.4

$1.2-10.5$

178

356 
ADPF (FBC) MODEL PARAMETERS

Depth-by-depth Analysis

Table A35

$9.5 \mathrm{~mm}$ Ceramic Beads

Entrance Data Included

$\underline{\mathrm{Re}} \quad \underline{\mathrm{L}} \underline{\mathrm{Pe}}_{\mathrm{r}}-\underline{95 \% \text { Conf。Int。 }} \mathrm{k}_{\mathrm{r}}-\underline{95 \% \text { Conf。Int。 }}$

$\begin{array}{llllll}373 & 51 & 4.91 & 4.51-5.31 & 1.67 & 1.53=1.80\end{array}$

$102 \quad 5.59 \quad 5.11=6.07 \quad 1.46 \quad 1.34=1.59$

$\begin{array}{lllll}152 & 5.37 \quad 4.90-5.83 \quad 1.53 \quad 1.39 & =1.66\end{array}$

$204 \quad 5.65 \quad 5.13-6.16 \quad 1.45 \quad 1.32-1.58$

$254 \quad 5.64 \quad 5.23-6.05 \quad 1.45 \quad 1.35=1.56$

$\begin{array}{lllllll}281 & 51 & 4.26 & 3.95 & -4.57 & 1.45 & 1.34\end{array}-1.56$

$1024.90 \quad 4.53-5.26 \quad 1.26 \quad 1.17-1.36$

$\begin{array}{llllll}152 & 4.70 & 4.29 & -5.11 & 1.32 & 1.20-1.43\end{array}$

$204 \quad 4.93 \quad 4.46-5.41 \quad 1.25 \quad 1.13=1.37$

$\begin{array}{llllll}254 & 4.92 & 4.48 & -5.36 & 1.26 & 1.14\end{array}-1.37$

$23151 \quad 4.22 \quad 3.92-4.53 \quad 1.20 \quad 1.11-1.29$

$\begin{array}{lllll}102 & 4.59 & 4.24-4.93 \quad 1.10 \quad 1.02 & =1.19\end{array}$

$152 \quad 4.38 \quad 4.03-4.74 \quad 1.16 \quad 1.06-1.25$

$204 \quad 4.90 \quad 4.43-5.37 \quad 1.03 \quad 0.93=1.13$

$254 \quad 5.02 \quad 4.64-5.39 \quad 1.01 \quad 0.93-1.08$

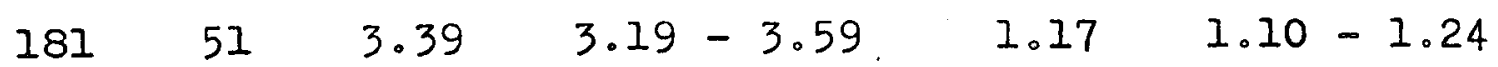

$102.3 .95 \quad 3.65-4.24 \quad 1.01 \quad 0.93-1.08$

$1523.83 \quad 3.50-4.15 \quad 1.04 \quad 0.95-1.13$

$204 \quad 4.23 \quad 3.87-4.63 .0 .94 \quad 0.85-1.03$

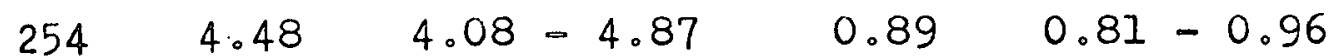


Table A35 (contd。)

\begin{tabular}{|c|c|c|c|c|c|}
\hline \multirow{2}{*}{\multicolumn{6}{|c|}{$\frac{\mathrm{Re}}{(\mathrm{mm})}$}} \\
\hline & & & & & \\
\hline \multirow[t]{5}{*}{120} & 51 & 2.068 & $2.52-2.84$ & 0.98 & $0.92=1.04$ \\
\hline & 102 & 2.99 & $2.77-3.22$ & 0.88 & $0.81-0.94$ \\
\hline & 152 & 3.09 & $2.81-3.37$ & 0.85 & $0.77-0.93$ \\
\hline & 204 & 3.42 & $3.04-3.80$ & 0.77 & $0.68-0.86$ \\
\hline & 254 & 3.77 & $3.40-4.15$ & 0.70 & $0.63-0.77$ \\
\hline \multirow[t]{3}{*}{63} & 51 & 1.58 & $1.48-1.68$ & 0.88 & $0.82-0.94$ \\
\hline & 102 & 1.96 & $1.78-2.15$ & 0.71 & $0.64-0.78$ \\
\hline & 152 & 2.20 & $i .95-2.46$ & 0.63 & $0.56-0.70$ \\
\hline
\end{tabular}


ADPF ( $M B C$ ) MODEL PARAMETERS

Depth-by-depth Analysis

$9.5 \mathrm{~mm}$ Ceramic Beads
Table A36

Entrance Data Included

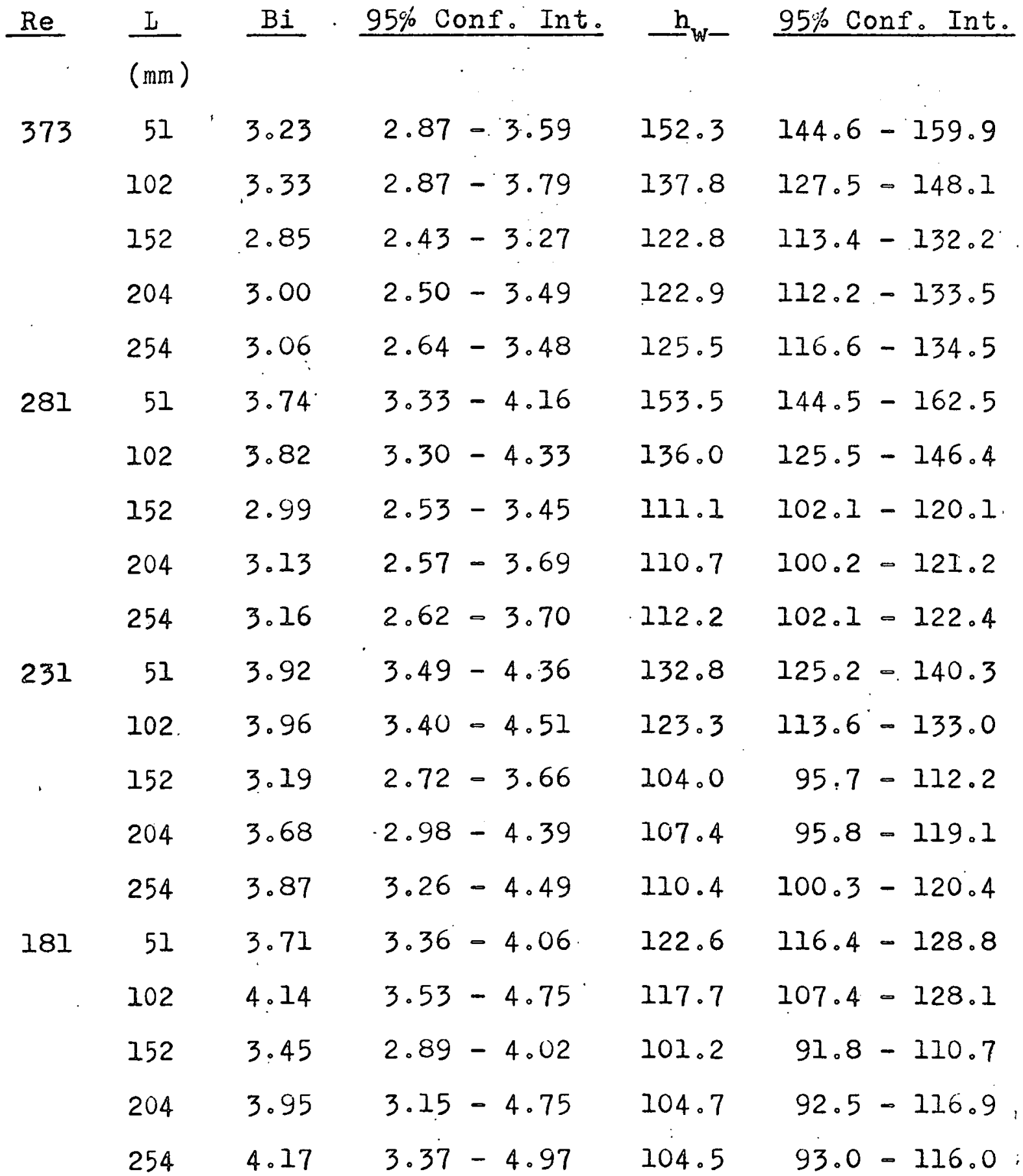




\section{Table A36 (contd。)}

$\underline{\text { Re }} \quad \underline{\mathrm{L}} \quad \underline{\mathrm{B}} \quad \underline{95 \% \text { Conf。Into }} \underline{h}_{\mathrm{w}} \quad \underline{95 \% \text { Conf. Int. }}$

(mm)

$120 \quad 51 \quad 4.50 \quad 3.99-5.01 \quad 124.8 \quad 116.5-133.2$

$102 \quad 4.11 \quad 3.49-4.73 \quad 102.0 \quad 92.8-111.2$

$152 \quad 4.24 \quad 3.40-5.08$. $101.9 \quad 90.0=113.9$

$204^{\circ} 4.29 \quad 3.21=5.38 \quad 93.3 \quad 79.4=107.3$

$254 \quad 5.69 \quad 4.15-7.23 \quad 112.1 \quad 92.2-132.0$

$\begin{array}{llllll}6351 \quad 5.41 \quad 4.65-6.17 & 134.4 \quad 122.0-147.0\end{array}$

$102 \quad 5.40 \quad 4.12-6.67 \quad 107.9 \quad 91.4-124.4$

$1528.69 \quad 5.04-12.3 \cdot 154.8 \quad 106.4-203.1$ 


\section{ADPF (FBC) MODEL PARAMETERS}

Depth-by-depth Analysis

$9.5 \mathrm{~mm}$ Ceranic Beads
Table A37

Entrance Data Included

\begin{tabular}{|c|c|c|c|c|c|}
\hline $\mathrm{Re}$ & $\underline{I}$ & $\mathrm{Pe}_{\mathrm{a}-}$ & $95 \%$ Conf. Int & $\underline{k}_{a-}$ & $95 \%$ Conf。Int. \\
\hline & $(\mathrm{mm})$ & & & & \\
\hline \multirow[t]{5}{*}{373} & 51 & 0.82 & $0.66-0.98$ & 10.0 & $8.0-11.9$ \\
\hline & 102 & 0.75 & $0.55-0.94$ & 11.0 . & $8.1=13.9$ \\
\hline & 152 & 0.63 & $0.43-0.83$ & 13.0 & $8.9-17.1$ \\
\hline & 204 & 0.57 & $0.40-0.75$ & 14.3 & $9.9-18.7$ \\
\hline & 254 & 0.57 & $0.45-0.70$ & 14.3 & $11.2-17.4$ \\
\hline \multirow[t]{5}{*}{281} & 51 & 0.78 & $0.64-0.92$ & 7.9 & $6.6-9.2$ \\
\hline & 102 & 0.64 & $0.48-0.80$ & 9.6 & $7.2-12.0$ \\
\hline & 152 & 0.59 & $0.42-0.75$ & 10.5 & $7.6-13.4$ \\
\hline & 204 & 0.53 & $0.39-0.67$ & 11.7 & $8: 6-14.8$ \\
\hline & 254 & 0.55 & $0.46-0.64$ & 11.2 & $9.4-13.0$ \\
\hline \multirow[t]{5}{*}{231} & 51 & 0.78 & $0.64-0.92$ & 6.5 & $5.3-.7 .6$ \\
\hline & 102 & 0.63 & $0.48-0.78$ & 8.0 & $6.1-9.9$ \\
\hline & 152 & 0.54 & $0.41-0.66$ & 9.4 & $7.2-11.6$ \\
\hline & 204 & 0.50 & $0.38=0.62$ & 10.1 & $7.6-12.6$ \\
\hline & 254 & 0.57 & $0.47-0.67$ & 8.9 & $7.3-10.4$ \\
\hline \multirow[t]{5}{*}{181} & 51 & 0.71 & $0.61-0.81$ & 5.6 & $4.8-6.4$ \\
\hline & 102 & 0.61 & $0.47-0.74$ & 6.5 & $5.1-8.0$ \\
\hline & 152 & 0.52 & $0.44-0.61$ & 7.6 & $6.4=8.8$ \\
\hline & 204 & 0.52 & $0.41-0.62$ & 7.7 & $6.1-9.3$ \\
\hline & 254 & 0.51 & $0.42-0.60$ & 7.8 & $6.4-9.1$ \\
\hline
\end{tabular}


Table A37 (contà.)

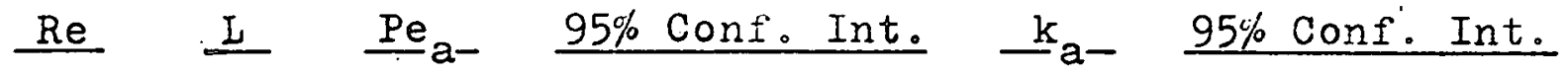
(mm)

120

$51 \quad 0.67$

$1020.56 \quad 0.46-0.66$

$1520.54 \quad 0.45-0.64$

$204 \quad 0.49 \quad 0.40-0.58$

254

63

$\begin{array}{rllll}51 & 0.58 & 0.51-0.66 & 2.4 & 2.1-2.7 \\ 102 & 0.52 & 0.44-0.60 & 2.7 & 2.3-3.1 \\ 152 & 0.52 & 0.44-0.60 & 2.7 & 2.3-3.0\end{array}$


APPENDIX B

Experimentai temperature measurements

( $A 11$ temperatures in ${ }^{\circ} \mathrm{C}$ ) 
RUN NUMBER-FLOW RATE-BED. DEPTH CORRESPONDENCE.

12. $7 \mathrm{~mm}$ Ceramic Beads

Table BI

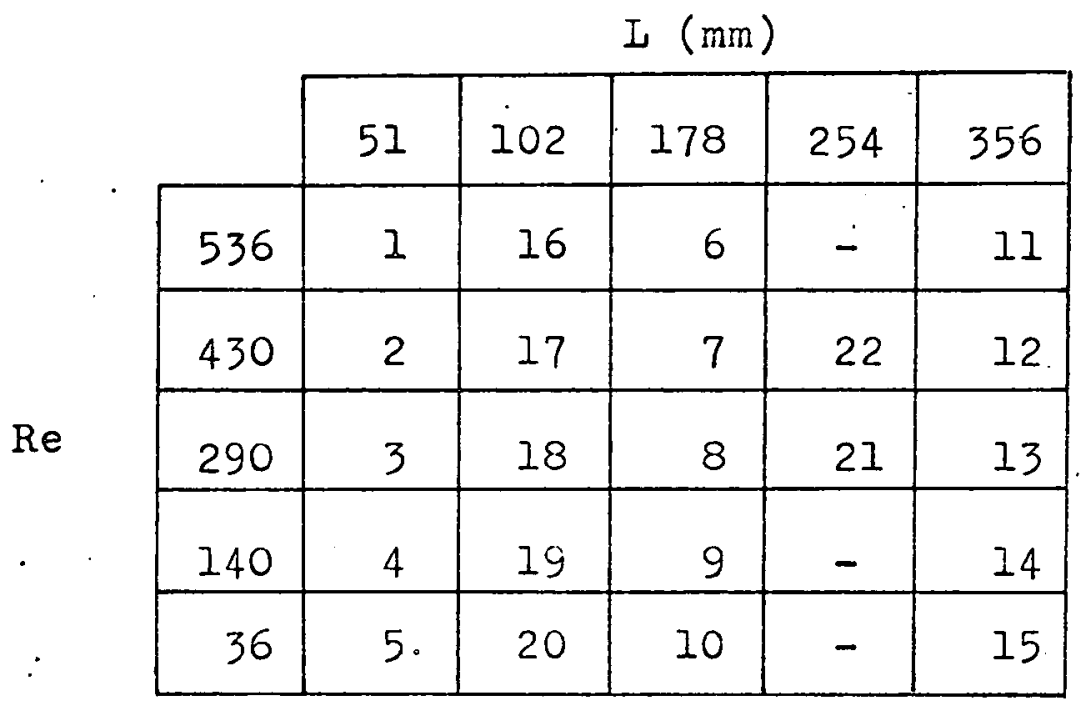

$9.5 \mathrm{~mm}$ Ceramic Beads

Table B2

\begin{tabular}{|c|c|c|c|c|c|}
\hline & \multicolumn{5}{|c|}{$\mathrm{I}(\mathrm{mm})$} \\
\hline & 51 & 102 & 15.2 & 204 & 254 \\
\hline 373 & 6 & 7 & 13 & 19 & 24 \\
\hline 281 & 1 & 8 & 14 & 20 & 25 \\
\hline 231 & 2 & 9 & 15 & 21 & 26 \\
\hline 181 & 3 & 10 & 16 & 22 & 27 \\
\hline 120 & 4 & 11 & 17 & 23 & 28 \\
\hline 63 & 5 & 12 & 18 & - & - \\
\hline
\end{tabular}


RUN NUMBER-FLOW RATE-BED DEPTH CORRESPONDENCE.

$6.4 \mathrm{~mm}$ Ceramic Beads

Table B3

\begin{tabular}{|r|r|r|r|r|r|}
\cline { 2 - 6 } \multicolumn{1}{c|}{} & 29 & 80 & 141 & 208 & 267 \\
\hline 274 & 1 & 8 & 15 & 22 & 29 \\
\hline 206 & 2 & 9 & 16 & 23 & 30 \\
\hline 171 & 3 & 10 & 17 & 24 & 31 \\
\hline 138 & 4 & 11 & 18 & 25 & 32 \\
\hline 109 & 5,36 & 12,37 & 19,38 & 26,39 & 33,40 \\
\hline 73 & 6 & 13 & 20 & 27 & 34 \\
\hline 45 & 7 & 14 & 21 & 28 & 35 \\
\hline
\end{tabular}

$9.5 \mathrm{~mm}$ Steel Balls

Table B4

\begin{tabular}{|r|r|r|r|r|r|}
\multicolumn{1}{c|}{} & \multicolumn{1}{c|}{$\mathrm{L}(\mathrm{mm})$} \\
\cline { 2 - 7 } & 54 & 112 & 163 & 213 & 259 \\
\hline 468 & 1 & 6 & 11 & 16 & 20 \\
\hline 356 & 2 & 7 & 12 & 17 & 21 \\
\hline 224 & 3 & 8 & 13 & 18 & 22 \\
\hline 146 & 4,23 & 9,24 & 14,25 & 19,26 & - \\
\hline 77 & 5 & 10 & 15 & - & - \\
\hline
\end{tabular}


Run number $1 \quad \mathrm{r}_{0}=23.4 \quad \mathrm{~T}_{\mathrm{w}}=105.1$

$\begin{array}{llllll}24.8 & 25.3 & 26.6 & 30.6 & 37.3 & 42.4\end{array}$

$24.7 \quad 25.0 \quad 25.6 \quad 30.5: 35.6 \quad=$

$\begin{array}{llllllll}33.3 & 34.1 & 37.0 & 38.6 & 36.5 & 48.5 & 61.7 & 62.4\end{array}$

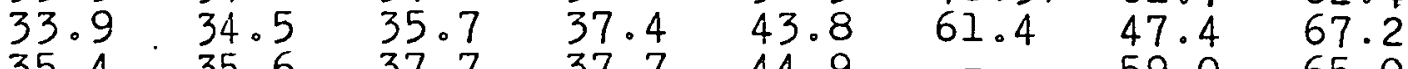

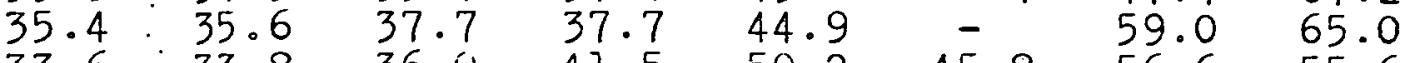

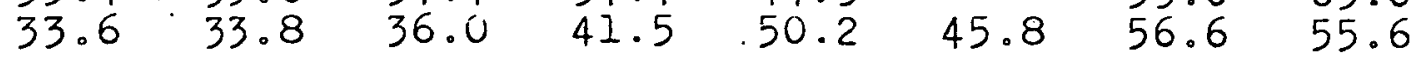

Run number 2

$$
\mathrm{T}_{\mathrm{O}}=22.4 \quad \mathrm{~T}_{\mathrm{w}}=104.9
$$

$\begin{array}{llllll}24.9 & 25.8 & 26.9 & 32.1 & 38.8 & 44.2\end{array}$

$\begin{array}{lllll}24.8 & 25.2 & 25.8 & 31.7 & 37.2\end{array}$

$\begin{array}{llllllll}34.6 & 35.8 & 39.4 & 41.5 & 38.4 & 52.0 & 65.7 & 67.3\end{array}$ $\begin{array}{llllllll}35.5 & 36.8 & 38.0 & 40.5 & 46.4 & 66.0 & 50.7 & 71.5\end{array}$ $\begin{array}{llllllll}37.6 & 38.0 & 39.6 & 39.6 & 49.6 & - & 62.8 & 68.4\end{array}$ $\begin{array}{llllllll}35.6 & 35.5 & 39.1 & 44.0 & 55.0 & 49.5 & 63.9 & 59.9\end{array}$

Run number 3

$\mathrm{T}_{\mathrm{O}}=23.0 \quad \mathrm{~T}_{\mathrm{W}}=106.0$

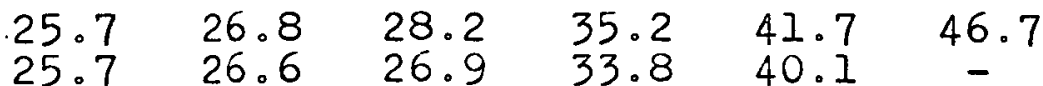

$\begin{array}{llllllll}38.3 & 40.0 & 44.5 & 46.9 & 41.7 & 58.7 & 71.6 & 74.2\end{array}$ $\begin{array}{llllllll}39.6 & 41.4 & 43.3 & 46.1 & 51.1 & 71.8 & 55.7 & 78.3 \\ 41.5 & 42.1 & 44.0 & 43.3 & 58.0 & - & 69.5 & 73.6\end{array}$

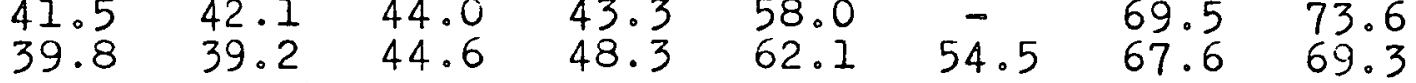

Run number $\quad 4 \quad \mathrm{~T}_{\mathrm{O}}=22.7 \quad \mathrm{~T}_{\mathrm{w}}=105.6$

$\begin{array}{llllll}28.6 & 30.6 & 32.5 & 39.7 & 46.8 & 51.9\end{array}$

$\begin{array}{llllll}28.6 & 30.1 & 30.6 & 38.2 & 45.7 & -\end{array}$

$\begin{array}{llllllll}49.4 & 53.8 & 55.6 & 54.5 & 51.1 & 73.5 & 80.5 & 85.6\end{array}$

$\begin{array}{llllllll}50.9 & 51.3 & 54.9 & 60.2 & 61.6 & 74.6 & 64.8 & 83.9\end{array}$

$\begin{array}{llllllll}52.9 & 52.9 & 55.5 & 55.7 & 71.6 & - & 79.1 & 81.1\end{array}$

$\begin{array}{llllllll}52.6 & 49.5 & 55.2 & 51.9 & 75.4 & 66.7 & 79.9 & 84.2\end{array}$

Run number 5

$$
\mathrm{T}_{0}^{\mathrm{T}_{0}}=22.6 \quad \mathrm{~T}_{\mathrm{W}}=105.3
$$

$\begin{array}{llllll}38.8 & 40.1 & 42.8 & 50.0 & 56.1 & 58.5\end{array}$

$\begin{array}{lllll}37.7 & 39.7 & 41.1 & 49.7 & 55.2\end{array}$

$\begin{array}{llllllll}76.1 & 79.1 & 80.9 & 83.3 & 86.6 & 95.6 & 97.2 & 101.7\end{array}$

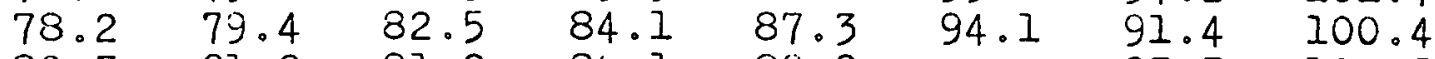

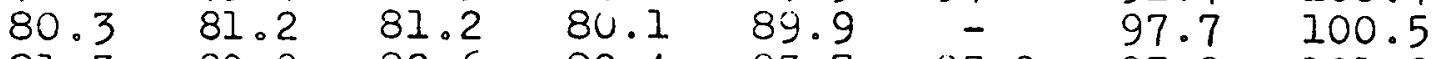
$\begin{array}{llllllll}81.3 & 80.0 & 82.6 & 82.4 & 93.7 & 93.0 & 97.9 & 101.9\end{array}$ 
Run number $6 \quad \mathrm{~T}_{0}=.23 .3 \quad \mathrm{~T}_{\mathrm{W}}=105.4$

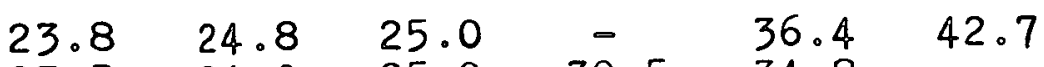

$23.5 \quad 24.0 \quad 25.0 \quad 30.5 \quad 34.8 \quad$

$\begin{array}{llllllll}- & 60.0 & 50.0 & 62.9 & 63.5 & 75.1 & 73.5 & 82.3\end{array}$

$\begin{array}{llllllll}61.0 & 52.1 & 58.8 & 59.0 & 70.7 & 76.2 & 85.9 & 87.4\end{array}$

$\begin{array}{llllllll}62.1 & 62.4 & 67.4 & 66.2 & 72.9 & 75.9 & 81.7 & 80.9\end{array}$

$\begin{array}{llllllll}57.8 & 50.2 & 55.7 & 58.9 & 60.8 & 70.4 & 67.0 & 72.5\end{array}$

Run number $7 \quad \mathrm{~T}_{\mathrm{O}}=23.3 \quad \mathrm{~T}_{\mathrm{W}}=105.3$

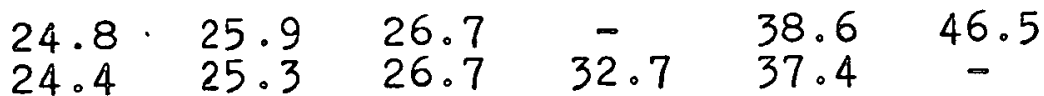

$\begin{array}{llllllll}- & 64.8 & 54.8 & 67.5 & 67.9 & 78.8 & 77.2 & 85.6 \\ 65.7 & 56.8 & 63.3 & 63.8 & 74.9 & 81.1 & 88.4 & 92.6 \\ 66.3 & 66.5 & 71.4 & 70.3 & 77.4 & 79.7 & 85.5 & 84.9 \\ 62.4 & 55.2 & 59.7 & 63.7 & 66.0 & 74.5 & 72.0 & 76.2\end{array}$

Run number $8 \quad \mathrm{~T}_{\mathrm{O}}=22.9, \quad \mathrm{~T}_{\mathrm{W}}=105.4$

$\begin{array}{llllll}26.3 & 27.7 & 28.6 & 33.8 & 41.5 & 51.1\end{array}$

$25.7 \quad 26.7 \quad 28.0 \quad 35.1 \quad 39.9 \quad-$

$\begin{array}{llllllll}61.5 & 70.3 & 61.2 & 73.0 & 74.2 & 82.9 & 81.8 & 89.8\end{array}$

$\begin{array}{llllllll}71.7 & .62 .5 & 69.0 & 69.9 & 79.1 & 85.5 & 89.5 & 96.4\end{array}$

$\begin{array}{llllllll}72.5 & 73.0 & 77.2 & 76.2 & 82.1 & 84.8 & 89.9 & 90.9\end{array}$

$\begin{array}{llllllll}69.5 & 62.0 & 65.7 & 69.8 & 72.2 & 79.8 & 77.8 & 81.7\end{array}$

Run number $9 \quad \mathrm{I}_{0}=22.8 \quad \mathrm{~T}_{\mathrm{w}}=104.9$

$\begin{array}{llllll}29.8 & 31.6 & 32.6 & 39.4 & 45.8 & 54.5\end{array}$

$28.7 \quad 29.2 \quad 31.4 \cdot 41.2 \quad 44.1 \quad-$

$\begin{array}{llllllll}77.3 & 86.4 & 77.8 & .88 .7 & 86.9 & 92.1 & 93.3 & 100.1\end{array}$

$\begin{array}{llllllll}88.4 & 79.5 & 84.9 & 83.4 & 92.4 & .95 .4 & 99.3 & 101.7\end{array}$

$\begin{array}{llllllll}86.5 & 88.7 & 89.3 & 90.8 & 94.3 & 94.4 & 97.2 & 101.9\end{array}$

$\begin{array}{llllllll}84.8 & 78.3 & 82.9 & 86.0 & 86.5 & 93.2 & 89.2 & 93.0\end{array}$

Run number 10 . $\mathrm{I}_{\mathrm{O}}=22.3 \quad \mathrm{~T}_{\mathrm{W}}=105.0$.

$\begin{array}{llllll}43.7 & 45.6 & 46.8 & 51.8 & 57.5 & 60.8\end{array}$

$\begin{array}{llllll}43.4 & 42.4 & 45.5 & 53.7 & 56.4 & -\end{array}$

$\begin{array}{llllllll}104.5 & 105.6 & 104.8 & 106.3 & 106.7 & 107.5 & 107.8 & 108.3\end{array}$

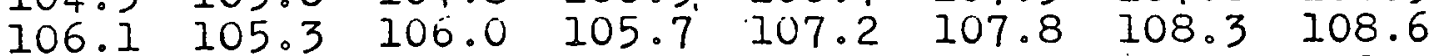

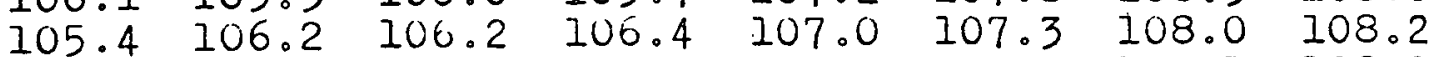

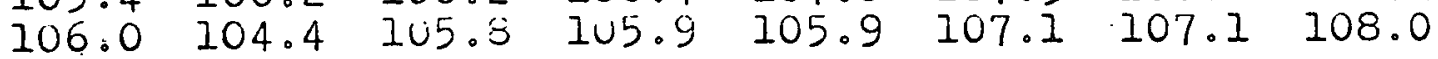


Run number 11. $\mathrm{T}_{\mathrm{O}}=20.5 \quad \mathrm{~T}_{\mathrm{w}}=104.4$

$\begin{array}{llllll}21.9 & 23.0 & 23.6 & 27.7 & 34.7 & 41.1\end{array}$

$\begin{array}{llllll}21.9 & 22.3 & 23.6 & 28.7 & 33.1 & -\end{array}$

$\begin{array}{llllllll}82.1 & 79.5 & 33.5 & 85.0 & 87.5 & 91.8 & 93.6 & 97.0\end{array}$

$\begin{array}{llllllll}82.5 & 84.6 & 84.2 & 83.2 & 91.4 & 90.8 & 95.2 & 95.3\end{array}$

$\begin{array}{llllllll}82.1 & 80.3 & 81.9 & 82.6 & 86.2 & 91.8 & 91.1 & 94.2\end{array}$

$\begin{array}{llllllll}82.5 & 82.0 & 83.7 & 82.4 & 84.5 & 89.0 & 88.1 & 91.0\end{array}$

Kun number, $12 \quad: \mathrm{T}_{0}=20.8 \quad \mathrm{~T}_{\mathrm{w}}=105.1$

$\begin{array}{llllll}22.9 & 23.9 & 24.8 & 29.5 & 36.8 & 44.6\end{array}$

$22.3 \quad 23.2 \quad 24.8 \quad 30.6 \quad 35.6 \quad-$

$\begin{array}{llllllll}86.5 & 84.1 & 87.7 & 89.2 & 91.3 & 95.2 & 96.6 & 99.8\end{array}$

$\begin{array}{llllllll}86.9 & 88.8 & 87.9 & 87.5 & 93.1 & 93.9 & 98.0 & 98.0\end{array}$

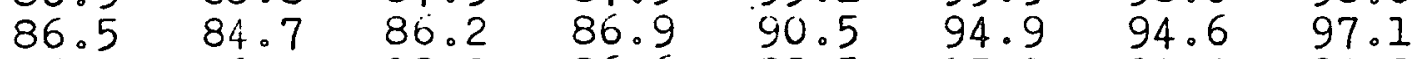

$\begin{array}{llllllll}86.7 & 86.3 & 88.0 & 86.6 & 88.5 & 93.0 & 92.4 & 94.8\end{array}$

Run number $13 \quad \mathrm{~T}_{0}=20.5 \quad \mathrm{iT}_{\mathrm{w}}=105.3$

$\begin{array}{llllll}23.8 & 25.7 & 26.6 & 31.6 & 39.6 & 48.4\end{array}$

$\begin{array}{lllll}23.5 & 24.8 & 26.2 & 33.4 & 38.4\end{array}$

$\begin{array}{llllllll}92.6 & 90.2 & 93.1 & 94.8 & 96.1 & 99.0 & 100.3 & 102.8\end{array}$

$\begin{array}{llllllll}92.7 & 94.5 & 93.1 & 93.1 & 95.8 & 97.9 & 100.8 & 101.4\end{array}$

$\begin{array}{llllllll}92.2 & 90.7 & 92.1 & 93.0 & 95.8 & 98.8 & 99.0 & 99.8\end{array}$

$\begin{array}{llllllll}92.4 & 92.1 & 93.5 & 92.5 & 94.4 & 97.5 & 97.7 & 99.1\end{array}$

Run number $14 \quad \mathrm{i}_{0}=21.0 \quad \mathrm{i}_{\mathrm{w}}=105.1$

$\begin{array}{llllll}28.7 & 30.1 & 31.1 & 36.6 & 44.7 & 53.5\end{array}$

$27.0 \quad 27.6 \quad 29.7 \quad 39.4 \quad 42.9 \quad-$

$\begin{array}{llllllll}103.4 & 101.7 & 103.7 & 104.5 & 104.7 & 105.8 & 106.2 & 107.3\end{array}$

$\begin{array}{llllllll}103.2 & 103.9 & 103.8 & 103.6 & 104.0 & 106.3 & 106.0 & 107.3\end{array}$

$\begin{array}{llllllll}102.9 & 101.8 & 102.7 & 103.9 & 104.6 & 105.4 & 105.4 & 105.7\end{array}$

$102.9 \quad 103.0 \quad 103.3 \quad 102.8 \quad 104.5 \quad 105.0 \quad 106.0106 .1$

Run number $15 \quad \mathrm{~T}_{0}=20.8 \quad \mathrm{~T}_{\mathrm{w}}=105.2$

$\begin{array}{llllll}38.8 & 41.4 & 42.1 & 47.3 & 54.7 & 57.3\end{array}$

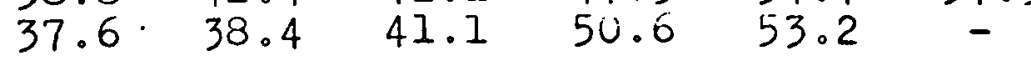

$\begin{array}{llllllll}106.3 & 106.0 & 106.3 & 106.6 & 106.8 & 107.7 & 107.8 & 108.2\end{array}$

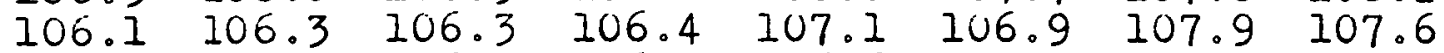
$\begin{array}{llllllll}106.3 & 105.7 & 106.3 & 106.2 & 106.6 & 107.2 & 107.5 & 107.6\end{array}$ $\begin{array}{llllllll}106.4 & 106.2 & 106.3 & 106.2 & 106.9 & 107.3 & 107.6 & 107.6\end{array}$ 
Run number $\quad 16$

$$
\mathrm{T}_{0}=23.5 \quad \mathrm{~T}_{\mathrm{W}}=106.2
$$

$\begin{array}{llllll}24.9 & 25.8 & 27.7 & 35.1 & 38.5 & 48.9\end{array}$

$\begin{array}{llllll}25.3 & 26.7 & 27.7 & 31.4 & 37.7 & -\end{array}$

$\begin{array}{llllllll}52.5 & 49.2 & 55.5 & 49.2 & 60.6 & 76.0 & 74.8 & 85.2\end{array}$

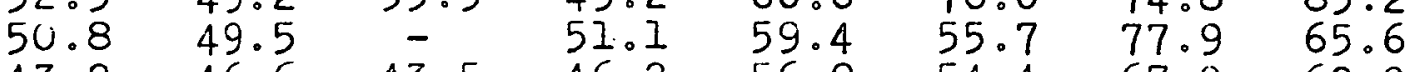

$\begin{array}{llllllll}43.2 & 46.6 & 43.5 & 46.2 & 56.9 & 54.4 & .67 .0 & 62.0\end{array}$

$\begin{array}{llllllll}51.3 & 47.9 & 51.5 & 53.0 & 55.9 & 65.3 & 64.8 & 77.1\end{array}$

Run number $\quad 17$

$$
\mathrm{T}_{0}=23.2 \quad \mathrm{~T}_{\mathrm{w}}=106.2
$$

$\begin{array}{llllll}24.9 & 25.8 & 27.6 & 35.9 & 39.1 & 50.5 \\ 25.2 & 26.7 & 27.6 & 31.6 & 38.7 & -\end{array}$

$\begin{array}{llllllll}58.0 & 53.7 & 61.5 & 53.5 & 64.6 & 79.4 & 78.0 & 89.1\end{array}$

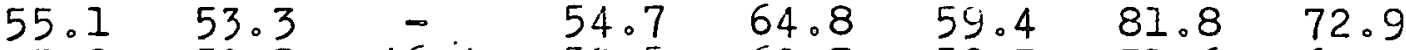

$\begin{array}{llllllll}45.9 & 50.8 & 46.4 & 50.5 & 60.7 & 59.3 & 71.6 & 67.4\end{array}$

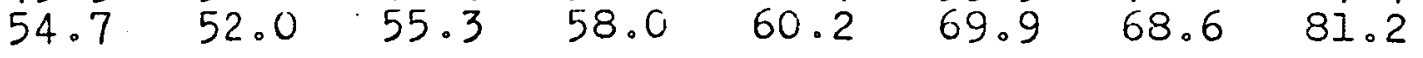

Run number $18 . \quad \mathrm{i}_{0}=23.6 \quad \mathrm{i}_{\mathrm{W}}=107.1$

$\begin{array}{llllll}25.7 & 26.7 & 28.7 & 37.5 & 40.1 & 51.8 \\ 26.2 & 27.8 & 28.7 & 32.8 & 39.7 & -\end{array}$

$\begin{array}{llllllll}60.4 & 55.5 & 62.7 & 54.9 & 66.1 & 80.7 & 79.1 & 90.1\end{array}$

$\begin{array}{llllllll}57.3 & 55.4 & - & 56.7 & 66.7 & 62.6 & 82.8 .74 .6\end{array}$

$\begin{array}{llllllll}48.1 & 52.9 & 48.6 & 52.7 & 62.3 & 62.1 & 73.0 & 70.5 \\ 56.8 & 54.3 & 56.9 & 59.6 & 62.3 & 71.2 & 70.5 & 82.1\end{array}$

Run number $19 \quad \mathrm{~T}_{0}=23.5 \quad \mathrm{i}_{\mathrm{w}}=106.2$

$\begin{array}{llllll}28.7 & 30.7 & 32.7 & 42.6 & 45.1 & 56.3\end{array}$

$29.7 \quad 31.7 \quad 32.9 . \quad 37.4 \quad 45.8 \quad-$

$\begin{array}{llllllll}70.7 & 69.9 & 76.2 & 69.0 & 78.2 & 90.5 & 89.6 & .97 .4\end{array}$

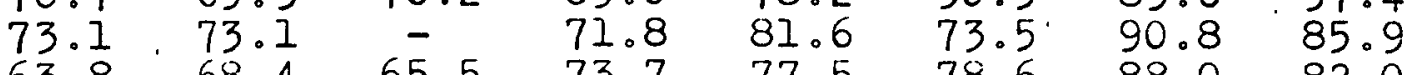

$\begin{array}{llllllll}63.8 & 68.4 & 65.5 & 73.7 & 77.5 & 78.6 & 88.0 & 82.0\end{array}$

$\begin{array}{llllllll}68.6 & 67.2 & 63.3 & 73.1 & 77.0 & 81.1 & 78.4 & 90.0\end{array}$

Run number $20 \quad \mathrm{~T}_{\mathrm{O}}=23.2 \quad \mathrm{I}_{\mathrm{W}}=105.4$

$\begin{array}{llllll}39.6 & 40.9 & 45.6 & 54.0 & 55.1 & 61.2\end{array}$

$40.6 \quad 43.8 \quad 43.6 \quad 49.0 \quad 56.2 \quad-$

$\begin{array}{llllllll}95.7 & 94.8 & 97.2 & 95.3 & 99.0 & 102.8 & 103.7 & 105.6\end{array}$

$\begin{array}{llllllll}96.3 & 96.0 & - & 97.6 & 101.2 & 99.3 & 104.7 & 104.7\end{array}$

$\begin{array}{llllllll}93.7 & 95.3 & 94.0 & 95.8 & 98.6 & 99.1 & 103.5 & 103.0\end{array}$

$\begin{array}{llllllll}94.9 & 93.7 & 94.3 & 96.3 & 96.3 & 101.8 & 100.6 & 104.6\end{array}$ 
Run number $21 \quad \mathrm{~T}_{\mathrm{O}}=23.9 \quad \mathrm{~T}_{\mathrm{w}}=106.2$

$\begin{array}{llllll}26.7 & 27.8 & 29.5 & 34.6 & 40.8 & 52.5\end{array}$

$27.2 \quad 28.7 \quad 29.6 \quad 34.1 \quad 40.6 \quad-$

$\begin{array}{llllllll}84.7 & 83.4 & 85.9 & 85.8 & 88.2 & 94.6 & 94.3 & 98.8\end{array}$

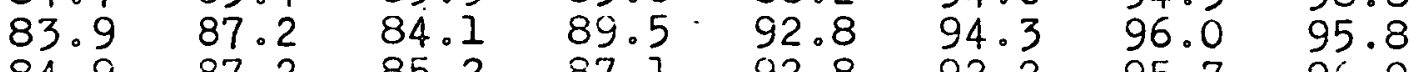

$\begin{array}{llllllll}84.9 & 87.2 & 85.2 & 87.1 & 92.8 & 92.2 & 95.7 & 96.9\end{array}$

$\begin{array}{llllllll}85.9 & 84.4 & 86.0 & 85.7 & 88.7 & 91.4 & 92.6 & 97.6\end{array}$

Run number $22 \quad \mathrm{I}_{0}=24.2 \quad \mathrm{~T}_{\mathrm{W}}=106.4$

$\begin{array}{llllll}25.8 & 26.6 & 27.8 & 30.7 & 37.8 & 47.8\end{array}$

$\begin{array}{llllllll}75.1 & 74.2 & 76.5 & 78.0 & 78.7 & 89.3 & 88.6 & 93.0\end{array}$

$\begin{array}{llllllll}74.4 & 78.3 \cdot 75.6 & 81.0 & 86.2 & 86.6 & 91.1 & 89.5\end{array}$

$\begin{array}{llllllll}75.9 & 78.4 & 76.7 & 78.2 & 86.0 & 83.7 & 90.0 & 88.5\end{array}$

$\begin{array}{llllllll}76.3 & 75.1 & 76.7 & 79.1 & 80.4 & 85.2 & 86.1 & 92.4\end{array}$

9.5 mII CERAMIC BEADS

Run number $1 \quad \mathrm{I}_{\mathrm{O}}=27.2 \quad \mathrm{~T}_{\mathrm{W}}=103.3$

$\begin{array}{llllll}28.2 & 28.7 & 32.6 & 34.6 & 35.6 & 37.6\end{array}$

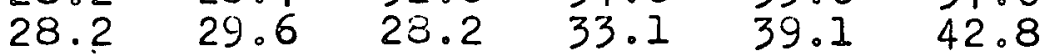

$\begin{array}{llllllll}35.6 & 35.9 & 35.8 & 39.8 & 48.0 & 61.1 & 60.9 & 68.8\end{array}$

$\begin{array}{llllllll}34.9 & 35.6 & 36.7 & 40.0 & 49.1 & 62.2 & 59.0 & 73.6\end{array}$

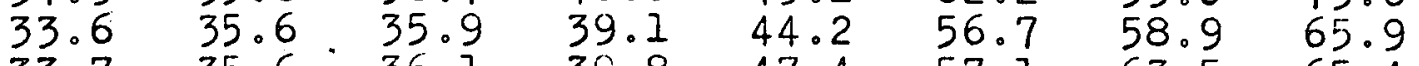

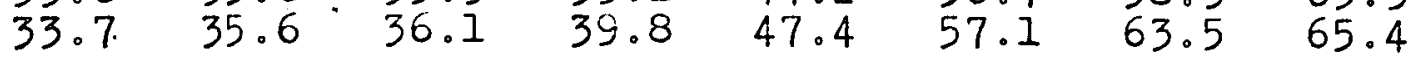

Run number $2 \quad \mathrm{~T}_{0}=23.9 \quad \mathrm{~T}_{\mathrm{w}}=104.6$

$\begin{array}{llllll}24.9 & 25.3 & 29.6 & 31.6 & 33.1 & 35.6\end{array}$

$\begin{array}{llllllll}32.8 & 33.8 & 33.0 & 38.8 & 46.8 & 61.2 & 60.9 & 69.7\end{array}$

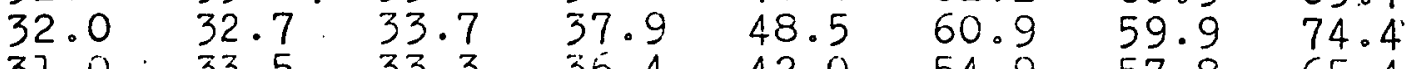

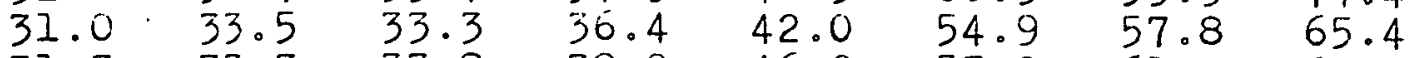

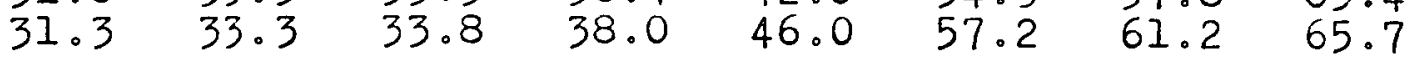

Run number $3 \quad \mathrm{~T}_{\mathrm{O}}=25.1 \quad \mathrm{~T}_{\mathrm{W}}=104.5$

$\begin{array}{llllll}26.3 & 27.2 & 31.6 & 34.1 & 36.6 & 38.6\end{array}$

$\begin{array}{llllll}26.3 & 28.7 & 25.8 & 33.1 & 40.1 & 44.3\end{array}$

$\begin{array}{llllllll}37.3 & 38.1 & 37.4 & 44.1 & 52.1 & 66.4 & 65.4 & 72.8\end{array}$

$\begin{array}{llllllll}36.0 & 36.6 & 38.0 & 42.0 & 47.6 & 59.8 & 63.6 & 70.6\end{array}$

$\begin{array}{llllllll}35.0 & 37.4 & 38.0 & 42.0 & 47.6 & 59.8 & 63.6 & 70.6\end{array}$

$\begin{array}{llllllll}35.2 & 38.3 & 38.5 & 43.6 & 50.4 & 62.2 & 64.3 & 68.8\end{array}$ 
Run number 4

$$
\eta_{0}=25.3 \quad T_{w}=104.3
$$

$\begin{array}{llllll}28.7 & 29.6 & 34.1 & 37.1 & 40.1 & 41.6\end{array}$

$28.2 \quad 31.1 \quad 26.7 \quad 35.6 \quad 43.6 \quad 48.2$

$\begin{array}{llllllll}43.9 & 43.9 & 43.4 & 51.5 & 58.0 & 70.9 & 70.9 & 78.1\end{array}$

$\begin{array}{llllllll}40.9 & 43.7 & 43.9 & 47.4 & 58.2 & 71.0 & 69.1 & 82.5\end{array}$

$\begin{array}{llllllll}39.7 & 42.5 & 43.5 & 49.1 & 54.7 & 66.3 & 69.8 & 76.3\end{array}$

$\begin{array}{llllllll}41.4 & 44.4 & 44.7 & 51.0 & 58.7 & 68.1 & 68.3 & 78.1\end{array}$

Run number $5 \quad \mathrm{~T}_{0}=26.0 \quad \mathrm{~T}_{\mathrm{W}}=104.2$

$\begin{array}{llllll}32.6 & 34.6 & 40.6 & 44.6 & 46.7 & 48.2\end{array}$

$\begin{array}{llllll}32.6 & 35.6 & 32.6 & 42.6 & 49.8 & 54.4\end{array}$

$\begin{array}{llllllll}61.1 & 60.6 & 58.9 & 65.5 & 70.8 & 82.4 & 81.6 & 89.6\end{array}$

$\begin{array}{llllllll}54.9 & 55.6 & 60.7 & 63.3 & 71.9 & 80.4 & 79.3 & 88.7\end{array}$

$\begin{array}{llllllll}53.3 & 56.0 & 59.1 & 65.7 & 70.0 & 78.8 & 80.0 & 85.8\end{array}$

$\begin{array}{llllllll}57.4 & 58.0 & 58.5 & 65.3 & 72.2 & 80.1 & 81.6 & 88.2\end{array}$

Run number 6

$$
\mathrm{T}_{0}=28.7 \quad \mathrm{~T}_{\mathrm{W}}=103.9
$$

$29.1 \quad 29.6 \quad 32.6 \quad 34.6 \quad 34.6 \quad 37.6$

$29.1 \quad 29.6 \quad 30.6 \quad 33.1 \quad 38.6 \quad 41.2$

$\begin{array}{llllllll}34.7 & 35.5 & 34.9 & 39.3 & 46.1 & 57.9 & 58.1 & 65.6\end{array}$

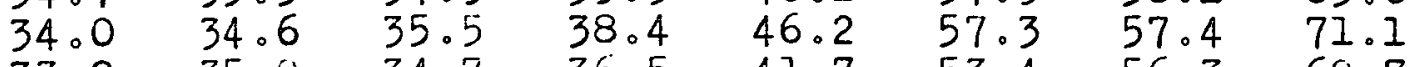

$\begin{array}{llllllll}33.2 & 35.0 & 34.7 & 36.5 & 41.7 & 53.4 & 56.3 & 60.7\end{array}$

$\begin{array}{llllllll}33.6 & 34.6 & 35.1 & 37.6 & 45.7 & 54.0 & 57.0 & 63.2\end{array}$

Run number 7

$i_{v}=29.1 \quad \mathrm{~T}_{\mathrm{W}}=104.1$

$\begin{array}{llllll}29.6 & 30.1 & 33.1 & 35.6 & 35.1 & 39.1\end{array}$

$\begin{array}{llllll}29.6 & 30.1 & 29.1 & 33.6 & 39.1 & 42.6\end{array}$

$\begin{array}{llllllll}41.2 & 39.1 & 42.3 & 48.4 & 56.8 & 73.3 & 69.6 & 78.8\end{array}$

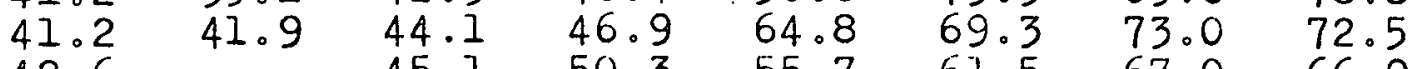

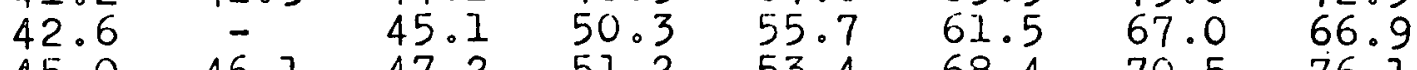

$\begin{array}{llllllll}45.0 & 46.1 & 47.2 & 51.2 & 53.4 & 68.4 & 70.5 & 76.1\end{array}$

Run number $8 \quad \mathrm{I}_{\mathrm{O}}=27.5, \quad \mathrm{~T}_{\mathrm{w}}=104.3$

$\begin{array}{llllll}28.2 & 29.1 & 34.6 & 35.6 & 35.6 & 39.6\end{array}$

$28.2 \quad 29.6 \quad 28.2 \quad 33.6 \quad 39.6 \quad 43.6$

$\begin{array}{llllllll}44.2 & 40.8 & 45.8 & 51.6 & 60.7 & 75.6 & 72.3 & 81.9\end{array}$

$\begin{array}{llllllll}43.9 & 44.8 & 47.9 & 48.6 & 64.7 & 75.4 & 73.7 & 83.0\end{array}$

$\begin{array}{llllllll}44.6 & 48.7 & 48.2 & 53.7 & 58.8 & 65.4 & 70.6 & 70.9\end{array}$

$\begin{array}{llllllll}47.7 & 49.1 & 49.8 & 54.4 & 57.0 & 70.3 & 72.8 & 79.4\end{array}$ 
Run number $9 \quad \mathrm{~T}_{0}=28.7 \quad \mathrm{~T}_{\mathrm{w}}=104.5$

$\begin{array}{llllll}29.6 & 30.6 & 36.1 & 37.1 & 37.6 & 41.1\end{array}$

$29.6 \quad 31.1 \quad 29.6 \quad 35.1 \quad 41.6 \quad 45.5$

$\begin{array}{llllllll}46.8 & 43.4 & 48.4 & 54.3 & 62.7 & 77.9 & 74.5 & 84.3\end{array}$

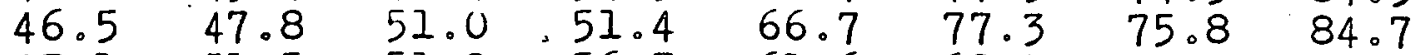

$\begin{array}{llllllll}47.1 & 51.5 & 51.2 & 56.7 & 61.6 & 68.0 & 73.2 & 72.3\end{array}$

$\begin{array}{llllllll}50.7 & 52.9 & 53.3 & 56.8 & 60.2 & 73.5 & 75.0 & 82.3\end{array}$

Run number $10 \quad \mathrm{~T}_{0}=26.7 \quad \mathrm{I}_{\mathrm{W}}=104.2$

$\begin{array}{llllll}28.7 & 29.6 & 34.6 & 37.6 & 37.6 & 40.6\end{array}$

$28.7 \quad 30.1 .28 .2 \quad 35.1 \quad 41.6 \quad 45.1$

$\begin{array}{llllllll}50.0 & 45.4 & 51.0 & 56.2 & 64.5 & 80.4 & 75.5 & 85.8\end{array}$

$\begin{array}{llllllll}49.0 & 51.9 & 53.2 & 55.6 & 73.1 & 78.6 & 78.9 & 84.1\end{array}$

$\begin{array}{llllllll}49.0 & 54.7 & 53.9 & 60.0 & 64.7 & 70.5 & 75.3 & 76.4\end{array}$

$\begin{array}{llllllll}54.2 & 56.3 & 57.2 & 58.8 & 63.2 & 76.4 & 78.1 & 85.3\end{array}$

Run number II $\mathrm{T}_{0}=23.3 \quad \mathrm{II}_{\mathrm{w}}=103.9$

$\begin{array}{llllll}26.7 & 28.0 & 33.1 & 36.8 & 37.6 & 40.6\end{array}$

$\begin{array}{llllll}26.5 & 28.9 & 25.8 & 33.6 & 41.6 & 45.7\end{array}$

$\begin{array}{llllllll}54.4 & 50.8 & 57.6 & 64.1 & 69.3 & 81.2 & 78.9 & 90.1\end{array}$

$\begin{array}{llllllll}54.8 & 57.5 & 57.2 & 63.4 & 75.4 & 80.6 & 79.9 & 86.4\end{array}$

$\begin{array}{llllllll}58.7 & 60.9 & 61.9 & 65.8 & 69.7 & 77.1 & 76.6 & 82.9\end{array}$

$\begin{array}{llllllll}60.6 & 60.0 & 62.5 & 65.7 & 67.4 & 77.9 & 81.0 & 90.0\end{array}$

Run number 12

$$
\mathrm{r}_{0}=24.0 \quad \mathrm{~T}_{\mathrm{w}}=203.8
$$

$\begin{array}{llllll}31.1 & 32.8 & 38.6 & 44.6 & 44.6 & 46.7\end{array}$

$\begin{array}{llllll}30.6 & 33.8 & 25.8 & 40.6 & 47.7 & 50.0\end{array}$

$\begin{array}{llllllll}71.5 & 67.2 & 72.9 & 78.2 & 82.8 & 88.9 & 88.4 & 95.5\end{array}$

$\begin{array}{llllllll}72.7 & 75.7 & 75.0 & 78.3 & 84.9 & 90.0 & 89.2 & 95.0\end{array}$

$\begin{array}{llllllll}75.6 & 76.8 & 77.9 & 81.6 & 82.4 & 88.0 & 88.7 & 92.8\end{array}$

$\begin{array}{llllllll}76.2 & 75.5 & 79.0 & 79.1 & 82.7 & 90.7 & 90.3 & 96.8\end{array}$

Run number $13 \quad I^{\prime \prime} \mathrm{O}=23.3 \quad \mathrm{I}_{\mathrm{W}}=103.8$

$\begin{array}{llllll}23.9 & 24.4 & 31.1 & 31.6 & 29.6 & 33.1\end{array}$

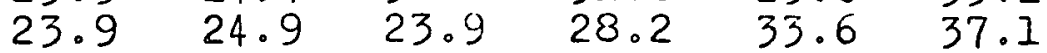

$\begin{array}{llllllll}47.0 & 46.1 & 50.0 & 59.6 & 57.9 & 67.5 & 78.1 & 72.3\end{array}$

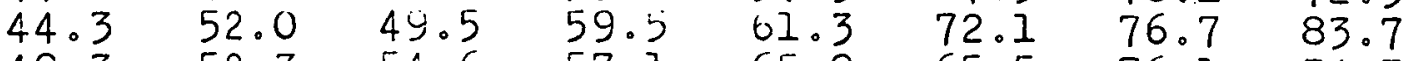

$\begin{array}{llllllll}49.3 & 52.3 & 54.6 & 57.1 & 65.8 & 65.5 & 76.1 & 74.7\end{array}$

$\begin{array}{llllllll}47.5 & 44.5 & 55.0 & 47.3 & 64.4 & 64.7 & 76.3 & 75.8\end{array}$ 
Run number $\quad 14$

$\mathrm{T}_{0}=23.0 \quad \mathrm{~T}_{\mathrm{w}}=103.8$

$24.2 \quad 24.9 \quad 31.8 \quad 32.6 \quad 30.9 \cdot 34.2$

$23.9 \quad 25.3 \quad 23.9 \quad 29.1 \quad 35.1 \quad 38.4$

$\begin{array}{llllllll}50.9 & 50.9 & 53.5 & 63.3 & 62.1 & 70.6 & 80.9 & 75.9\end{array}$

$\begin{array}{llllllll}48.4 & 56.5 & 54.1 & 63.7 & 65.1 & 75.7 & 79.3 & 86.4 \\ 53.8 & 57.9 & 59.2 & 61.7 & 69.7 & 68.9 & 79.4 & 77.9\end{array}$

$\begin{array}{llllllll}51.9 & 48.9 & 59.7 & 51.8 & 67.7 & 68.9 & 79.4 & 79.0\end{array}$

Run number $15 \quad \mathrm{~T}_{0}=23.1 \quad \mathrm{r}_{\mathrm{w}}=103.9$

$\begin{array}{llllll}24.9 & 25.8 & 31.6 & 33.1 & 32.6 & 35.6 \\ 24.7 & 26.3 & 24.4 & 30.6 & 37.1 & 40.8\end{array}$

$\begin{array}{llllllll}55.5 & 56.4 & 56.6 & 66.0 & 64.4 & 73.6 & 80.9 & 78.3\end{array}$

$\begin{array}{llllllll}51.7 & 58.4 & 57.1 & 64.9 & 67.4 & 79.3 & 80.1 & 88.3\end{array}$

$\begin{array}{llllllll}56.5 & 58.5 & 63.0 & 63.7 & 73.1 & 72.3 & 81.5 & 80.0\end{array}$

$\begin{array}{llllllll}54.6 & 52.6 & 62.7 & 54.6 & 69.2 & 73.2 & 82.0 & 82.0\end{array}$

Run number $16 \quad \mathrm{~T}_{\mathrm{O}}=23.1 \quad \mathrm{~T}_{\mathrm{W}}=103.9$

$\begin{array}{llllll}25.3 & 26.3 & 33.6 & 34.6 & 34.6 & 37.6\end{array}$

$25.3 \quad 26.9 \quad 24.4 \quad 32.1 \quad 39.1 \quad 42.3$

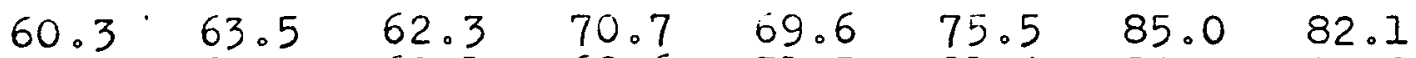

$\begin{array}{lllllll}56.5 .63 .4 & 62.1 & 69.6 & 71.3 & 81.4 & 84.0 & 90.8\end{array}$

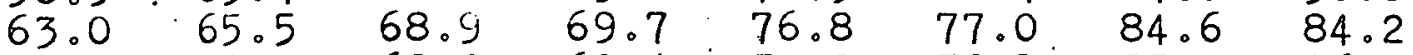

$\begin{array}{llllllll}59.4 & 58.4 & 68.0 & 60.4 & 74.2 & 79.1 & 85.3 & 86.9\end{array}$

Run number $\quad 17 \quad T_{0}^{\prime}=23.8 \quad T_{\mathrm{w}}=103.0$

$\begin{array}{llllll}26.7 & 28.5 & 35.9 & 37.6 & 37.6 & 40.6\end{array}$

$26.6 \quad 29.2 \quad 25.3 \quad 35.1 \quad 42.1 \quad 45.8$

$\begin{array}{llllllll}71.8 & 75.1 & 73.0 & 79.2 & 78.4 & 85.3 & 88.8 & 90.5\end{array}$

$\begin{array}{llllllll}73.3 & 70.1 & 69.0 & 75.0 & 77.6 & 85.4 & 88.7 & 93.5\end{array}$

$\begin{array}{llllllll}72.3 & 74.5 & 76.5 & 79.9 & 83.3 & 86.6 & 88.4 & 92.8\end{array}$

$\begin{array}{llllllll}69.8 & 68.9 & 76.2 & 68.2 & 80.5 & 86.7 & 89.7 & 91.5\end{array}$

Run number $18 \quad \mathrm{~T}_{0}=23.6: \mathrm{T}_{\mathrm{w}}=102.9$

$\begin{array}{llllll}31.1 & 33.1 & 40.8 & 43.6 & 44.1 & 46.7\end{array}$

$\begin{array}{llllll}30.8 & 34.1 & 25.8 & 40.6 & 48.2 & 51.4\end{array}$

$\begin{array}{llllllll}89.5 & 90.5 & 90.5 & 93.3 & 92.6 & 96.9 & 97.1 & 100.0\end{array}$

$\begin{array}{llllllll}84.0 & 87.3 & 85.4 & 89.6 & 90.6 & 95.5 & 96.9 & 99.7 .\end{array}$

$\begin{array}{llllllll}88.8 & 89.0 & 91.0 & 92.2 & 94.1 & 95.6 & 96.6 & 97.6\end{array}$

$\begin{array}{llllllll}84.1 & 87.2 & 88.5 & 86.3 & 92.9 & 94.5 & 97.6 & 98.8\end{array}$ 
Run number 19

$\mathrm{T}_{\mathrm{O}}=24.0$

$\mathrm{T}_{\mathrm{w}}=103.0$

$\begin{array}{llllll}25.3 & 25.5 & 32.1 & 32.6 & 30.6 & 34.1\end{array}$

$25.1 \quad 25.8 \quad 24.9 \quad 29.1 \quad 34.6 \quad 37.4$

$\begin{array}{llllllll}56.7 & 64.0 & 64.2 & 68.2 & 70.9 & 82.3 & 87.4 & 86.6\end{array}$

$\begin{array}{llllllll}57.2 & 60.2 & 59.2 & 61.5 & 70.3 & 72.6 & 80.7 & 81.1\end{array}$

$\begin{array}{llllllll}55.2 & 56.3 & 58.0 & 62.4 & 67.9 & 73.6 & 80.8 & 78.9 \\ 55.9 & 57.5 & 55.2 & 59.5 & 68.2 & 65.7 & 79.5 & 82.6\end{array}$

Run number $20 \quad \mathrm{~T}_{0}=24.0 \quad \mathrm{~T}_{\mathrm{w}}=103.2$

$\begin{array}{llllll}25.5 & 26.3 & 33.6 & 33.6 & 32.1 & 35.6\end{array}$

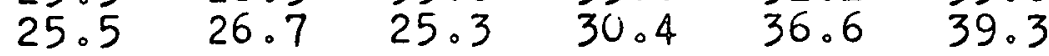

$\begin{array}{llllllll}62.3 & 68.8 & 70.4 & 72.9 & 75.2 & 84.1 & 90.0 & 88.9\end{array}$

$\begin{array}{llllllll}61.8 & 65.1 & 64.9 & 65.9 & 74.9 . & 77.6 & 84.7 & 83.6\end{array}$

$\begin{array}{llllllll}60.7 & 58.6 & 63.4 & 6.7 .2 & 73.1 & 77.1 & 84.0 & 82.1\end{array}$

$\begin{array}{llllllll}61.3 & 62.4 & 60.0 & 64.1 & 72.8 & 69.6 & 82.8 & 85.1\end{array}$

Run number $21 \quad \mathrm{i}_{\mathrm{O}}=22.8 \quad \mathrm{~T}_{\mathrm{w}}=103.7$

$\begin{array}{llllll}24.6 & 25.3 & 35.1 & 33.6 & 32.1 & 35.1\end{array}$

$24.4 \quad 25.8 \cdot 24.1 \quad 30.1$. $37.1 \quad 40.4$

$\begin{array}{llllllll}63.8 & 70.2 & 69.6 & 76.0 & 77.3 & 86.6 & 91.8 & 90.7\end{array}$

$\begin{array}{llllllll}65.1 & 66.9 & 63.3 & 66.6 & 77.4 & 78.3 & 87.4 & 84.7\end{array}$

$\begin{array}{llllllll}61.7 & 65.4 & 65.4 & 70.0 & 74.6 . & 81.4 & 85.4 & 89.3\end{array}$

$\begin{array}{llllllll}6.3 .0 & 64.0 & 62.3 . & 66.6 & 75.8 & 71.4 & 85.3 & 87.2\end{array}$

Run number 22

$$
\mathrm{T}_{0}=22.9 \quad \mathrm{~T}_{\mathrm{W}}=103.4
$$

$\begin{array}{llllll}25.2 & 25.8 & 35.6 & 35.1 & 33.8 & 36.6\end{array}$

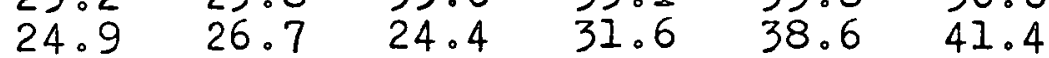

$\begin{array}{llllllll}69.6 & 75.9 & 74.7 & 80.0 & 81.1 & 89.0 & 94.1 & 93.6\end{array}$

$\begin{array}{llllllll}71.0 & 72.5 & 68.8 & 72.2 & 81.9 & 85.7 & 90.3 & 90.2\end{array}$

$\begin{array}{llllllll}68.5 & 71.6 & 71.3 & 75.2 & 79.9 & 83.3 & 88.9 & 90.4\end{array}$

$\begin{array}{llllllll}69.3 & 71.1 & 69.7 & 72.6 & 79.9 & 75.5 & 87.9 & 90.1\end{array}$

Run number $23 \quad \mathrm{i}_{0}=21.6 \quad \mathrm{~T}_{\mathrm{w}}=103.8$

$\begin{array}{llllll}25.1 & 26.5 & 36.6 & 36.1 & 35.2 & 38.6\end{array}$

$24.9 \quad .27 .5 \quad 23.5 \quad 33.1 \quad 40.1 \quad 43.3$

$\begin{array}{llllllll}77.5 & 82.0 & 82.9 & 80.6 & 85.9 & 93.8 & 97.2 & 97.2\end{array}$

$\begin{array}{llllllll}77.8 & 7.9 .1 & 74.9 & 79.5 & 87.7 & 90.2 & 94.6 & 93.6\end{array}$

$\begin{array}{llllllll}76.8 & 78.7 & 79.1 & 82.4 & 85.5 & 89.5 & 92.7 & 93.3\end{array}$

$\begin{array}{llllllll}78.5 & 80.1 & 80.7 & 79.9 & 86.3 & 80.7 & 90.0 & 95.9\end{array}$ 
Run number $24 \quad \mathrm{~T}_{\mathrm{O}}=23.0 \quad \mathrm{~T}_{\mathrm{W}}=103.5$

$\begin{array}{llllll}23.9 & 24.4 & 34.8 & 30.9 & 29.6 & 33.1 \\ 23.9 & 24.9 & 23.9 & 28.2 & 33.6 & 36.3\end{array}$

$\begin{array}{llllllll}64.9 & 66.7 & 69.1 & 69.3 & 76.6 & 84.4 & 85.6 & 89.8\end{array}$

$\begin{array}{llllllll}67.8 & 66.7 & 69.3 & 72.8 & 76.4 & 79.2 & 87.1 & 83.8\end{array}$

$\begin{array}{llllllll}63.4 & 65.3 & 65.0 & 70.2 & 72.7 & 83.4 & 83.7 & 86.4\end{array}$

$\begin{array}{llllllll}63.2 & 66.4 & 69.6 & 69.9 & 76.2 & 75.7 & 86.9 & 87.7\end{array}$

Run number $25 \quad T_{0}=23.3 \quad T_{W}=103.4$

$24.4 \quad 24.9 \cdot 36.1 \quad 32.1 \quad 31.1 \quad 34.1$

$24.4 \quad 25.3 \quad 24.4 \quad 29.6 \cdot 35.6 \quad 39.3$

$\begin{array}{llllllll}69.1 & 71.8 & 73.0 & 73.0 & 80.1 & 87.5 & 88.3 & 92.5\end{array}$

$\begin{array}{llllllll}74.8 & 73.7 & 74.8 & 77.1 & 79.3 & 82.6 & 89.1 & 85.6\end{array}$

$\begin{array}{llllllll}68.5 & 73.5 & 69.8 & 78.1 & 77.2 & 86.1 & 87.4 & 88.7\end{array}$

$\begin{array}{llllllll}69.0 & 69.6 & 72.9 & 74.8 & 80.7 & 79.4 & 90.4 & 91.2\end{array}$

Run number $26 \quad \mathrm{~T}_{\mathrm{O}}=22.5 \quad \mathrm{~T}_{\mathrm{W}}=103.8$

$\begin{array}{llllll}23.9 & 24.9 & 33.6 & 31.6 & 31.6 & 34.6 \\ 23.9 & 24.9 & 23.7 & 29.6 & 36.4 & 39.4\end{array}$

$\begin{array}{llllllll}72.8 & 74.0 & 76.9 & 75.9 & 82.4 & 88.7 & 89.7 & 95.0\end{array}$

$\begin{array}{llllllll}75.3 & 71.8 & 76.0 & 77.9 & 82.9 & 87.2 & 90.3 & 91.0 \\ 71.0 & 76.4 & 71.6 & 82.2 & 81.7 & 88.9 & 87.9 & 90.6\end{array}$

$\begin{array}{llllllll}6.9 .6 & 72.7 & 73.7 & 77.7 & 81.7 & 88.9 & 87.9 & 90.6 \\ & & & & & 82.2 & 91.8 & 92.6\end{array}$

Run number $27 \quad \mathrm{I}_{\mathrm{O}}=23.1 \quad \mathrm{Ti}_{\mathrm{W}}=104.3$

$\begin{array}{llllll}25.2 & 25.8 & 36.1 & 34.0 & 34.6 & 37.1\end{array}$

$24.9 \quad 26.4 \quad 24.5 \quad 32.0 \quad 39.1 \quad 42.0$

$\begin{array}{llllllll}79.7 & 79.6 & 83.1 & 81.1 & 85.7 & 92.9 & 93.7 & 97.2\end{array}$

$\begin{array}{llllllll}81.3 & 77.5 & 80.9 & 81.3 & 85.6 & 89.8 & 92.1 & 94.1\end{array}$

$\begin{array}{llllllll}76.2 & 81.9 & 77.4 & 84.9 & 85.9 & 90.7 & 92.0 & 93.1\end{array}$

$\begin{array}{llllllll}74.4 & 77.4 & 76.2 & 82.1 & 86.4 & 36.5 & 94.4 & 96.3\end{array}$

Run number $28 \quad \mathrm{I}_{\mathrm{O}}=23.5 \quad \mathrm{~T}_{\mathrm{W}}=1.03 .9$

$\begin{array}{llllll}26.7 & 28.2 & 34.6 & 37.8 & 37.9 & 40.6\end{array}$

$\begin{array}{llllll}26.7 & 29.1 & 25.5 & 34.6 & 42.3 & 46.1\end{array}$

$\begin{array}{llllllll}88.2 & 87.4 & 91.0 & 89.7 & 92.2 & 97.2 & 97.2 & 100.7\end{array}$

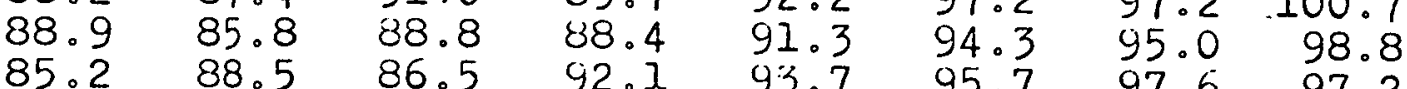

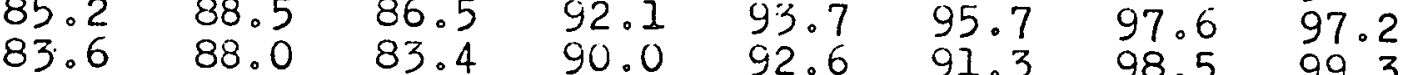


Run number $I \quad T_{0}=22.6 \quad T_{W}=101.0$

$\begin{array}{llllll}25.1 & 25.4 & 39.3 & 37.9 & 32.8 & 40.5\end{array}$

$25.2 \quad 26.0 \quad 30.0 \quad 30.0 \quad 39.6 \quad 34.9$

$\begin{array}{llllllll}25.7 & 26.0 & 26.0 & 25.0 & 31.7 & 35.3 & 45.9 & 46.0\end{array}$

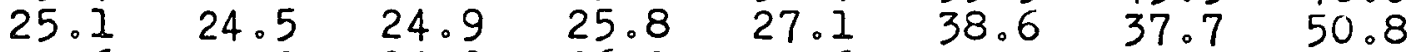

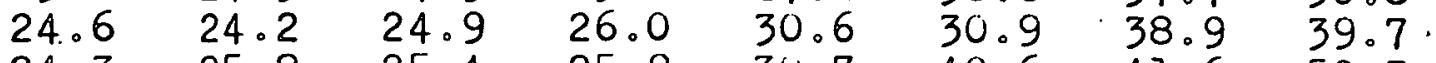

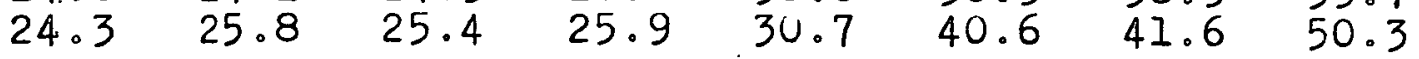

Run number $2 \quad \mathrm{i}_{\mathrm{O}}=22.2 \quad \mathrm{~T}_{\mathrm{W}}=101.1$

$\begin{array}{llllll}25.3 & 25.9 & 41.1 & 38.5 & 35.3 & 42.4\end{array}$

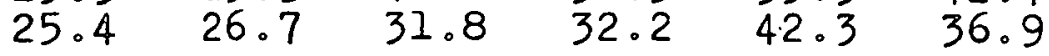

$\begin{array}{llllllll}26.6 & 27.4 & 27.7 & 26.2 & 34.5 & 39.1 & 51.5 & 51.2\end{array}$

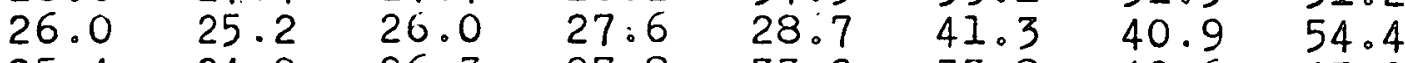

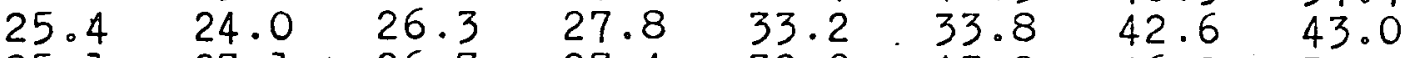

$\begin{array}{lllllll}25.1 & 27.1 \cdot 26.7 & 27.4 & 32.9 & 43.2 & 46.2 & 52.2\end{array}$

Run number $3 \quad I_{O}=22.3 \quad I_{W}=101.4$

$25.6 \quad 26.3 \cdot 41.9 \quad 38.5 \quad 37.2 \quad 43.7$

$\begin{array}{llllll}25.7 & 27.2 & 33.3 & 34.1 & 43.7 & 38.3\end{array}$

$\begin{array}{llllllll}27.5 & 28.3 & 28.7 & 27.2 & 36.3 & 41.9 & 52.7 & 54.9\end{array}$

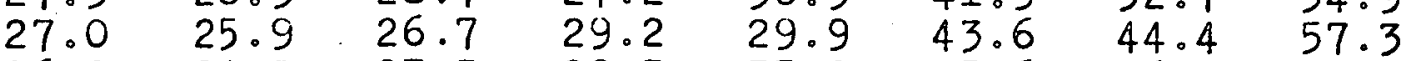

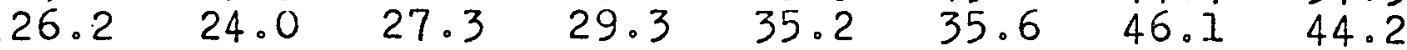

$\begin{array}{llllllll}26.1 & 28.2 & 27.7 & 28.7 & 34.6 & 45.0 & 50.3 & 53.7\end{array}$

Run number $4 \quad \mathrm{r}_{\mathrm{O}}=22.0 \quad \mathrm{~T}_{\mathrm{W}}=101.5$

$\begin{array}{llllll}26.0 & 26.9 & 42.9 & 39.6 & 39.1 & 45.0\end{array}$

$26.1 \quad 28.2 \quad 35.6 \quad 36.5 \quad 45.0 \quad 39.7$

$\begin{array}{llllllll}29.0 & 29.6 & 30.4 & 28.9 & 38.5 & 46.4 & 53.6 & 59.3\end{array}$

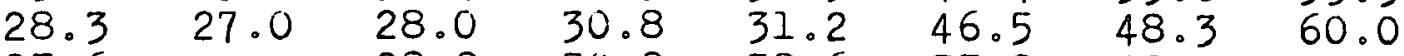

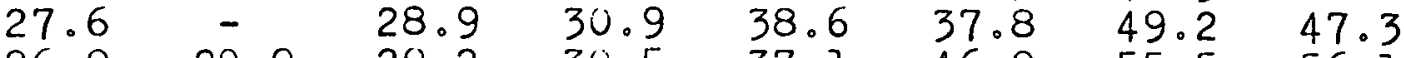

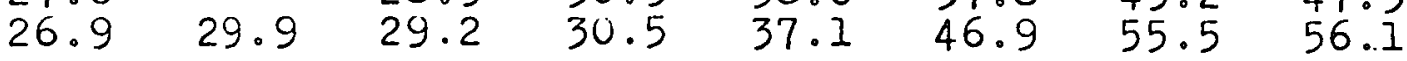

Run number $5 \quad{ }^{\prime}{ }^{\prime}{ }_{U}=22.0 \quad T_{W}=101.1$

$\begin{array}{llllll}26.7 & 27.6 & 43.4 & 40.8 & 40.2 & 45.9\end{array}$

$\begin{array}{llllll}26.7 & 29.4 & 37.1 & 37.8 & 45.9 & 40.5\end{array}$

$\begin{array}{llllllll}30.8 & 31.2 & 31.8 & 30.6 & 41.1 & 49.8 & 56.4 & 62.5\end{array}$

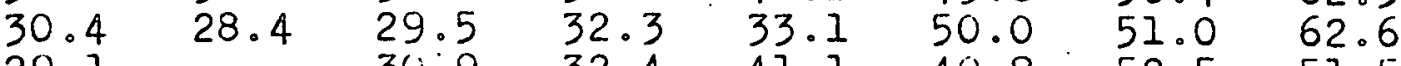

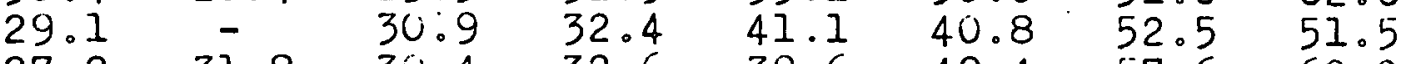

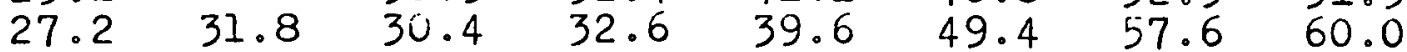


Run number 6

$$
\mathrm{T}_{0}=21.7 \quad \mathrm{~T}_{\mathrm{w}}=101.1
$$

$\begin{array}{llllll}28.3 & 30.0 & 45.3 & 43.0 & 43.5 & 47.6\end{array}$

$28.2 \quad 32.5 \quad 40.7 \quad 41.2 \quad 49.4 \quad 44.1$

$\begin{array}{llllllll}35.1 & 37.0 & 36.4 & 35.3 & 47.9 & 58.1 & 65.4 & 69.3\end{array}$ $\begin{array}{llllllll}34.4 & 32.5 & 34.7 & 37.1 & 38.3 & 54.7 & 52.9 & 68.4\end{array}$

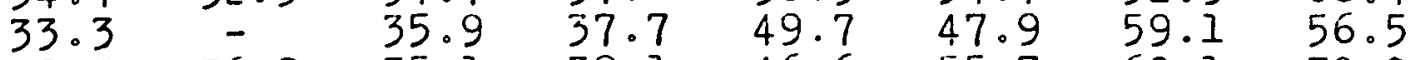
$\begin{array}{llllllll}29.4 & 36.8 & 35.1 & 38.1 & 46.6 & 55.7 & 62.1 & 70.0\end{array}$

Run number $7 \quad \mathrm{I}_{\mathrm{O}}=21.6 \quad \mathrm{~T}_{\mathrm{w}}=101.2$

$\begin{array}{llllll}32.1 & 34.7 & 47.9 & 46.6 & 46.6 & 50.9\end{array}$

$\begin{array}{llllll}31.8 & 37.7 & 44.1 & 44.3 & 54.3 & 47.1\end{array}$

$\begin{array}{llllllll}41.3 & 43.7 & 43.8 & 42.9 & 55.7 & 66.7 & 72.9 & 76.6\end{array}$

$\begin{array}{llllllll}40.7 & 38.8 & 42.9 & 44.6 & 46.2 & 61.9 & 62.0 & 75.9 \\ 39.1 & - & 43.3 & 46.0 & 56.7 & 57.2 & 68.6 & 65.7\end{array}$ $\begin{array}{llllllll}30.3 & 44.4 & 41.9 & 46.0 & 53.4 & 64.9 & 68.8 & 76.4\end{array}$

Run number 8

$$
\mathrm{T}_{\mathrm{O}}=20.1 \quad \mathrm{~T}_{\mathrm{W}}=102.1
$$

$\begin{array}{llllll}22.6 & 22.9 & 37.8 & 33.6 & 29.4 & 34.8\end{array}$

$22.7 \quad 23.3 \quad 26.9 \cdot 26.9 \cdot 37.9 \quad 33.8$

$\begin{array}{llllllll}25.9 & 26.2 & 27.9 & 30.2 & 37.7 & 54.2 & 53.8 & 73.5\end{array}$

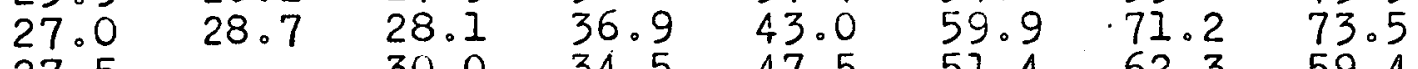

$\begin{array}{llllllll}27.5 & \overline{1} & 30.0 & 34.5 & 47.5 & 51.4 & 62.3 & 59.4 \\ 26.5 & 27.2 & 26.4 & 31.2 & 44.5 & 52.8 & 59.5 & 61.0\end{array}$

Run number $9 \quad \mathrm{i}_{\mathrm{O}}^{\mathrm{i}}=20.0 \quad \mathrm{I}_{\mathrm{w}}=101.5$

$\begin{array}{llllll}23.1 & 23.6 & 39.7 & 36.2 & 32.1 & 37.7\end{array}$

$\begin{array}{llllll}23.2 & 24.1 & 28.8 & 29.0 & 41.4 & 35.7\end{array}$

$\begin{array}{llllllll}28.3 & 28.7 & 30.8 & 33.2 & 42.3 & 58.0 & 58.5 & 76.4\end{array}$

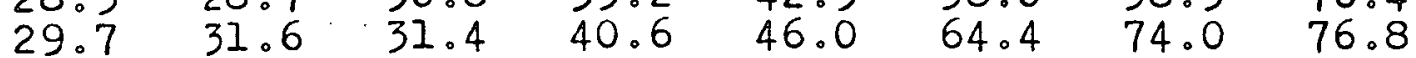

$\begin{array}{llllllll}30.4 & \overline{1} & 32.7 & 38.2 & 51.5 & 55.5 & 65.0 & 63.1 \\ 29.2 & 29.8 & 29.2 & 33.8 & 47.8 & 57.5 & 62.7 & 64.5\end{array}$

Run number $\quad 10 \quad 1_{0}^{1}=19.9 \quad T^{1}=101.4$

$\begin{array}{llllll}23.4 & 24.1 & 41.1 & 37.7 & 34.4 & 39.4\end{array}$

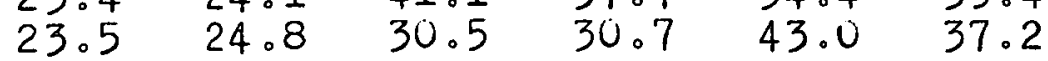

$\begin{array}{llllllll}30.4 & 31.0 & 33.1 & 35.9 & 45.2 & 64.3 & 62.8 & 78.7 .\end{array}$

$\begin{array}{llllllll}32.0 & 34.4 & 34.7 & 44.0 & 48.1 & 66.8 & 76.3 & 78.7\end{array}$

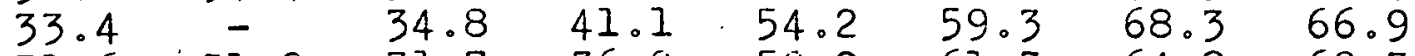

$\begin{array}{llllllll}31.6 & 31.9 & 31.7 & 36.0 & 50.2 & 61.3 & 64.8 & 69.3\end{array}$ 
Run number $11 \quad \mathrm{~T}_{0}=19.8 \quad \mathrm{~T}_{\mathrm{w}}=101.5$

$\begin{array}{llllll}23.9 & 24.5 & 42.3 & 39.5 & 37.2 & 41.3\end{array}$

$23.8 \quad 25.4 \cdot 32.2 \quad 32.8 \quad 44.3 \quad 38.5$

$\begin{array}{llllllll}33.5 & 33.9 & 36.2 & 38.9 & 49.2 & 68.9 & 67.5 & 81.2\end{array}$

$\begin{array}{llllllll}35.5 & 37.7 & 37.3 & 46.4 & 51.6 & 69.7 & 78.8 & 80.5\end{array}$

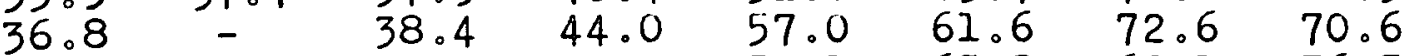

$\begin{array}{llllllll}34.6 & 35.0 & 34.7 & 39.7 & .54 .1 & 65.8 & 69.1 & 76.5\end{array}$

Run number $12 \quad \mathrm{~T}_{0}=19.8 \quad \mathrm{~T}_{\mathrm{W}}=101.4$

$24.9 \quad 25.7 \quad 43.9 \quad 41.4 \quad 40.1 \quad 43.3$

$\begin{array}{llllll}24.7 & 27.4 & 35.4 & 36.2 & 46.3 & 40.9\end{array}$

$\begin{array}{llllllll}38.9 & 40.1 & 41.9 & 45.2 & 54.9 & 74.6 & 73.6 & 81.9\end{array}$

$\begin{array}{llllllll}42.0 & 43.6 & 43.4 & 53.9 & 56.9 & 75.5 & 81.7 & 82.6\end{array}$

$\begin{array}{llllllll}42.7 & - & 45.1 & 49.6 & 62.3 & 67.4 & 77.4 & 75.3\end{array}$

$\begin{array}{llllllll}40.1 & 39.4 & 39.1 & 45.0 & 59.7 & .72 .1 & 73.7 & 81.2\end{array}$

Run number $13 \quad \mathrm{i}_{0}=19.7 \quad \mathrm{~T}_{\mathrm{W}}=101.3$

$\begin{array}{llllll}25.8 & 27.0 & 44.9 & 42.6 & 42.0 & 44.8\end{array}$

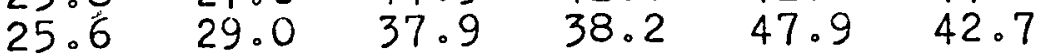

$\begin{array}{llllllll}44.1 & 45.6 & 46.1 & 51.1 & 59.3 & 76.2 & 77.8 & 82.6\end{array}$ $\begin{array}{llllllll}47.8 & 47.8 & 48.4 & 57.7 & 62.2 & 78.4 & 83.8 & 85.4\end{array}$ $\begin{array}{llllllll}47.6 & - & 49.9 & 55.0 & 65.5 & 70.0 & 78.9 & 78.0 \\ 44.7 .44 .5 & 44.6 & 49.7 & 64.1 & 74.2 & 77.2 & 82.7\end{array}$

Run number $14 \quad 1_{0}^{\prime}=19.6 \quad T^{1}=101.3$

$\begin{array}{llllll}29.2 & 31.2 & 47.1 & 45.6 & 45.3 & 48.5\end{array}$

$28.7 \quad 34.2 \quad 42.4 \quad 42.4 \quad 52.2 \quad 46.1$

$\begin{array}{llllllll}57.9 & 60.6 & 59.9 & 65.6 & 72.2 & 82.7 & 84.8 & 88.8\end{array}$

$\begin{array}{llllllll}60.9 & 62.0 & 62.6 & 69.1 & 73.0 & 85.2 & 89.4 & 90.4\end{array}$

$60.8:-\begin{array}{lllllll}63.5 & 69.6 & 75.9 & 80.4 & 85.7 & 86.0\end{array}$

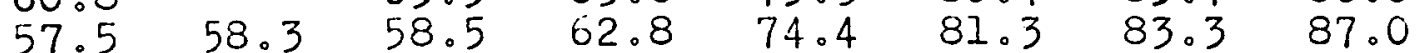

Run number $15 \quad \mathrm{i}_{\mathrm{O}}^{\prime}=26.9 \quad \mathrm{~T}_{\mathrm{w}}=102.7$

$\begin{array}{llllll}28.8 & 29.6 & 51.3 & 48.6 & 40.3 & 44.4\end{array}$

$\begin{array}{llllll}28.8 & 29.9 & 38.1 & 34.8 & 40.8 & 40.1\end{array}$

$\begin{array}{llllllll}40.3 & 41.6 & 43.6 & 45.6 & 62.2 & 71.1 & 85.2 & 82.2\end{array}$

$\begin{array}{llllllll}40.9 & 41.3 & 45.4 & 46.7 & 59.8 & 68.7 & 75.6 & 78.3\end{array}$

$\begin{array}{llllllll}41.5 & 43.3 & 44.3 & 52.3 & 59.0 & 75.6 & .73 .3 & 80.8\end{array}$

$\begin{array}{llllllll}41.7 & 41.4 & 41.4 & 48.2 & 59.8 & 73.8 & 79.2 & 81.2\end{array}$ 
Run number . $16 \quad T_{0}=27.0 \quad T_{w}=103.0$

$\begin{array}{llllll}29.6 & 31.0 & 53.7 & 50.4 & 42.4 & 46.1\end{array}$

$29.8 \quad 31.5 \cdot 40.6 \quad 37.2 \quad 42.9 \quad 42.8$

$\begin{array}{llllllll}45.7 & 46.8 & 48.5 & 50.4 & 67.3 & 74.0 & 87.8 & 84.8\end{array}$

$\begin{array}{llllllll}45.5 & 46.2 & 49.6 & 51.8 & 63.7 & 72.8 & 78.5 & 80.8\end{array}$

$\begin{array}{llllllll}46.2 & 48.1 & 49.2 & 57.7 & 64.9 & 78.1 & 76.8 & 83.8\end{array}$

$\begin{array}{llllllll}46.3 & 46.0 & 45.5 & 53.4 & 63.9 & 77.5 & 83.3 & 84.5\end{array}$

Run number $\quad 17 \quad \mathrm{~T}_{0}=27.2 \quad \mathrm{~T}_{\mathrm{w}}=103.0$

$\begin{array}{llllll}30.5 & 31.9 & 54.8 & 51.8 & 43.7 & 47.4\end{array}$

$\begin{array}{llllll}30.5 & 32.7 & 41.8 & 38.9 & 44.2 & 44.8\end{array}$

$\begin{array}{lllllll}49.0: 50.0 & 52.0 & 53.6 & 68.4 & 77.4 & 89.7 & 86.7\end{array}$

$\begin{array}{llllllll}48.4 & 49.4 & 52.6 & 55.5 & 65.8 & 76.1 & 80.4 & 83.2\end{array}$

$\begin{array}{llllllll}49.0 & 51.3 & 52.2 & 61.3 & 68.3 & 79.9 & 78.8 & 85.8\end{array}$

$\begin{array}{llllllll}49.3 & 49.2 & 48.5 & 56.8 & 67.4 & 79.8 & 86.2 & 86.6\end{array}$

Run number $18 \quad \mathrm{~T}_{0}=27.4 \quad \mathrm{~T}_{\mathrm{W}}=102.3$

$\begin{array}{llllll}31.2 & 33.1 & 55.9 & 53.2 & 44.7 & 49.0\end{array}$

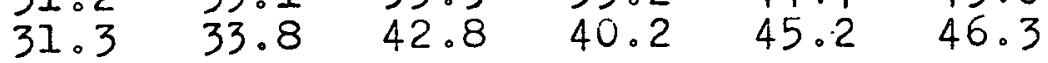

$\begin{array}{llllllll}53.3 & 54.0 & 57.0 & 57.9 & 71.4 & 80.7 & 90.7 & 88.0\end{array}$

$\begin{array}{llllllll}52.9 & 53.7 & 56.3 & 59.4 & 68.8 & 78.5 & 82.1 & 85.7\end{array}$

$\begin{array}{llllllll}53.7 & 55.4 & 56.3 & 65.3 & 71.3 & 82.7 & 79.0 & 87.8\end{array}$

$\begin{array}{llllllll}53.6 & 53.6 & 52.6 & 59.9 & 69.6 & 81.6 & 87.8 & 87.9\end{array}$

Run number 19

$i_{0}=26.1 \quad T_{W}=102.7$

$\begin{array}{llllll}31.5 & 34.1 & 57.2 & 55.5 & 46.0 & 52.7\end{array}$

$\begin{array}{llllll}31.6 & 34.7 & 44.4 & 42.4 & 46.9 & 48.8\end{array}$

$\begin{array}{llllllll}61.0 & 62.0 & 65.3 & 67.7 & 77.8 & 84.7 & 90.2 & 91.2\end{array}$

$\begin{array}{llllllll}60.4 & 61.2 & 63.9 & 60.2 & 72.2 & 83.1 & 86.4 & 89.0 \\ 61.5 & 63.4 & 64.1 & 73.3 & 77.5 & 85.8 & 84.6 & 91.2\end{array}$

$\begin{array}{llllllll}61.5 & 63.4 & 64.1 & 73.3 & 77.5 & 85.8 & 84.6 & 91.2 \\ 62.1 & 61.8 & 62.0 & 65.6 & 77.6 & 83.8 & 90.5 & 92.0\end{array}$

Run number $20 \quad \mathrm{~T}_{0}=25.9 \quad \mathrm{r}_{\mathrm{w}}=102.9$

$\begin{array}{lllllll}34.1 & 37.1 & 60.1 & 58.1 & 48.3 & 56.2\end{array}$

$\begin{array}{llllll}34.4 & 37.8 & 46.3 & 44.3 \cdot & 49.4 & 50.9\end{array}$

$\begin{array}{llllllll}70.5 & 71.7 & 73.9 & 76.0 & 83.1 & 38.7 & 94.4 & 94.6\end{array}$

$\begin{array}{llllllll}70.0 & 70.5 & 72.6 & 74.3 & 79.0 & 88.1 & 90.7 & 92.9\end{array}$

$\begin{array}{llllllll}70.9 & 72.3 & 73.0 & 79.7 & 83.7 & 89.1 & 88.3 & 93.7\end{array}$

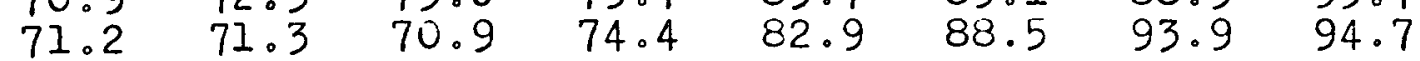


Run number $21 \quad T_{0}=24.4 \quad T_{W}=103.0$

$\begin{array}{llllll}37.5 & 40.3 & 62.3 & 60.9 & 51.8 & 59.7\end{array}$

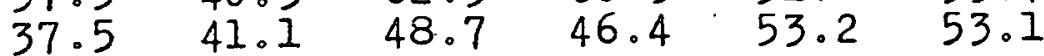

$\begin{array}{llllllll}80.8 & 82.3 & 83.2 & 84.6 & 89.0 & 94.0 & 97.6 & 97.6\end{array}$ $\begin{array}{llllllll}80.8 & 80.8 & 82.3 & 83.3 & 86.8 & 93.0 & 94.7 & 96.8 \\ 81.0 & 82.0 & 82.8 & 86.4 & 89.8 & 93.0 & 93.6 & 96.5\end{array}$ $\begin{array}{llllllll}80.9 & 81.3 & 80.7 & 83.0 & 88.9 & 93.6 & 97.1 & 97.8\end{array}$

Run number 22

$$
\mathrm{T}_{\mathrm{O}}=26.7 . \quad \mathrm{w}_{\mathrm{w}}=102.9
$$

$\begin{array}{llllll}29.2 & 30.2 & 50.9 & 49.1 & 40.4 & 45.0\end{array}$

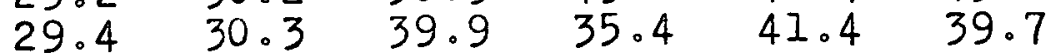

$\begin{array}{llllllll}53.6 & 56.8 & 58.2 & 60.9 & 67.3 & 76.4 & 77.9 & 83.9\end{array}$

$\begin{array}{llllllll}55.7 & 52.5 & 58.0 & 56.5 & 71.2 & 72.0 & 78.6 & 79.5 \\ 47.9 & 54.0 & 55.1 & 64.3 & 71.5 & 77.8 & 79.0 & 86.0\end{array}$

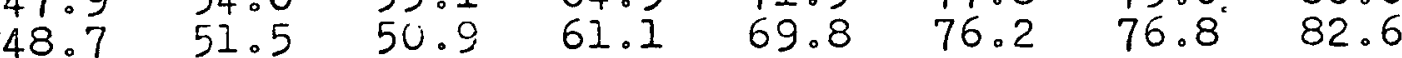

Run number $\quad 23 \quad \mathrm{~T}_{\mathrm{O}}=26.9 \quad \mathrm{~T}_{\mathrm{w}}=103.0$

$\begin{array}{llllll}29.5 & 30.9 & 53.6 & 50.8 & 42.4 & 46.6\end{array}$

$29.8 \quad 31.2 \quad 41.7 \quad 37.4 \quad 43.2 \quad 42.9$

$\begin{array}{llllllll}59.6 & 61.3 & 64.4 & 65.4 & 71.7 & 80.8 & 83.1 & 86.2\end{array}$

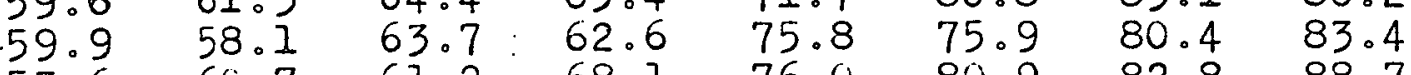

$\begin{array}{llllllll}53.6 & 60.7 & 61.2 & 68.1 & 76.0 & 80.9 & 82.8 & 88.7\end{array}$

$\begin{array}{llllllll}54.2 & 57.0 & 56.5 & 66.8 & 72.3 & 80.0 & 80.8 & 87.0\end{array}$

Run number $24 \quad \mathrm{~T}_{\mathrm{O}}=27.1 \quad \mathrm{~T}_{\mathrm{W}}=102.6$

$\begin{array}{llllll}30.2 & 32.1 & 54.9 & 52.0 & 43.5 & 47.9\end{array}$

$\begin{array}{llllll}30.5 & 32.2 & 42.7 & 39.0 & 44.3 & 44.9\end{array}$

$\begin{array}{llllllll}62.9 & 64.6 & 67.3 & 68.5 & 74.0 & 83.5 & 85.9 & 88.0\end{array}$

$\begin{array}{llllllll}62.7 & 61.4 & 66.8 & 65.2 & 78.0 & 77.9 & 81.8 & 85.2\end{array}$

$\begin{array}{llllllll}57.1 & 64.3 & 65.8 & 70.7 & 78.4 & 82.7 & 85.6 & 90.6\end{array}$

$\begin{array}{llllllll}57.8 & 60.4 & 59.9 & 70.0 & 75.5 & 81.9 & 83.4 & 88.8\end{array}$

Run number $\cdot 25$

$\mathrm{T}_{0}=27.1 \quad \mathrm{~T}_{\mathrm{w}}=102.3$

$\begin{array}{llllll}31.0 & 33.3 & 56.2 & 53.7 & 44.6 & 50.0\end{array}$

$\begin{array}{llllll}31.3 & 33.6 & 43.6 & 40.5 & 45.4 & 46.8\end{array}$

$\begin{array}{llllllll}70.8 & 69.5 & 71.7 & 72.9 & 77.7 & 86.5 & 88.7 & 90.7\end{array}$

$\begin{array}{llllllll}67.3 & 66.3 & 71.4 & 69.7 & 80.5 & 80.8 & 84.2 & 86.9\end{array}$

$\begin{array}{llllllll}61.0 & 68.7 & 68.0 & 76.2 & 80.6 & 85.8 & 89.6 & 92.5\end{array}$

$\begin{array}{llllllll}62.3 & 65.1 & 63.9 & 75.0 & 73.3 & 84.6 & 86.8 & 89.1\end{array}$ 
Run number $26 \quad \mathrm{~T}_{0}=25.5 \quad \mathrm{~T}_{\mathrm{w}}=102.9$

$\begin{array}{lllllll}32.4 & 35.0 & 58.0 & 55.7 & 46.0 & 52.8\end{array}$

$\begin{array}{llllll}32.7 & 35.3 & 45.0 & 42.4 & 46.9 & 48.9\end{array}$

$\begin{array}{llllllll}74.1 & 75.0 & 77.4 & 78.3 & 82.1 & 88.5 & 91.0 & 92.6\end{array}$

$\begin{array}{llllllll}74.0 & 72.9 & 76.0 & 76.4 & 85.5 & 87.0 & 88.1 & 90.8\end{array}$

$\begin{array}{llllllll}67.6 & 74.0 & 73.1 & 80.4 & 85.0 & 88.5 & 89.9 & 94.7\end{array}$

$\begin{array}{llllllll}69.8 & 73.4 & 70.6 & 79.8 & 81.4 & 88.1 & 89.8 & 91.5\end{array}$

Run number $27 \quad \mathrm{i}_{0}=25.8: \mathrm{q}_{\mathrm{w}}=102.9$

$\begin{array}{llllll}33.9 & 36.8 & 59.4 & 57.6 & 47.6 & 55.3 \\ 34.2 & 37.4 & 46.3 & 43.8 & 48.6 & 50.5\end{array}$

$\begin{array}{llllllll}80.6 & 81.5 & 83.0 & 84.2 & 87.0 & .91 .6 & 94.0 & 95.0\end{array}$

$\begin{array}{llllllll}80.4 & 79.4 & 81.9 & 82.3 & 89.6 & 90.2 & 92.2 & 94.7\end{array}$

$\begin{array}{llllllll}76.1 & 80.7 & 80.4 & 85.3 & 89.4 & 92.1 & 93.0 & 96.9 \\ 77.3 & 80.0 & 78.4 & 84.4 & 89.0 & 91.5 & 93.3 & 94.6\end{array}$

Run number $28 \quad T_{0}=23.9 \quad T_{\mathrm{w}}=102.1$

$\begin{array}{llllll}35.4 & 38.9 & 55.2 & 59.5 & 51.0 & 59.1\end{array}$

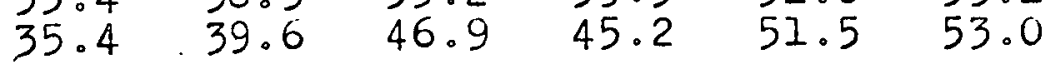

$\begin{array}{llllllll}90.6 & 91.0 & 91.0 & 92.8 & 94.0 & 96.9 & 98.7 & 98.9\end{array}$

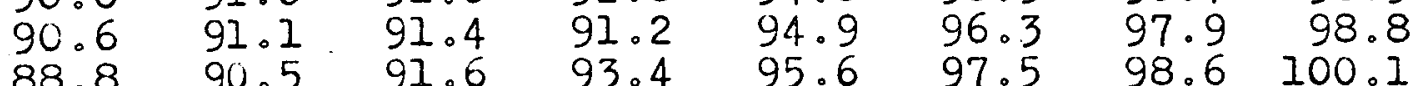

$\begin{array}{rrrrrrrr}88.8 & 90.5 & 91.6 & 93.4 & 95.6 & 97.5 & 98.6 & 100.1 \\ 89.2 & 90.7 & 91.3 & 92.2 & 95.9 & 97.3 & 97.9 & 99.8\end{array}$

Run number $29 \quad 1_{0}^{\prime}=24.6 \quad I^{\prime}=102.0$

$\begin{array}{llllll}27.5 & 28.6 & 47.0 & 48.3 & 39.5 & 44.6\end{array}$

$\begin{array}{llllll}27.8 & 28.7 & 37.4 & 34.1 & 40.4 & 39.3\end{array}$

$\begin{array}{llllllll}59.9 & 63.0 & 62.7 & 65.4 & 74.2 & 79.4 & 88.4 & 85.3\end{array}$

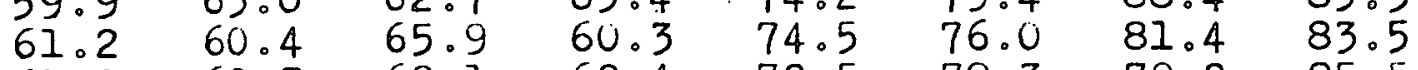

$\begin{array}{llllllll}61.2 & 62.3 & 62.1 & 62.4 & 72.5 & 78.3 & 79.2 & 85.5 \\ 59.5 & 60.2 & 61.1 & 67.3 & 72.0 & 82.0 & 81.0 & 88.6\end{array}$

Run number: $30 \quad \mathrm{I}_{\mathrm{O}}=24.5 \quad \mathrm{Ii}_{\mathrm{w}}=101.8$

$\begin{array}{llllll}27.9 & 29.2 & 47.6 & 49.6 & 41.4 & 46.0\end{array}$

$28.2 \quad 29.6 \quad 39.4 \quad 35.9 \quad 42.1 \quad 41.9$

$\begin{array}{llllllll}65.9 & 68.2 & 67.4 & 70.8 & 78.2 & 82.4 & 90.2 & 87.1\end{array}$

$\begin{array}{llllllll}66.0 & 66.5 & 69.9 & 65.5 & 78.2 & 80.2 & 83.0 & 87.2\end{array}$

$\begin{array}{llllllll}67.4 & 66.9 & 67.3 & 67.6 & 75.5 & 80.9 & 80.8 & 87.4\end{array}$

$\begin{array}{llllllll}64.5 & 64.9 & 65.9 & 71.6 & 75.2 & 84.4 & 82.9 & 90.4\end{array}$ 
Run number $31 \quad \mathrm{I}_{0}=24.4 \quad \mathrm{~T}_{\mathrm{W}}=101.7$

$\begin{array}{llllll}28.1 & 29.9 & 47.8 & 50.7 & 42.4 & 47.2\end{array}$

$\begin{array}{llllll}28.4 & 30.0 & 40.3 & 36.9 & 43.1 & 43.8\end{array}$

$\begin{array}{llllllll}69.5 & 71.0 & 71.1 & 74.2 & 80.4 & 84.9 & 91.0 & 89.0\end{array}$

$\begin{array}{llllllll}69.5 & 70.9 & 73.8 & 68.8 & 81.4 & 82.4 & 84.9 & 89.7\end{array}$

$\begin{array}{llllllll}71.3 & 70.2 & 71.1 & 71.3 & 77.7 & 82.8 & 82.4 & 88.9\end{array}$

$\begin{array}{llllllll}67.8 & 68.5 & 69.4 & 74.7 & 77.8 & 86.0 & 84.6 & 91.8\end{array}$

Run number 32

$$
T_{0}=24.2 \quad T_{W}=102.3
$$

$\begin{array}{llllll}.28 .6 & 30.5 & 48.0 & 51.9 & 43.7 & 48.8\end{array}$

$\begin{array}{llllll}28.8 & 31.0 & 41.4 & 38.5 & 44.1 & 45.6\end{array}$

$\begin{array}{llllllll}74.7 & 74.2 & 78.7 & .77 .7 & 82.7 & 86.7 & 93.2 & 91.6\end{array}$

$\begin{array}{llllllll}74.0 & 74.0 & 77.4 & 73.5 & 85.1 & 87.7 & 87.1 & 91.0\end{array}$

$\begin{array}{llllllll}74.8 & 74.3 & 75.3 & 74.2 & 80.9 & 84.5 & 84.7 & 90.4\end{array}$

$\begin{array}{llllllll}72.0 & 74.3 & 74.0 & 78.7 & 80.9 & 87.5 & 87.5 & 93.0\end{array}$

Run number 33

$$
\mathrm{T}_{0}^{\prime}=23.3 \quad \mathrm{~T}_{\mathrm{w}}=102.2
$$

$\begin{array}{llllll}27.9 & 30.5 & 47.3 & 52.7 & 44.8 & 50.9\end{array}$

$27.9 \quad 30.9 \quad 42.0 \quad 39.7 \quad 45.5 \quad 47.8$

$\begin{array}{llllllll}84.6 & 82.4 & 87.3 & 84.4 & 86.5 & 89.2 & 95.5 & 93.9\end{array}$

$\begin{array}{llllllll}81.7 & 82.9 & 82.4 & 82.6 & 91.2 & 91.4 & 92.7 & 96.1\end{array}$

$\begin{array}{llllllll}84.3 & 83.9 & 84.8 & 84.7 & 88.5 & 91.6 & 91.5 & 95.4\end{array}$

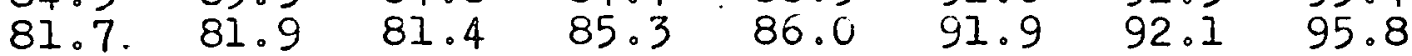

Run number $34 . \mathrm{T}_{0}=23.5 \quad \mathrm{~T}_{w}=102.0$

$\begin{array}{llllll}29.8 & 32.7 & 48.8 & 54.7 & 46.3 & 53.5\end{array}$

$29.9 \quad 33.3 \quad 43.5 \quad 41.4 \quad 46.7 \quad 49.3$

$\begin{array}{llllllll}89.9 & 88.1 & 91.9 \cdot 89.9 & 91.0 & 93.9 & 97.8 & 96.9\end{array}$

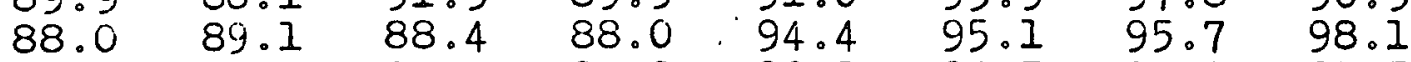

$\begin{array}{llllllll}90.3 & 90.5 & 90.3 & 90.0 & 92.3 & 94.7 & 94.7 & 97.5\end{array}$

$\begin{array}{llllllll}88.4 & 87.7 & 88.3 & 96.5 & 91.0 & 96.1 & 95.0 & 97.9\end{array}$

Run number $\quad 35$

$$
\mathrm{I}_{0}=23.3 \quad \mathrm{i}_{\mathrm{w}}=102.3
$$

$\begin{array}{lllllll}35.0 & 38.5 & 52.7 & 59.2 & 50.9 & 59.2\end{array}$

$\begin{array}{llllll}35.0 & 39.1 & 46.7 & 45.0 & 51.5 & 52.7\end{array}$

$\begin{array}{llllllll}96.0 & 95.7 & 97.2 & 96.6 & 97.3 & 100.0 & 101.1 & 100.8\end{array}$

$\begin{array}{llllllll}95.8 & 96.5 & 96.4 & \text { Y5.7 } & 98.2 & 99.6 & 100.4 & 101.2\end{array}$

$\begin{array}{llllllll}96.7 & 96.9 & 96.6 & 96.8 & 97.9 & 99.8 & 98.9 & 101.1\end{array}$

$\begin{array}{llllllll}96.4 & 95.4 & 96.4 & 96.9 & 97.5 & 100.0 & 99.5 & 101.3\end{array}$ 
Run number $36 \quad \mathrm{r}_{0}=23.4 \quad \mathrm{r}_{\mathrm{w}}=103.0$

$\begin{array}{llllll}27.8 & 29.6 & 44.6 \quad- & 44.9 & 48.3\end{array}$

$27.4 \quad 31.2 \quad 41.4 \quad 38.6 \quad 45.6 \quad 45.4$

$\begin{array}{llllllll}30.8 & 31.9 & 34.4 & 33.5 & 43.1 & 53.0 & 61.0 & 73.0\end{array}$

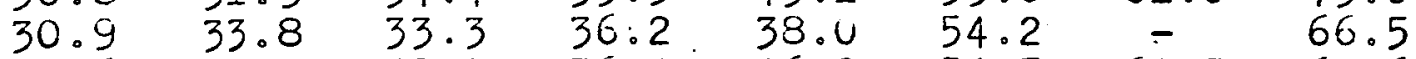

$\begin{array}{llllllll}25.6 & 32.5 & 32.0 & 36.4 & 46.2 & 54.7 & 60.5 & 62.6\end{array}$

$\begin{array}{llllllll}32.1 & 32.5 & 33.2 & 38.8 & 44.4 & 59.6 & 64.4 & 70.7\end{array}$

Run number .37

$$
\mathrm{T}_{0}=23.7 \quad \mathrm{~T}_{\mathrm{w}}=103.2
$$

$29.0 \quad 30.7 \quad 43.5 \quad-\quad 45.4 \quad 48.9$

$28.6 \quad 32.4 \cdot 42.3 \quad 39.5 \quad 46.1 \quad 43.9$

$\begin{array}{llllllll}44.1 & 45.6 & \cdot 51.0 & 50.7 & 62.2 & 72.0 & 77.5 & 73.8\end{array}$

$\begin{array}{llllllll}40.2 & 45.4 & 49.0 & 49.3 & 62.8 & 63.9 & 78.0 & 87.0\end{array}$

$\begin{array}{llllllll}41.2 & 48.5 & 41.2 & 53.7 & 56.2 & 66.7 & 71.7 & 84.5\end{array}$

$\begin{array}{llllllll}50.4 & 41.7 & 47.3 & 49.0 & .62 .1 & 72.3 & 70.0 & 78.2\end{array}$

Run number $38 \quad \mathrm{~T}_{\mathrm{O}}=23.7 \quad \mathrm{~T}_{\mathrm{W}}=102.3$

$\begin{array}{llllll}29.5 & 31.3 & 43.9 & - & 45.5 & 48.4 \\ 29.0 & 33.0 & 42.5 & 39.6 & 46.3 & 44.1\end{array}$

$\begin{array}{llllllll}56.1 & 57.6 & 57.0 & 61.6 & 72.9 & 81.2 & 84.3 & 85.9\end{array}$

$\begin{array}{llllllll}54.3 & 57.3 & 58.6 & 61.7 & 75.2 & 79.2 & 85.5 & 84.4\end{array}$

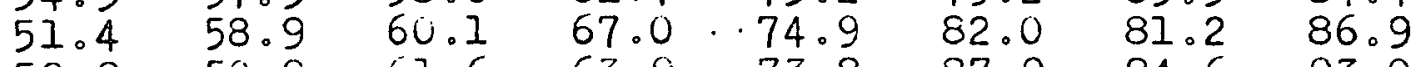

$\begin{array}{llllllll}59.9 & 59.9 & 61.6 & .63 .9 & 73.8 & 87.9 & 84.6 & 93.0\end{array}$

Run number $\quad 39 \quad \mathrm{~T}_{0}=23.9 \quad \mathrm{~T}_{\mathrm{w}}=102.3$

$29.8 \cdot 31.06 \quad 42.4 \quad-\quad 45.6 \quad 48.5$

$29.2 \quad 33.3 \quad 43.1 \quad 39.7 \quad 46.3 \quad 44.0$

$\begin{array}{llllllll}73.2 & 71.9 & 75.6 & 78.2 & 81.7 & 89.7 & 95.7 & 93.4\end{array}$

$\begin{array}{llllllll}71.1 & 74.8 & 72.1 & 76.0 & 80.1 & 87.3 & 88.5 & 92.4\end{array}$

$\begin{array}{llllllll}71.5 & 72.8 & 75.7 & 75.9 & 81.7 & 87.6 & 85.4 & 92.8\end{array}$

$\begin{array}{llllllll}71.3 & 75.6 & 72.2 & 74.4 & 83.7 & 84.8 & 92.0 & 92.4\end{array}$

Run number $40 \quad T_{0}=23.9 \quad \mathrm{~T}_{\mathrm{w}}=101.6$

$\begin{array}{llllll}29.9 & 31.5 & 41.7 & - & 45.6 & 48.4\end{array}$

$29.2 \quad 33.3 \quad 43.5 \quad 39.6 \quad 46.3 \quad 44.3$

$\begin{array}{llllllll}79.0 & 81.8 & 81.6 & 83.6 & 87.7 & 93.4 & 97.2 & 97.3\end{array}$

$\begin{array}{llllllll}80.7 & 81.5 & 83.0 & 83.6 & 86.9 & 90.8 & 91.2 & 96.0\end{array}$

$\begin{array}{llllllll}78.0 & 79.7 & 78.1 & 82.3 & 88.3 & 90.7 & 92.6 & 93.6\end{array}$

$\begin{array}{llllllll}80.5 & 80.3 & 81.2 & 83.1 & 85.5 & 92.4 & 91.5 & 95.7\end{array}$ 
Run number 1

$\begin{array}{llllll}26.1 & 26.5 & 42.0 & 32.7 & 32.4 & 37.2\end{array}$

$\begin{array}{llllll}26.1 & 26.9 & 32.0 & 29.1 & 38.5 & 36.3\end{array}$

$\begin{array}{llllll}33.0 & 39.0 & 35.2 & 36.9 & 47.1 & 61.9\end{array}$

$\begin{array}{llllll}34.2 & 32.6 & 36.3 & 38.0 & 46.0 & 52.0\end{array}$

$\begin{array}{llllll}33.0 & - & 33.7 & 36.4 & 44.9 & 45.1\end{array}$

$\begin{array}{llllll}32.6 & 31.5 & 34.8 & 37.5 & 45.1 & 49.9\end{array}$

Run number 2

$26.9 \quad 27.3 \quad 42.9$

$26.927 .8 \quad 33.9$

$35.9 \quad 42.4 \quad 38.2$

$36.4 \quad 35.1 \quad 39.0$

$35.5 \quad-\quad 36.3$

$34.5 \quad 33.5 \quad 37.0$

. Run number 3

$\begin{array}{llllll}29.2 & 31.4 & 44.4 & 37.2 & 39.6 & 43.1\end{array}$

$\begin{array}{llllll}28.8 & 30.3 & 38.0 & 34.2 & 44.2 & 41.4\end{array}$

$\begin{array}{llllllll}44.4 & 51.8 & 47.2 & 47.5 & 61.5 & 70.3 & 75.0 & 79.9 \\ 44.5 & 43.1 & 49.0 & 49.7 & 57.8 & 61.8 & 66.4 & 64.9 \\ 44.4 & - & 45.7 & 49.3 & 58.9 & 54.9 & 69.6 & 77.8 \\ 42.4 & 40.1 & 45.8 & 49.8 & 52.7 & 63.8 & 65.6 & 76.6\end{array}$

Run number 4

$$
\mathrm{i}_{0}^{\prime}=23.9
$$$$
\mathrm{T}_{\mathrm{W}}=101.7
$$

$\begin{array}{llllll}32.4 & 32.6 & 46.4 & 41.2 & 42.6 & 45.4\end{array}$

$\begin{array}{llllll}31.5 & 33.3 & 41.6 & 37.4 & 46.8 & 44.3\end{array}$

$\begin{array}{llllllll}52.0 & 57.7 & 55.7 & 57.3 & 69.3 & 77.3 & 83.0 & 85.9\end{array}$

$\begin{array}{llllllll}51.3 & 51.2 & 52.0 & 56.9 & 64.8 & 69.5 & 73.6 & 74.3\end{array}$

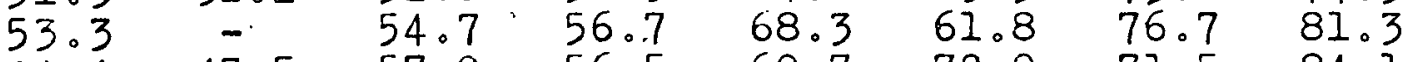

$\begin{array}{llllllll}44.4 & 47.5 & 57.0 & 56.5 & 60.7 & 72.9 & 71.5 & 84.1\end{array}$

Run number 5

$I_{0}=23.8$

$1^{\prime}=101.7$

$41.9 \quad 41.9 \quad 51.4 \quad 47.2 \quad 49.0 \quad 51.9$

$40.6 \quad 41.6 \quad 46.9 \quad 42.8 \quad 54.5 \quad 50.5$

$\begin{array}{llllllll}75.1 & 72.6 & 76.1 & 70.6 & 79.2 & 88.6 & 88.4 & 94.9\end{array}$

$\begin{array}{llllllll}67.6 & 71.9 & 68.0 & 73.8 & 77.2 & 83.6 & 83.8 & 86.9\end{array}$

$\begin{array}{llllllll}70.3 & - & 70.4 & 72.8 & 80.0 & 77.5 & 84.8 & 88.1\end{array}$

$\begin{array}{llllllll}66.0 & 65.0 & 71.8 & 71.2 & 75.1 & 83.7 & 81.5 & 89.9\end{array}$ 
Run number $6 \quad \mathrm{~T}_{0}=24.5 \quad \mathrm{~T}_{\mathrm{w}}^{\mathrm{T}}=101.3$

$\begin{array}{llllll}28.3 & 28.9 & 45.0 & 46.3 & 35.0 & 38.9\end{array}$

$\begin{array}{llllll}28.3 & 29.4 & 34.0 & 31.1 & 41.6 & 37.2\end{array}$

$\begin{array}{llllllll}46.7 & 45.7 & 47.9 & 51.4 & 63.6 & 66.9 & 77.2 & 79.5\end{array}$

$\begin{array}{llllllll}45.5 & 46.6 & 48.2 & 50.5 & 53.4 & 70.2 & 73.4 & 81.6\end{array}$

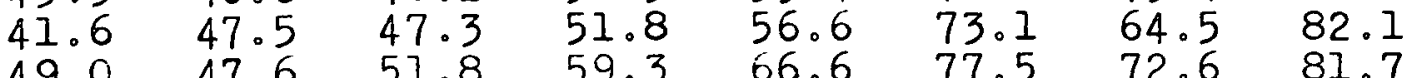

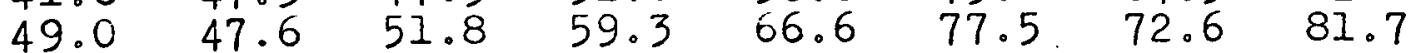

Run number $7 \quad \mathrm{~T}_{0}=24.3 \quad \mathrm{~T}_{\mathrm{W}}=101.5$

$\begin{array}{llllll}28.9 & 29.4 & 45.3 & 47.0 & 36.8 & 40.2\end{array}$

$\begin{array}{llllll}28.8 & 29.8 & 35.5 & 32.3 & 42.9 & 38.8\end{array}$

$\begin{array}{llllllll}52.2 & 51.4 & 53.3 & 56.5 & 67.2 & 71.2 & 80.2 & 82.3\end{array}$

$\begin{array}{llllllll}51.3 & 51.4 & 53.5 & 55.4 & 57.8 & 74.3 & 76.9 & 84.0 \\ 46.4 & 52.8 & 52.3 & 57.1 & 61.6 & 76.0 & 69.1 & 84.1\end{array}$

$\begin{array}{llllllll}53.0 & 53.1 & 55.7 & 64.7 & 71.0 & 81.1 & 75.9 & 84.5\end{array}$

Run number $8 \quad T_{0}=22.6 \quad I_{\mathrm{w}}=103.0$

$\begin{array}{llllll}28.1 & 29.0 & 44.1 & 48.4 & 39.0 & 41.6\end{array}$

$\begin{array}{llllll}27.6 & 29.7 & 36.7 & 33.0 & 44.9 & 42.5\end{array}$

$\begin{array}{llllllll}65.0 & 62.3 & 63.4 & 66.1 & 72.2 & 79.2 & 83.6 & 90.0\end{array}$

$\begin{array}{llllllll}62.8 & 64.9 & 64.3 & 66.3 & 67.6 & 83.5 & 85.3 & 88.9\end{array}$

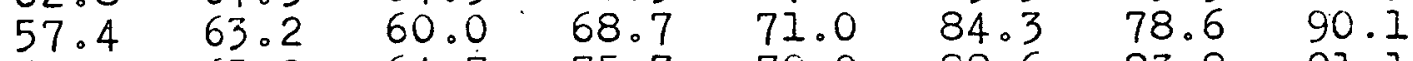

$\begin{array}{llllllll}62.5 & 65.2 & 64.7 & 75.7 & 79.0 & 88.6 & 83.8 & 91.1\end{array}$

Run number $9 \quad T_{0}=22.8 \quad T_{w}=1.03 .0$

$\begin{array}{llllll}33.9 & 35.7 & 47.7 & 53.1 & 44.8 & 45.7\end{array}$

$33.2 \quad 36.4 \quad 42.9 \quad 38.9 \quad 49.6 \quad 46.9$

$\begin{array}{llllllll}79.2 & 77.8 & 78.5 & 81.7 & 83.6 & 87.7 & 92.1 & 94.8\end{array}$

$\begin{array}{llllllll}78.2 & 79.0 & 78.5 & 78.7 & 82.4 & 92.0 & 93.4 & 94.9\end{array}$

$\begin{array}{llllllll}73.1 & 78.3 & 75.9 & 80.6 & 82.5 & 91.1 & 86.6 & 95.6 \\ 76.7 & 79.8 & 78.6 & 83.9 & 88.7 & 95.1 & 91.9 & 96.9\end{array}$

Run number $\quad 10 \quad \mathrm{~T}_{0}=22.8 \quad \mathrm{~T}_{\mathrm{w}}=102.8$

$41.3 \cdot 42.6 \quad 52.1 \quad 58.9 \quad 51.1 \quad 50.6$

$\begin{array}{llllll}40.6 & 42.3 & 46.1 & 43.5 & 55.7 & 51.3\end{array}$

$\begin{array}{llllllll}88.2 & 88.2 & 89.1 & 90.3 & 92.0 & 94.5 & 97.6 & 98.8\end{array}$

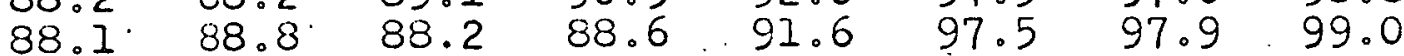

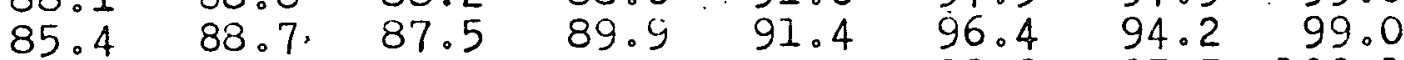

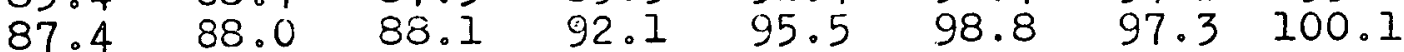


Run number

11

$\mathrm{T}_{0}=24.4$

$\mathrm{I}_{W}=103.6$

$\begin{array}{llllll}27.8 & 28.2 & 41.5 & 46.8 & 34.9 & 38.0\end{array}$

$\begin{array}{llllll}27.7 & 28.9 & 33.8 & 30.9 & 42.0 & 37.6\end{array}$

$\begin{array}{llllllll}59.1 & 58.7 & 63.0 & 67.2 & 77.3 & 78.2 & 82.8 & 86.2\end{array}$

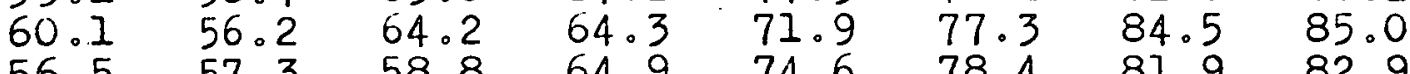

$\begin{array}{llllllll}56.5 & 57.3 & 58.8 & 64.9 & 74.6 & 78.4 & 81.9 & 82.9\end{array}$

$\begin{array}{llllllll}54.8 & 60.9 & 58.7 & 68.0 & 72.1 & 84.7 & 82.0 & 88.4\end{array}$

Run number $12 \quad \mathrm{~T}_{0}=23.8 \quad \mathrm{~T}_{\mathrm{w}}=103.0$

$27.9 \cdot 28.8 \quad 44.5 \quad 47.3 \quad 36.5 \quad 39.0$

$27.8 \cdot 29.4 \quad 34.8 \quad 32.1 \quad 43.1 \quad 39.1$

$\begin{array}{llllllll}66.3 & 65.4 & 69.0 & 70.5 & 78.4 & 81.5 & 86.4 & 88.7\end{array}$

$\begin{array}{llllllll}65.9 & 60.7 & 68.4 & 67.2 & 76.0 & 80.7 & 86.0 & 87.0\end{array}$

$\begin{array}{llllllll}64.3 & 64.2 & 63.5 & 69.2 & 78.7 & 81.4 & 84.2 & 85.8\end{array}$

$\begin{array}{llllllll}61.9 & 64.7 & 65.6 & 74.9 & 75.2 & 86.9 & 85.3 & 90.4\end{array}$

Run number $13 \quad \mathrm{~T}_{\mathrm{O}}=23.8 \quad \mathrm{~T}_{\mathrm{w}}=103.0$

$\begin{array}{llllll}30.2 & 31.1 & 46.2 & 49.6 & 40.4 & 42.6\end{array}$

$29.5 \quad 32.2 \quad 38.5 \quad 35.3 \quad 45.8 \quad 43.2$

$\begin{array}{llllllll}78.6 & 77.6 & 79.4 & 80.7 & 86.2 & 89.8 & 92.3 & 93.8\end{array}$

$\begin{array}{llllllll}78.0 & 73.8 & 78.5 & 78.0 & 83.9 & 88.1 & 92.1 & 91.9\end{array}$

$\begin{array}{llllllll}76.5 & 76.2 & 75.5 & 80.0 & 85.5 & 88.7 & 90.4 & 92.3\end{array}$

$\begin{array}{llllllll}75.7 & 76.9 & 78.6 & 83.3 & 83.6 & 92.5 & 91.3 & 95.6\end{array}$

Run number $14 \quad \mathrm{~T}_{0}=24.0 . \quad \mathrm{T}_{\mathrm{W}}=103.0$

$\begin{array}{llllll}33.8 & 35.1 & 48.0 & 52.6 & 43.5 & 44.9\end{array}$

$\begin{array}{llllll}32.6 & 35.9 & 41.9 & 38.4 & 48.5 & 47.0\end{array}$

$\begin{array}{llllllll}86.7 & 85.8 & 87.4 & 87.9 & 93.2 & 95.1 & 96.9 & 97.2\end{array}$

$\begin{array}{llllllll}86.5 & 82.7 & 86.5 & 86.4 & 90.0 & 92.9 & 96.9 & 95.9\end{array}$

$\begin{array}{llllllll}84.7 & 84.7 & 84.0 & 88.1 & 90.04 & 93.8 & 94.0 & 96.7\end{array}$

$\begin{array}{llllllll}86.2 & 85.9 & 87.4 & 89.6 & 89.6 & 96.5 & 95.5 & 98.7\end{array}$

- Run number 15 $\quad \mathbb{T}_{0}=24.1 \quad \mathbb{T}_{W}=103.0$

$\begin{array}{llllll}42.4 & 43.9 & 54.7 & 60.2 & 50.9 & 51.8\end{array}$

$\begin{array}{llllll}41.8 & 43.3 & 46.8 & 44.3 & 57.1 & 52.4\end{array}$

$\begin{array}{llllllll}97.8 & 96.8 & 98.0 & 98.2 & 99.6 & 100.8 & 101.7 & 102.0\end{array}$

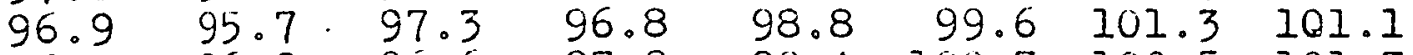

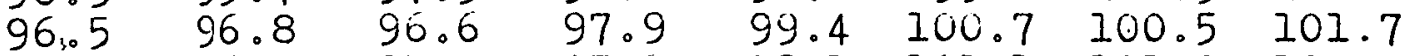

$\begin{array}{llllllll}96.4 & 96.7 & 97.0 & 97.9 & 98.1 & 101.1 & 101.2 & 102.3\end{array}$ 
Run number $\quad 16$

$$
{ }^{\mathrm{T}^{1}}=25.8 \quad \mathrm{~T}_{\mathrm{W}}=103.0
$$

$\begin{array}{llllll}29.5 & 30.2 & 45.0 & 46.2 & 36.8 & 39.6\end{array}$

$\begin{array}{llllll}29.6 & 30.9 & 35.7 & 33.2 & 42.8 & 38.5\end{array}$

$\begin{array}{llllllll}65.7 & 67.3 & 69.2 & 70.2 & 75.6 & 82.2 & 84.6 & 87.4 \\ 66.2 & 64.5 & 68.5 & 71.8 & 79.7 & 85.4 & 84.4 & 87.7 \\ 68.1 & 69.7 & 71.4 & 77.5 & 79.3 & 86.9 & 84.8 & 90.9 \\ 67.9 & 71.3 & 70.1 & 72.8 & 80.8 & 85.5 & 88.4 & 93.6\end{array}$

Run number $\quad 17$

$$
I_{0}=26.0 \quad T_{W}=103.0
$$

$\begin{array}{llllll}30.6 & 31.7 & 46.2 & 47.9 & 39.3 & 41.8\end{array}$ $\begin{array}{llllll}30.6 & 32.5 & 37.9 & 34.9 & 44.4 & 40.6\end{array}$

$\begin{array}{llllllll}71.7 & 73.8 & 75.2 & 76.0 & 80.4 & 86.4 & 87.8 & 90.8 \\ 72.1 & 71.0 & 74.4 & 77.6 & 83.7 & 89.1 & 87.6 & 91.0 \\ 74.3 & 75.4 & 77.0 & 81.7 & 83.4 & 90.6 & 88.4 & 93.7 \\ 74.0 & 77.0 & 75.5 & 78.2 & 84.7 & 89.0 & 91.3 & 96.1\end{array}$

Run number $\quad 18$

$$
\mathrm{T}_{\mathrm{O}}=25.6 \quad \mathrm{~T}_{\mathrm{W}}=103.0
$$

$33.2 \cdot 34.8 \quad 48.0 \quad 49.9 \quad 42.6 \quad 44.3$

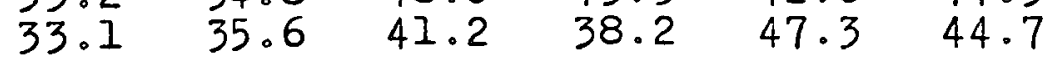

$\begin{array}{llllllll}82.4 & 84.5 & 85.3 & 86.5 & 88.7 & 93.0 & 93.7 & 95.0\end{array}$

$\begin{array}{llllllll}83.0 & 82.1 & 84.7 & 86.0 & 91.6 & 94.9 & 94.8 & 96.0\end{array}$

$\begin{array}{llllllll}83.2 & 85.6 & 86.5 & 89.6 & 90.8 & 95.7 & 94.8 & 97.9\end{array}$

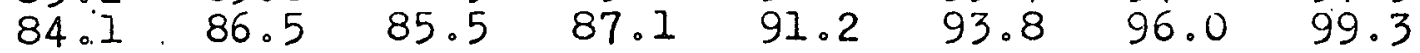

Run number 19. $\mathrm{T}_{\mathrm{O}}=25.1 \quad \mathrm{iT}_{\mathrm{W}}=103.0$

$\begin{array}{llllll}38.0 & 40.2 & 51.3 & 54.6 & 46.4 & 47.4\end{array}$

$\begin{array}{llllll}37.5 & 40.0 & 44.7 & 42.0 & 51.7 & 48.8\end{array}$

$\begin{array}{llllllll}93.8 & 95.1 & 95.7 & 96.0 & 97.3 & 99.4 & 99.0 & 100.1\end{array}$

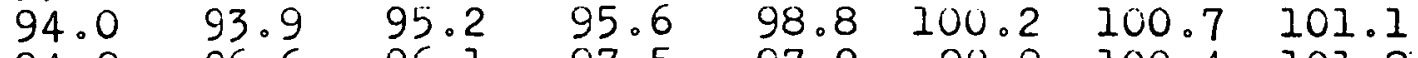
$\begin{array}{llllllll}94.9 & 96.6 & 96.1 & 97.5 & 97.9 & 99.9 & 100.4 & 101.8\end{array}$ $\begin{array}{llllllll}95.6 & 96.4 & 96.2 & 96.7 & 98.1 & 100.0 & 101.1 & 102.6\end{array}$

Run number $20 \quad T_{0}=24.7 \quad T_{w}=102.3$

$\begin{array}{llllll}27.6 & 28.2 & 43.5 & 46.3 & 34.7 & 37.1 \\ 27.7 & 28.9 & 33.6 & 31.0 & 41.4 & 37.6\end{array}$

$\begin{array}{llllllll}74.6 & 75.7 & 73.3 & 78.0 & 78.7 & 87.3 & 89.6 & 87.7 \\ 74.8 & 77.3 & 75.9 & 79.9 & 82.3 & 87.2 & 88.0 & 92.8 \\ 73.1 & 79.0 & 75.3 & 86.2 & 81.7 & 87.8 & 87.3 & 92.1 \\ 74.4 & 75.8 & 73.4 & 77.7 & 81.3 & 87.3 & 88.6 & 92.0\end{array}$


Run number

$T_{0}=24.7$ $\mathrm{T}_{\mathrm{w}}=102.3$

$\begin{array}{llllll}29.1 & 29.8 & 44.7 & 47.7 & 37.8 & 39.8\end{array}$

$\begin{array}{llllll}29.2 & 30.7 & 36.4 & 33.4 & 43.3 & 39.5\end{array}$

$\begin{array}{llllllll}80.6 & 81.2 & 79.2 & 82.6 & 84.0 & 90.7 & 92.8 & 91.1\end{array}$

$\begin{array}{llllllll}80.6 & 82.8 & 81.2 & 84.7 & 86.5 & 90.8 & 91.3 & 95.4\end{array}$

$\begin{array}{llllllll}78.9 & 84.0 & 80.8 & 84.6 & 86.4 & 91.3 & 91.0 & 94.6\end{array}$

$\begin{array}{llllllll}80.2 & 81.3 & 79.3 & 82.7 & 86.0 & 90.6 & 92.0 & 94.2\end{array}$

Run number 22

$$
\mathrm{T}_{0}=24.9 \quad \mathrm{~T}_{\mathrm{w}}=101.8
$$

$\begin{array}{llllll}31.0 & 32.4 & 45.7 & 49.9 & 41.4 & 42.9\end{array}$

$\begin{array}{llllll}30.9 & 33.5 & 39.7 & 36.4 & 45.7 & 43.7\end{array}$

$\begin{array}{llllllll}89.6 & 89.9 & 88.5 & .90 .4 & 92.8 & 96.1 & 97.9 & 97.2\end{array}$

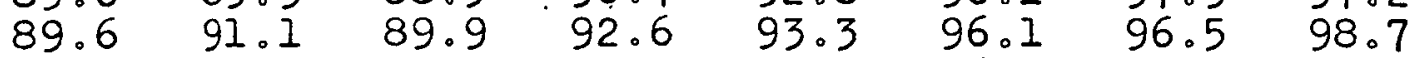

$\begin{array}{llllllll}87.8 & 91.3 & 89.3 & 91.5 & 93.7 & 96.7 & 96.6 & 98.2\end{array}$

$\begin{array}{llllllll}89.6 & 90.5 & 38.9 & 90.9 & 92.8 & 95.5 & 97.2 & 97.9\end{array}$

Run number $\cdot 23$

$$
\mathrm{T}_{0}=24.5 . \quad \mathrm{T}_{\mathrm{W}}=102.1
$$

$32.1 \quad 33.8 \quad 39.8 \quad-\quad 43.5 \quad 46.2$

$\begin{array}{llllll}32.4 & 35.7 & 41.7 & 44.2 & 44.3 & 42.2\end{array}$

$\begin{array}{llllllll}43.6 & 49.5 & 43.5 & 51.1 & 60.0 & 78.3 & 71.8 & 87.3\end{array}$

$\begin{array}{llllllll}56.6 & 48.6 & 58.6 & 51.6 & 59.3 & 65.6 & 72.5 & 76.0 \\ 49.4 & 47.5 & 47.9 & 56.9 & 59.3 & 69.4 & 66.2 & 74.8\end{array}$

$\begin{array}{llllllll}49.4 & 47.5 & 47.9 & 56.9 & 59.3 & 69.4 & 66.2 & 74.8 \\ 46.9 & 49.4 & 49.1 & 48.6 & 62.9 & 75.2 & 70.2 & -\end{array}$

Run number $24 \quad \mathrm{I}_{0}=22.9 \quad \mathrm{~T}_{\mathrm{w}}=102.2$

$29.4 \cdot 31.0 \quad 40.1 \quad-\quad 42.3 \quad 44.9$

$\begin{array}{llllll}30.7 & 33.3 & 41.9 & 41.0 & 44.2 & 39.1\end{array}$

$\begin{array}{llllllll}72.5 & 71.7 & 74.4 & 78.5 & 83.6 & 88.3 & 88.9 & 93.2\end{array}$

$\begin{array}{llllllll}73.6 & 71.0 & 74.6 & 74.2 & 82.1 & 80.9 & 87.1 & 89.9\end{array}$

$\begin{array}{llllllll}69.3 & 70.4 & 70.1 & 80.2 & 83.0 & 88.3 & 88.7 & 91.4\end{array}$

$\begin{array}{llllllll}71.4 & 72.0 & 71.2 & 70.1 & 81.2 & 88.2 & 88.3 & 93.8\end{array}$

Run number 25 . i' ${ }^{\prime}=22.8 \quad \mathrm{~T}_{\mathrm{w}}=102.2$

$29.0 .30 .9 \quad 40.1 \cdot \overline{1} \quad 42.2 \quad 45.0$

$\begin{array}{llllll}30.7 & 33.2 & 41.8 & 41.0 & 44.3 & 39.1\end{array}$

$\begin{array}{llllllll}82.4 & 85.6 & 84.3 & 86.7 & 90.1 & 93.0 & 92.6 & 97.4\end{array}$

$\begin{array}{llllllll}82.8 & 85.6 & 85.7 & 37.1 & 88.0 & 92.9 & 95.1 & 97.0\end{array}$

$\begin{array}{llllllll}84.5 & 83.5 & 87.4 & 86.4 & 92.8 & 94.5 & 96.6 & 96.1\end{array}$

$\begin{array}{llllllll}84.6 & 86.1 & 86.9 & 87.3 & 89.6 & 93.8 & 93.8 & 97.5\end{array}$ 
Run number $26 \quad \mathrm{~T}_{0}=23.2 \quad \mathrm{~T}_{\mathrm{W}}=102.4$ $\begin{array}{llllll}30.0 & 31.9 & 42.3 \quad & - & 42.9 & 45.5\end{array}$ $\begin{array}{llllll}31.3 & 33.2 & 42.1 & 41.6 & 44.8 & 39.7\end{array}$

$\begin{array}{llllllll}91.0 & 91.8 & 91.6 & 93.8 & 94.0 & 96.7 & 96.9 & 98.7\end{array}$ $\begin{array}{llllllll}91.0 & 89.2 & 90.6 & 90.7 & 92.0 & 93.4 & 97.5 & 96.2\end{array}$ $\begin{array}{llllllll}88.2 & 89.6 & 89.6 & 90.8 & 93.9 & 96.2 & 95.8 & 97.4\end{array}$

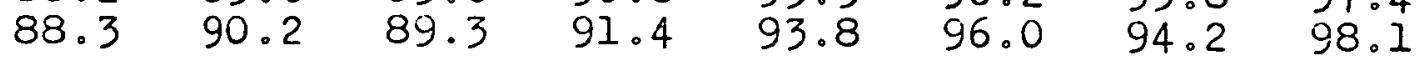

